\title{
UCRL-TR-219836
}

\section{Radionuclide Transport in Tuff and Carbonate Fractures from Yucca Flat, Nevada Test Site}

Mavrik Zavarin, Mackenzie R. Johnson, Sarah K. Roberts, Ronald Pletcher, Timothy P. Rose, Annie B. Kersting, Gail Eaton, Qinhong Hu, Erick Ramon, Justin Walensky, and Pihong Zhao

March 21, 2005 


\section{Disclaimer}

This document was prepared as an account of work sponsored by an agency of the United States Government. Neither the United States Government nor the University of California nor any of their employees, makes any warranty, express or implied, or assumes any legal liability or responsibility for the accuracy, completeness, or usefulness of any information, apparatus, product, or process disclosed, or represents that its use would not infringe privately owned rights.

Reference herein to any specific commercial product, process, or service by trade name, trademark, manufacturer, or otherwise, does not necessarily constitute or imply its endorsement, recommendation, or favoring by the United States Government or the University of California.

The views and opinions of authors expressed herein do not necessarily state or reflect those of the United States Government or the University of California, and shall not be used for advertising or product endorsement purposes.

\section{Auspices Statement}

This work was performed under the auspices of the U.S. Department of Energy by University of California, Lawrence Livermore National Laboratory under Contract W-7405-Eng-48.

This report has been reproduced directly from the best available copy.

Available for a processing fee to U.S. Department of Energy and its contractors, in paper, from U.S. Department of Energy, Office of Scientific and Technical Information

P.O. Box 62, Oak Ridge, TN 37831-0062

Phone: 865.576 .8401

Fax: 865.576 .5728

Email: reports@adonis.osti.gov

Available electronically at http://www.osti.gov/bridge

Available for sale to the public from

U.S. Department of Commerce, National Technical Information Service

5285 Port Royal Road, Springfield, VA 22161

Phone: 800.553 .6847

Fax: 703.605.6900

Email: orders@ntis.gov

Online ordering: http://www.ntis.gov/ordering.htm

\section{OR}

Lawrence Livermore National Laboratory

Technical Information Department's Digital Library http://www.llnl.gov/library/ 


\title{
Radionuclide Transport in Tuff and Carbonate Fractures from Yucca Flat, Nevada Test Site
}

\author{
Mavrik Zavarin ${ }^{1}$, Mackenzie R. Johnson ${ }^{1}$, Sarah K. Roberts ${ }^{1}$, Ronald \\ Pletcher ${ }^{1}$, Timothy P. Rose ${ }^{2}$, Annie B. Kersting ${ }^{2}$, Gail Eaton ${ }^{2}$, \\ Qinhong $\mathrm{Hu}^{2}$, Erick Ramon ${ }^{2}$, Justin Walensky ${ }^{2}$, and Pihong Zhao ${ }^{2}$ \\ ${ }^{1}$ Environmental Science Division \\ Energy and Environment Directorate \\ ${ }^{2}$ Chemical Biology and Nuclear Sciences Division \\ Chemistry and Materials Sciences Directorate \\ Lawrence Livermore National Laboratory \\ Livermore, California
}

Prepared for the Underground Test Area Project

U. S. Department of Energy

National Nuclear Security Administration

Nevada Site Office

Final Report

December 1, 2005 


\section{TABLE OF CONTENTS}

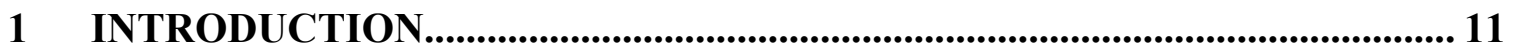

1.1 Synthetic Parallel-Plate Fractured Tuff Experiments ........................................ 11

1.2 Naturally Fractured Tuff Experiments.......................................................... 12

1.3 Synthetically Fractured Carbonate Experiments .............................................. 13

1.4 Modeling Experimental Results.................................................................. 14

2 FRACTURE TRANSPORT METHODS ............................................................. 14

$2.1 \quad$ Rock Core Preparation and Characterization.................................................... 14

2.1.1 Core Porosity, Density, and Permeability ................................................. 15

2.1.2 Core Mineralogy.................................................................................. 16

2.1.3 Fracture Lining Mineralogy of Tuffs ....................................................... 17

2.2 Flow-Through Experiment Apparatus ....................................................... 18

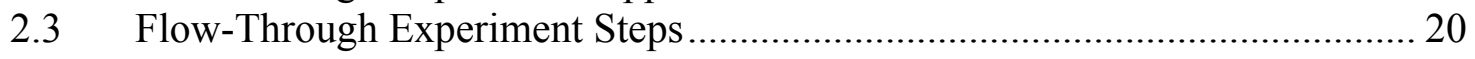

2.3.1 Background Solution.......................................................................... 20

2.3.2 Sorption Solution ................................................................................ 23

$2.4 \quad$ Details Regarding Core Experiments.............................................................. 27

2.4.1 Tuff Cores......................................................................................... 27

2.4.1.1 Synthetic Parallel-Plate Fracture.............................................................. 27

2.4.1.2 Colloid Transport in Parallel-Plate Fracture .......................................... 27

2.4.1.3 Fe-Coated Parallel-Plate Fracture …………....................................... 28

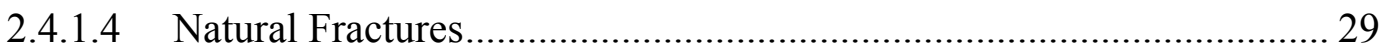

2.4.2 Carbonate Fractures............................................................................. 29

2.4.2.1 Synthetic Parallel-Plate Fractures …………………………................. 29

2.4.2.2 Brazil Test Induced Fracture................................................................. 29

2.5 Effluent and Starting Solution Analysis ……….......................................... 30

2.6 Post-Test Core Characterization ..................................................................... 30

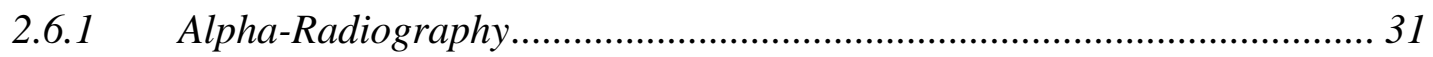

2.6.2 SEM and SIMS .............................................................................. 31

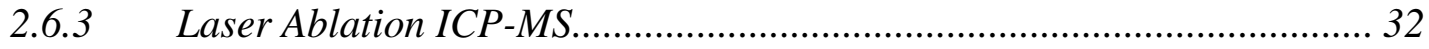

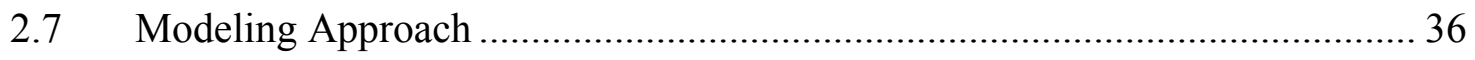

2.7.1 Parameter Effects on Radionuclide Breakthrough ................................... 39

3 RESULTS AND DISCUSSION ........................................................................ 41

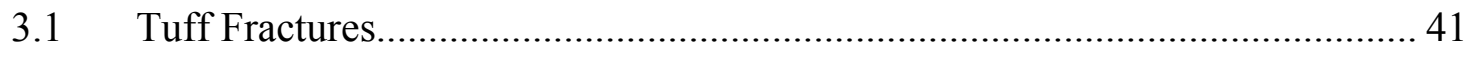

3.1.1 Synthetic Parallel-Plate Fractures .......................................................... 42

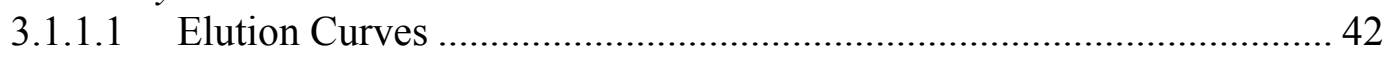

3.1.1.2 Core Characterization - Autoradiography ............................................... 46

3.1.1.3 Core Characterization - SEM and SIMS of TCU-5 ............................ 49

3.1.1.4 Core Characterization - Laser Ablation …………………………........ 52

3.1.2 Fe-Coated Parallel-Plate Fracture ……………..................................... 53

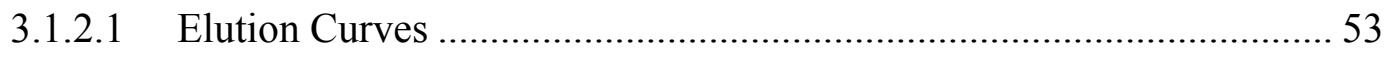

3.1.2.2 Core Characterization - Laser Ablation ................................................ 55 
3.1.3 Natural Fractures ........................................................................ 56

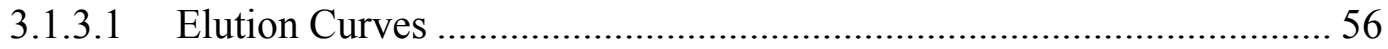

3.1.3.2 Core Characterization - Laser Ablation .................................................. 60

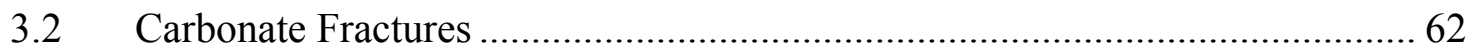

3.2.1 Elution Curves - Synthetic Parallel-Plate Fractures................................ 62

3.2.2 Elution Curves - Brazil Test Induced Fracture......................................... 66

3.2.3 Core Characterization - Autoradiography, SEM, and SIMS ..................... 67

3.2.4 Core Characterization - Laser Ablation ................................................... 69

3.2.5 Carbonate Core ${ }^{13} \mathrm{C}$ Transport ........................................................... 71

4 REACTIVE TRANSPORT MODELING ............................................................ 74

$4.1 \quad$ Radionuclide Transport in Tuff Cores ........................................................ 76

4.2 Radionuclide Transport in Carbonate Cores ................................................... 86

5 CONCLUSIONS AND RECOMMENDATIONS................................................ 92

6 ACKNOWLEDGEMENTS ……………………................................................... 94

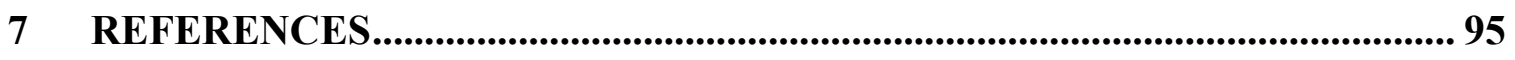

8 APPENDIX. FRACTURE TRANSPORT DATA............................................ 98

8.1 Flow-Through Run Parameters and Elution Data............................................ 98

8.2 Photographs of TCU And LCA Cores Used in Flow-Through Experiments. 134

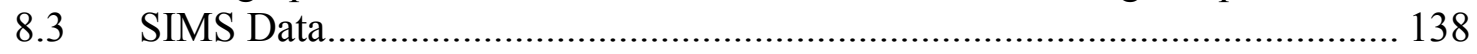




\section{LIST OF FIGURES}

Figure 2.1. Photograph of experimental set-up showing membrane sealed core in flowthrough reactor. Gradient HPLC pump that controlled flow rate is behind the flowthrough reactor, and the fraction collector for outflow solutions is seen at right. .... 19

Figure 2.2. Fracture flow experiment diagram where sketches (a) to (e) show steps in experiment preparation (slotted fractures). Sample core (a) has reference flats ground on end surfaces and at relative azimuths of 0,90 , and $180^{\circ}$ on the cylindrical surface (b); core is cut in half (c); is laid open and a $500 \mu \mathrm{m}$ wide slot is ground into one side (d); finally it is reassembled (e) for experiments. (Images (a)-(e) from Durham et al. (2001)).................................................................................... 19

Figure 2.3. Photograph of natural tuff core UE-7az 1678.2-1679.0 on left, and same core on right after precipitation with iron oxide (TCU-6)............................................. 28

Figure 2.4. X-ray diffraction pattern of iron oxide precipitate indicating amorphous nature of precipitate with phase match to hematite.

Figure 2.5. Examples of signal responses for elements from laser ablation on a tuff sample.

Figure 2.6. (a) Linearity between responses of intrinsic tuff elements and numbers of laser pulses at a nominal $100_{-} \mu \mathrm{m}$ spot size. (b) Crater depth and shape at a nominal $100_{-} \mu \mathrm{m}$ spot size; the number of laser pulses indicated in the figure caption......... 34

Figure 2.7. Surface profiling of a tuff sample with a rough surface (100_ $\mu \mathrm{m}$ spot size, 20

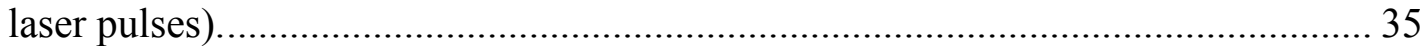

Figure 2.8. Calibration curves using NIST Standard Reference Material glasses (SRM

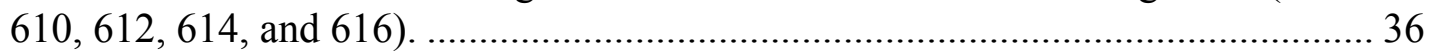

Figure 2.9. Relationship between fracture flow experiments and simulation of radionuclide transport using a 2D CRUNCH model.

Figure 2.10. Comparison of 2D CRUNCH model (solid lines) and analytical solution (dashed lines) breakthrough curves. See text for parameter information.

Figure 2.11. Effect of retardation in the fracture to breakthrough at the downstream boundary (no breakthrough observed for $\mathrm{R}_{\text {fracture }}=1000$ ).

Figure 2.12. Effect of retardation in the matrix to breakthrough at the downstream boundary.

Figure 2.13. Effect of diffusion tortuosity term $(\tau)$ to breakthrough at the downstream boundary.

Figure 3.1. TCU-2 breakthrough plot (log scale y-axis). The two vertical lines represent the beginning and end of the sorption pulse. Cs and Sm not observed.

Figure 3.2. TCU-2 breakthrough plot (linear scale y-axis). Sorption pulse timeframe magnified. The two vertical lines represent the beginning and end of the sorption pulse. Cs and Sm not observed.

Figure 3.3. TCU-5 breakthrough plot (log scale y-axis). The two vertical lines represent the beginning and end of the sorption pulse. Cs and Sr not included in sorption cocktail.

Figure 3.4. TCU-5 sorption pulse (linear scale y-axis). Sorption pulse timeframe magnified. The two vertical lines represent the beginning and end of the sorption pulse. Cs and Sr not included in sorption cocktail. 
Figure 3.5. One-half of TCU-2 is shown (a) and the radiography results are overlain on the core in (b). The dark spots and lines shown in (b) are concentrated alpha tracks.

Figure 3.6. Tuff Confining Unit-5 (TCU-5) is shown in (a) and the results of the radiography are overlain on the core in (b). Red circle in (b) outlines areas shown in Figure 3.7.

Figure $3.7(a, b)$. The CR-39 film is overlain on the TCU-5 core showing the areas where $\alpha$-activity has the greatest $\alpha$-track density. It should be noted the other fragments in the figure do not show as pronounced $\alpha$-activity as the darker fragments. Red circle in (a) indicates area shown in Figure 3.8a; blue circle indicates area shown in Figure $3.8 \mathrm{~b}$.

Figure 3.8. SEM images of the two high $\alpha$-activity mineral groupings in Figure 3.7a. (a) lower left mineral grouping at $15 \mathrm{kV}$ and $600 \mu \mathrm{m}$. (b) upper right mineral grouping at $15 \mathrm{kV}$ and $750 \mu \mathrm{m}$.

Figure 3.9. Image from Figure 3.7a with the addition of the SIMS and electron microprobe data. Radionuclide counts reported in white determined using SIMS; mineralogy shown in yellow determined using electron microprobe. Note the orders of magnitude increase in all four radionuclide counts in the Fe- and Mn-oxides relative to the rock matrix, composed mostly of zeolitic and feldspar minerals. ..... 50

Figure 3.10. Graphs showing relationship between Mn, Fe, and Pu for the TCU-5 SIMS analysis. (A) Mn and $\mathrm{Pu}$ counts, (B) $\mathrm{Fe}$ and $\mathrm{Pu}$ counts, and (C) $\mathrm{Mn}+\mathrm{Fe}$ and $\mathrm{Pu}$ counts.

Figure 3.11. Distribution of ${ }^{88} \mathrm{Sr}$ and ${ }^{133} \mathrm{Cs}$ obtained from surface profiling in TCU-2 core using LA/ICP-MS. Y-axis: intensity ratio denotes the signal of a tracer divided by the signal of internal standard (aluminum for tuff). Response of another intrinsic element (silicon) in tuff is also shown in the figure to indicate the stability across the profile depth, as expected from its "uniform" distribution.

Figure 3.12. Distribution of ${ }^{133} \mathrm{Cs}$ obtained from surface profiling in TCU-5 core sample using LA/ICP-MS.

Figure 3.13. TCU-6 breakthrough plot (log scale y-axis). The two vertical lines represent the beginning and end of the sorption pulse. Cs not observed....

Figure 3.14. TCU-6 sorption pulse (linear scale y-axis). Sorption pulse timeframe magnified. The two vertical lines represent the beginning and end of the sorption pulse. Cs not observed.

Figure 3.15. Distribution of ${ }^{237} \mathrm{~Np}$ and ${ }^{238} \mathrm{U}$ obtained from surface profiling in TCU-6 core using LA/ICP-MS. Symbols represent data; lines represent background intensity ratios.

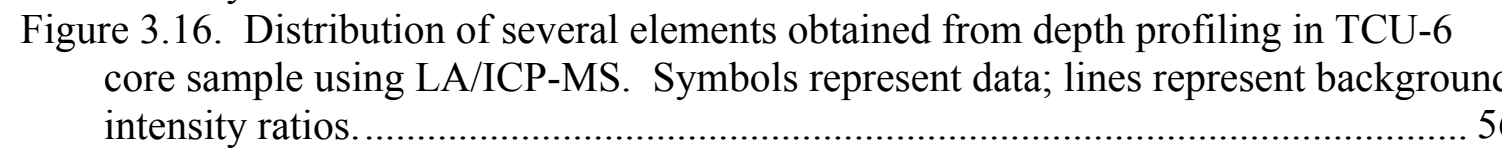

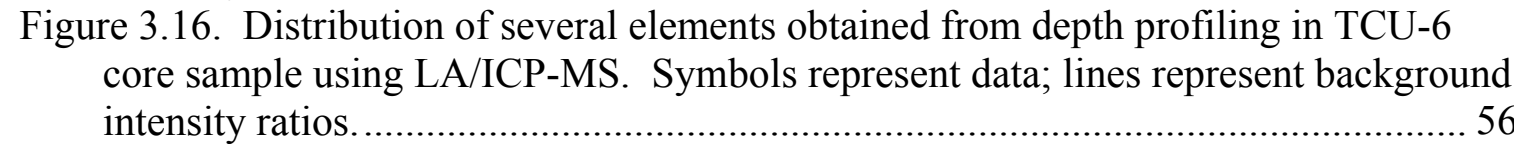

Figure 3.16. Distribution of several elements obtained from depth profiling in TCU-6
core sample using LA/ICP-MS. Symbols represent data; lines represent background
intensity ratios.............................................................................................

Figure 3.17. TCU-3 breakthrough plot (log scale y-axis). Cs, Sr, Sm, Pu not observed.58

Figure 3.18. TCU-3 sorption pulse (linear scale y-axis). Sorption pulse timeframe magnified. Cs, Sr, Sm, and Pu not observed....................................................5

Figure 3.19. TCU-4 breakthrough plot (log scale y-axis)........................................ 59

Figure 3.20. TCU-4 sorption pulse (linear scale y-axis). Sorption pulse timeframe magnified. 
Figure 3.21. Distribution of ${ }^{88} \mathrm{Sr}$ and ${ }^{133} \mathrm{Cs}$ obtained from surface profiling in TCU-3 core using LA/ICP-MS.

Figure 3.22. Distribution of several isotopes obtained from depth profiling in TCU-4 core sample using LA/ICP-MS. Symbols represent data; lines represent background intensity ratios.

Figure 3.23. Distribution of tracer isotopes obtained from depth profiling in TCU-4 core sample using LA/ICP-MS. Symbols represent data; lines represent background intensity ratios.

Figure 3.24. LCA-1 breakthrough plot. The two vertical lines represent the beginning and end of the sorption pulse. Sm and Pu not observed. Radionuclide concentration increases after 5 days are attributed to measurement/sampling errors.

Figure 3.25. LCA-1 sorption pulse. Sorption pulse timeframe magnified. The two vertical lines represent the beginning and end of the sorption pulse. Sm and Pu not observed.

Figure 3.26. LCA-2 breakthrough plot. The two vertical lines represent the beginning and end of the sorption pulse.

Figure 3.27. LCA-2 sorption pulse. Sorption pulse timeframe magnified. The two vertical lines represent the beginning and end of the sorption pulse.

Figure 3.28. LCA-3 breakthrough plot. Sm not observed.

Figure 3.29. LCA-3 sorption pulse. Sorption pulse timeframe magnified. Sm not observed.

Figure 3.30. (a) Post-test fractured surface of LCA-1. (b) The CR-39 film overlain on LCA-1. Alpha tracks are observed throughout, with concentrated clusters visible as dark patches and veins. (c) \#1-5 circles are the location of the plugs used in SEM and SIMS.

Figure 3.31. (a) The post-test LCA-2 core. (b) alpha tracks are overlain on LCA-2. The dark regions show the alpha tracks.

Figure 3.32. Distribution of isotopes obtained from surface profiling in LCA-2 core using LA/ICP-MS. Symbols represent data; lines represent background intensity ratios.

Figure 3.33. Distribution of several isotopes obtained from depth profiling in LCA-2 core sample using LA/ICP-MS. Symbols represent data; lines represent background intensity ratios.

Figure 3.34. $\delta^{13} \mathrm{C}$ (permil) plotted as a function of time for LCA-3 tracer experiment. Values shown are \pm 2 permil.

Figure 4.1. Model fits to TCU-2 elution data. Analytical solution fit to data (black) (Pu data not fit; Sm elution not observed); tritium and Re breakthrough over measured Reimus et al. (2002) tortuosity range (purple); Np, U, and Pu breakthrough using predicted retardation (red).

Figure 4.2. Model fits to TCU-3 elution data. Analytical solution fit to data (black) (Pu, $\mathrm{Sr}, \mathrm{Cs}$, and Sm data not fit); tritium and Re breakthrough over measured Reimus et al. (2002) tortuosity range (purple); $\mathrm{Np}, \mathrm{U}$, and Pu breakthrough using predicted retardation (red); $\mathrm{Pu}, \mathrm{Sr}, \mathrm{Cs}$, and $\mathrm{Sm}$ stepped profiles are measured concentrations integrated over a large sample volume to improve detection limits. 
Figure 4.3. Model fits to TCU-4 elution data. Analytical solution fit to data (black); tritium and Re breakthrough over measured Reimus et al. (2002) tortuosity range (purple); $\mathrm{Np}$ and U breakthrough using predicted retardation (red).

Figure 4.4. Model fits to TCU-5 elution data. Analytical solution fit to data (black); tritium and Re breakthrough over measured Reimus et al. (2002) tortuosity range (purple); $\mathrm{Np}, \mathrm{U}, \mathrm{Pu}$, and $\mathrm{Sm}$ breakthrough using predicted retardation (red); $\mathrm{Pu}$ and Sm breakthrough using predicted retardation but assuming colloid-associated radionuclide fraction does not diffuse (green).

Figure 4.5. Model fits to TCU-6 elution data. Analytical solution fit to data (black) (Pu, $\mathrm{Sr}$, and $\mathrm{Sm}$ data not fit; Cs did not elute); tritium and Re breakthrough over measured Reimus et al. (2002) tortuosity range (purple); $\mathrm{Np}, \mathrm{U}, \mathrm{Pu}$, and $\mathrm{Sr}$ breakthrough using predicted retardation (red).....

Figure 4.6. Model fits to LCA-1 elution data. Analytical solution fit to data (black); Np, $\mathrm{U}, \mathrm{Sr}$, and Cs breakthrough using predicted retardation (red); Sr breakthrough using 2D CRUNCH model which accounts for background radionuclide concentrations(blue)

Figure 4.7. Model fits to LCA-2 elution data. Analytical solution fit to data (black); Np, $\mathrm{U}$, Sr, and Cs breakthrough using predicted retardation (red); Sr breakthrough using 2D CRUNCH model which accounts for background radionuclide concentrations(blue)

Figure 4.8. Model fits to LCA-3 elution data. Analytical solution fit to data (black); Np, $\mathrm{U}$, Sr, and Cs breakthrough using predicted retardation (red); Sr breakthrough using 2D CRUNCH model which accounts for background radionuclide concentrations(blue).....

Figure 8.1. TCU-2 Synthetic parallel plate "slotted" fracture ..................................... 134

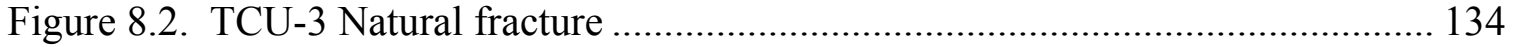

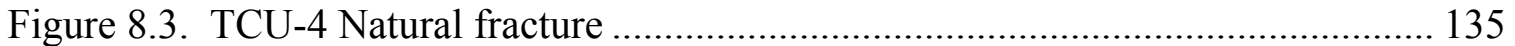

Figure 8.4. TCU-5 Synthetic parallel plate "slotted" fracture ........................................ 135

Figure 8.5. TCU-6 Iron oxide coated synthetic parallel plate "slotted" fracture........... 136

Figure 8.6. LCA-2 Synthetic parallel plate "slotted" fracture ...................................... 136

Figure 8.7. LCA-3 Brazil test induced fracture ......................................................... 137 


\section{LIST OF TABLES}

Table 2.1. Experimental core parameters .................................................................... 15

Table 2.2. Tuff Confining Unit and Lower Carbonate Aquifer core mineralogy............ 17

Table 2.3. Duration (in days) of each experimental stage for the individual cores ......... 20

Table 2.4. Composition of background solutions used in flow-through experiments ..... 21

Table 2.5. Composition of TCU waters at Yucca Flat................................................... 21

Table 2.6. Composition of LCA waters at Yucca Flat................................................. 22

Table 2.7. Salt compounds used in making flow-through experiment solutions............. 23

Table 2.8. Radionuclide composition of solutions used in flow-through experiments. .. 25

Table 2.9. Percentage of radionuclides present as colloids. ............................................ 25

Table 2.10. The Pu isotope composition of experimental solutions. * ........................... 26

Table 2.11. Matrix of post-characterization procedures. ............................................. 31

Table 2.12. Parameters used to evaluate effects of parameters on breakthrough........... 40

Table 3.1. Fraction of radionuclides eluted over the timeframe of each experiment ...... 42

Table 3.2 Exposure times for the rock cores on which $\alpha$-radiography was performed ... 46

Table 3.3. Carbon isotope results from the LCA-3 experiment.................................... 71

Table 4.1. Predicted and fitted radionuclide retardation and diffusion parameters for tuff

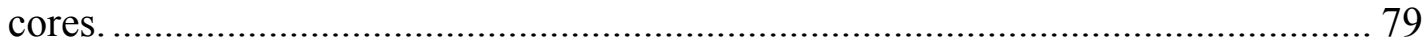

Table 4.2. Predicted and fitted radionuclide retardation and diffusion parameters for

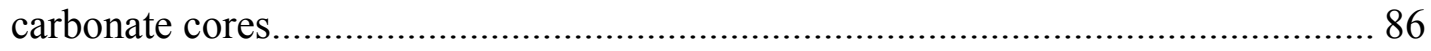

Table 8.1. TCU-2 Experimental run parameters....................................................... 98

Table 8.2. TCU-2 Core mineralogy ....................................................................... 98

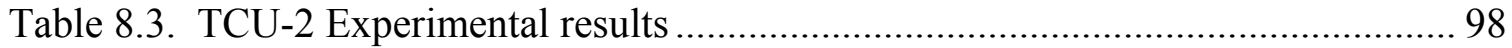

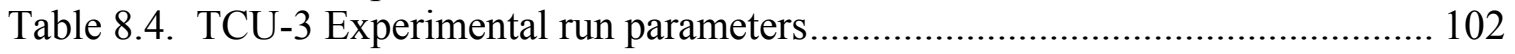

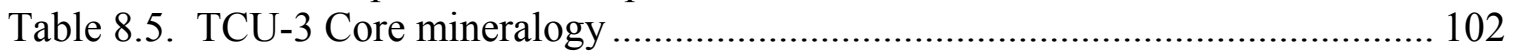

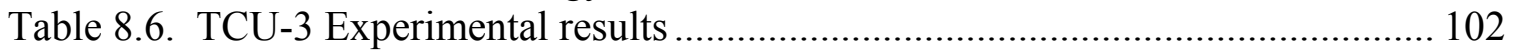

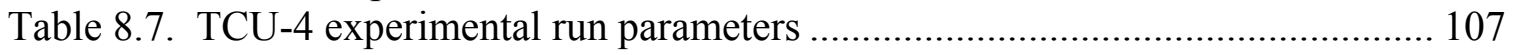

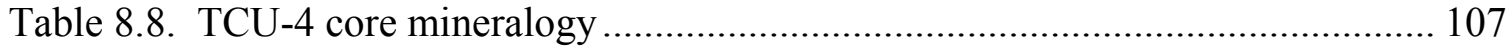

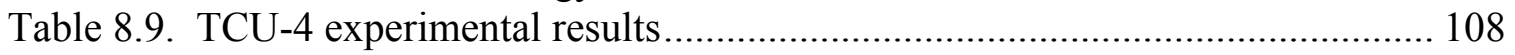

Table 8.10. TCU-5 experimental run parameters .................................................... 113

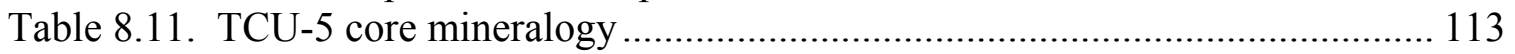

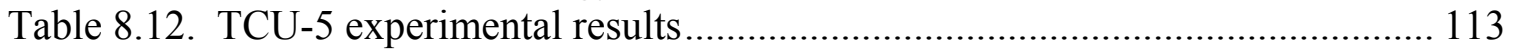

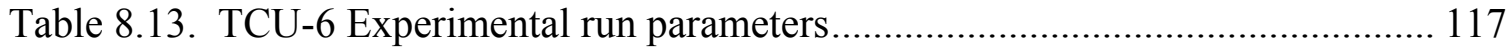

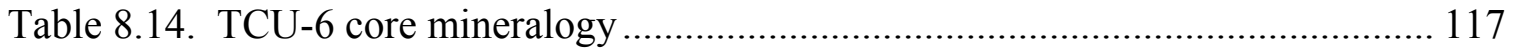

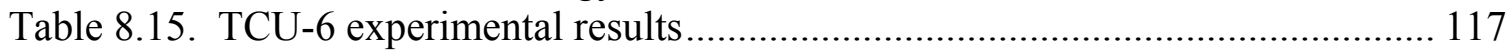

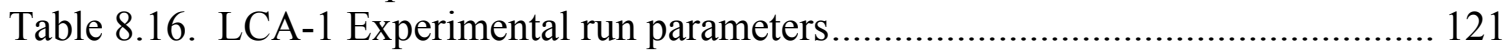

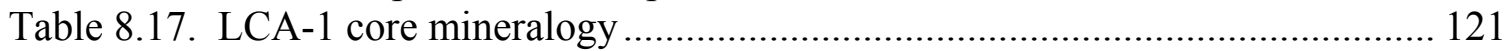

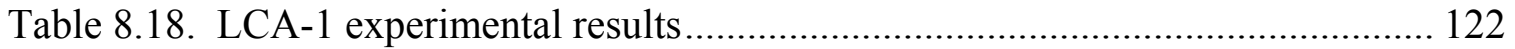

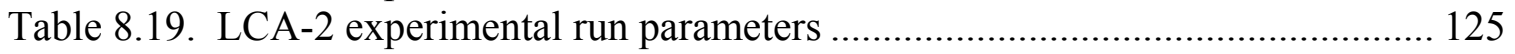

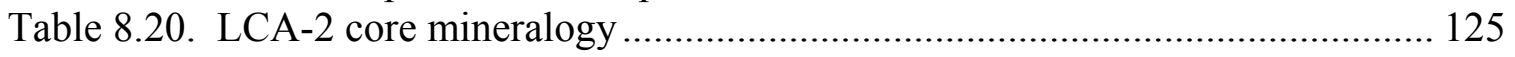

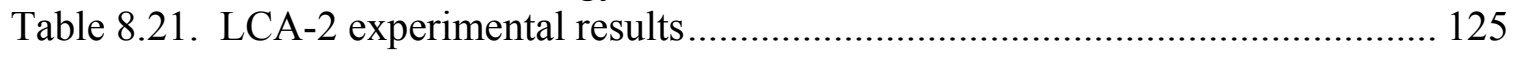

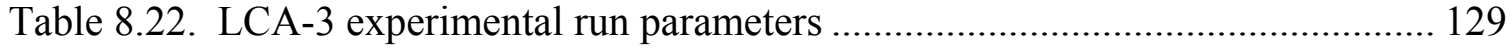

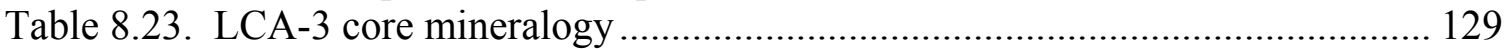

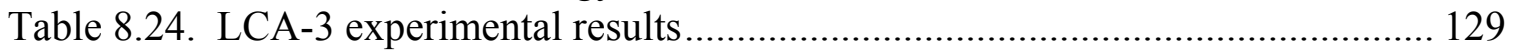

Table 8.25. Data from SIMS measurements for TCU-5 ....................................... 138

Table 8.26. Data from SIMS measurements for LCA-2 ........................................... 139 


\section{INTRODUCTION}

In the Yucca Flat basin of the Nevada Test Site (NTS), 747 shaft and tunnel nuclear detonations were conducted primarily within the tuff confining unit (TCU) or the overlying alluvium. The TCU in the Yucca Flat basin is hypothesized to reduce radionuclide migration to the regional carbonate aquifer (lower carbonate aquifer) due to its wide-spread aerial extent and chemical reactivity. However, shortcuts through the TCU by way of fractures may provide a migration path for radionuclides to the lower carbonate aquifer (LCA). It is, therefore, imperative to understand how radionuclides migrate or are retarded in TCU fractures. Furthermore, understanding the migration behavior of radionuclides once they reach the fractured LCA is important for predicting contaminant transport within the regional aquifer.

The work presented in this report includes: 1) information on the radionuclide reactive transport through Yucca Flat TCU fractures (likely to be the primary conduit to the LCA), 2) information on the reactive transport of radionuclides through LCA fractures and 3) data needed to calibrate the fracture flow conceptualization of predictive models. The predictive models are used to define the extent of contamination for the Underground Test Area (UGTA) project.

Because of the complex nature of reactive transport in fractures, a stepwise approach to identifying mechanisms controlling radionuclide transport was used. In the first set of TCU experiments, radionuclide transport through simple synthetic parallel-plate fractured tuff cores was examined. In the second, naturally fractured TCU cores were used. For the fractured LCA experiments, both parallel-plate and rough-walled fracture transport experiments were conducted to evaluate how fracture topography affects radionuclide transport. Tuff cores were prepared from archived UE-7az and UE-7ba core obtained from the USGS core library, Mercury, Nevada. Carbonate cores were prepared from archived ER-6-1 core, also obtained from the USGS core library, Mercury, Nevada.

\subsection{Synthetic Parallel-Plate Fractured Tuff Experiments}

Three synthetic parallel-plate fractures (labeled TCU-2, TCU-5, and TCU-6) were created using non-fractured tuff TCU core. Two cores were prepared that did not contain alteration minerals (TCU-2 and TCU-5). One core (TCU-6) was lined with synthetic minerals by precipitating the iron oxide hematite onto the fracture surface (metal oxides are the second most common fracture lining mineral in these tuffs (Prothro, 1998)).

Reactive transport experiments were performed by injecting a solution containing Cs(I), $\mathrm{Sr}(\mathrm{II}), \mathrm{Sm}(\mathrm{III}), \mathrm{Pu}(\mathrm{IV}), \mathrm{Np}(\mathrm{V})$, and U(VI) into the fractured core. The concentrations of sorbing radionuclides were kept low to minimize the potential of competitive sorption 
effects. ${ }^{1}$ Two non-sorbing species, ${ }^{3} \mathrm{H}$ and $\mathrm{ReO}_{4}{ }^{-}$, were also included. The radionuclides $^{2}$ used span a variety of sorption strengths and represent a large fraction of the radiologic source term (RST) at the NTS. In one of the cores (TCU-5), clinoptilolite colloids were included both in the radionuclide cocktail and background solution. ${ }^{3}$ This allowed us to examine the potential role of colloids in facilitating transport of strongly sorbing radionuclides, such as $\mathrm{Pu}$.

At the end of the transport experiments, the fractures were split open and the surface was characterized by autoradiography, Scanning Electron Microscopy (SEM), and secondary ion mass spectrometry (SIMS). A micro-scale profiling technique, laser ablation interfaced with ICP-MS (LA/ICP-MS) developed for the Yucca Mountain Project (Hu et al., 2001) was employed to examine radionuclide location on the fracture surface (surface profiling), as well as inside the tuff matrix perpendicular to the fracture (depth profiling). The spatial resolution achievable with LA/ICP-MS is about $50 \mu \mathrm{m}$. Some samples were profiled with SIMS, which has a finer spatial resolution, to compare the results between LA/ICP-MS and SIMS. This analysis was performed on radionuclides that did not elute from the fractures over the experiment time frame (1 to 2 week flow-through experiments). Tuff cores were prepared from archived UE-7az and UE-7ba core located at the USGS core library, Mercury, Nevada.

\subsection{Naturally Fractured Tuff Experiments}

Reactive transport studies using natural fractures were conducted to compare with the more controlled parallel-plate fracture-flow experiments. Reactive solutes included the same combination of sorbing and non-sorbing radionuclides. Two naturally-fractured cores (TCU-3 and TCU-4) with mineral alteration coatings were used; fracture lining minerals were characterized by SEM. The fractured cores were encapsulated in a flow reactor using the same methods used in the synthetic fracture experiments. At the conclusion of the experiments, the fractures were opened and characterized by laser ablation spectrometry (SIMS and autoradiography were not used because of method limitations for topographically heterogeneous surfaces). The laser ablation results provided information on the transport distance of radionuclides that did not elute from the fracture over the experiment time frame. The breakthrough data from these naturally fractured cores were compared to the synthetic parallel-plate fractures to gain an

\footnotetext{
${ }^{1}$ We tested for competitive sorption effects by comparing fracture transport model simulations using experimental radionuclide concentrations with those using trace radionuclide concentrations. The model results for these two cases were nearly identical, suggesting that competitive sorption effects were unlikely.

2 It is important to note that the term "radionuclide" should be reserved for those unstable isotopes. However, in this report, we use the term "radionuclide" to encompass both stable and unstable tracer and sorbing isotopes that were studied in this report. The term "radionuclide" was used loosely to simplify the discussion of transport results. In general the stable and unstable isotopes of the same element are expected to behave identically from the standpoint of transport and reaction chemistry.

${ }^{3} \mathrm{Sr}$ and $\mathrm{Cs}$ were omitted from this fracture transport experiment.
} 
understanding of transport differences between topographically heterogeneous and parallel-plate fractures. Tuff cores were prepared from archived UE-7az core located at the USGS core library, Mercury, Nevada.

\subsection{Synthetically Fractured Carbonate Experiments}

An important but poorly understood aspect of radionuclide transport at the NTS is the reactive transport of radionuclides in LCA fractures. At Yucca Flat, several underground nuclear tests were conducted near the LCA unit (e.g. Bilby) while others were conducted within the LCA itself, either near or above the water table (e.g. Bourbon). Because the LCA is the regional aquifer unit and a potentially important radionuclide transport pathway, we conducted a set of laboratory experiments to examine radionuclide transport in carbonate fractures.

We evaluated the reactive transport of radionuclides (Cs(I), $\mathrm{Sr}(\mathrm{II}), \mathrm{Sm}(\mathrm{III}), \mathrm{Pu}(\mathrm{IV})$, $\mathrm{Np}(\mathrm{V})$, and $\mathrm{U}(\mathrm{VI})$, and ${ }^{3} \mathrm{H}$ and $\mathrm{ReO}_{4}{ }^{-}$tracers) in artificially fractured LCA rocks (radionuclide cocktail identical to TCU experiments). Carbonate cores were prepared from archived ER-6-1 core located at the USGS core library, Mercury, Nevada. Plutonium(IV) is expected to sorb strongly. Neptunium(V) is expected to sorb weakly though calcite is believed to be an important contributor to its overall retardation. Samarium is a very strong sorber and behaves similar to other trivalent RST radionuclides (Am, Eu, Ho). Strontium retardation in carbonate is driven by exchange for $\mathrm{Ca}$ on the calcite surface and formation of a solid solution. Uranium(VI) and Cs sorption to calcite is weak. Details regarding the speciation and sorption behavior of each radionuclide can be found in Section 2.3.2.

In addition to the radionuclides listed above, an attempt was made to measure the effective reactivity of calcite on the fractures and the matrix by including ${ }^{13} \mathrm{C}$ in the radionuclide cocktail in one experiment. This was expected to provide a measure of the accessibility of the fracture fluid to radionuclide-retarding calcite on the fracture surface and in the matrix.

Three LCA cores were prepared. Two cores were prepared with synthetic parallel-plate fractures and one core was prepared with a topographically rough fracture surface. The preparation of a synthetic topographically rough fracture was accomplished using the Brazil method, as described in Durham et al. (2001). Results from the rough fracture experiment were used to elucidate the degree to which surface roughness affects the reactivity and flow dynamics of the fracture (Durham et al., 2001, have previously shown this to be the case).

At the conclusion of the fracture experiments, the distribution of radioactive components that were not transported entirely through the column was examined using autoradiography. LA/ICP-MS and SIMS were also used to identify the distribution of radionuclides, as in the TCU core experiments. 


\subsection{Modeling Experimental Results}

At the conclusion of all effluent and post-test fracture analyses, we modeled the reactive transport of radionuclides in the fractures and compared these results to the experimental data. Data were modeled using either the CRUNCH code (an updated version of the GIMRT code (Steefel and Yabusaki, 1995)) combined with our surface complexation and ion exchange sorption database (Zavarin and Bruton, 2004a; 2004b) or using the analytical solution of Tang et al. (1981). Based on these comparisons, improvements to our conceptual model and sorption database parameters were suggested and effective retardation coefficients were calculated. Our modeling approach is described in detail in Section 2.7.

\section{FRACTURE TRANSPORT METHODS}

\subsection{Rock Core Preparation and Characterization}

Core characteristics for each fracture flow-through experiment are listed in Table 2.1. The tuff cores had an original diameter of $57 \mathrm{~mm}$ (2.25 inches). Each core was cut to a length of approximately $100 \mathrm{~mm}$ and then sub-cored to a $45 \mathrm{~mm}$ diameter using a diamond impregnated water-cooled core barrel. ${ }^{4}$ The carbonate cores had an original diameter of $83 \mathrm{~mm}$ (3.25 inches) and were sub-cored to a diameter of $70 \mathrm{~mm}$. The ends of each core were ground with a precision grinding machine to the size designated for each of the two flow-through reactors. Further descriptions regarding the preparation of parallel-plate, iron oxide coated, and Brazil fractured cores are reported in Section 2.4. The Appendix contains photographs of the prepared cores used in the flow-through tests.

\footnotetext{
${ }^{4}$ Core TCU-4 was cut to $58 \mathrm{~mm}$ because the natural fracture did not extend out to 100 $\mathrm{mm}$.
} 
Table 2.1. Experimental core parameters

\begin{tabular}{|c|c|c|c|c|c|c|c|c|c|c|c|}
\hline Exp\# & $\begin{array}{l}\text { Well and depth } \\
\text { (feet) }\end{array}$ & Wt. (g) & $\begin{array}{l}\text { Length } \\
(\mathrm{mm})\end{array}$ & $\begin{array}{l}\text { Diam } \\
(\mathrm{mm})\end{array}$ & $\begin{array}{l}\text { Slot width } \\
\quad(\mathrm{mm})^{1}\end{array}$ & $\begin{array}{c}\text { Porosity } \\
(\%)\end{array}$ & $\begin{array}{l}\text { Permeability } \\
(\mathrm{md})^{2}\end{array}$ & $\begin{array}{c}\text { Bulk } \\
\text { Density } \\
(\mathrm{g} / \mathrm{cm} 3)\end{array}$ & $\begin{array}{c}\text { Inflow } \\
\text { Tube Vol. } \\
(\mathrm{mL})\end{array}$ & $\begin{array}{c}\text { Outflow } \\
\text { Tube Vol. } \\
(\mathrm{mL})\end{array}$ & $\begin{array}{c}\text { Flow } \\
\text { Rate } \\
(\mathrm{mL} / \mathrm{min})\end{array}$ \\
\hline \multicolumn{12}{|c|}{ TCU: Slotted Cores } \\
\hline TCU-2 & $\begin{array}{c}\text { UE-7az } \\
1798.8-1799.5\end{array}$ & $\sim 253.4$ & 101.99 & 44.37 & 38.84 & 29.1 & 0.108 & 1.70 & 1.49 & 0.23 & 0.0152 \\
\hline TCU-5 & $\begin{array}{c}\text { UE-7ba } \\
1626.2-1627.0\end{array}$ & 234.171 & 101.8 & 44.38 & 38.06 & 30.9 & 0.124 & 1.64 & 1.56 & 0.23 & 0.0159 \\
\hline TCU-6 & $\begin{array}{c}\text { UE-7az } \\
1678.2-1679.0\end{array}$ & 187.269 & 90.58 & 44.31 & 38.06 & 33.7 & 0.128 & 1.49 & 1.56 & 0.23 & 0.020 \\
\hline \multicolumn{12}{|c|}{ TCU: Natural Fractures } \\
\hline TCU-3 & $\begin{array}{c}\text { UE-7az } \\
1678.2-1679.0\end{array}$ & $\sim 197.6$ & 96.19 & 44.25 & (na) & 33.7 & 0.128 & 1.49 & 1.49 & 0.23 & 0.0152 \\
\hline TCU-4 & $\begin{array}{c}\text { UE-7az } \\
1779.9-1780.2 \\
\end{array}$ & 156.039 & 58.38 & 44.45 & (na) & 30.8 & 0.04 & 1.56 & 1.49 & 0.23 & 0.0151 \\
\hline \multicolumn{12}{|c|}{ LCA: Slotted Cores } \\
\hline LCA-1 & $\begin{array}{c}\text { ER-6-1 } \\
2604.7-2605.7\end{array}$ & $\sim 1114.0$ & 112.78 & 70.52 & 63.6 & 2.2 & 0.009 & 2.77 & 2.35 & 0.16 & 0.014 \\
\hline LCA-2 & $\begin{array}{c}\text { ER-6-1 } \\
2732.2-2733.1\end{array}$ & 1171 & 115.64 & 70.65 & 65.28 & 1.6 & 0.043 & 2.79 & 1.70 & 0.31 & 0.0215 \\
\hline \multicolumn{12}{|c|}{ LCA: Induced Fracture } \\
\hline LCA-3 & $\begin{array}{c}\text { ER-6-1 } \\
2552.1-2553.1\end{array}$ & 1209 & 112.54 & 70.56 & (na) & 1.7 & 0.002 & 2.8 & 1.70 & 0.31 & 0.0194 \\
\hline
\end{tabular}

${ }^{1}$ Method used to prepare slotted cores is described in detail in Section 2.4.

${ }^{2}$ Units of permeability are presented as millidarcy (md). 1 Darcy $=9.87 \times 10^{-13} \mathrm{~m}^{2}$.

\subsubsection{Core Porosity, Density, and Permeability}

The porosity, density, and permeability of each core is reported in Table 2.1 .

Measurements were made by sub-coring one inch diameter $(2.54 \mathrm{~cm})$ plugs from rock adjacent to the prepared fractured cores and shipping the plugs to Core Laboratories Inc. (Aurora, CO) for analysis. Specific physical properties (length, diameter, weight, and bulk volume) of each plug sample were measured and recorded. Samples were dried in an oven for 24 hours at $180^{\circ} \mathrm{F}\left(80^{\circ} \mathrm{C}\right)$ before permeability and porosity measurements were recorded. Permeability (using nitrogen) and porosity (using helium) were measured for each sample according to standard procedures (API RP 27, 1952; API RP 40, 1960).

For porosity, samples were placed into a Coberly-Stevens Boyle's Law porosimeter and injected with helium at approximately $100 \mathrm{psig}$. Corresponding pressures and volumes were measured and Boyle's Law was used to calculate sample grain volume. Pore volume was determined by subtracting the calculated grain volume from the measured bulk volume. Grain density and bulk density values could also be calculated from these measurements. 
For permeability, samples were placed into a Hassler-Sleeve core holder. The annulus of the core holder was pressurized to a pre-determined value ( $400 \mathrm{psig}$ minimum) to seal the sample. Nitrogen gas was forced through the sample at a given pressure under steadystate conditions. The flow rate was measured and permeability to air was calculated. A Klinkenberg-corrected permeability value was obtained using these values.

\subsubsection{Core Mineralogy}

The mineralogy of the tuff and carbonate cores was determined by x-ray diffraction (XRD). X-ray scans were collected using a Scintag PAD-V generator equipped with a $\mathrm{Cu}$ x-ray tube operated at $45 \mathrm{kV}$ and $35 \mathrm{~mA}$, and a Sieffert goniometer with a solid-state detector. Diffraction patterns were collected in step scan mode at 4 seconds per $0.02^{\circ} 2 \theta$. Collimation was provide by a $1^{\circ}$ divergence and $2^{\circ}$ scatter slit on the x-ray tube and a 0.3 $\mathrm{mm}$ scatter and $0.2 \mathrm{~mm}$ registration slit on the detector. Samples were scanned from 2 to $72^{\circ} 2 \theta$. Mineral detection limits range from 1 to 10 percent, depending on the mineral and its crystallinity. Due to the high detection limits, we could not identify or quantify mafic minerals which were observed visually as trace constituents.

Quantitative analyses were performed using the Rietveld method which is based on fitting a calculated XRD pattern to the observed pattern. Mineral quantification using the Rietveld method involved two steps. First, the phases present in each sample were identified using an XRD pattern processing software program (Jade, version 3.0, Materials Data, Inc., Livermore, CA), which utilizes data from the Joint Committee on Powder Diffraction Standards Powder Diffraction File (JCPDS-PDF). After the mineral phases were identified, the Rietveld method was employed. A least squares refinement was carried out until a best fit was obtained between the observed powder diffraction pattern and the calculated pattern based on the crystal structures and lattice parameters of phases determined to be present. The Rietveld analyses were performed using a quantitative XRD software program (Siroquant, version 2.0, Sietronics, Australia). To assess the overall accuracy of the method, a known quantity of corundum was added to each sample. The results of the quantitative analyses are reported in Table 2.2. Trace quantities of mafic minerals were visually observed in the tuff cores but were not identified by XRD. 
Table 2.2. Tuff Confining Unit and Lower Carbonate Aquifer core mineralogy

\begin{tabular}{|c|c|c|c|c|c|c|c|c|}
\hline Exp\# & Quartz & Cristobalite & Clay $^{1}$ & $\begin{array}{l}\mathrm{Na}-\mathrm{Ca} \\
\text { Feldspar }\end{array}$ & $\begin{array}{c}\mathrm{K} \\
\text { Feldspar }\end{array}$ & $\begin{array}{l}\text { Clinoptilolite/ } \\
\text { Heulandite }\end{array}$ & Calcite & Sum \\
\hline TCU-2 & 128 & 17 & $89^{\mathrm{a}}$ & 195 & 290 & 271 & 21 & 101 \\
\hline TCU-3 & 6.5 & 7.3 & $1.3^{\mathrm{b}}$ & 1.7 & 40.8 & 41.3 & 1.2 & 100 \\
\hline TCU-4 & 4.4 & 13.0 & $13.1^{\mathrm{a}}$ & 6.7 & 11.6 & 49.8 & 1.3 & 100 \\
\hline TCU-5 & 11.4 & 2.5 & $1.0^{\mathrm{a}}$ & 31.0 & 37.1 & 16.9 & - & 100 \\
\hline TCU-6 & 6.5 & 7.3 & $1.3^{\mathrm{b}}$ & 1.7 & 40.8 & 41.3 & 1.2 & 100 \\
\hline
\end{tabular}

Lower Carbonate Aquifer Core

\begin{tabular}{cccc} 
Exp\# & Calcite & $\begin{array}{r}\text { Dolomite } \\
\text {----- }\end{array}$ & Mass Percent \\
& ------ \\
\hline LCA-1 & 10.7 & 89.3 & 100 \\
LCA-2 & 17.3 & 82.8 & 100 \\
LCA-3 & 12.7 & 87.3 & 100
\end{tabular}

${ }^{1}$ Clay may include illite and/or montmorillonite

${ }^{\text {a }}$ Clay is $100 \%$ illite

${ }^{\mathrm{b}}$ Clay is $92 \%$ illite, $8 \%$ montmorillonite

\subsubsection{Fracture Lining Mineralogy of Tuffs}

Three of the TCU core samples selected for this study contained natural fractures that were coated with secondary alteration minerals. A small portion of each fracture surface was sent to Bob Dickerson (Stoller-Navarro Joint Venture) for mineral identification. Sample characterization included an initial assessment using a binocular microscope followed by analysis on a Scanning Electron Microscope (SEM) equipped with an Energy Dispersive Spectrometer (EDS). In all three samples, the zeolite minerals clinoptilolite and mordenite were the only fracture-coating phases that were observed. Full descriptions of the samples are as follows.

\section{Sample\#: UE-7az 1691.6-1692.3}

Microscopic Examination: Yellowish-brown, non-welded, zeolitized ash-flow tuff with a prominent fracture coated with white, secondary minerals. Small vugs present and partially occluded by translucent minerals.

SEM Examination: The fracture-coating minerals on this sample appear to be mordenite and clinoptilolite. The mordenite forms a matt-like layer of interconnected needle-like minerals, as well as forming ridge-like structures. The mordenite layer is formed on top of a layer composed primarily of clinoptilolite. EDS spectra support the presence of mordenite and clinoptilolite. (EDS spectra cannot differentiate between mordenite and the very similar-looking erionite, but XRD data from the previous study failed to identify erionite in Yucca Flat tuffs). In this sample, the paragenesis appears to be: clinoptilolite; mordenite. 


\section{Sample\#: UE-7az 1779.95-1780.25 (TCU-4)}

Microscopic Examination: Pale pinkish-brown zeolitized bedded tuff with near-vertical fracture coated with white, semi-lustrous secondary minerals.

SEM Examination: The fracture-coating minerals on this sample appear to be mordenite and clinoptilolite. In this sample the mordenite is volumetrically the most abundant mineral, followed by a lesser volume of clinoptilolite. The paragenesis appears to be: clinoptilolite; mordenite.

\section{Sample\#: UE-7az 1678.2-1679.0 (TCU-3 and -6)}

Microscopic Examination: Pale grayish-brown, non-welded, zeolitized ash-flow tuff. Near-vertical fracture surface is coated with white secondary minerals.

SEM Examination: The fracture-coating minerals in this sample appear to be mordenite and clinoptilolite. As in the two previous samples, the mordenite forms a matt of interweaved needles deposited upon a substrate of clinoptilolite crystals. EDS spectra support the idea that the lath-like crystals beneath the mordenite are clinoptilolite and not feldspar. The paragenesis appears to be: clinoptilolite; mordenite.

\subsection{Flow-Through Experiment Apparatus}

Two existing flow-through reactors were used to perform the transport experiments. A photograph of the $45 \mathrm{~mm}$ core apparatus is shown in Figure 2.1, and a schematic of the apparatus is shown in Figure 2.2. The core is sealed on the outside with flexible tubular membranes. The entire core is subjected to external pressure to squeeze the membrane against the outside of the core to prevent fluid flow along the core wall. All fluid flow is therefore confined to the inside of the core. Water was used as the confining pressure medium and was controlled by a syringe pump kept at constant pressure of 10 PSI. Fluid flow through the core was controlled by a gradient HPLC pump (Gilson 305) set to a rate of $0.02 \mathrm{~mL} / \mathrm{min}$, although actual flow rates ranged from 0.015 to $0.019 \mathrm{~mL} / \mathrm{min}$ for the different cores. Measured flow rates for each experiment are reported in Tables 8.1, 8.4, 8.7, 8.10, 8.13, 8.16, 8.19, and 8.22 of the Appendix. 


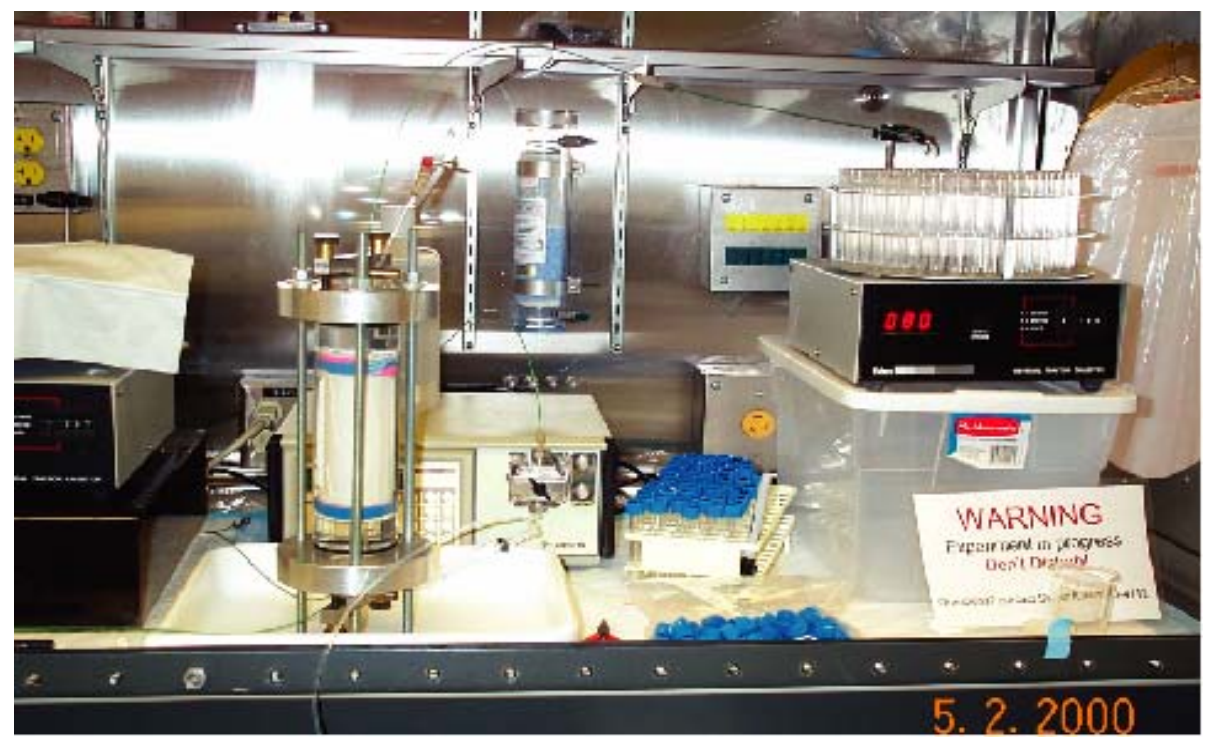

Figure 2.1. Photograph of experimental set-up showing membrane sealed core in flowthrough reactor. Gradient HPLC pump that controlled flow rate is behind the flowthrough reactor, and the fraction collector for outflow solutions is seen at right.

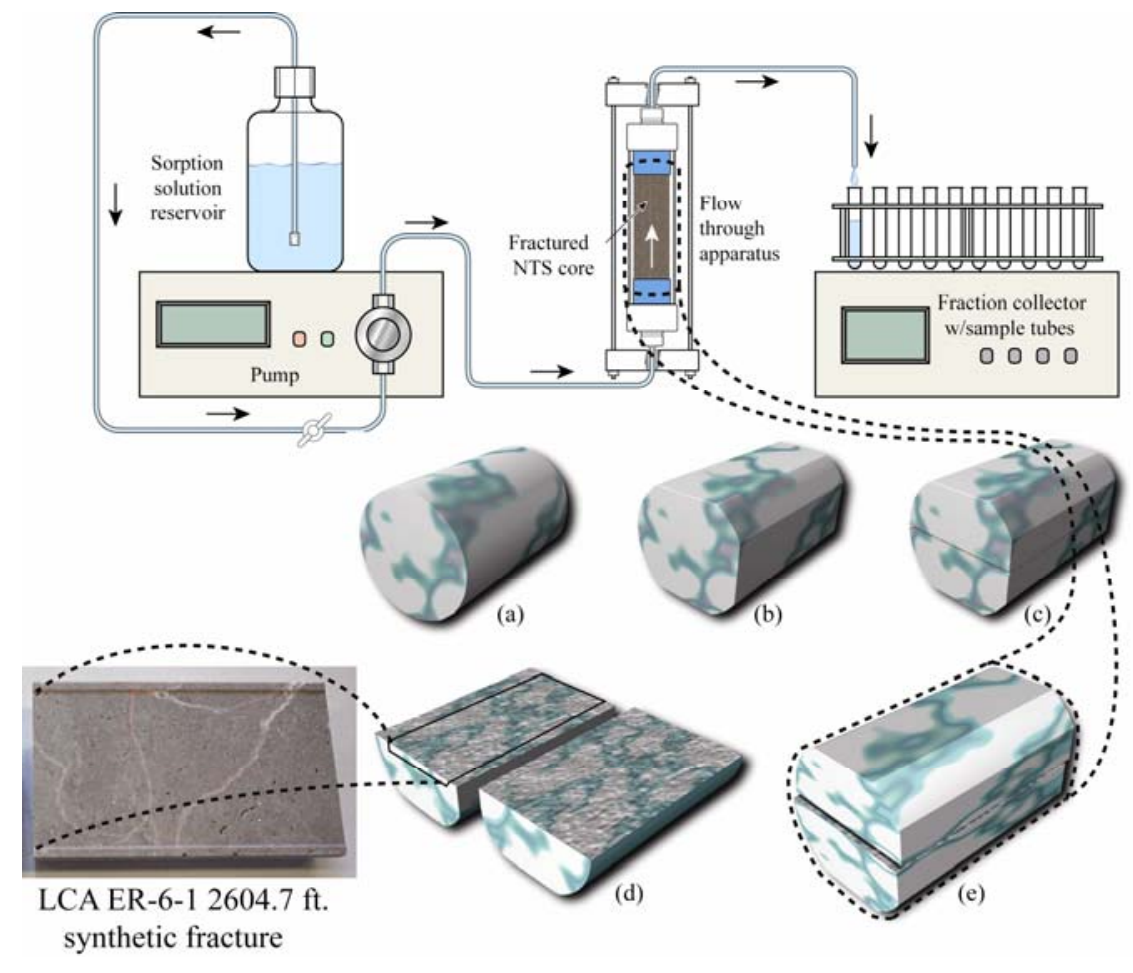

Figure 2.2. Fracture flow experiment diagram where sketches (a) to (e) show steps in experiment preparation (slotted fractures). Sample core (a) has reference flats ground on end surfaces and at relative azimuths of 0,90 , and $180^{\circ}$ on the cylindrical surface (b); core is cut in half (c); is laid open and a $500 \mu \mathrm{m}$ wide slot is ground into one side (d); finally it is reassembled (e) for experiments. (Images (a)-(e) from Durham et al. (2001)). 


\subsection{Flow-Through Experiment Steps}

Each of the flow-through experiments occurred in four stages: a $\mathrm{CO}_{2}(\mathrm{~g})$ flush, core saturation, a sorption pulse, and a desorption stage. Table 2.3 provides a summary of the stage durations for each experiment.

Table 2.3. Duration (in days) of each experimental stage for the individual cores

\begin{tabular}{lcccccccc}
\hline & TCU-2 & TCU-3 & TCU-4 & TCU-5 & TCU-6 & LCA-1 & LCA-2 & LCA-3 \\
\hline CO $_{2 \text { (g) }}$ & 0.95 & 4.07 & 0.78 & 1.03 & 0.77 & 4.29 & 6.00 & 1.03 \\
Core Saturation & 10.11 & 8.04 & 7.26 & 7.72 & 5.31 & 8.02 & 7.04 & 7.04 \\
Sorption & 0.68 & 0.70 & 0.71 & 0.51 & 0.67 & 0.70 & 0.70 & 0.70 \\
Desorption & 9.26 & 8.33 & 11.24 & 7.72 & 10.10 & 6.20 & 9.22 & 10.46 \\
\hline
\end{tabular}

To ensure full saturation of the core, it was necessary to remove air from the core. One method used to ensure core saturation is to apply a vacuum to the core followed by introduction of water. Alternatively, carbon dioxide can be flushed through the core. Unlike the air it replaces, $\mathrm{CO}_{2}$ (g) will readily dissolve in water. As the $\mathrm{CO}_{2}$ (g) dissolves, it is replaced by the water that is introduced into the core. For the present set of experiments, $\mathrm{CO}_{2}$ (g) was pumped through the core for 18.5 hours (TCU-6) to six days (LCA-2) followed by introduction of background solutions.

After the $\mathrm{CO}_{2}$ (g) flush, a background solution was pumped through the core for a period of 5 to 10 days (TCU-6 and TCU-2, respectively). Flushing the core with background solution provided reasonable confidence that the core was fully saturated, the $\mathrm{CO}_{2}$ (g) had dissolved, and the core was at equilibrium with the background solution prior to the addition of radionuclides.

The sorption solution pulse was typically pumped through the core for 16 to 17 hours, although the pulse lasted only 12.35 hours for the TCU-5 experiment. Data collection began simultaneously with the introduction of the sorption solution, and continued for a period lasting 6 to 11 days (LCA-1 and TCU-4, respectively) to capture the effects of desorption and diffusion. The sorption pulse is delineated by the vertical black lines on the breakthrough plots that are presented in Sections 3.1 and 3.2.

\subsubsection{Background Solution}

The synthetic background solution composition used in the TCU and LCA experiments (Table 2.4) was based on measured concentrations of major ions in groundwaters sampled from the respective hydrostratigraphic units (Tables 2.5 and 2.6, culled from the UGTA geochemistry database, Stoller-Navarro, 2004). Sulfate, nitrate, and fluoride were omitted from the background solution because their role in radionuclide retardation is expected to be minimal. The calcium concentration was adjusted by equilibrating 
background solutions with calcite to minimize calcite dissolution/precipitation during flow-through experiments. The solution composition used in the LCA-1 experiment differs significantly from that in the LCA-2 and LCA-3 experiments. Based on models of the LCA fluid composition (Table 2.6), it was determined that the equilibrium $\mathrm{CO}_{2}$ (g) fugacity of LCA waters was $2 \%$. In the LCA-1 experiment, the background solution was prepared by bubbling $2 \% \mathrm{CO}_{2}$ (g) into the starting solution; this resulted in a $\mathrm{pH}$ and carbonate alkalinity consistent with the average LCA composition. However, the solution proved to be unstable because the $\mathrm{CO}_{2}$ (g) degassed, resulting in significant calcite precipitation. Therefore, the LCA-2 and LCA-3 experiment solution was prepared at a higher $\mathrm{pH}$ and lower carbonate alkalinity (retaining calcite equilibrium) to improve solution composition stability. The effect of solution composition on predicted and observed radionuclide retardation in LCA cores is discussed later in this report. Table 2.7 lists the chemicals used to obtain the desired compositions of the TCU and LCA synthetic groundwaters.

Table 2.4. Composition of background solutions used in flow-through experiments

\begin{tabular}{|c|c|c|c|c|c|c|c|}
\hline & pH & ${ }^{1} \mathrm{HCO}_{3}$ & $\mathbf{N a}$ & $\mathrm{Ca}$ & Mg & $\mathbf{K}$ & $\mathrm{Cl}$ \\
\hline TCU-2,3,4 & 8.3 & $4.2 \mathrm{E}-3$ & 4.4E-3 & $1.2 \mathrm{E}-4$ & $2.0 \mathrm{E}-5$ & $1.4 \mathrm{E}-4$ & 4.9E-4 \\
\hline TCU-5 & 8.1 & $3.2 \mathrm{E}-3$ & $4.6 \mathrm{E}-3$ & $2.4 \mathrm{E}-4$ & $5.8 \mathrm{E}-5$ & $1.8 \mathrm{E}-4$ & $3.2 \mathrm{E}-4$ \\
\hline TCU-6 & 8.3 & $3.8 \mathrm{E}-3$ & $4.4 \mathrm{E}-3$ & $1.5 \mathrm{E}-4$ & $2.3 \mathrm{E}-5$ & $1.5 \mathrm{E}-4$ & 4.2E-4 \\
\hline LCA-1 & 7.1 & 5.0E-3 & $2.6 \mathrm{E}-3$ & $5.2 \mathrm{E}-4$ & $7.3 \mathrm{E}-4$ & $2.4 \mathrm{E}-4$ & 5.1E-4 \\
\hline LCA-2,3 & 7.9 & $5.5 \mathrm{E}-4$ & $2.7 \mathrm{E}-3$ & $1.4 \mathrm{E}-3$ & 7.9E-4 & $2.5 \mathrm{E}-4$ & $5.3 \mathrm{E}-3$ \\
\hline
\end{tabular}

${ }_{1}^{1}$ Total carbonate in solution reported as $\mathrm{mol} / \mathrm{L} \mathrm{HCO}_{3}{ }^{-}$.

Table 2.5. Composition of TCU waters at Yucca Flat

\begin{tabular}{|c|c|c|c|c|c|c|c|c|c|c|c|c|}
\hline SITE_ID & $\begin{array}{c}\text { Sample } \\
\text { Date }\end{array}$ & $\begin{array}{l}\text { Water } \\
\text { Temp }\end{array}$ & $\mathrm{pH}$ & $\mathrm{Ca}$ & $\mathrm{Mg}$ & $\mathrm{Na}$ & $\mathrm{K}$ & ${ }^{1} \mathrm{HCO}_{3}$ & $\mathrm{Cl}$ & $\mathrm{SO}_{4}$ & $\mathrm{NO}_{3} \quad \mathrm{I}$ & $\mathrm{F}$ \\
\hline & & ${ }^{\circ} \mathrm{C}$ & & $---\cdot$ & ---- & --------- & -------- & -- mg/L & --- & ---- & -------. & ------ \\
\hline Test Well \#7 & $2 / 3 / 1958$ & 20.6 & 7.3 & 1.0 & 0.2 & 113 & 4.6 & 286 & 8 & 2.1 & n.d. & 2.4 \\
\hline U-4u PS\#2a & $8 / 16 / 1999$ & n.d. & 8.2 & 13.1 & 2.7 & 72 & 14 & 160 & 5.8 & 12 & n.d. & 0.7 \\
\hline ER-2-1 & $9 / 3 / 2003$ & 21.3 & 9.3 & 3.1 & 0.3 & 73 & 3.8 & 189 & 4.4 & 15.9 & 2.4 & 1.8 \\
\hline UE-10 ITS \#3 & $8 / 25 / 1988$ & n.d. & 8.32 & 7.8 & 0.4 & 209 & 21.5 & 543 & 10.2 & 42.8 & 5.5 & n.d. \\
\hline Average & & 21 & 8.3 & 6.3 & 0.9 & 117 & 11.0 & 295 & 7.1 & 18 & $<4.0$ & 1.6 \\
\hline Standard deviation & & & 0.8 & 5.4 & 1.2 & 64 & 8.4 & 174 & 2.5 & 17 & & 0.9 \\
\hline Average & & & & $1.6 \mathrm{E}-4$ & $3.7 \mathrm{E}-5$ & $5.1 \mathrm{E}-3$ & $2.8 \mathrm{E}-4$ & $4.8 \mathrm{E}-3$ & $2.0 \mathrm{E}-4$ & $1.9 \mathrm{E}-4$ & $<6.5 \mathrm{E}-5$ & $8.6 \mathrm{E}-5$ \\
\hline Standard Deviation & & & & $1.3 \mathrm{E}-4$ & $4.9 \mathrm{E}-5$ & $2.8 \mathrm{E}-3$ & $2.2 \mathrm{E}-4$ & $2.9 \mathrm{E}-3$ & 7.2E-5 & $1.8 \mathrm{E}-4$ & & $4.5 \mathrm{E}-5$ \\
\hline
\end{tabular}


Table 2.6. Composition of LCA waters at Yucca Flat

\begin{tabular}{|c|c|c|c|c|c|c|c|c|c|c|c|c|}
\hline SITE_ID & Sample Date & $\begin{array}{l}\text { Water } \\
\text { Temp } \\
{ }^{\circ} \mathrm{C}\end{array}$ & $\mathrm{pH}$ & $\mathrm{Ca}$ & $\mathrm{Mg}$ & $\mathrm{Na}$ & K & ${ }^{1} \mathrm{HCO}_{3}$ & $\mathrm{Cl}$ & $\mathrm{SO}_{4}$ & $\mathrm{NO}_{3}$ & $\mathrm{~F}$ \\
\hline USGS Water Well C & $9 / 11 / 1990$ & 36 & 7.3 & 74.5 & 28.2 & 126 & 13.2 & 584 & 33.2 & 65 & n.d. & 1.1 \\
\hline Water Well C-1 & 9/25/1996 & 37 & 6.7 & 73 & 27 & 120 & 14 & 580 & 33 & 66 & n.d. & 1.1 \\
\hline ER-6-1 & 10/9/1992 & 43.7 & 7.87 & 33.4 & 12.2 & 47 & 8.32 & 237 & 11.8 & 32.1 & 0.58 & 0.68 \\
\hline ER-6-1 \#2 & $1 / 16 / 2003$ & 39.9 & 7.6 & 33.6 & 14 & 47.1 & 6.3 & 256 & 10 & 34 & 1.1 & 0.8 \\
\hline ER-3-1 & $10 / 16 / 1996$ & 37.8 & 6.69 & 94.9 & 35.1 & 143 & 19 & 741 & 43.4 & 68.1 & $<0.05$ & 1.38 \\
\hline $\mathrm{U}-3 \mathrm{cn} \# 5$ & $1 / 29 / 1997$ & 42.4 & 7.21 & 39.6 & 16.7 & 53.4 & 7.9 & 262 & 29.5 & 36.2 & $<0.05$ & 0.87 \\
\hline UE-1h (651 m depth) & $5 / 26 / 1993$ & 25.3 & 8.2 & 15.3 & 7.5 & 102 & 25 & 276 & 43.6 & 25 & n.d. & 0.7 \\
\hline UE-1c & $8 / 31 / 1988$ & 26 & 7.98 & 34.1 & 13.2 & 33.7 & 12.7 & 238 & 6.7 & 34.1 & 2.4 & 0.5 \\
\hline UE-1q & $7 / 10 / 1992$ & 31.5 & 7.8 & 29.4 & 15.3 & 31.2 & 4.6 & 199 & 5.3 & n.d. & n.d. & n.d. \\
\hline UE-10j (765-773 m depth) & $3 / 17 / 1997$ & 32.7 & 6.43 & 101 & 42.3 & 64 & 12.3 & 504 & 24 & 83 & n.d. & 0.3 \\
\hline UE-10j (732-740 m depth) & $3 / 20 / 1997$ & 32.3 & 6.73 & 68 & 30 & 43 & 8.3 & 403 & 16 & 67 & n.d. & 0.3 \\
\hline UE-10j (691-699 m depth) & $3 / 24 / 1997$ & 32.1 & 6.96 & 56 & 25.4 & 35 & 6.9 & 349 & 12.5 & 60.8 & n.d. & 0.3 \\
\hline Average & & & 7.3 & 51 & 21 & 60 & 11 & 368 & 20 & 49 & $<1.4$ & 0.7 \\
\hline Standard deviation & & & 0.6 & 29 & 11 & 36 & 6 & 173 & 14 & 21 & & 0.4 \\
\hline Average & & & & $1.3 \mathrm{E}-3$ & $8.7 \mathrm{E}-4$ & $2.6 \mathrm{E}-3$ & $2.8 \mathrm{E}-4$ & $6.0 \mathrm{E}-3$ & $5.7 \mathrm{E}-4$ & $5.1 \mathrm{E}-4$ & $<2.2 \mathrm{E}-5$ & $3.8 \mathrm{E}-5$ \\
\hline Standard Deviation & & & & $7.2 \mathrm{E}-4$ & 4.7E-4 & $1.6 \mathrm{E}-3$ & $1.6 \mathrm{E}-4$ & $2.8 \mathrm{E}-3$ & 4.0E-4 & $2.2 \mathrm{E}-4$ & & $1.9 \mathrm{E}-5$ \\
\hline
\end{tabular}




\begin{tabular}{|c|c|c|}
\hline Experiment & Compound $^{(1)}$ & Ideal Wt. $(\mathrm{g})^{(2)}$ \\
\hline \multirow{4}{*}{$\begin{array}{l}\text { TCU-2 } \\
\text { TCU-4 } \\
\text { TCU-6 }^{(3)}\end{array}$} & $\mathrm{CaCl}_{2} \cdot 2 \mathrm{H}_{2} \mathrm{O}$ & 0.2200 \\
\hline & $\mathrm{KCl}$ & 0.1663 \\
\hline & $\mathrm{MgCl}_{2} \cdot 6 \mathrm{H}_{2} \mathrm{O}$ & 0.04357 \\
\hline & $\mathrm{NaHCO}_{3}$ & 3.7515 \\
\hline \multirow{6}{*}{ LCA-1 } & $\mathrm{HCl}^{(4)}$ & 11 \\
\hline & $\mathrm{NaHCO}_{3}$ & 1.6815 \\
\hline & $\mathrm{KHCO}_{3}$ & 0.2845 \\
\hline & $\mathrm{Na}_{2} \mathrm{HCO}_{3}$ & 0.3768 \\
\hline & $4 \mathrm{MgCO}_{3} \bullet \mathrm{Mg}(\mathrm{OH})_{2} \bullet 5 \mathrm{H}_{2} \mathrm{O}$ & 0.8767 \\
\hline & $\mathrm{CaHCO}_{3}$ & 1.2386 \\
\hline \multirow{4}{*}{$\begin{array}{l}\text { LCA-2 } \\
\text { LCA-3 }\end{array}$} & $\mathrm{CaCl}_{2} \cdot 2 \mathrm{H}_{2} \mathrm{O}$ & 1.3173 \\
\hline & $\mathrm{KCl}$ & 0.2635 \\
\hline & $\mathrm{MgCl}_{2}$ & 0.7786 \\
\hline & $\mathrm{NaHCO}_{3}$ & 2.2272 \\
\hline
\end{tabular}

\footnotetext{
${ }^{1}$ All chemicals used were reagent grade compounds.

${ }^{2}$ Ideal weight based on making $10 \mathrm{~L}$ of solution. All measured weights were within $0.1 \%$ of ideal weight.

${ }^{3}$ Target concentrations in the TCU-5 colloid solution were obtained using appropriate amounts of $1000 \mathrm{ppm}$ standards. Only $5 \mathrm{~L}$ of solution were made for TCU-6, thus the ideal weights were half of those listed above for the other TCU experiments; measured weights were still within $0.1 \%$ of the ideal.

${ }^{4}$ The solution recipe for LCA-1 was calculated using $1 \mathrm{~N} \mathrm{HCl}$; the value presented is in $\mathrm{mL}$.
}

\subsubsection{Sorption Solution}

As described in the Section 1.1, radionuclides used in the flow-through experiments were chosen because they represent a significant fraction of the radiologic source term at the NTS. They were also chosen because they were expected to represent a wide range of radionuclide retardation behavior. Table 2.8 summarizes the radionuclide composition of these solutions. The solutions were prepared by spiking the prepared background solutions with the appropriate amount of each radionuclide. The concentration of each radionuclide was chosen based on a combination of instrument detection limits, expected background concentrations in equilibrium with LCA and TCU rock, solubility limits, and sorption linearity.

Of the radionuclides included in the sorption solution, ${ }^{3} \mathrm{H}$ and $\mathrm{ReO}_{4}{ }^{-}$will behave as nonsorbing tracers. The only difference in their transport behavior will result from the lower diffusivity of $\mathrm{ReO}_{4}{ }^{-}$and possible charge exclusion effects due to the negative charge on the $\mathrm{ReO}_{4}{ }^{-}$anion. Its diffusivity in water is significantly less than that of tritium 
$\left(1.46 \times 10^{-5}\right.$ and $2.24 \times 10^{-5} \mathrm{~cm}^{2} / \mathrm{sec}$, respectively). The tracer $\mathrm{ReO}_{4}{ }^{-}$was used as analog to $\mathrm{TcO}_{4}^{-}\left(\mathrm{D}_{0}=1.48 \times 10^{-5} \mathrm{~cm}^{2} / \mathrm{sec}\right)$.

The predominant $\mathrm{Cs}$ and $\mathrm{Sr}$ species in solution will be $\mathrm{Cs}^{+}$and $\mathrm{Sr}^{2+}$ cations. The $\mathrm{Cs}^{+}$ cation sorbs predominantly by ion exchange to clays and zeolites (Zavarin and Bruton, 2004a). In particular, $\mathrm{Cs}^{+}$sorbs by ion exchange to illite/mica very effectively. Thus, its migration in zeolitized rock (Table 2.2) is expected to be greatly retarded. In fractured carbonate rock without fracture lining minerals, we expect $\mathrm{Cs}^{+}$to migrate nearly unretarded since its sorption to calcite is negligible and other sorbing minerals are not present in the bulk rock. The $\mathrm{Sr}^{2+}$ cation sorbs effectively by ion exchange to clays and zeolites as well. However, it also may sorb by surface complexation to iron oxides and by exchange with $\mathrm{Ca}^{2+}$ on calcite to form a solid solution (Zavarin and Bruton, 2004b). As in the case of $\mathrm{Cs}^{+}, \mathrm{Sr}^{2+}$ migration in zeolitized rock is expected to be greatly retarded. In carbonate rock, $\mathrm{Sr}^{2+}$ may be retarded but the effectiveness of calcite as a $\mathrm{Sr}^{2+}$ sorber will depend on its accessible reactive surface area.

The $\mathrm{Sm}(\mathrm{III}), \mathrm{Pu}(\mathrm{IV}), \mathrm{Np}(\mathrm{V})$, and $\mathrm{U}(\mathrm{VI})$ radionuclides can form a variety of aqueous complexes with $\mathrm{CO}_{3}{ }^{2-}, \mathrm{OH}^{-}$, or both under the experimental solution conditions. Sm(III) will complex with $\mathrm{CO}_{3}{ }^{2-}$ to form $\mathrm{SmCO}_{3}{ }^{+}$and $\mathrm{Sm}\left(\mathrm{CO}_{3}\right)_{2}{ }^{-}$at our experimental solution conditions. The formation of $\operatorname{Sm}\left(\mathrm{CO}_{3}\right)_{2}{ }^{-}$will tend to reduce sorption because the negative charge of most mineral surfaces at $\mathrm{pH} \sim 8.5$ will result in electrostatic repulsion. Nevertheless, the strong affinity of Sm for most mineral surfaces is expected to result in minimal Sm transport in both tuff and carbonate fractures (Zavarin and Bruton, 2004a; $2004 b)$ in the absence of colloids. $\mathrm{Np}(\mathrm{V})$ is expected to be in solution as the free cation, $\mathrm{NpO}_{2}{ }^{+}$, and complexed with $\mathrm{CO}_{3}{ }^{2-}$ to form $\mathrm{NpO}_{2} \mathrm{CO}_{3}{ }^{-}$. As in the case of $\mathrm{Sm}(\mathrm{III}), \mathrm{Np}(\mathrm{V})$ sorption decreases with the formation of the negatively charged aqueous complex. $\mathrm{Np}(\mathrm{V})$ only has a weak affinity for silicate and carbonate minerals in general (Zavarin and Bruton, 2004a; 2004b). Thus its sorption to tuff and carbonate rock is expected to be weak. $\mathrm{Pu}(\mathrm{IV})$ is expected to be in solution as the hydroxide complex, $\mathrm{Pu}(\mathrm{OH})_{4}{ }^{0}$, and as the hydroxycarbonate complex, $\mathrm{Pu}(\mathrm{OH})_{2}\left(\mathrm{CO}_{3}\right)_{2}{ }^{2-}$. As for other radionuclides, the formation of negatively-charged aqueous species will tend to reduce sorption. This was observed in sorption experiments reported in Kersting et al. (2003). Nevertheless, Pu(IV) expresses a moderate affinity for aluminosilicate and calcite surfaces. $\mathrm{Pu}(\mathrm{IV})$ has a very strong affinity for iron oxide and manganese oxide minerals. However, due to the trace quantity of these minerals in the tuff and carbonate rock, they are unlikely to affect the overall transport behavior of $\mathrm{Pu}(\mathrm{IV})$.

Because $\mathrm{Pu}$ (IV) is known to have an extremely low solubility limit, all of the sorption solutions were tested for the presence of $\mathrm{Pu}$ colloids to determine if the measured $\mathrm{Pu}$ was present as an aqueous species or as a colloid. Each sorption solution was centrifuged at 4500 RPM for 3 hours to remove any colloids $10 \mathrm{~nm}$ or larger from the supernatant solution. The radionuclide concentrations of the supernatant fluid were compared to the radionuclide concentrations of the non-centrifuged sorption solution. If the noncentrifuged solution had a higher concentration of a given radionuclide, it was assumed that the element was transported as a colloidal substance. Table 2.9 summarizes the percentage of each radionuclide that was transported as a colloid during each experiment 
(LCA-1 solution was not available for this analysis). In the TCU experiments that did not include zeolite colloids, $4.2 \%$ of the $\mathrm{Pu}$ was colloidal while essentially no colloidal $\mathrm{Pu}$ was present in two of the carbonate solutions (LCA-2 and LCA-3). While it will be shown in Section 3 that only a limited amount of Sm eluted through each of the cores (except in the presence of zeolite colloids), it appears that a significant fraction of the Sm was initially colloidal, possibly as a result of solubility limits. However, because of its potential to sorb to container walls, the colloidal fraction reported in Table 2.9 for Sm may have been the result of experimental error.

\begin{tabular}{|c|c|c|c|c|c|c|c|c|}
\hline Sample \# & $\begin{array}{l}\text { Tritium } \\
\text { cnts/hr. }\end{array}$ & $\begin{array}{l}\mathrm{Re} \\
--\end{array}$ & $\mathrm{Np}$ & U & $\begin{array}{c}\mathrm{Pu} \\
-\mathrm{mol} / \mathrm{L} \\
\end{array}$ & $\mathrm{Sr}$ & Cs & Sm \\
\hline TCU-2 & $2.7 \mathrm{E}+2$ & $9.8 \mathrm{E}-6$ & $4.5 \mathrm{E}-6$ & $4.5 \mathrm{E}-6$ & $5.6 \mathrm{E}-9$ & $1.0 \mathrm{E}-4$ & $1.1 \mathrm{E}-4$ & $8.2 \mathrm{E}-7$ \\
\hline TCU-3 & $2.6 \mathrm{E}+2$ & $9.2 \mathrm{E}-6$ & $3.0 \mathrm{E}-6$ & $4.6 \mathrm{E}-6$ & $6.9 \mathrm{E}-9$ & $9.5 \mathrm{E}-5$ & $9.8 \mathrm{E}-5$ & $8.8 \mathrm{E}-7$ \\
\hline TCU-4 & $2.6 \mathrm{E}+2$ & $1.1 \mathrm{E}-5$ & $3.8 \mathrm{E}-6$ & $5.8 \mathrm{E}-6$ & $5.2 \mathrm{E}-9$ & $1.0 \mathrm{E}-4$ & $9.6 \mathrm{E}-5$ & $7.5 \mathrm{E}-7$ \\
\hline TCU-5 & $7.1 \mathrm{E}+1$ & $9.1 \mathrm{E}-6$ & $4.7 \mathrm{E}-6$ & $4.0 \mathrm{E}-6$ & $6.3 \mathrm{E}-9$ & $1.0 \mathrm{E}-6^{*}$ & $1.0 \mathrm{E}-7^{*}$ & $7.6 \mathrm{E}-8^{2}$ \\
\hline TCU-6 & $3.4 \mathrm{E}+2$ & $8.4 \mathrm{E}-6$ & $2.8 \mathrm{E}-6$ & $4.2 \mathrm{E}-6$ & $5.1 \mathrm{E}-9$ & $8.4 \mathrm{E}-5$ & $8.5 \mathrm{E}-5$ & $5.4 \mathrm{E}-7$ \\
\hline LCA-1 & $2.8 \mathrm{E}+2$ & $9.3 \mathrm{E}-6$ & $6.5 \mathrm{E}-6$ & $4.7 \mathrm{E}-6$ & $6.0 \mathrm{E}-9$ & $9.3 \mathrm{E}-5$ & $1.2 \mathrm{E}-4$ & $8.4 \mathrm{E}-7$ \\
\hline LCA-2 & $2.8 \mathrm{E}+2$ & $9.5 \mathrm{E}-6$ & $5.4 \mathrm{E}-6$ & $4.3 \mathrm{E}-6$ & $5.4 \mathrm{E}-9$ & $8.4 \mathrm{E}-5$ & $7.8 \mathrm{E}-5$ & $8.2 \mathrm{E}-7$ \\
\hline LCA-3 & $2.2 \mathrm{E}+2$ & $8.2 \mathrm{E}-6$ & $4.7 \mathrm{E}-6$ & $3.7 \mathrm{E}-6$ & $4.2 \mathrm{E}-9$ & $8.1 \mathrm{E}-5$ & $8.0 \mathrm{E}-5$ & $4.9 \mathrm{E}-7$ \\
\hline
\end{tabular}

Table 2.9. Percentage of radionuclides present as colloids.

\begin{tabular}{lccccccc}
\hline & $\mathrm{Re}$ & $\mathrm{Np}$ & $\mathrm{U}$ & $\mathrm{Pu}$ & $\mathrm{Sr}$ & $\mathrm{Cs}$ & $\mathrm{Sm}$ \\
\hline TCU2, TCU-3, TCU-4 and TCU-6 & 0 & 0 & 0 & 4.2 & 0 & 0 & 33.1 \\
TCU-5 (with zeolite colloids) & 0 & 0 & 0 & 49.6 & - & - & 91.5 \\
\hline LCA-2 and LCA-3* & 0 & 0 & 1.0 & 0 & 0.1 & 0.5 & 86.3 \\
\hline
\end{tabular}

* Analysis was not performed on LCA-1 solution.

The $\mathrm{Pu}$ isotope composition used in each experiment varied significantly. The TCU-2, TCU-3, and LCA-1 solutions were composed primarily of ${ }^{242} \mathrm{Pu}$. Based on autoradiography results from these cores, experiments TCU-4, TCU-5, TCU-6, LCA-2, and LCA-3 were spiked with ${ }^{238} \mathrm{Pu}$ to increase the $\mathrm{Pu}$ activity and allow for better $\mathrm{Pu}$ autoradiography resolution in the cores. Pu isotope compositions of each of the solutions are reported in Table 2.10 .

To include $\mathrm{Pu}(\mathrm{IV})$ in the sorption solutions, two $\mathrm{Pu}(\mathrm{IV})$ stock solutions were used. Both $\mathrm{Pu}$ stock solutions were purified from ${ }^{241} \mathrm{Am}$, the $\beta$-decay daughter of ${ }^{241} \mathrm{Pu}$, using TEVA resin (Eichrom Technologies, Inc.) columns, then the final effluents were diluted into 1 $\mathrm{mol} / \mathrm{L} \mathrm{HNO}_{3}$. A Tri-Carb 2500 Liquid Scintillation analyzer from Packard Instrument Company was used for alpha liquid scintillation counting ( $\alpha \mathrm{LSC}$ ) of $\mathrm{Pu}$. 
The first $\mathrm{Pu}(\mathrm{IV})$ stock solution (referred as $\mathrm{Pu}-242$ stock) contained $0.0098 \%{ }^{238} \mathrm{Pu}$, $0.0040 \%{ }^{239} \mathrm{Pu}, 0.104 \%{ }^{240} \mathrm{Pu}, 0.047 \%{ }^{241} \mathrm{Pu}$, and $99.84 \%{ }^{242} \mathrm{Pu}$ by mass. The oxidation state of $\mathrm{Pu}(\mathrm{IV})$ in this stock was confirmed using a Guided Wave Model 260 Fiber Optic spectrophotometer. The major isotope ${ }^{242} \mathrm{Pu}$ in this stock was quantified in ICP-MS analyses. The initial concentration of $\mathrm{Pu}$ in the starting solution was $\sim 5 \times 10^{-9} \mathrm{~mol} / \mathrm{L}$.

The isotopic contents of the second $\mathrm{Pu}$ stock solution (referred as $\mathrm{Pu}-238$ enriched stock) were $7.030 \%{ }^{238} \mathrm{Pu}, 87.192 \%{ }^{239} \mathrm{Pu}, 5.57 \%{ }^{240} \mathrm{Pu}, 0.153 \%{ }^{241} \mathrm{Pu}$ and $0.051 \%{ }^{242} \mathrm{Pu}$ by mass as determined by $\alpha$-spectrometry. Because of the limited quantity, the oxidation state of the Pu-238 stock solution could be confirmed only using solvent extraction with 4-Benzoyl-3-methyl-1-phenyl-2-pyrozolln-5-one (PMBP). The extraction results showed that $>90 \pm 5 \%$ was $\mathrm{Pu}(\mathrm{IV})$. This Pu stock solution, used in TCU-4, TCU-5, TCU-6, LCA2 and LCA-3, increased Pu alpha activity from $16 \mathrm{dpm} / \mathrm{mL}$ to $341 \mathrm{dpm} / \mathrm{mL}$ (compared to the earlier $\mathrm{Pu}-242$ solution) while only increasing total $\mathrm{Pu}$ concentrations by $10 \%$, from $\sim 5 \times 10^{-9}$ to $\sim 5.5 \times 10^{-9} \mathrm{~mol} / \mathrm{L}$.

A $\mathrm{Np}(\mathrm{V})$ stock solution in $1 \mathrm{~mol} / \mathrm{L} \mathrm{HNO}_{3}$ was used as the $\mathrm{Np}$ spike. The oxidation state of $\mathrm{Np}(\mathrm{V})$ was confirmed using a Guided Wave Model 260 Fiber Optic spectrophotometer. A Tri-Carb 2500 Liquid Scintillation analyzer from Packard Instrument Company was used for $\alpha \mathrm{LSC}$ of ${ }^{237} \mathrm{~Np}$. An $\alpha, \beta$ discrimination mode was used in the LSC for ${ }^{237} \mathrm{~Np}$ to reduce the counting interference from $\beta$-emitter protactinium-234, a daughter of ${ }^{237} \mathrm{~Np}$. Gamma spectrometry with a high purity germanium detector was used for accurate nuclear counting at $29.4 \mathrm{keV}$ to determine the concentrations of ${ }^{237} \mathrm{~Np}$ in the stock and sample solutions. The initial concentrations of $\mathrm{Np}(\mathrm{V})$ in various TCU and LCA solutions were in the range of 3 to $6 \times 10^{-6} \mathrm{~mol} / \mathrm{L}$.

Table 2.10. The Pu isotope composition of experimental solutions.*

\begin{tabular}{|l|c|c|c|c|c|}
\cline { 2 - 6 } \multicolumn{1}{l|}{$\begin{array}{l}\text { TCU-2 and TCU-3 } \\
\text { Low Pu-activity solution }\end{array}$} & 0.0098 & 0.0040 & 0.1040 & 0.0470 & 99.840 \\
\hline $\begin{array}{l}\text { TCU-4 and TCU-6 } \\
\text { High Pu-activity solution }\end{array}$ & 0.6 & 7.9 & 0.6 & 0.1 & 90.8 \\
\hline $\begin{array}{l}\text { TCU-5 colloid experiment) } \\
\text { High Pu-activity solution with colloids }\end{array}$ & 0.6 & 7.9 & 0.6 & 0.1 & 90.8 \\
\hline \hline $\begin{array}{l}\text { LCA-1 } \\
\text { Low Pu-activity solution }\end{array}$ & 0.0098 & 0.0040 & 0.1040 & 0.0470 & 99.840 \\
\hline $\begin{array}{l}\text { LCA-2 and LCA-3 } \\
\text { High Pu-activity solution }\end{array}$ & 0.6 & 7.9 & 0.6 & 0.1 & 90.8 \\
\hline
\end{tabular}

*Values presented as percents. 


\subsection{Details Regarding Core Experiments}

Initial cutting and sub-coring of fractured core was described in Section 2.1. Table 2.1 lists the specifications for each experiment. Below we describe, in detail, the methods used to prepare the various fracture flow-through experiments.

\subsubsection{Tuff Cores}

\subsubsection{Synthetic Parallel-Plate Fracture}

The subcores described in Section 2.1 were sawed in half and opposing sides of the core were ground flat and parallel to the saw-cut (used for orientation purposes during grinding). The two inner faces were then ground flat with a fine-grained diamond impregnated grinding wheel. The same machine was used to grind a $500 \mu \mathrm{m}$-deep trench in one of the surfaces such that when the two halves were re-joined there would be a synthetic fracture (a "slot") with a $500 \mu \mathrm{m}$ aperture (see Figure 2.2 (a)-(e)). After both ends of the core had been ground flat (and thus perpendicular to the length of the core), the halves were placed in an ultrasonic bath of deionized water for five minutes to remove any fine-grained particles from the pores that were trapped during the machining. The cores were then placed in a $50^{\circ} \mathrm{C}$ oven for 48 hours. Finally, the two halves were glued together by applying Devcon ${ }^{\circledR}$ Flexane quick-drying, chemically-resistant rubber epoxy to the external edges of the synthetic fracture. The core was then ready to be placed in the flow-through apparatus.

\subsubsection{Colloid Transport in Parallel-Plate Fracture}

To investigate the role of colloids in radionuclide transport, a radionuclide cocktail that included colloids was injected in to a slotted fracture. ${ }^{5}$ The slotted fracture was prepared as described in Section 2.4.1.1. However, both the background and radionuclide cocktail solutions were prepared with clinoptilolite colloids. The colloid concentration was 63 $\mathrm{mg} / \mathrm{L}$; the average clinoptilolite particle size was $192 \mathrm{~nm} .{ }^{6}$ Prior to injection of the radionuclide cocktail, sufficient background colloid-containing solution was injected to reach a steady state colloid load in the fracture fluid - the colloid concentration in the starting solution and in the effluent were equal $(63.2$ and $63.1 \mathrm{mg} / \mathrm{L}$, respectively). The steady-state colloid load is believed to be more representative of field conditions where colloid generation and filtration rates have likely reached steady state.

\footnotetext{
${ }^{5} \mathrm{Sr}$ and $\mathrm{Cs}$ were omitted from the cocktail. The Sm concentration was reduced to $\sim 10^{-7}$ $\mathrm{mol} / \mathrm{L}$ to minimize the likelihood of saturation of colloid surface sites.

${ }^{6}$ The clinoptilolite colloid size was measured using a Brookhaven Instruments, Inc., particle size analyzer which uses the principles of dynamic light scattering to estimate particle size.
} 


\subsubsection{Fe-Coated Parallel-Plate Fracture}

To investigate the effect of radionuclide sorption on NTS rocks that contain iron oxide coatings, hematite $\left(\mathrm{Fe}_{2} \mathrm{O}_{3}\right)$ was precipitated onto a synthetically fractured TCU core (Figure 2.3). The precipitation method was derived from that of Shwertmann and Cornell (1991) for goethite and ferrihydrite. The procedure included mixing $210 \mathrm{~mL}$ of 0.2 molar solution of $\mathrm{Fe}\left(\mathrm{NO}_{3}\right)_{3} \cdot 9 \mathrm{H}_{2} \mathrm{O}$ with $155.3 \mathrm{~mL}$ of 1 molar $\mathrm{KOH}$. The starting solution was kept at a neutral $\mathrm{pH}$ (7.9) to avoid alteration of the zeolitized tuff. Two halves of a watersaturated synthetic fracture were placed flat side down into the solution and reacted at $70^{\circ} \mathrm{C}$ for a period of 3 days. The $\mathrm{pH}$ dropped slightly during the reaction and was adjusted back to $\mathrm{pH} 8$ with 1 molar $\mathrm{KOH}$. After removal from the oven, the core pieces were soaked in milli-Q water for a period of days to remove excess salts, then dried at $50^{\circ} \mathrm{C}$ overnight. Precipitate was identified by x-ray diffraction to be dominated by a high surface area iron oxide with diffraction peaks resembling that of hematite (Figure 2.4). The surface area of the precipitate was measured to be $226 \mathrm{~m}^{2} / \mathrm{g}$ by BET method.
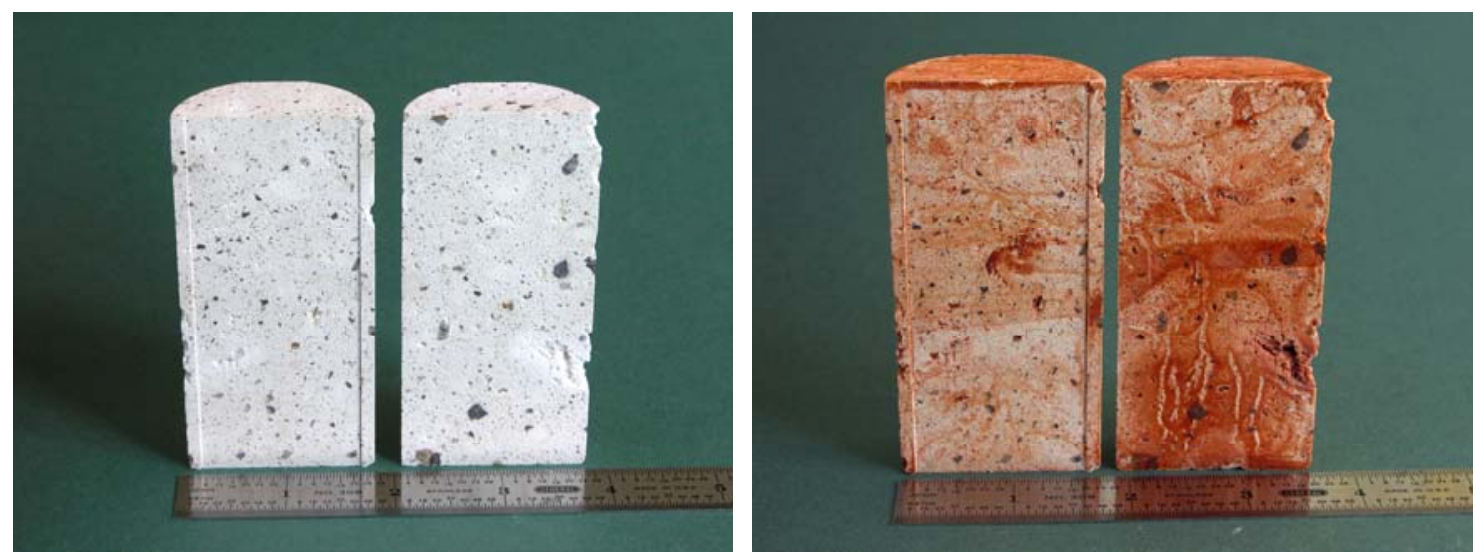

Figure 2.3. Photograph of natural tuff core UE-7az 1678.2-1679.0 on left, and same core on right after precipitation with iron oxide (TCU-6). 


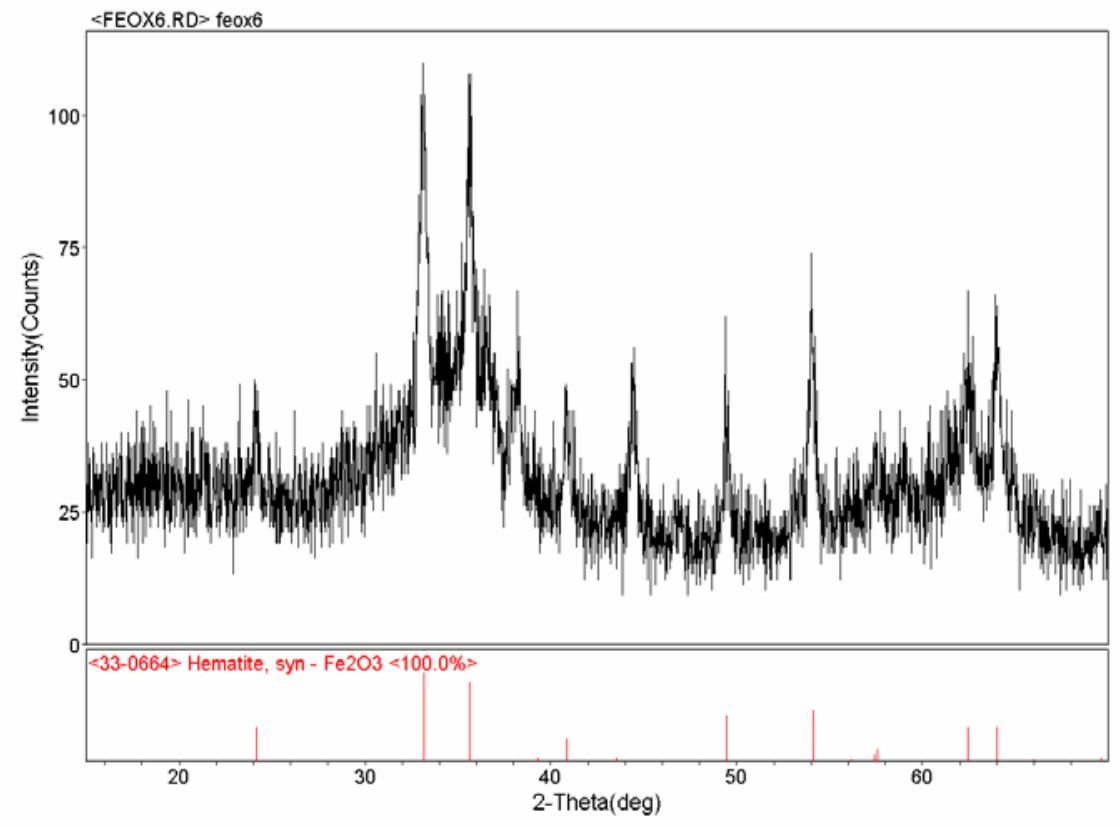

Figure 2.4. X-ray diffraction pattern of iron oxide precipitate indicating amorphous nature of precipitate with phase match to hematite.

\subsubsection{Natural Fractures}

Naturally fractured cores were also subcored (see Table 2.1), taking care to capture as much of the natural fracture as possible. The ends were then ground flat as described earlier, and both halves were ultrasonicated to remove fine particles. The cores were then glued with Flexane and loaded into the flow-through reactor as described previously.

\subsubsection{Carbonate Fractures}

\subsubsection{Synthetic Parallel-Plate Fractures}

The synthetic fractures were prepared in the carbonate cores using the same procedure outlined for the tuff cores (see Sections 2.1 and 2.4.1.1). The carbonate cores were subcored to $70 \mathrm{~mm}$, and the carbonate cores were cut to $110 \mathrm{~mm}$ in length. Core parameters for LCA experiments are listed in Table 2.1.

\subsubsection{Brazil Test Induced Fracture}

Five reference flats were precision ground on LCA-3 in preparation for inducing a fracture. The reference flats, on each end and three on the cylindrical surface are flat, parallel, and perpendicular. The separation distance between the two flats on opposite sides of the cylinder, called the $0^{\circ}$ and $180^{\circ}$ flats, form the basis for fracture normal displacement measurements. After grinding and measurement of separation distance, a single tensile fracture was driven parallel to the $0^{\circ}$ and $180^{\circ}$ flats by "Brazil" testing, i.e., 
axial line loading of the cylindrical surface, using a very stiff loading machine to minimize damage collateral to the main fracture. (see Figure 2.2 (a)-(e)). This method was previously described in Durham et al. (2001).

\subsection{Effluent and Starting Solution Analysis}

$\mathrm{Ca}, \mathrm{Na}, \mathrm{K}$, and $\mathrm{Mg}$ concentrations were analyzed using a Thermo Jarrell Ash IRIS inductively coupled plasma atomic emission spectrometer (ICP/AES) or a liquid chromatography column. Effluent $\mathrm{Cs}, \mathrm{Sr}, \mathrm{Np}, \mathrm{U}, \mathrm{Pu}, \mathrm{Re}$, and Sm concentration were analyzed on an Agilent HP4500 ICP-MS and a Thermo X7 ICP-MS. Typically, samples were diluted 2-100 times with 2\% nitric acid; an internal standard was always included.

Tritium and $\mathrm{Np}$ were measured using scintillation counting. A Tri-Carb 2500 Liquid Scintillation analyzer from Packard Instrument Company was used for liquid scintillation counting of $\alpha$-emitters ${ }^{237} \mathrm{~Np}$ and Tritium. An $\alpha, \beta$ discrimination mode was used in LSC for ${ }^{237} \mathrm{~Np}$ to reduce the counting interference from $\beta$-emitter ${ }^{234} \mathrm{~Pa}$, a daughter of ${ }^{237} \mathrm{~Np}$. In general, Np results from ICP-MS analyses had a better detection limit and were favored during data interpretation.

Bicarbonate was analyzed on an O.I. Corporation Model 545D carbon analyzer. Standard solutions were first analyzed to generate a calibration curve. A fit to these points generated the equation necessary to calculate the $\mathrm{C}$ concentration in solution.

\subsection{Post-Test Core Characterization}

Following the synthetic aperture (parallel-plate) flow-through experiments, $\alpha-$ radiography, Scanning Electron Microscopy (SEM), Secondary Ion Mass Spectrometry (SIMS), and Laser Ablation ICP-MS (LA-ICP-MS) were used to determine the location of radionuclides in the cores. First, $\alpha$-radiography was used to image the distribution of radionuclides on the core surface. This requires the surface is flat; thus, $\alpha$-radiography was only performed on the parallel-plate experiments because the uneven surfaces of the natural and Brazil-test induced fractures did not provide a flat working surface. Second, SEM was used to determine the mineralogy associated with the $\alpha$-activity and give a detailed profile of the topography of the core surface. SIMS was used to identify mineral phases and characterize radionuclide migration. The primary rationale for secondary ion mass spectrometry (SIMS) is that its combination of spatial resolution (1 micron) and sensitivity (sub-ppm to ppm detection limits) would allow the detection and association of $\mathrm{Pu}$ and other radionuclides with specific mineral phases on complex microgranular surfaces. Because the SEM and SIMS analyses required prior knowledge of sorption activity, these two sets of analyses could only be performed on those flat surfaces characterized by $\alpha$-radiography. Laser Ablation ICP-MS, on the other hand, can be performed on samples with significant topography. Thus, because it has similar sensitivity in terms of radionuclide concentration, LA-ICP-MS was used to complement the SIMS analysis. Table 2.11 summarizes the post characterization completed for all the experiments. 
Table 2.11. Matrix of post-characterization procedures.

Treatment

\begin{tabular}{|c|c|c|c|c|}
\hline & Autoradiography ${ }^{(1)}$ & SEM $^{(2)}$ & SIMS $^{(2)}$ & LA-ICP-MS \\
\hline TCU-2 & $\mathrm{X}$ & & & $\mathrm{X}$ \\
\hline TCU-3 & & & & $\mathrm{X}$ \\
\hline TCU-4 & & & & $X$ \\
\hline TCU-5 & $\mathrm{X}$ & $\mathrm{X}$ & $\mathrm{X}$ & $X$ \\
\hline TCU-6 & $X$ & & & $\mathrm{X}$ \\
\hline LCA-1 & $\mathrm{X}$ & $X^{(3)}$ & $X^{(3)}$ & $\mathrm{X}$ \\
\hline LCA-2 & $\mathrm{X}$ & & $X^{(4)}$ & $\mathrm{X}$ \\
\hline LCA-3 & & & & $\mathrm{X}$ \\
\hline \multicolumn{5}{|c|}{$\begin{array}{l}{ }^{1} \text { Autoradiography is optimal on flat surface and thus was not performed on any of the } \\
\text { natural or Brazil-test induced fractures. } \\
{ }^{2} \text { SEM and SIMS were only performed on samples characterized using autoradiography. } \\
{ }^{3} \text { Results from this work are pending. }\end{array}$} \\
\hline
\end{tabular}

\subsubsection{Alpha-Radiography}

Alpha-radiography is an in-situ, non-destructive technique based upon the decay properties of $\alpha$-emitting radionuclides to visualize their spatial distribution. Plutonium and $\mathrm{Np}$ isotopes used in the flow-through experiments are $\alpha$-emitters, and hence can be detected by using CR-39 film, a polymer of polyallyl diglycol carbonate plastic produced by Track Analysis Systems, Ltd. in Bristol, U.K. The film has a high sensitivity toward 1 $\mathrm{MeV}$ protons, $6 \mathrm{MeV} \alpha$-emissions, and an excellent optical quality making it ideal for identification of nuclear material (Cartwright, 1978). Small squares of thin plastic (60 $\mathrm{mm}$ x $60 \mathrm{~mm}$ x $1 \mathrm{~mm}$ squares with engraved ID numbers) were placed in direct contact with the fractured rock surfaces. During the exposure process, $\alpha$ particles are released from their source on the core and strike the film, forming an indentation. Following exposure, the $\alpha$ tracks were etched by placing the plastic in a sodium hydroxide solution. A high-resolution flatbed scanner (Epson Perfection 640U) was used to digitize the radiographs. The images were enhanced using a grayscale background resulting in the $\alpha$ activity appearing black in the images.

Three sets of sealed-source plutonium standards for radiography were produced by electrochemically depositing Pu onto 1-inch steel planchets. Further information on the standards can be found in Esser and Kersting (2003).

\subsubsection{SEM and SIMS}

Isotopes monitored included ${ }^{16} \mathrm{O},{ }^{24} \mathrm{Mg},{ }^{30} \mathrm{Si},{ }^{42} \mathrm{Ca},{ }^{88} \mathrm{Sr},{ }^{90} \mathrm{Zr},{ }^{133} \mathrm{Cs},{ }^{147} \mathrm{Sm},{ }^{149} \mathrm{Sm},{ }^{232} \mathrm{Th}$, ${ }^{235} \mathrm{U},{ }^{237} \mathrm{~Np},{ }^{238} \mathrm{U},{ }^{239} \mathrm{Pu},{ }^{242} \mathrm{Pu}$, and ${ }^{242} \mathrm{PuH}$ (plutonium hydride formed during mass spectrometry analysis). The Pu isotopes were chosen based on their abundance. Since a 
stable Sm(III) chloride solution was used, the two most common isotopes of Sm were monitored. Other isotopes that were not used in the radionuclide cocktail were observed for their prominence in geologic samples. Because of the relatively rough surface of the plugs, an image of the location of where analysis was occurring was not obtained, but SEM was able to decipher these areas from other impressions, i.e. vugs. Jeol Scanning Microscope (JSM) - 35CF and S-4500 scanning electron microscopes were used to determine the mineralogy associated with the areas analyzed by SIMS and other areas where SIMS will be performed.

\subsubsection{Laser Ablation ICP-MS}

Laser ablation refers to the process in which an intense burst of energy delivered by short laser pulses is used to vaporize a minute (in the range of nanograms) sample from a specific location. The chemical composition of the vaporized sample is then analyzed by an inductively coupled plasma-mass spectrometer (ICP-MS). Since 1985, laser ablation coupled with ICP-MS (LA/ICP-MS) has evolved as a powerful analytical tool for solid sampling and analysis (e.g., Russo et al., 2000; 2002). LA/ICP-MS can determine simultaneously a large number of chemical elements at low detection limits, typically in the range of nanograms to low-micrograms per gram.

We used a laser ablation system (CETAC LSX-200, CETAC Technologies, Omaha, NE), with spot-size options ranging from $25 \mu \mathrm{m}$ to $350 \mu \mathrm{m}$, interfaced with an ICP-MS (Hewlett Packard 4500, Agilent Technologies, Palo Alto, CA; or X-Series ICP-MS, Thermo Electron Corporation, West Palm Beach, FL). During data acquisition, signal intensities (counts per second, cps) were recorded for a number of elements, including introduced radionuclides $\left({ }^{88} \mathrm{Sr},{ }^{133} \mathrm{Cs},{ }^{147} \mathrm{Sm},{ }^{185} \mathrm{Re},{ }^{237} \mathrm{~Np},{ }^{238} \mathrm{U}\right.$, and $\left.{ }^{242} \mathrm{Pu}\right)$ and others elements intrinsic to the rock (e.g., ${ }^{24} \mathrm{Mg},{ }^{27} \mathrm{Al},{ }^{29} \mathrm{Si},{ }^{44} \mathrm{Ca}$ ). Examples of signal response from LA/ICP-MS are shown in Figure 2.5; about 10 seconds after ablation from laser firing, elements are detected by the ICP-MS. Intensity in the y-axis indicates the signal response measured by the ICP-MS for the laser-ablated mass. The intensity during the pre-ablation period (before 10 seconds) was considered background, and subtracted during the integration of the intensity response. 


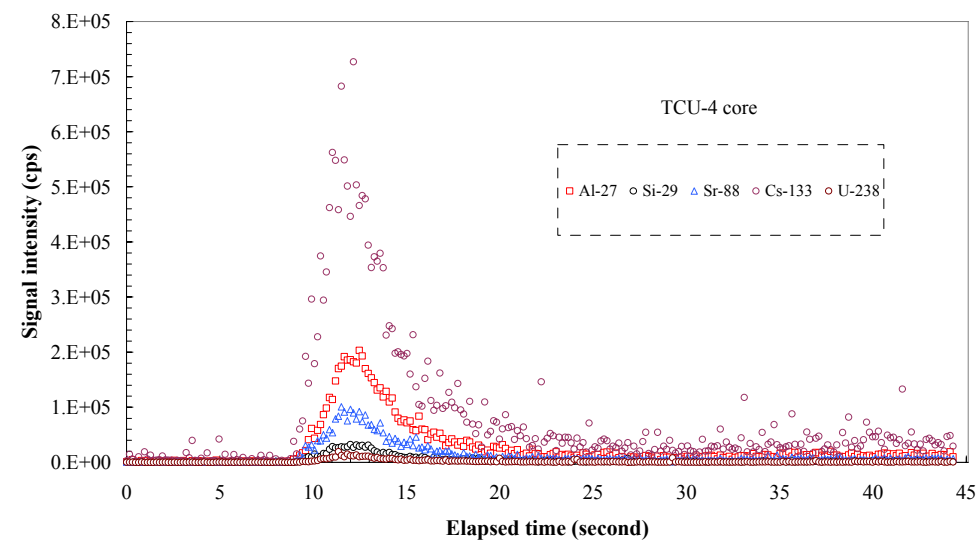

(a)

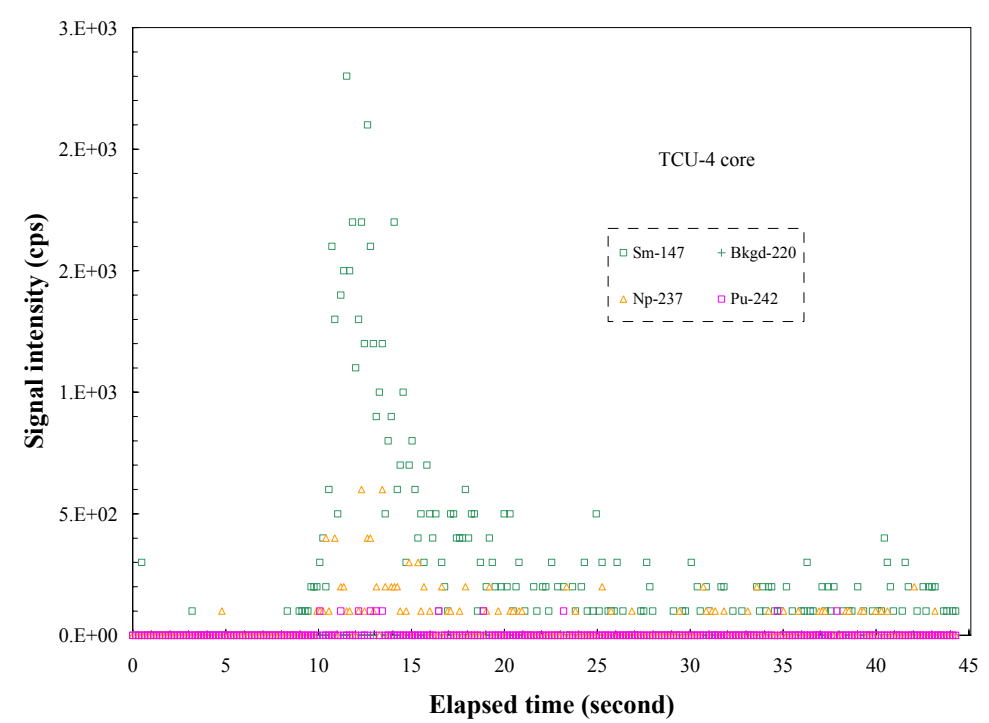

(b)

Figure 2.5. Examples of signal responses for elements from laser ablation on a tuff sample.

The distribution and concentration of different elements on a sample surface can be analyzed and mapped. Such surface mapping was conducted by firing laser pulses at a sample location on the rock surface, collecting signal response by ICP-MS, then scanning to a different location. If the rock surface is rough (i.e., natural fracture), the laser focus needs to be adjusted at each sampling location. In addition, depth mapping can be conducted by firing laser pulses at the same location and monitoring the number of fired laser pulses (which corresponds to the sampling depth).

The laser beam spot size dictates the spatial resolution during surface mapping, and the number of laser pulses determines the amount sampled; a combination of spot size and number of laser pulses can be optimized to meet different research objectives. A smaller spot size will, under the same number of laser pulses, sample less solid material, leading to potentially lower analytical precision. A spot size of $>100 \mu \mathrm{m}$ was found to generate reproducible responses, with measured relative standard deviations (RSD) for major intrinsic elements of about $10-15 \%$, along with micro-scale spatial resolution sufficient for many applications. 
Figure 2.6a shows the relationship between the signal response for nine elements intrinsic to the tuff as a function of laser pulse number. It is evident that the response is linear up to about 500 laser pulses, corresponding to a depth of about $800 \mu \mathrm{m}$. Beyond that depth, the laser starts to lose focus. Figure $2.6 \mathrm{~b}$ shows the shape and depth of a crater formed from laser ablation on tuff. The results confirm that the measured spot size of the crater is consistent with the spot size chosen from the laser. The crater exhibits a flat bottom after 50 laser pulses. However, rougher profiles are obtained with fewer laser pulses, most likely because this non-polished tuff sample had an initial surface roughness of several microns. Nevertheless, average crater depth is proportional to the number of laser pulses fired. This information provides us with confidence in correlating the number of laser pulses to the crater depth. We can, therefore, estimate transverse diffusion of radionuclides into the rock matrix during a fracture flow experiment by laser depth profiling.
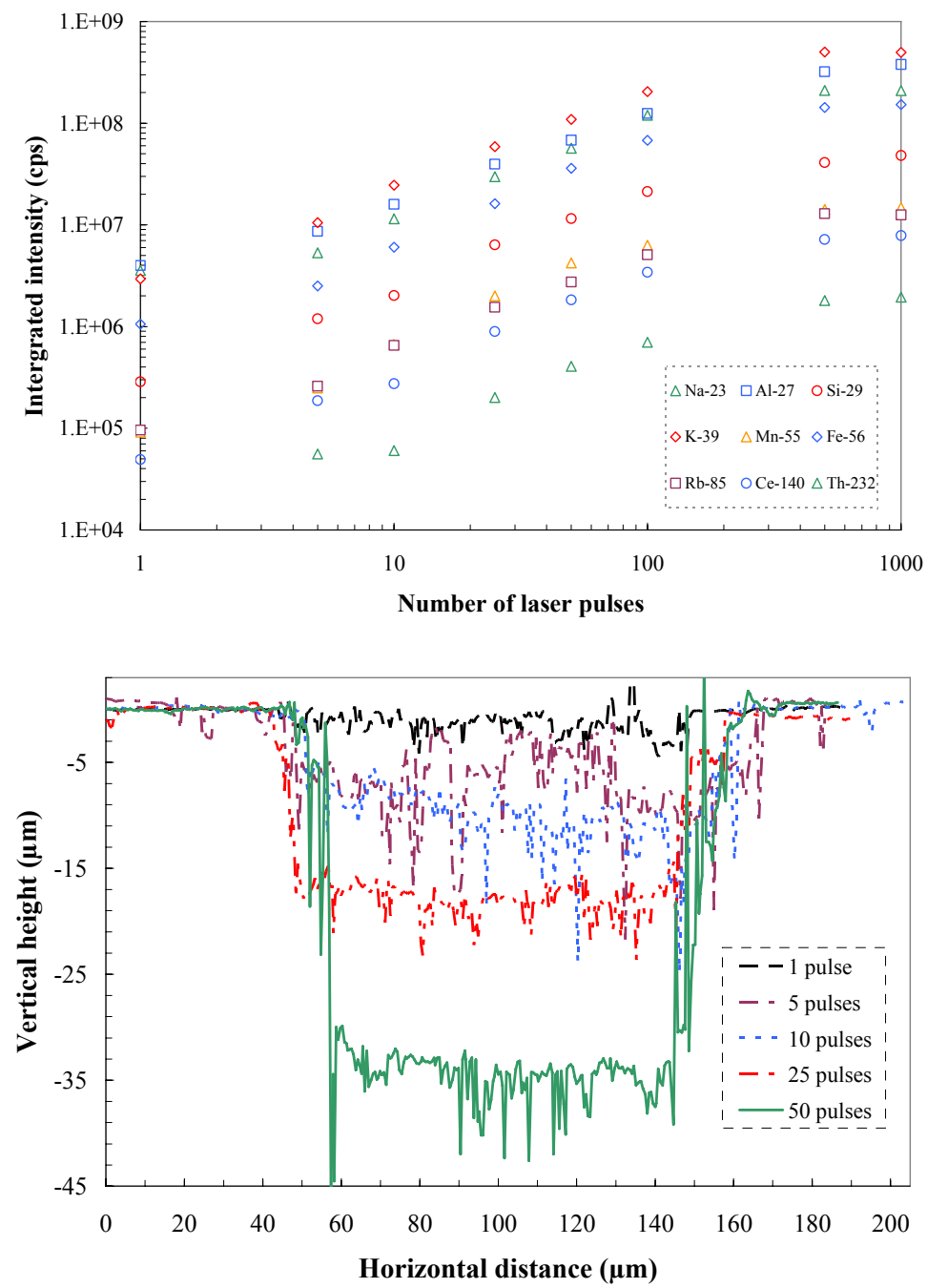

Figure 2.6. (a) Linearity between responses of intrinsic tuff elements and numbers of laser pulses at a nominal 100- $\mu \mathrm{m}$ spot size. (b) Crater depth and shape at a nominal $100-\mu \mathrm{m}$ spot size; the number of laser pulses indicated in the figure caption. 
For samples with a rough surface, the laser focus can be adjusted in the CETAC laser system at each sampling position. Figure 2.7 presents a surface profile of a tuff sample with rough (non-machined) surfaces for nine elements at a sampling interval of $1.5 \mathrm{~mm}$. At each sampling location, the laser focus was adjusted. The stable responses for these intrinsic tuff elements indicate that we have sample nearly the same volume of rock at each location.

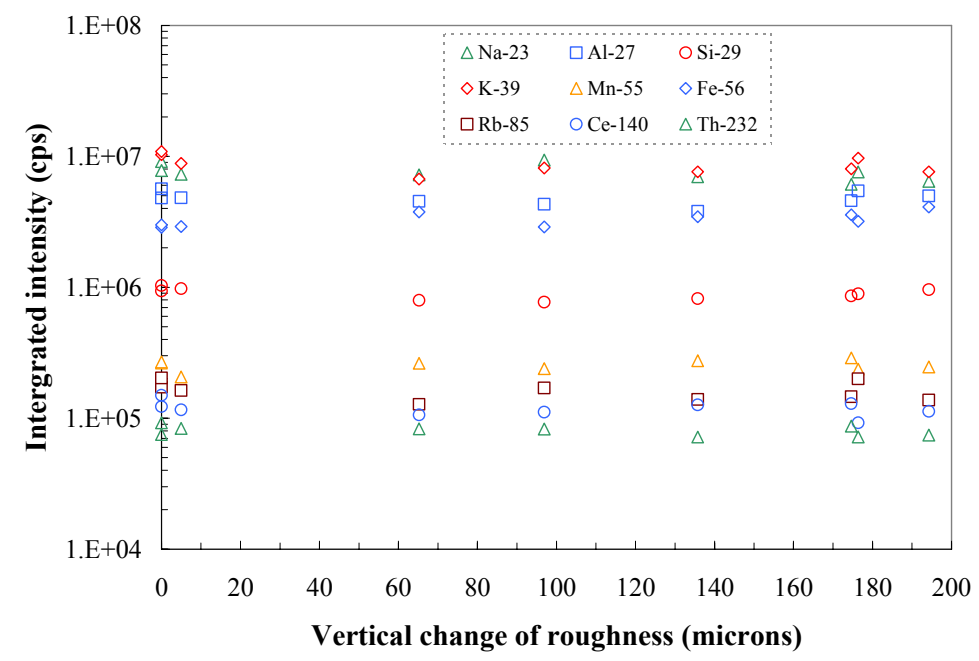

Figure 2.7. Surface profiling of a tuff sample with a rough surface $(100-\mu \mathrm{m}$ spot size, 20 laser pulses).

Quantitative measurement has been one of the major challenges in LA/ICP-MS analyses because of lack of matrix matching calibration. However, the concentration of an analysis can be calculated from a normalized ratio of both unknown and reference samples (Ghazi et al., 2000; Russo et al., 2002). The method of a single element internal standard calibration strategy is effective for overcoming the potential quantification problems of this method. Although knowing the absolute element concentration in a rock sample would be ideal, this issue can be circumvented when the relative spatial distribution of elements in the rock is of primary interest. To obtain calibration curves, four NIST glasses were used with a concentration range of about 0.02 to $500 \mathrm{mg} / \mathrm{kg}$ for many elements. Figure 2.8 shows example calibration curves for several isotopes of interest in this study. It is evident that the calibration curves are linear down to sub$\mathrm{mg} / \mathrm{kg}$ levels. 


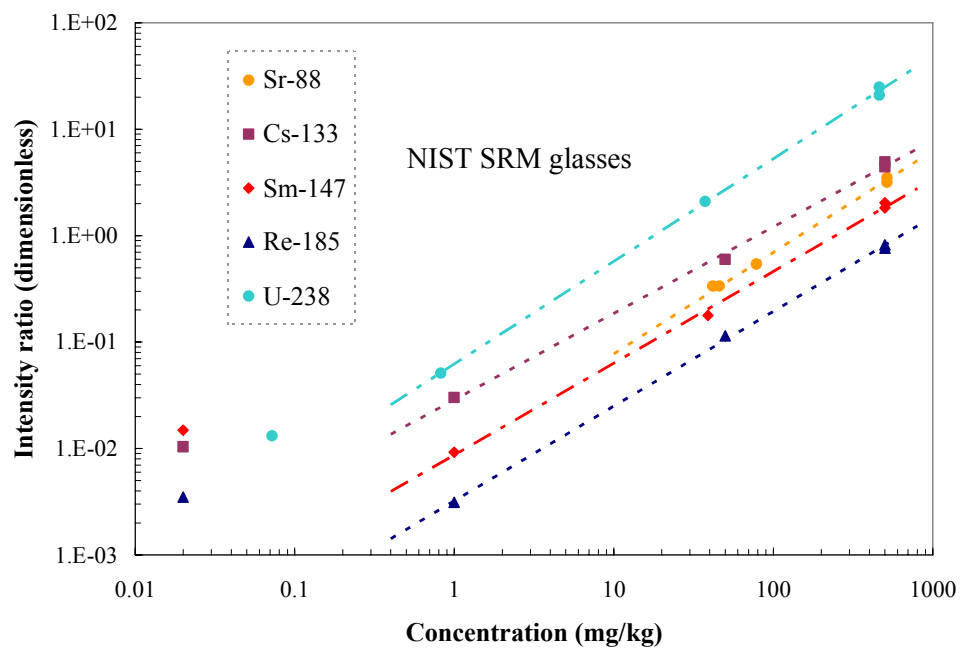

Figure 2.8. Calibration curves using NIST Standard Reference Material glasses (SRM 610, 612,614 , and 616).

For a tuff sample, Al consistently exhibits the best signal stability among the intrinsic elements (Hu et al., 2004). Therefore, a ratio approach can be used to obtain a normalized response and correct for LA/ICP-MS uncertainty by dividing the response of the element of interest (a radionuclide in this case) to that of Al. In the case of carbonate rock, calcium ( $\mathrm{Ca}$ ) can be used as the normalizing element instead of Al. During depth profiling, normalization accounts for the reduced signal as a function of depth and distinguishes it from a true decrease in the relative element concentration. Normalization during surface profiling also helps to improve data accuracy.

\subsection{Modeling Approach}

Modeling fracture transport was accomplished with either a 2D fracture transport model (CRUNCH code; an updated version of the OS3D/GIMRT code) (Steefel and Yabusaki, 1995) or using the analytical solution developed by Tang et al. (1981). An illustration of the 2D model of fracture transport used in the CRUNCH code is presented in Figure 2.9. The thickness of the matrix zone was either 22 or $35 \mathrm{~mm}$, depending on the core dimension. Synthetic fractured cores all had a half-aperture of $0.25 \mathrm{~mm}$; induced and natural fracture apertures were adjusted during modeling to fit the data. Sorption to fracture lining minerals, matrix mineral, and aqueous speciation was accomplished directly in the CRUNCH model based on surface complexation, ion exchange, and aqueous speciation thermodynamic parameters and mineral characteristics reported in Zavarin and Bruton (2004a; 2004b) and Zavarin et al. (2004). Simulations were typically run with 2 nodes in the fracture and 12 nodes in the matrix; the core length was divided into 20 nodes for a total of 280 grid blocks. This level of resolution was necessary to adequately simulate fracture flow and matrix diffusion. Matrix diffusion coefficients were based on recent experimental efforts of Reimus et al. (2002) for tuffs and Hershey et al. (2003) for carbonate rock, as will be described in the following section. Details 
regarding sorption modeling, transport parameter fitting, and sorption model validation, are reported in Section 4.

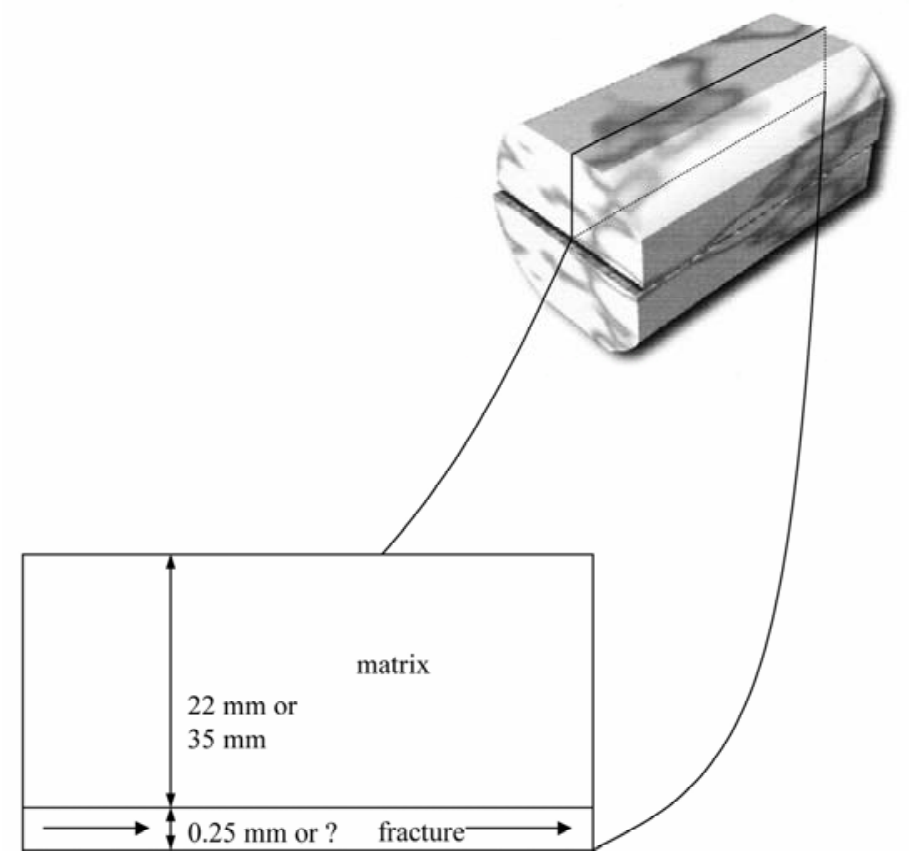

Figure 2.9. Relationship between fracture flow experiments and simulation of radionuclide transport using a 2D CRUNCH model.

The analytical solution developed by Tang et al. (1981) was used to model most transport experiments because of its greater computational efficiency. The analytic solution is based on an infinitely thick matrix, which does not reflect the relatively small amount of matrix available for diffusion in our core experiments (22 or $35 \mathrm{~mm}$ maximum thickness). However, due to the relatively fast flow rates and short radionuclide pulse, radionuclides were not expected to diffuse very far into the matrix. Thus, the analytical solution of Tang et al. (1981) was expected to work well. The analytical solution is of the following form for breakthrough from a fracture of length $z$ (meters):

$$
\begin{aligned}
& \frac{C}{C_{0}}=\frac{\exp (v z)}{\pi^{1 / 2}} \int_{l}^{\infty} \exp \left[-\xi^{2}-\frac{v^{2} z^{2}}{4 \xi^{2}}\right] \exp \left(-\eta z^{2}\right) . \\
& \left\{\exp \left[-\lambda^{1 / 2} Y\right] \operatorname{erfc}\left[\frac{Y}{2 T}-\lambda^{1 / 2} T\right]+\exp \left[\lambda^{1 / 2} Y\right] \operatorname{erf}\left[\frac{Y}{2 T}-\lambda^{1 / 2} T\right]\right\} d \xi
\end{aligned}
$$

where

$v=\frac{v}{2 D}$

$v$ is the groundwater velocity in the fracture ( $\mathrm{m} /$ day), $D=\alpha_{L} v+D^{*}$ is the hydrodynamic dispersion coefficient $\left(\mathrm{m}^{2} /\right.$ day $)$, 
$\alpha_{L}$ is the dispersivity along the fracture $(\mathrm{m})$,

$D^{*}$ is the diffusion coefficient for a particular solute in water $\left(\mathrm{m}^{2} / \mathrm{day}\right)$,

$l=\frac{Z}{2}\left(\frac{R_{f}}{D t}\right)^{1 / 2}$,

$R_{f}$ is the retardation factor for the fracture surface (or fracture lining),

$t \geq \frac{R_{f} z^{2}}{4 D \xi^{2}}$ is the time (day),

$\eta=\frac{\lambda R_{f}}{4 D \xi^{2}}$

$\lambda$ is the radionuclide decay constant $\left(\right.$ day $\left.^{-1}\right)$,

$Y=\frac{v^{2} \beta^{2} z^{2}}{4 A \xi^{2}}$

$\beta^{2}=\frac{4 R_{f} D}{v^{2}}$,

$A=\frac{b R_{f}}{\theta\left(R_{m} D^{\prime}\right)^{1 / 2}}$,

$b$ is the fracture half-aperture $(\mathrm{m})$,

$\theta$ is the matrix porosity,

$R_{m}$ is the retardation factor in the matrix,

$D^{\prime}=\tau D^{*}$ is the effective diffusion coefficient in the matrix $\left(\mathrm{m}^{2} /\right.$ day),

$\tau$ is the tortuosity factor, and

$T=\left(t-\frac{R_{f} z^{2}}{4 D \xi^{2}}\right)^{1 / 2}$.

To test the efficacy of the analytical solution, we compared the results of several analytic solutions to CRUNCH 2D simulations (Figure 2.10). The parameters used are similar to those expected in the TCU fracture flow experiments. Radionuclide retardation factors in the CRUNCH simulation were calculated internally, based on a flow-through solution composition and mineralogy from the test core (UE-7az 1714.7-1715.45). For the analytical solution, the matrix retardation factors for $\mathrm{U}, \mathrm{Np}$, and $\mathrm{Pu}$ were set to 19,62 , and 1691, respectively. These values were taken directly from the interrogation of CRUNCH simulation results. ${ }^{7}$ The porosity was set to $10 \%$, the diffusion coefficient for all radionuclides in water was $1 \times 10^{-5} \mathrm{~cm}^{2} / \mathrm{sec}$, the tortuosity was 0.17 , the column length was $0.103 \mathrm{~m}$, and the thickness of the matrix (for CRUNCH 2D simulation) was $22 \mathrm{~mm}$. The flow velocity was $1.306 \mathrm{~m} /$ day and the duration of the radionuclide pulse was 10 hours. There was no retardation in the fracture. Because the CRUNCH code is prone to

\footnotetext{
${ }^{7}$ The retardation factors used in the analytical solution are, thus, based on mechanistic model calculations but simplified to linear retardation factors. This method was used to assign radionuclide retardation factors in all predicted transport calculations using the analytical solution, as will be described in Section 4.
} 
numerical dispersion errors, dispersion in the analytic solution was varied to achieve a good match $(0.002 \mathrm{~m})$ with the CRUNCH results. Results (Figure 2.10) indicate that the two models behave nearly identically. Any differences appear to be related to numerical dispersion errors in the CRUNCH code. Furthermore, these results suggest that the infinite matrix thickness assumed in the analytic solution does not adversely affect the comparison with the 2D CRUNCH simulation that includes only a $22 \mathrm{~mm}$ thick matrix.

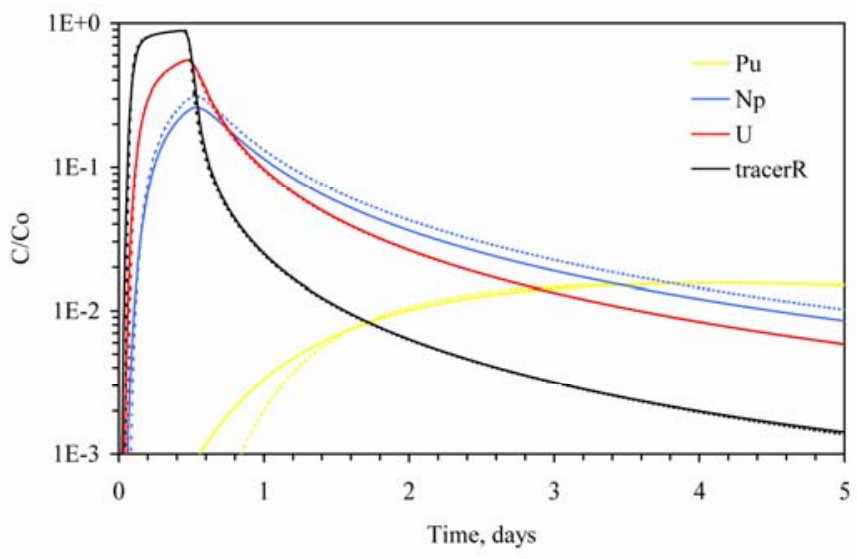

Figure 2.10. Comparison of 2D CRUNCH model (solid lines) and analytical solution (dashed lines) breakthrough curves. See text for parameter information.

\subsubsection{Parameter Effects on Radionuclide Breakthrough}

As an example, we present the effects of certain parameters on transport in a fracture using the analytical solution of Tang et al. (1981). Table 2.12 presents the baseline parameters used in these simulations. In Figure 2.11, all parameters were held constant except the fracture retardation factor $\left(R_{f}\right)$. As the fracture retardation factor increases, the peak breakthrough time increases, as expected. However, the peak concentration also decreases due to matrix diffusion. In Figure 2.12, all parameters were held constant except the matrix retardation factor $\left(R_{m}\right)$. In this case, the decrease in the peak concentration is more pronounced than when the fracture retardation factor was varied (Figure 2.11). The matrix provides a more significant radionuclide sink as $R_{m}$ increases. Importantly, the time of peak breakthrough shifts more gradually than in Figure 2.11. In Figure 2.13, all parameters were held constant except the tortuosity term $(\tau)$. The diffusion coefficient in water $\left(D_{0}\right)$ and $\tau$ are correlated and cannot be distinguished. Thus, varying the $\tau$ or $D_{0}$ has the same effect. However, $D_{0}$ is generally known for most elements. These results indicate that as the rate of diffusion into the matrix increases, the peak concentration decreases and tailing becomes more prominent. 
Table 2.12. Parameters used to evaluate effects of parameters on breakthrough.

\begin{tabular}{lrl} 
Half-fracture aperture & 0.00025 & $\mathrm{~m}$ \\
Matrix porosity & 0.30 & \\
Fracture fluid velocity & 1.5 & $\mathrm{~m} /$ day \\
Initial concentration & 1.0 & \\
Contaminant pulse length & 0.5 & day \\
Total experiment time & 30.0 & day \\
Fracture length & 0.1 & $\mathrm{~m}$ \\
Fracture retardation & 1 & $\mathrm{R}$ \\
Matrix retardation & 1 & $\mathrm{R}$ \\
Decay constant & $1 \mathrm{E}-10 \mathrm{day}^{-1}$ \\
Diffusion coefficient & $8.64 \mathrm{E}-5 \mathrm{~m}^{2} /$ day \\
Tortuosity factor & 0.169779 & \\
Dispersion coefficient & 0.01 & $\mathrm{~m}$ \\
\hline
\end{tabular}

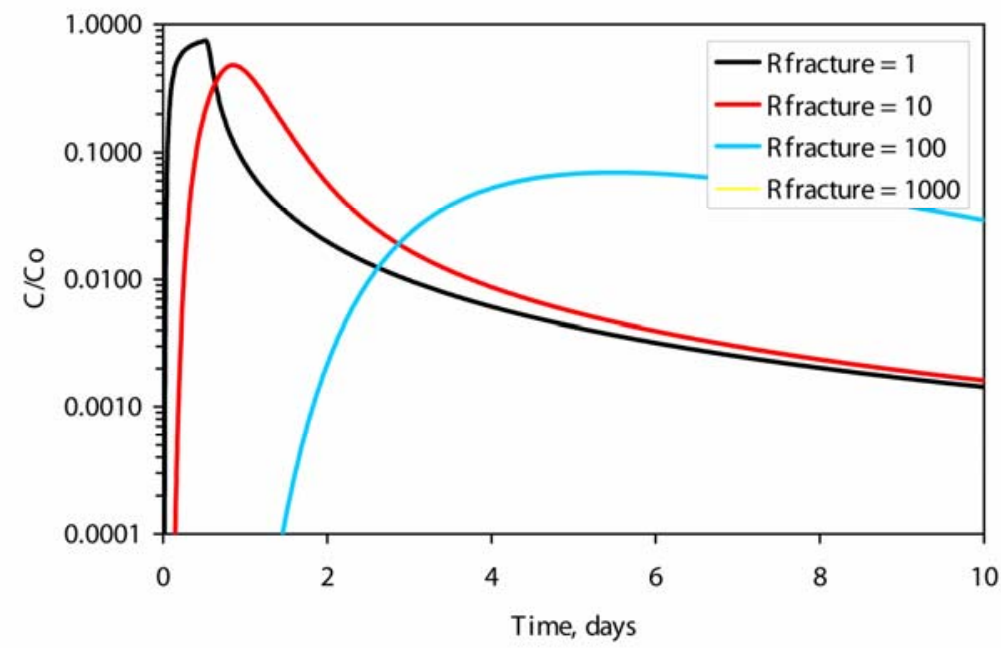

Figure 2.11. Effect of retardation in the fracture to breakthrough at the downstream boundary (no breakthrough observed for $R_{\text {fracture }}=1000$ ). 


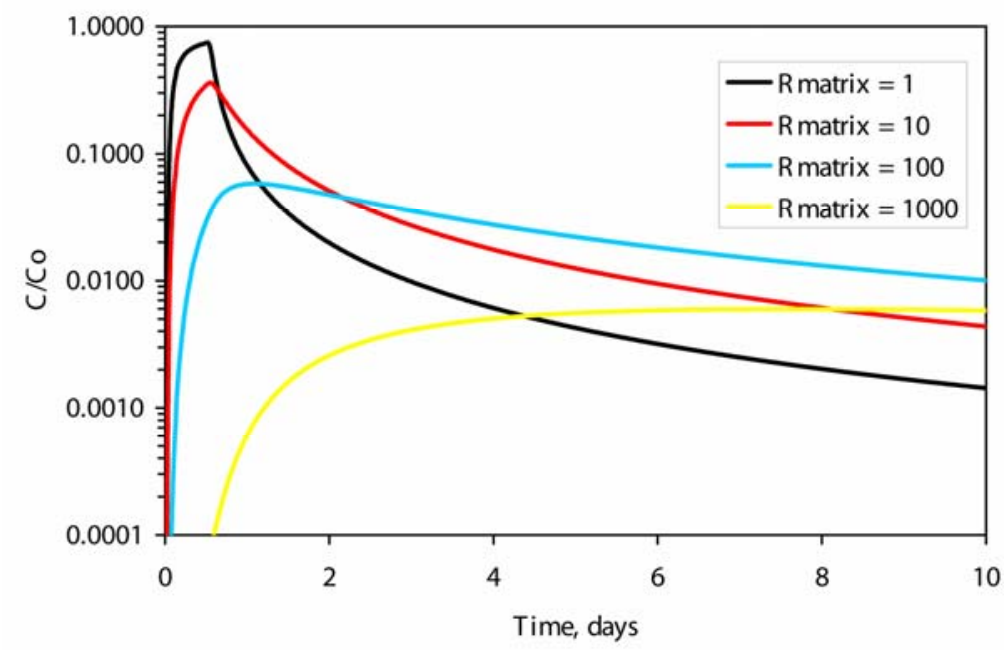

Figure 2.12. Effect of retardation in the matrix to breakthrough at the downstream boundary.

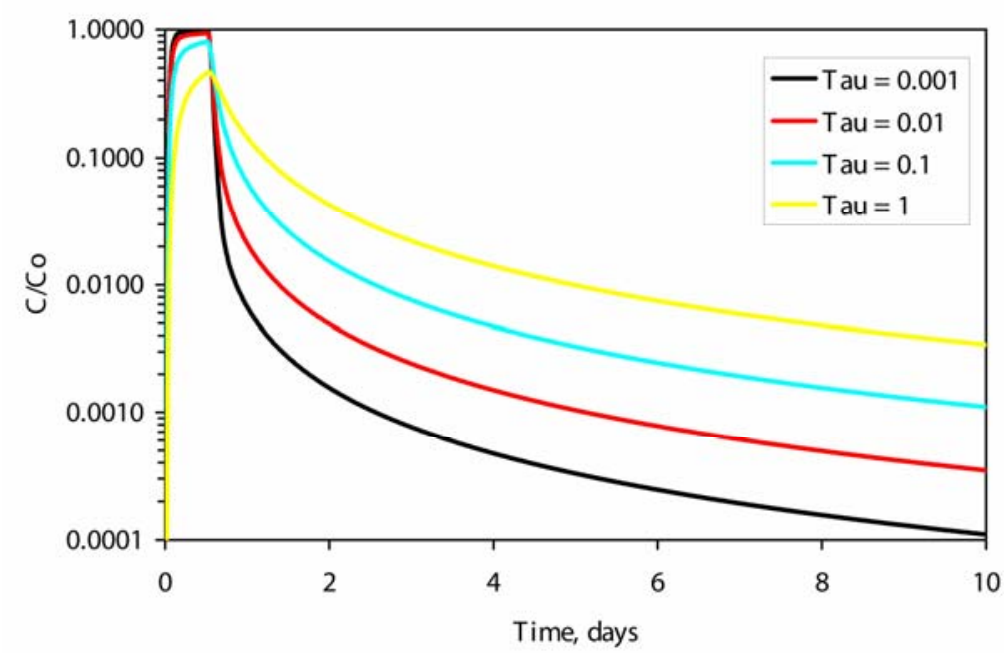

Figure 2.13. Effect of diffusion tortuosity term $(\tau)$ to breakthrough at the downstream boundary.

\section{RESULTS AND DISCUSSION}

\subsection{Tuff Fractures}

One salient feature of these experiments is the similarity between the results of the parallel-plate synthetic fracture experiments (TCU-2, TCU-5, and TCU-6) and the results of the natural fracture experiments (TCU-3 and TCU-4). While there are some minor differences, the differences are not so great as to nullify any comparison between the two 
sets of experiments. More importantly, this initial finding lends credibility to the use of a simplified fracture conceptual model in transport modeling, albeit only at the single fracture scale.

\subsubsection{Synthetic Parallel-Plate Fractures}

\subsubsection{Elution Curves}

Three synthetic parallel-plate fracture experiments were conducted. The TCU-2 experiment did not include fracture-lining minerals or colloids. The TCU-5 experiment did not include fracture-lining minerals but did include colloids. The TCU-6 experiment included high surface area iron oxide fracture linings but no colloids; results from TCU-6 are presented separately in Section 3.1.2. Below, we discuss and compare the results from the colloid-free and colloid-containing breakthrough experiments without the presence of fracture lining minerals.

In the colloid-free and colloid-containing parallel-plate breakthrough experiments (TCU2 and TCU-5, respectively), the Re tracer behaved as expected, following a nearly square wave that initially appears after approximately one pore volume and decreases immediately after the sorption pulse has passed through the entire core length. Based on tailing, some Re diffusion into the matrix does occur. However, nearly all the Re eluted over the timeframe of these experiments (Table 3.1). The tritium behavior is similar to that of Re, although the peak concentration is lower. The tritium tailing is greater than $\mathrm{Re}$ in these two experiments (Figures 3.1 to 3.4). Such a pattern is consistent with the relative diffusivity of Re and tritium in water $\left(D_{o}\right.$ of $1.46 \times 10^{-5}$ versus $2.24 \times 10^{-5} \mathrm{~cm}^{2} / \mathrm{sec}$, respectively). At the end of these experiments, 70 to $80 \%$ of tritium has eluted.

Table 3.1. Fraction of radionuclides eluted over the timeframe of each experiment

\begin{tabular}{lccccccccc}
\hline & Tritium & $\mathrm{Re}$ & $\begin{array}{c}\mathrm{Np} \\
\text { (LSC) }\end{array}$ & $\begin{array}{c}\mathrm{Np} \\
\text { (ICP-MS) }\end{array}$ & $\mathrm{U}$ & $\mathrm{Pu}$ & $\mathrm{Sr}$ & $\mathrm{Cs}$ & $\mathrm{Sm}$ \\
\hline TCU-2 & 0.72 & 0.96 & 0.53 & 0.67 & 0.72 & 0.03 & 0.00 & 0.00 & 0.00 \\
TCU-3 & 0.81 & 1.01 & 0.50 & $*$ & 0.62 & 0.00 & 0.00 & 0.00 & 0.00 \\
TCU-4 & 0.81 & 0.99 & 0.70 & 0.63 & 0.69 & 0.03 & 0.01 & 0.00 & 0.16 \\
TCU-5 & 0.80 & 0.80 & 0.56 & 0.52 & 0.52 & 0.33 & $\mathrm{a}$ & $\mathrm{a}$ & 0.59 \\
TCU-6 & 0.53 & 0.68 & 0.43 & 0.50 & 0.43 & 0.01 & 0.01 & 0.00 & 0.06 \\
\hline \hline LCA-1 & 0.77 & 0.98 & 0.63 & 0.79 & 0.82 & 0.00 & 3.08 & 0.87 & 0.00 \\
LCA-2 & 0.68 & 1.04 & 0.84 & 0.78 & 0.87 & 0.16 & 1.01 & 1.02 & 0.06 \\
LCA-3 & 0.89 & 0.99 & 0.84 & 0.96 & 0.96 & 0.55 & 1.02 & 0.99 & 0.00 \\
\hline
\end{tabular}

* ICP-MS Np measurements had calibration problems.

a Not included in the radionuclide cocktail.

In the TCU-2 experiment, no Cs was detected in the outflow (Figures 3.1), indicating that all of the Cs diffused into the matrix and sorbed onto the mineral surfaces ${ }^{8}$. When

\footnotetext{
${ }^{8}$ For further discussion of Cs matrix-diffusion, see section 3.1.1.4 on pages 52-53.
} 
colloids were added to the solution in TCU-5, Cs was only detected in two samples at $\sim 4$ days (Figure 3.3). The two values (average $3.39 \times 10^{-9} \mathrm{~mol} / \mathrm{L}$ ) are near the range of background Cs concentrations in TCU groundwater $\left(7.52 \times 10^{-9}\right.$ to $\left.3.76 \times 10^{-8} \mathrm{~mol} / \mathrm{L}\right)$ from Yucca Flat (SNJV, 2004). These Cs values, therefore, most likely reflect background Cs and not Cs pulse breakthrough. Furthermore, the low amount of Cs measured accounts for an insignificant fraction of the total Cs input into the fracture (Table 3.1). Thus, Cs was effectively retained in the fracture both in the presence and absence of colloids.

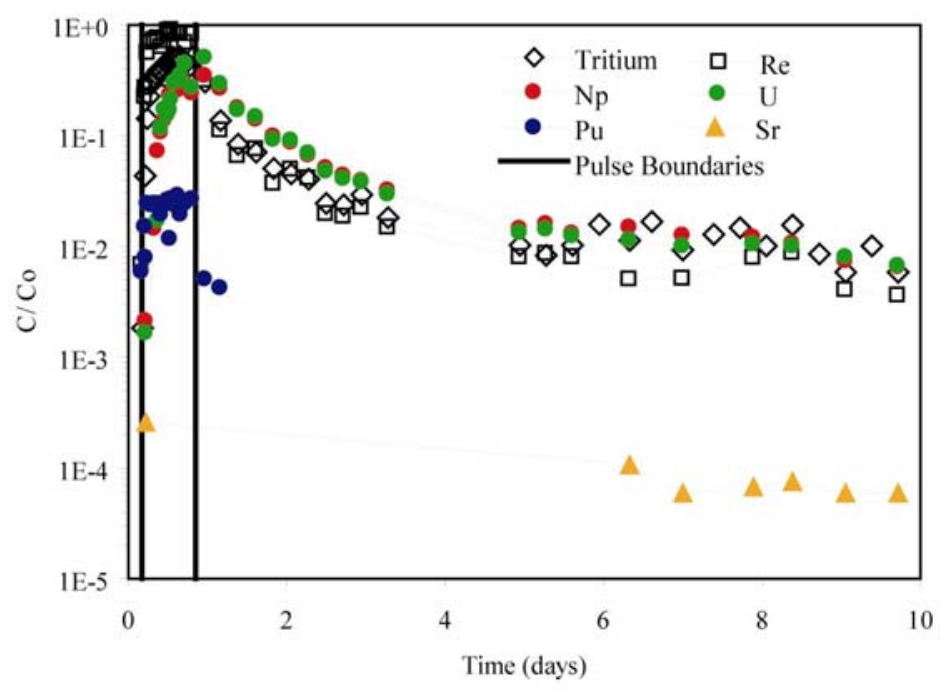

Figure 3.1. TCU-2 breakthrough plot (log scale y-axis). The two vertical lines represent the beginning and end of the sorption pulse. Cs and Sm not observed.

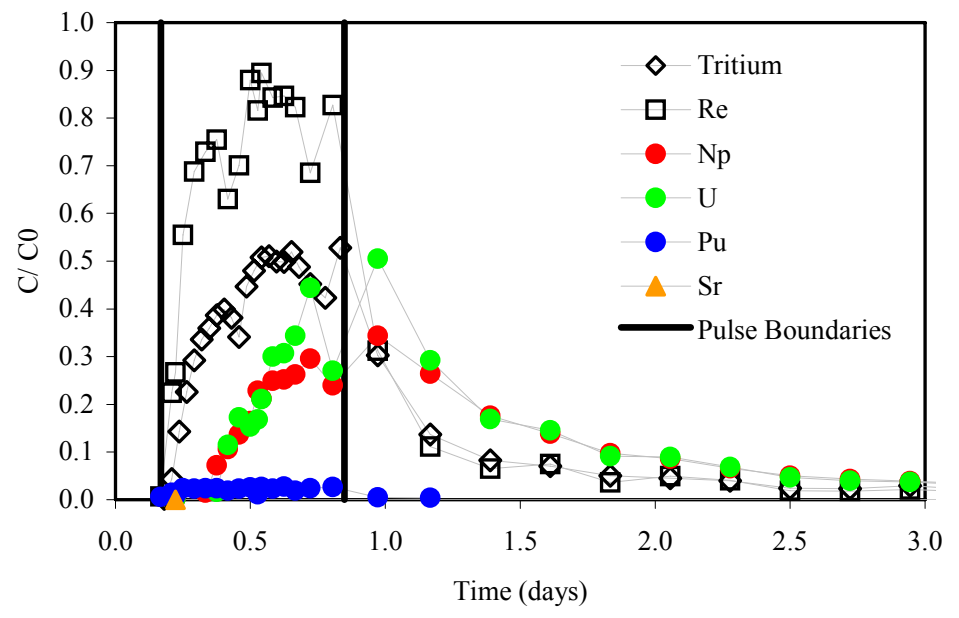

Figure 3.2. TCU-2 breakthrough plot (linear scale y-axis). Sorption pulse timeframe magnified. The two vertical lines represent the beginning and end of the sorption pulse. Cs and $\mathrm{Sm}$ not observed. 
Strontium was detected sporadically in TCU-2. Near the end of the experiment, the values stabilized at $7.42 \times 10^{-9} \mathrm{~mol} / \mathrm{L}$, significantly lower than the expected background $\mathrm{Sr}$ concentrations in TCU groundwater $\left(5.7 \times 10^{-7}\right.$ to $\left.1.1 \times 10^{-6} \mathrm{~mol} / \mathrm{L}\right)(\mathrm{SNJV}, 2004)$. It is likely that the low concentrations are the result of Sr leaching from ion exchange sites within the tuff cores. Laser ablation data described below corroborate this interpretation. Thus, the Sr pulse appears to be effectively retained in the fractured rock (Table 3.1). When colloids were added in the TCU-5 experiment, the Sr concentration in the effluent is near background $\left(1.0 \times 10^{-6} \mathrm{~mol} / \mathrm{L}\right)$. Sr was not included in the TCU-5 radionuclide cocktail. Thus, the Sr observed in the elution curve is a combination of $\mathrm{Sr}$ leached from the rock and Sr associated with the introduced colloids (see Table 2.8).

Samarium was not detected in TCU-2 but significant breakthrough was observed with the introduction of colloids (TCU-5). In the latter, Sm increased initially but rather than decreasing to the point of non-detection, the Sm values stabilized at a value equivalent to $5.56 \times 10^{-9} \mathrm{~mol} / \mathrm{L}$, only slightly lower than NTS background concentrations $\left(2.26 \times 10^{-9}\right.$ $\mathrm{mol} / \mathrm{L}$ ). In total, $60 \%$ of the Sm introduced to the fracture eluted. Furthermore, $91.5 \%$ of the initial Sm in TCU-5 was present associated with zeolite colloids. Based on these results, it appears that any significant transport of Sm in TCU fractures will likely be the result of colloid facilitated transport. It should, nevertheless, be noted that the observed Sm migration occurred in a $10 \mathrm{~cm}$ core; whether this transport mechanism is significant at the field scale requires further examination.

Plutonium was detected in both the TCU-2 and TCU-5 effluent during and immediately after the sorption pulse. The total concentration of Pu eluted in TCU-5 (33\%) is much higher than in TCU-2 (3\%) suggesting that colloids play a central role in Pu migration (Table 3.1). This observation of colloid facilitated $\mathrm{Pu}$ transport is consistent with field observations of Kersting et al. (1999). The high Pu breakthrough in TCU-5 indicates that a significant amount of $\mathrm{Pu}$ initially sorbed onto the colloids did not desorb, but instead was transported through the core. Approximately 50\% of the Pu was initially associated with colloids in the radionuclide cocktail. Thus, a fraction of the colloid-associated $\mathrm{Pu}$ appears to have been lost to the core either as a result of colloid filtration or $\mathrm{Pu}$ desorption from the migrating colloids (and subsequent sorption to the matrix). As in the case of Sm, whether the colloid facilitated transport mechanism is significant at the field scale will require further examination. However, these results suggest that significant $\mathrm{Pu}$ migration is likely to occur in the TCU only as a result of colloid facilitated transport.

$\mathrm{Np}$ and $\mathrm{U}$ transport was significantly retarded relative to the tracers. However, significant elution of these radionuclides occurred with and without colloids present. For both TCU-2 and TCU-5, 50 to $70 \%$ of the Np and U eluted from the fractures. Based on a comparison of breakthrough for the two fracture experiments, it does not appear that colloid facilitated transport is a significant mechanism for the transport of these radionuclides. 


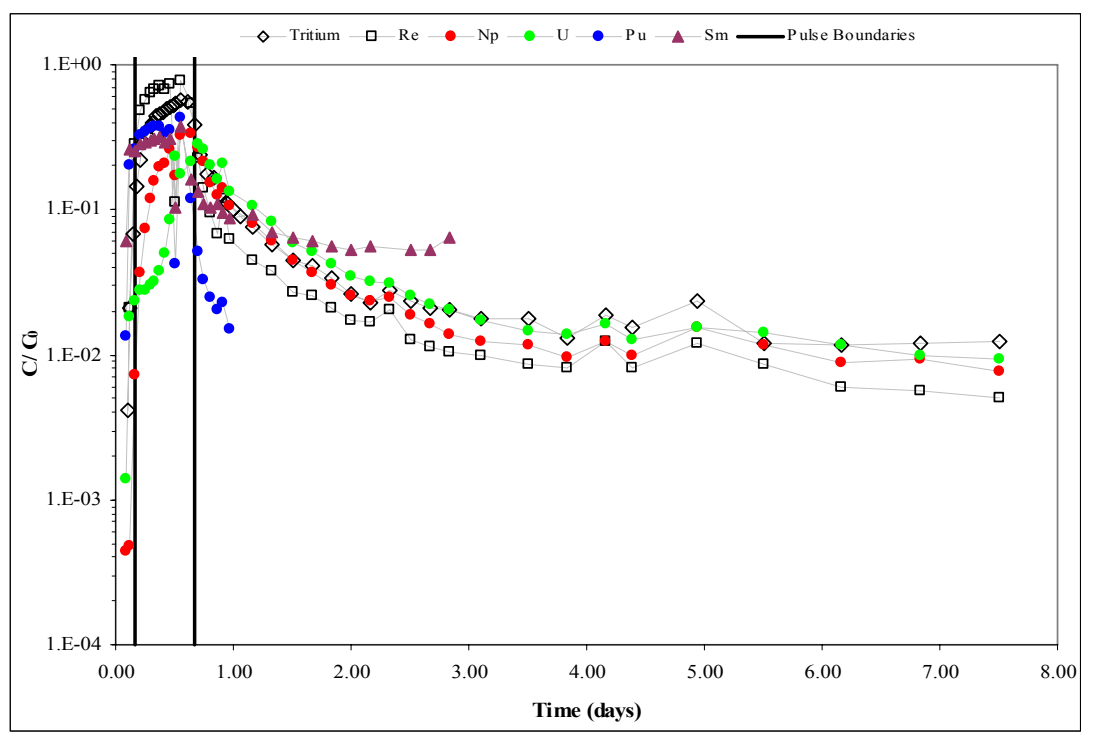

Figure 3.3. TCU-5 breakthrough plot (log scale y-axis). The two vertical lines represent the beginning and end of the sorption pulse. Cs and Sr not included in sorption cocktail.

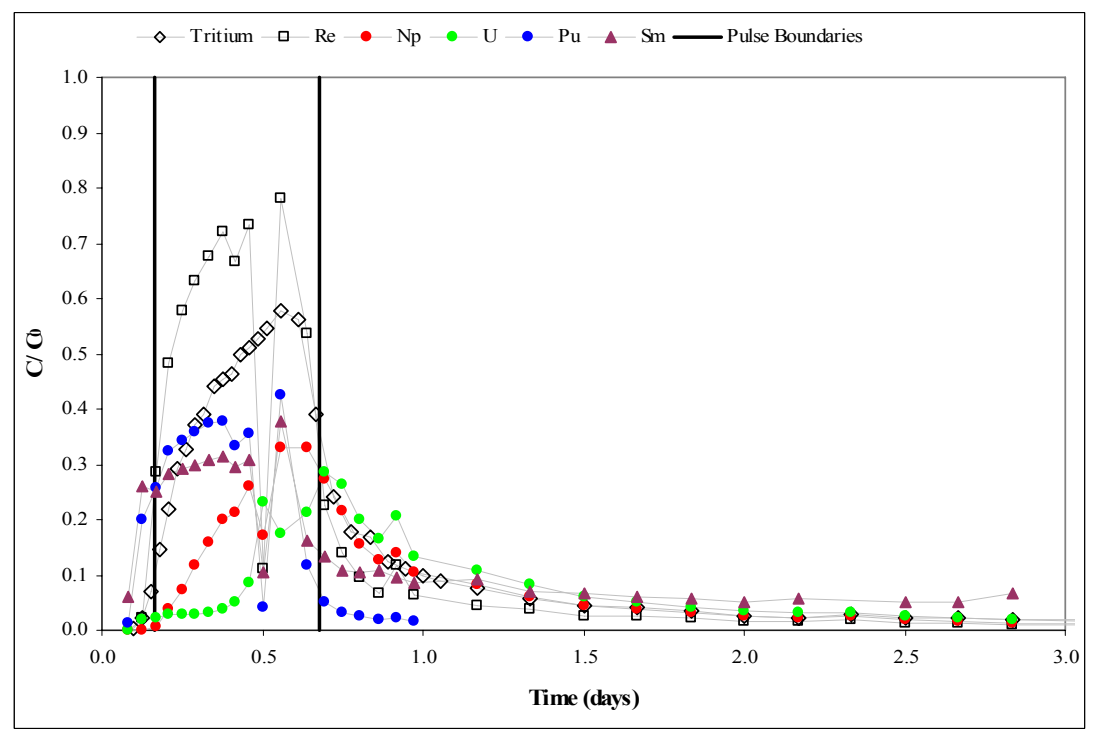

Figure 3.4. TCU-5 sorption pulse (linear scale y-axis). Sorption pulse timeframe magnified. The two vertical lines represent the beginning and end of the sorption pulse. Cs and $\mathrm{Sr}$ not included in sorption cocktail. 


\subsubsection{Core Characterization - Autoradiography}

Because the autoradiography film is rigid, radiography was performed only on those cores with smooth surfaces. The exposure times varied for each of these cores and are shown in Table 3.2.

Table 3.2 Exposure times for the rock cores on which $\alpha$-radiography was performed

\begin{tabular}{cc}
\hline Core & Exposure Time (days) \\
\hline Tuff Confining Unit 2 (TCU-2) & 8.92 \\
Tuff Confining Unit 5 (TCU-5) & 7.88 \\
Tuff Confining Unit 6 (TCU-6) & 8 \\
\hline \hline Lower Carbonate Aquifer 1 (LCA-1) & 6.75 \\
Lower Carbonate Aquifer 2 (LCA-2) & 5.75 \\
\hline
\end{tabular}

For the TCU-2 core, elution curves indicate that only a small percentage of Pu was eluted, with the majority remaining in the core (Figures 3.1. and 3.2). Yet very little total $\alpha$-activity was observed on the TCU-2 fracture surface (Figure 3.5 below). After this core was imaged, it was determined that the Pu activity in the radionuclide cocktail was too low to accurately measure by autoradiography. The Pu activity used in TCU-2 was mainly ${ }^{242} \mathrm{Pu}$. In later experiments, the Pu composition was spiked with ${ }^{238} \mathrm{Pu}$. The newly spiked solution had nearly the same concentration of $\mathrm{Pu}$, but a much higher alpha activity (See Section 2.6 for further discussion). Nevertheless, although the $\alpha$-tracks are not pronounced in the TCU-2 core, they occur throughout the core with approximately the same density. The observation of tracks throughout the core suggests that $\mathrm{Pu}$ (or possibly other $\alpha$-emitters) were distributed over the entire core. The presence of alpha tracks throughout the core suggests that some Pu migrated to the end of the core; this is consistent with $\mathrm{Pu}$ detection in the effluent (Figure 3.5). A limited number of areas that have more concentrated alpha tracks exist and appear to be mineralogically controlled. For example in Figure 3.5 (b), small gray areas (small dark dots and lines) are concentrated track clusters. 


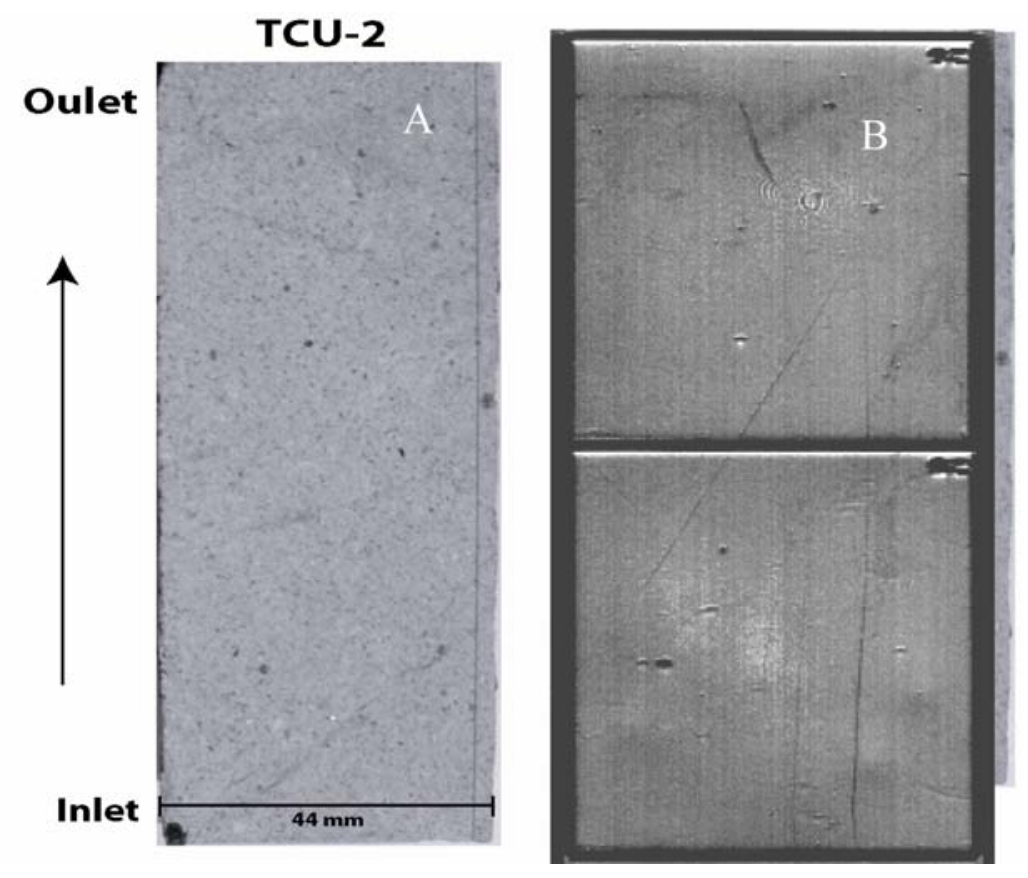

Figure 3.5. One-half of TCU-2 is shown (a) and the radiography results are overlain on the core in (b). The dark spots and lines shown in (b) are concentrated alpha tracks.

In contrast to TCU-2, the TCU-5 core was injected with a radionuclide cocktail that contained a higher activity of Pu. Furthermore, $\mathrm{Pu}$ (and the other radionuclides in the cocktail) sorbed to clinoptilolite colloids prior to injection into the fracture. There is abundant alpha activity throughout the TCU-5 core (Figure 3.6 (b)). The alpha activity is predominantly in the center of the core, with the distribution of plutonium correlated with apparent mineralogical differences on the surface. The correspondence of activity to observable mineralogy on the sub-millimeter scale is consistent with the surface composition and mineralogy playing a role in the distribution of residual $\mathrm{Pu}$ and $\mathrm{Np}$ in the cores.

In both the TCU-2 and the TCU-5 core, alpha activity does not rapidly decrease along the direction of flow in the transport experiments as significant activity is observed near both the inlet and outlet of the cores. This supports the conclusions drawn from the elution data, that $\mathrm{Pu}$ is transported to varying degrees through the core.

Subsequent examination of the TCU-5 autoradiography films (Figure 3.7) indicates the $\alpha$-activity had an affinity to darker minerals associated with the matrix. Upon physical examination, it appears that alpha-emitting radionuclides $(\mathrm{Np}, \mathrm{Pu})$ appear to have much stronger affinities toward specific mineralogy, primarily towards irregular, mafic minerals. In Figure 3.7, the areas of white clustered around dark minerals indicate high $\alpha$-activity. These concentrated areas were the focus of subsequent SEM, SIMS, and electron microprobe studies that describe the relationship between this specific mineralogy and the alpha-emitters. 

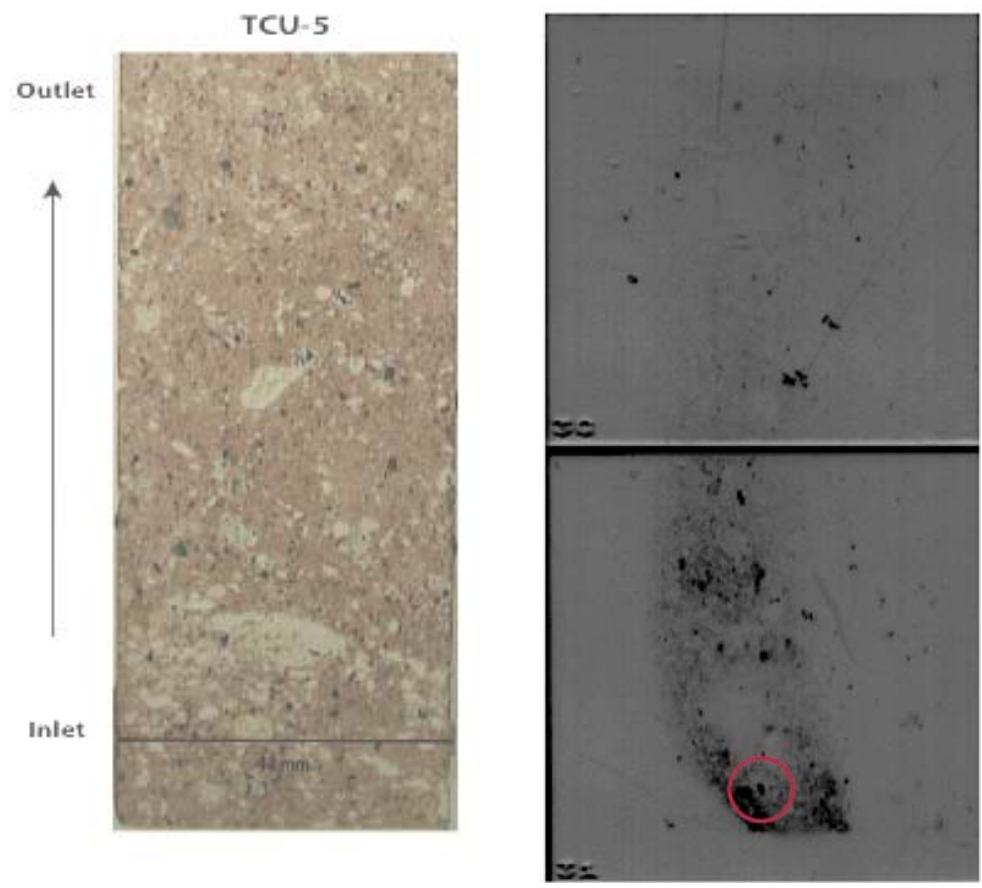

Figure 3.6. Tuff Confining Unit-5 (TCU-5) is shown in (a) and the results of the radiography are overlain on the core in (b). Red circle in (b) outlines areas shown in Figure 3.7.
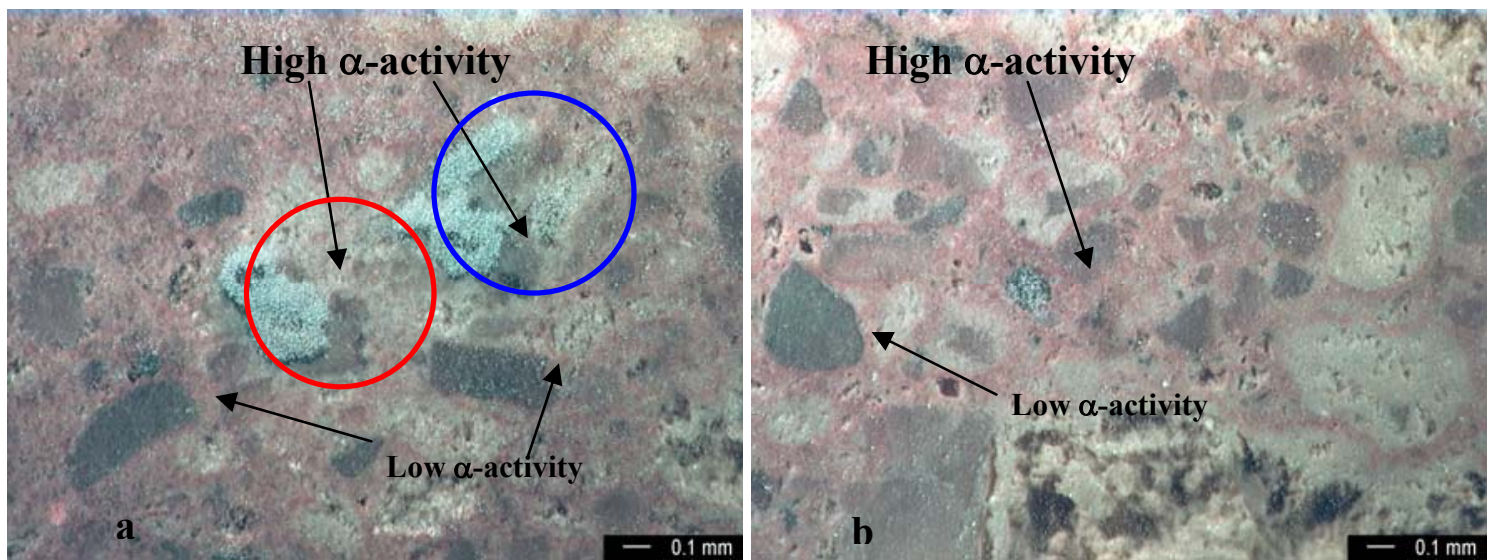

Figure 3.7 (a, b). The CR-39 film is overlain on the TCU-5 core showing the areas where $\alpha-$ activity has the greatest $\alpha$-track density. It should be noted the other fragments in the figure do not show as pronounced $\alpha$-activity as the darker fragments. Red circle in (a) indicates area shown in Figure 3.8a; blue circle indicates area shown in Figure 3.8b. 


\subsubsection{Core Characterization - SEM and SIMS of TCU-5}

From the qualitative SEM data for TCU-5 (Figure 3.8), the $\alpha$-activity on TCU-5 is associated with a mineral with substantial iron and manganese quantities, and a minor (but not trace) amount of titanium. Other similarly dark minerals showed identical chemical compositions. The gray minerals in Figure $3.7(\mathrm{a}, \mathrm{b})$ are associated with little to no activity and appear to be similar to the host matrix of potassium feldspar. The darker minerals, possibly biotite, were found to have concentrated areas of $\alpha$-activity throughout the TCU-5 core, as shown in Figure 3.9. Further analysis is needed to confirm the mineralogy of the tuff.
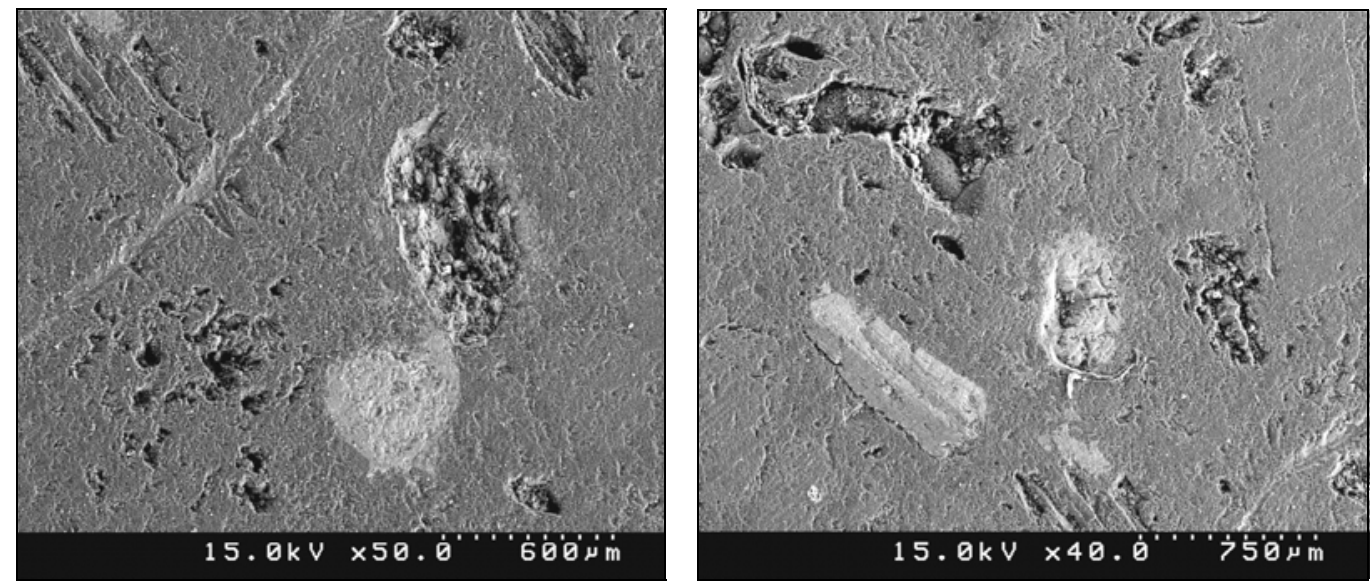

Figure 3.8. SEM images of the two high $\alpha$-activity mineral groupings in Figure 3.7a. (a) lower left mineral grouping at $15 \mathrm{kV}$ and $600 \mu \mathrm{m}$. (b) upper right mineral grouping at $15 \mathrm{kV}$ and $750 \mu \mathrm{m}$.

SIMS analysis was performed on TCU-5 to identify the alpha emitting radionuclides sorbed onto the core. Analyses were obtained on a transect corresponding to the highest density of alpha tracks located at the outlet of the core. These results are listed in the appendix (Table 8.25). The identification ${ }^{242} \mathrm{Pu},{ }^{237} \mathrm{~Np},{ }^{235} \mathrm{U}$, and ${ }^{149} \mathrm{Sm}$ is consistent with the elution data that suggest that $\mathrm{Pu}, \mathrm{Np}, \mathrm{U}$, and Sm were all transported through the TCU core. When combined with electron microprobe analyses, as in Figure 3.9, it is easy to see the aforementioned pattern of stronger radionuclide sorption to Fe and Mn minerals than to the matrix minerals.

Figure 3.10 further illustrates the relationship between sites of high Pu-activity and the concentration of $\mathrm{Fe}$ and $\mathrm{Mn}$ in the minerals at those sites. Note that all the high-Pu sites, except site 7, also had $\mathrm{Fe}$ and $\mathrm{Mn}$ counts, and that the Fe was typically higher than background but not as high as $\mathrm{Mn}$. A strong relationship between $\mathrm{Pu}$ and $\mathrm{Mn}$ has been observed in previous research (Duff et al., 1999). 


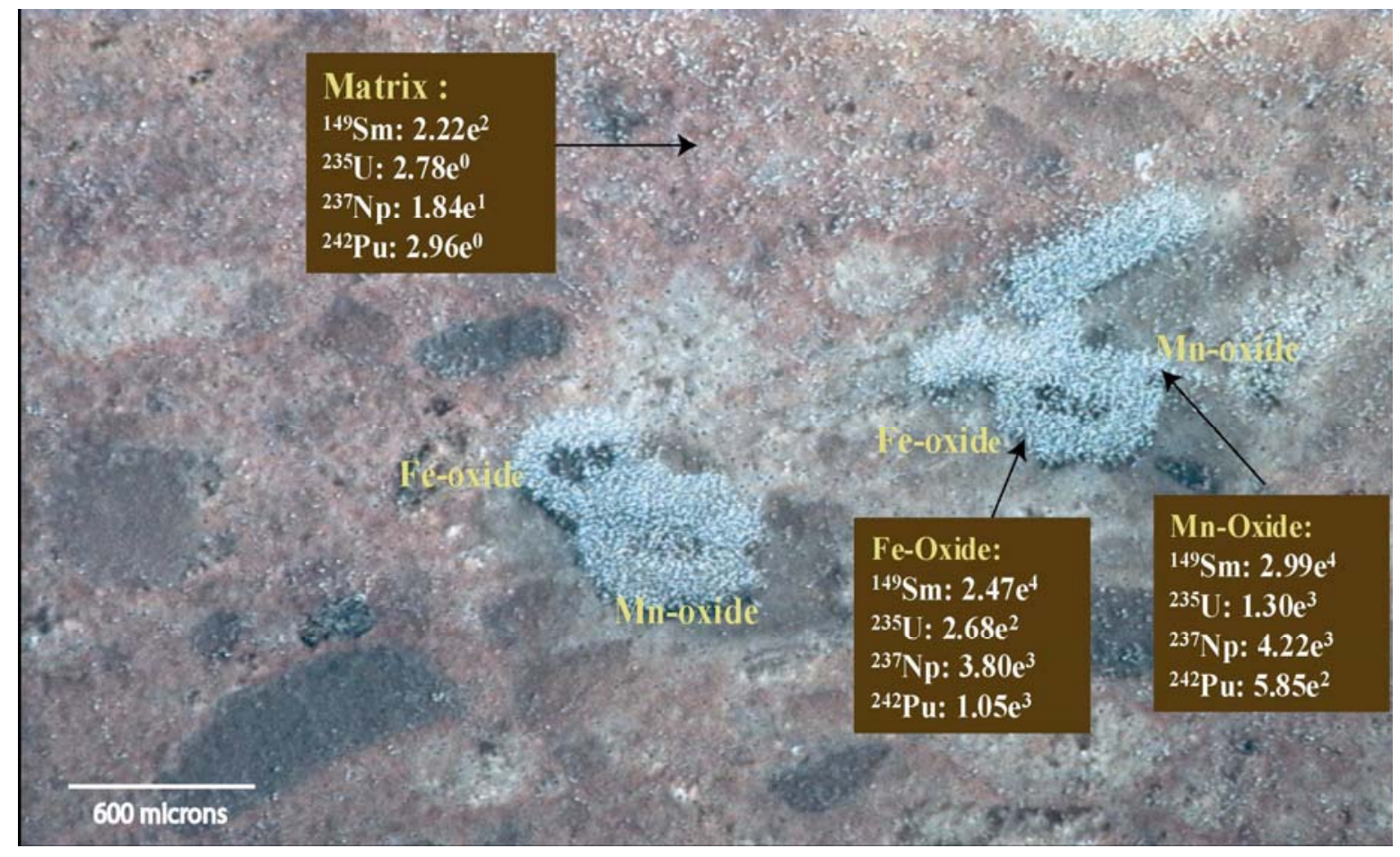

Figure 3.9. Image from Figure 3.7a with the addition of the SIMS and electron microprobe data. Radionuclide counts reported in white determined using SIMS; mineralogy shown in yellow determined using electron microprobe. Note the orders of magnitude increase in all four radionuclide counts in the $\mathrm{Fe}$ - and Mn-oxides relative to the rock matrix, composed mostly of zeolitic and feldspar minerals. 

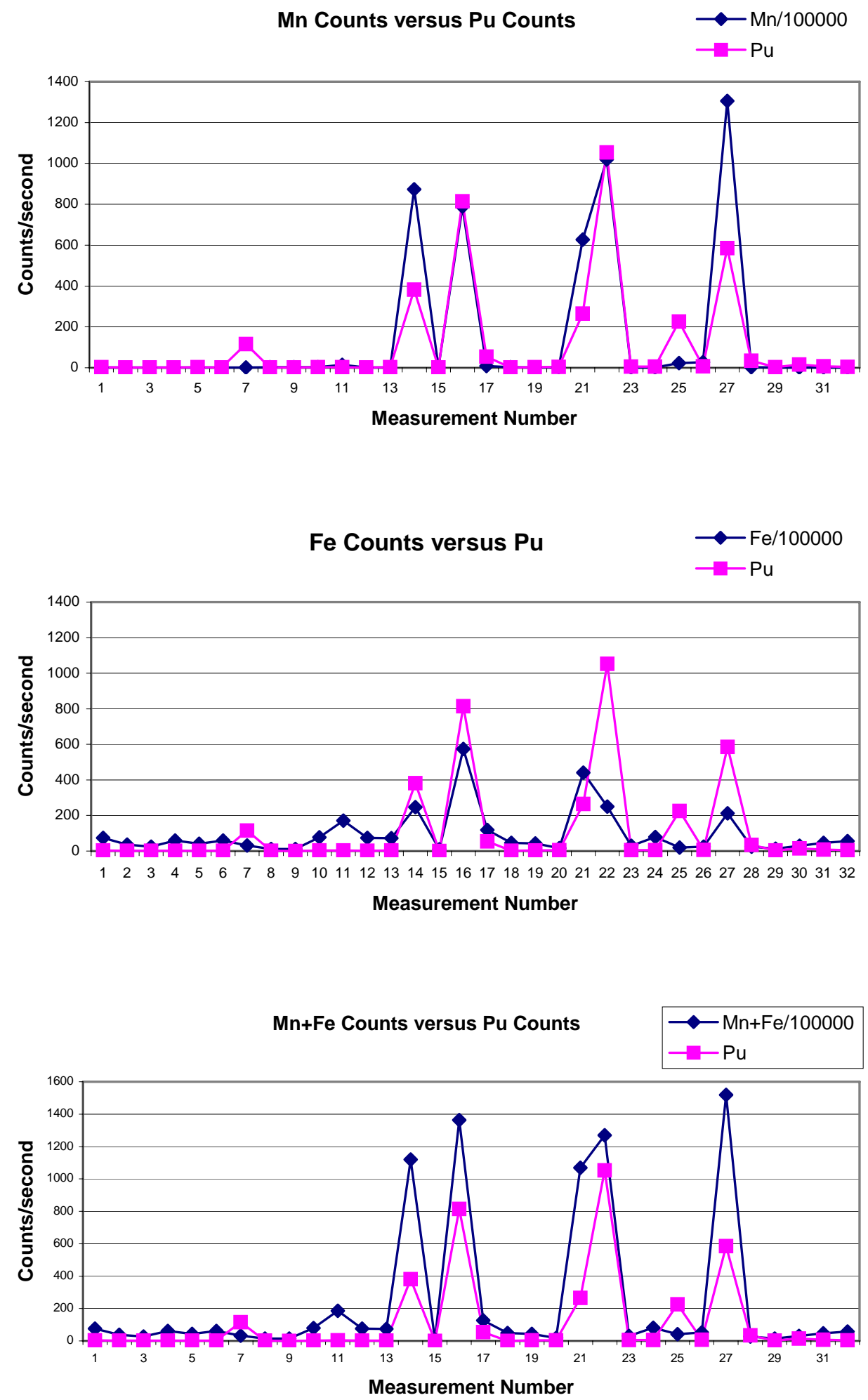

Figure 3.10. Graphs showing relationship between $\mathrm{Mn}, \mathrm{Fe}$, and Pu for the TCU-5 SIMS analysis. (A) Mn and Pu counts, (B) Fe and Pu counts, and (C) Mn+Fe and Pu counts. 


\subsubsection{Core Characterization - Laser Ablation}

For the TCU-2 experiment (parallel-plate, no colloids), measured radionuclide distribution on the fracture surface using LA/ICP-MS is consistent with radionuclide elution data. $\mathrm{Re}, \mathrm{Np}$, and $\mathrm{U}$ were not detected, all of which eluted to a great extent during the transport experiment, nor was Pu observed, likely because of its extremely low initial concentration $\left(5 \times 10^{-9} \mathrm{~mol} / \mathrm{L}\right)$. However, a distinct profile of $\mathrm{Sr}$ and $\mathrm{Cs}$ was obtained on the fracture surface (Figure 3.11). These radionuclides were not detected in the effluent. It is evident that the concentration of both $\mathrm{Sr}$ and $\mathrm{Cs}$ decreases dramatically with distance from the core inlet, and reaches background levels after about $0.6 \mathrm{~cm}$. Thus, it appears that $\mathrm{Cs}$ and $\mathrm{Sr}$ migrated less than $1 \mathrm{~cm}$ over the timeframe of the experiment. When compared with the flow velocities in the fracture $(1.2 \mathrm{~m} /$ day $)$ and the total experiment time ( $\sim 10$ days), we can estimate the effective retardation factor of both Cs and Sr to be $>>1200$. Note that the background level for $\mathrm{Sr}$ is higher than Cs, as tuff samples contain an appreciable amount of $\mathrm{Sr}$.

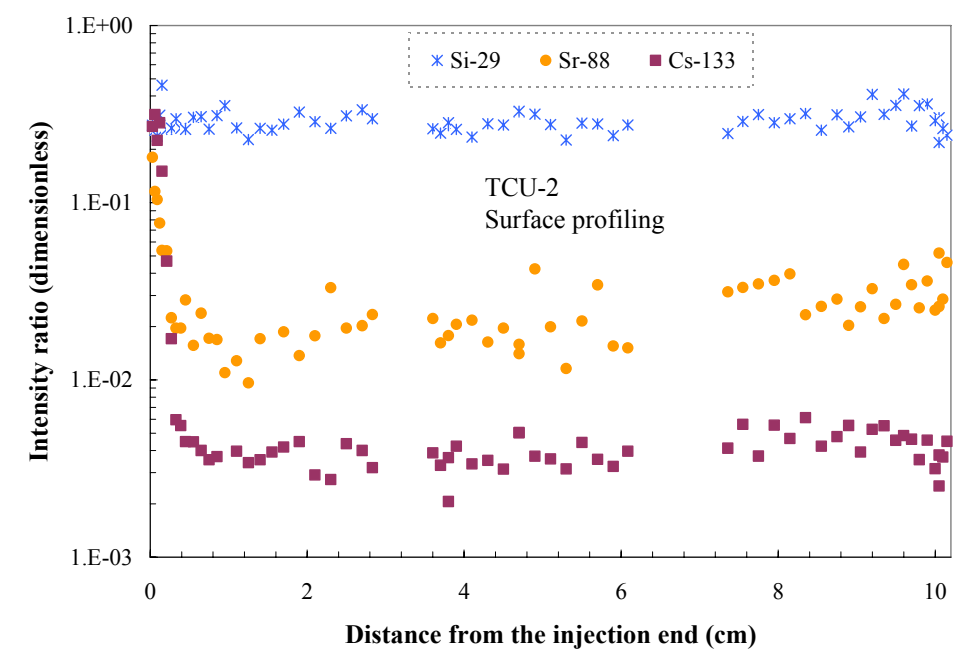

Figure 3.11. Distribution of ${ }^{88} \mathrm{Sr}$ and ${ }^{133} \mathrm{Cs}$ obtained from surface profiling in TCU-2 core using LA/ICP-MS. Y-axis: intensity ratio denotes the signal of a tracer divided by the signal of internal standard (aluminum for tuff). Response of another intrinsic element (silicon) in tuff is also shown in the figure to indicate the stability across the profile depth, as expected from its "uniform" distribution.

The elution data from TCU-5 (parallel-plate, with colloids) showed significant transport of Re, Sm, Np, U, and Pu (to some extent), and LA/ICP-MS analysis of the core did not indicate significant concentrations of these radionuclides. This does not necessarily mean that these radionuclides are not present on the core since detection limits of LA/ICP-MS may have prevented the detection of $\mathrm{Sm}$ and $\mathrm{Pu}$, as suggested from the TCU-2 analysis. Nevertheless, nearly all of Re, Np, and U eluted during the flow-through experiment and were unlikely to be observed by LA/ICP-MS. As in the case of the TCU-2 experiments, $\mathrm{Cs}$ and $\mathrm{Sr}$ were expected to migrate very little. However, the radionuclide cocktail used in the TCU-5 experiment did not contain these radionuclides. Thus, it should not be 
surprising that the Cs profile along the fracture length, shown in Figure 3.12, is uniform, reflecting background concentrations.

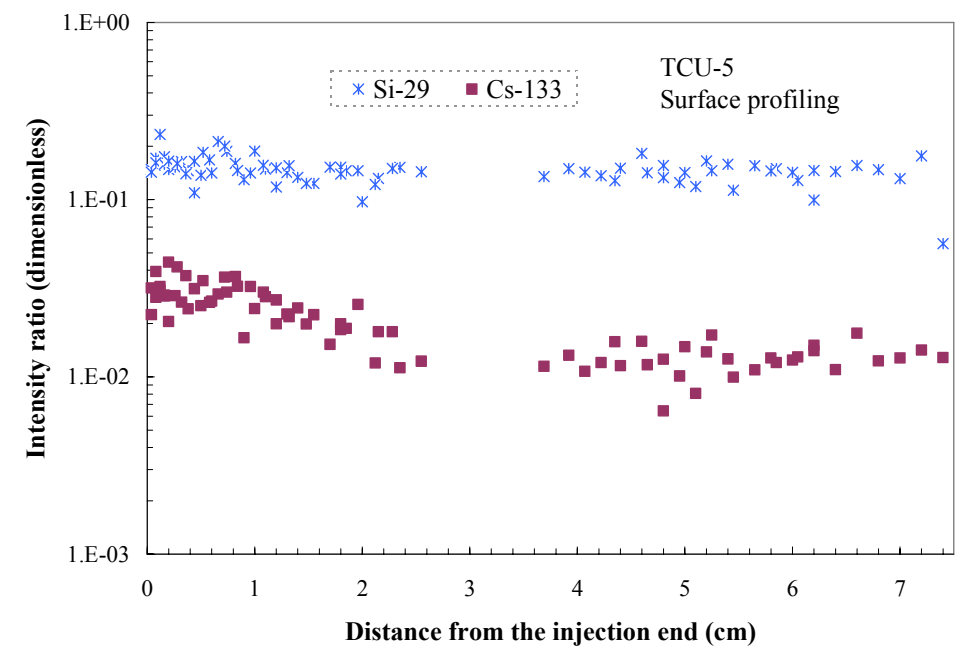

Figure 3.12. Distribution of ${ }^{133} \mathrm{Cs}$ obtained from surface profiling in TCU-5 core sample using LA/ICP-MS.

\subsubsection{Fe-Coated Parallel-Plate Fracture}

\subsubsection{Elution Curves}

Both Re and tritium produced the square elution curves typical of non-sorbing tracers (Figures 3.13 and 3.14). The relative concentrations of each tracer are comparable to those values measured for all the other tuff experiments. As noted for the other parallelplate tuff experiments, no Cs was detected in the TCU-6 outflow. The tail of the Sr curve exhibits a greater degree of variability than the other experiments (Figure 3.13). The average value measured during this portion of the experiment is $1.02 \times 10^{-7} \mathrm{~mol} / \mathrm{L}$, which is lower than the background concentration in Yucca Flat TCU waters $\left(5.7 \times 10^{-7}\right.$ to $1.1 \mathrm{x}$ $10^{-6} \mathrm{~mol} / \mathrm{L}$ ) as is likely the result of Sr leaching from the rock. 


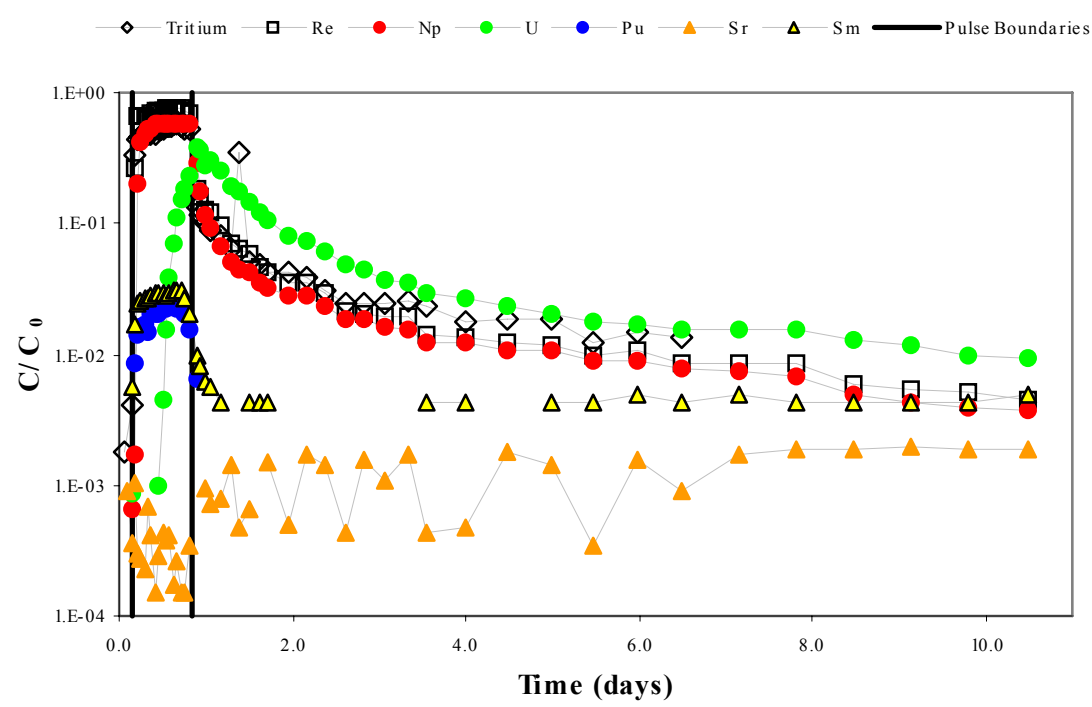

Figure 3.13. TCU-6 breakthrough plot (log scale y-axis). The two vertical lines represent the beginning and end of the sorption pulse. Cs not observed.

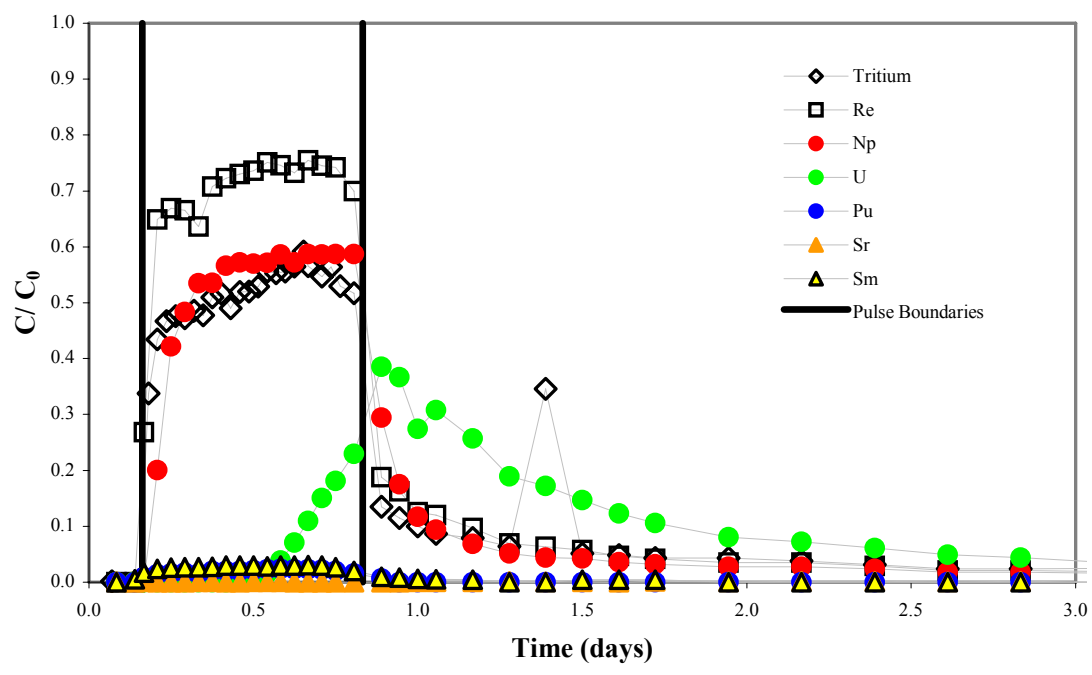

Figure 3.14. TCU-6 sorption pulse (linear scale y-axis). Sorption pulse timeframe magnified. The two vertical lines represent the beginning and end of the sorption pulse. Cs not observed.

Samarium and $\mathrm{Pu}$ produce nearly identical curves during the sorption pulse (Figure 3.14), although slightly more $\mathrm{Sm}$ than $\mathrm{Pu}$ eluted during this time. Following the pulse, the $\mathrm{Pu}$ concentration decreases rapidly, as in the other experiments, and the Sm concentration decreases until reaching a plateau. The Sm concentration remains steady at $2.33 \times 10^{-9}$ $\mathrm{mol} / \mathrm{L}$, which is approximately equal to the expected $2.26 \times 10^{-9} \mathrm{~mol} / \mathrm{L}$ background concentration.

$\mathrm{Np}$ and $\mathrm{U}$ are transported at drastically different rates when tuff is coated with Fe-oxide. In the absence of $\mathrm{Fe}$-oxide coatings, $\mathrm{U}$ and $\mathrm{Np}$ transport rates are nearly the same 
(Figures 3.1 to 3.4 ). It appears that $\mathrm{Np}$ transport is not affected significantly by the coating, as shown by the square shape of the Np curve during the sorption pulse (similar to TCU-2 and TCU-5 experiments). Uranium, on the other hand, appears to sorb to the Fe-oxide coating, significantly retarding its peak breakthrough. A more detailed examination of the role of iron oxide coatings is presented during transport data modeling (Section 4).

\subsubsection{Core Characterization - Laser Ablation}

For the TCU-6 experiment where a synthetic fracture was coated with iron oxide, we detected the presence of $\mathrm{Np}$ and $U$ on the fracture surface (Figure 3.15). The U interacts more strongly with the iron oxide than with the tuff matrix, which contributes to their delayed transport through the fracture core. Note that the background level for ${ }^{238} \mathrm{U}$ is quite high in tuff samples, which is reported to be $3.92 \mathrm{mg} / \mathrm{kg}$ (Peterman and Cloke, 2001). This limits our ability to distinguish between background $U$ and $U$ introduced to the column. The detected ${ }^{238} \mathrm{U}$ is only somewhat higher than background but rather uniformly distributed. The distribution of ${ }^{237} \mathrm{~Np}$ is also relatively uniform across the core length.

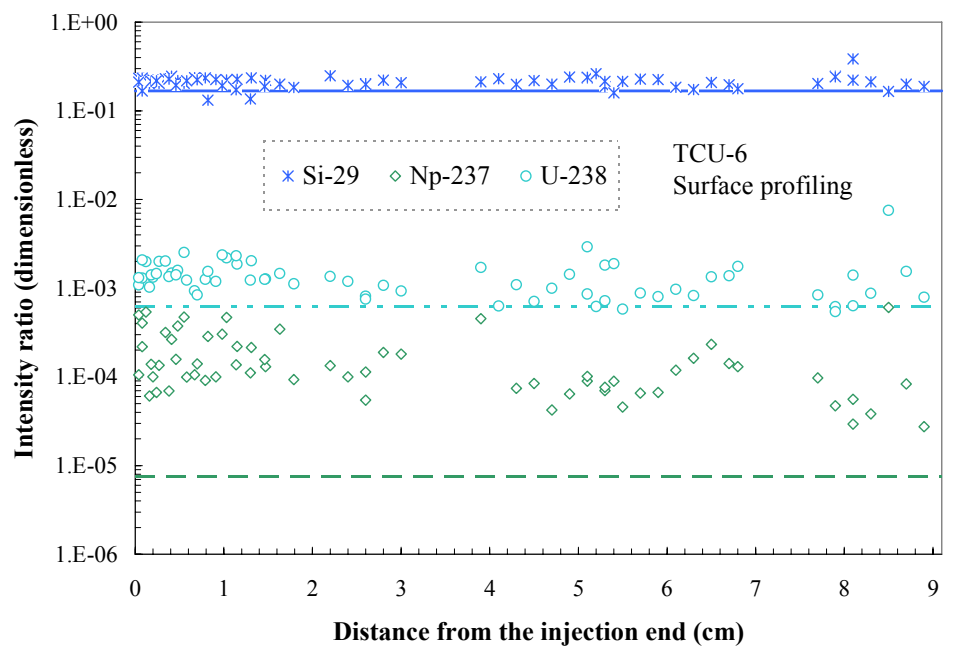

Figure 3.15. Distribution of ${ }^{237} \mathrm{~Np}$ and ${ }^{238} \mathrm{U}$ obtained from surface profiling in TCU-6 core using LA/ICP-MS. Symbols represent data; lines represent background intensity ratios.

Results from depth profiling indicate transverse diffusion during the fracture flow experiment. Figure 3.16 shows the profiling results obtained at a location $2 \mathrm{~mm}$ from the core inlet and perpendicular to the fracture surface. The number of laser pulses fired during each sampling corresponds to the sampling depth, as shown on the Y-axis. The relative concentrations of Sm and $U$ decrease gradually and reach background levels after less than $1 \mathrm{~mm}$, which is indicative of the diffusion depth. Non-uniform distribution of Si suggests possible changes in rock mineralogy with depth. Interestingly, the concentration of $\mathrm{Sr}$ appears to increase with sampling depth. This may be indicative of 
leaching of $\mathrm{Sr}$ from the matrix ion exchange sites during the desorption phase of the flow-through experiment.

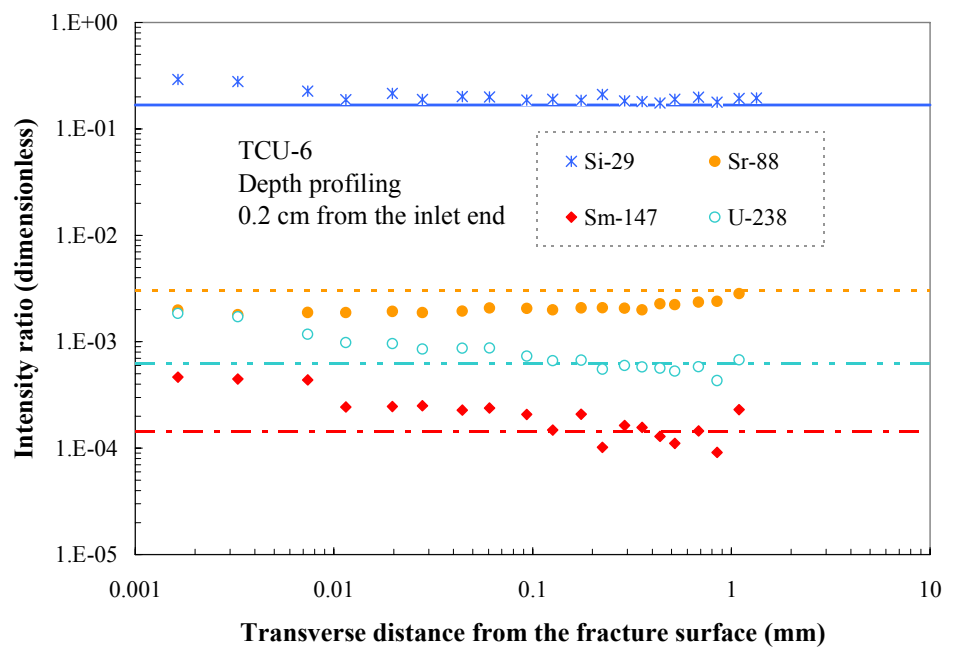

Figure 3.16. Distribution of several elements obtained from depth profiling in TCU-6 core sample using LA/ICP-MS. Symbols represent data; lines represent background intensity ratios.

\subsubsection{Natural Fractures}

\subsubsection{Elution Curves}

The Re and tritium tracers produced similar breakthrough curves in TCU-3 and TCU-4 as the tracers in the synthetic parallel-plate tuff experiments. Both the Re and tritium concentrations are slightly higher in TCU-4 than in the other experiments, which could be attributed to the shorter core length relative to all other tuff experiments (see Table 2.1). The shorter core length allowed for less matrix diffusion.

At first glance, less elution of $\mathrm{Cs}, \mathrm{Sm}, \mathrm{Sr}$, and $\mathrm{Pu}$ was observed in the TCU-3 experiment (Figures 3.17 and 3.18) than in the TCU-4 experiment (Figures 3.18 and 3.20). However, much of this can be attributed to the fact that TCU-4 samples were analyzed on an ICPMS that was capable of detecting much lower concentrations. The high clay content in the TCU-4 core $(13.8 \%$ in TCU-4 versus $1 \%$ in TCU-3 ) could account for some of the higher radionuclide breakthrough, particularly in the case of Sm, because some of the fine-grained clay particles may have eroded from the fracture walls and become incorporated into the solution as colloids. However, in both experiments, the fraction of eluted Cs and Sr was negligible (Table 3.1).

Cesium detected in the TCU-4 outflow is highest during the initial stages and eventually stabilizes at a level lower than the natural background measured in Yucca Flat TCU 
groundwater $\left(6.77 \times 10^{-9} \mathrm{~mol} / \mathrm{L}\right.$ versus $3.76 \times 10^{-8} \mathrm{~mol} / \mathrm{L}$, respectively). The $\mathrm{Sm}$ concentration in TCU-4 increases in the beginning of the experiment then stabilizes at $6.65 \times 10^{-10} \mathrm{~mol} / \mathrm{L}$, a level lower than expected background $\mathrm{Sm}\left(2.26 \times 10^{-9} \mathrm{~mol} / \mathrm{L}\right)$. As in TCU-2, the Sr in TCU-4 stabilized at a value lower than background $\left(7.00 \times 10^{-8} \mathrm{~mol} / \mathrm{L}\right.$ versus $5.71 \times 10^{-7}$ to $1.14 \times 10^{-6} \mathrm{~mol} / \mathrm{L}$, respectively). These results are similar to those seen in the parallel-plate fracture experiments.

Plutonium was not detected in TCU-3 but was detected primarily during the sorption pulse of TCU-4. Only $3 \%$ of the Pu injected into the core was recovered in the effluent. The small amount of Pu breakthrough, like the Sm breakthrough, may have resulted from either the short core length (which limited diffusion) or the resuspension of clay colloids during this experiment (which may have resulted in colloid-facilitated transport).

As with all the other tuff experiments, in both natural fractures, Np and U breakthrough was only slightly retarded compared to the tracers. This is, again, indicative of the very low sorption potential of the Yucca Flat TCU for Np and U. Unlike the other radionuclides discussed for these two experiments, more Np and U eluted in the TCU-3 experiment than in the TCU-4 experiment (see Figures 3.18 and 3.20, respectively). 


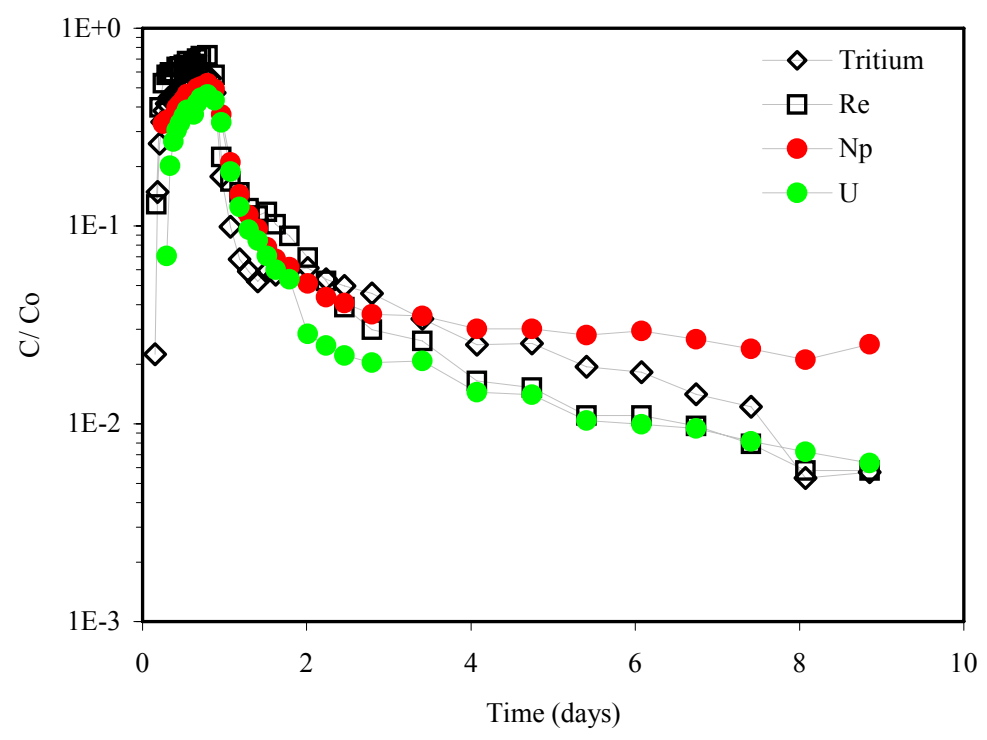

Figure 3.17. TCU-3 breakthrough plot (log scale y-axis). Cs, Sr, Sm, Pu not observed.

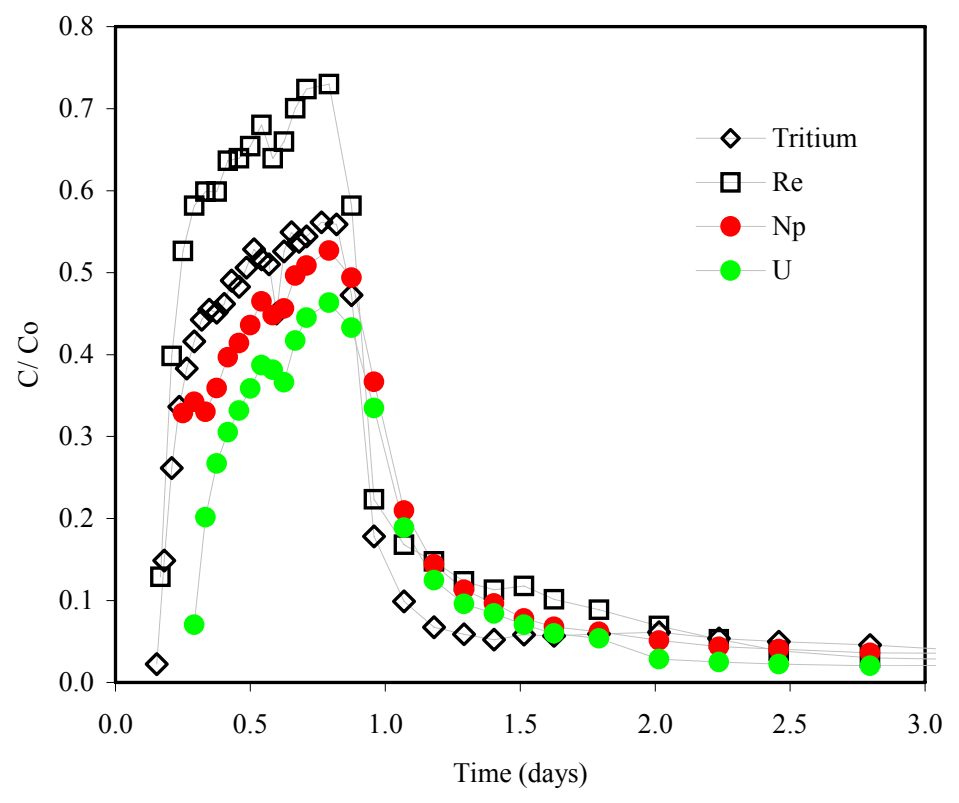

Figure 3.18. TCU-3 sorption pulse (linear scale y-axis). Sorption pulse timeframe magnified. Cs, Sr, Sm, and Pu not observed. 


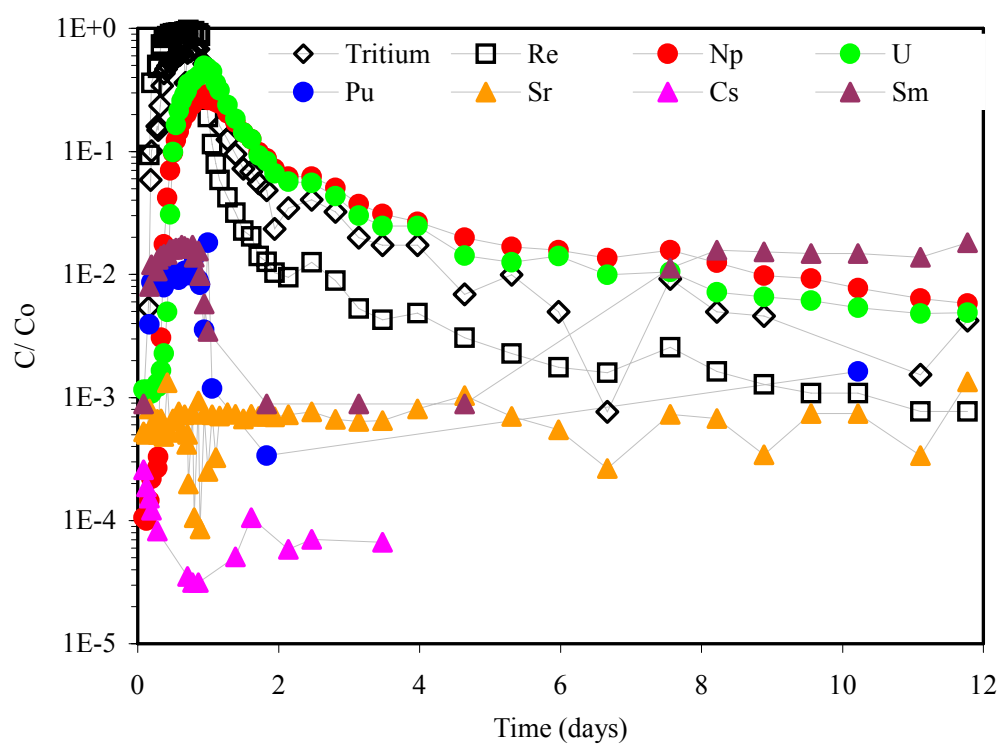

Figure 3.19. TCU-4 breakthrough plot ( $\log$ scale $y$-axis).

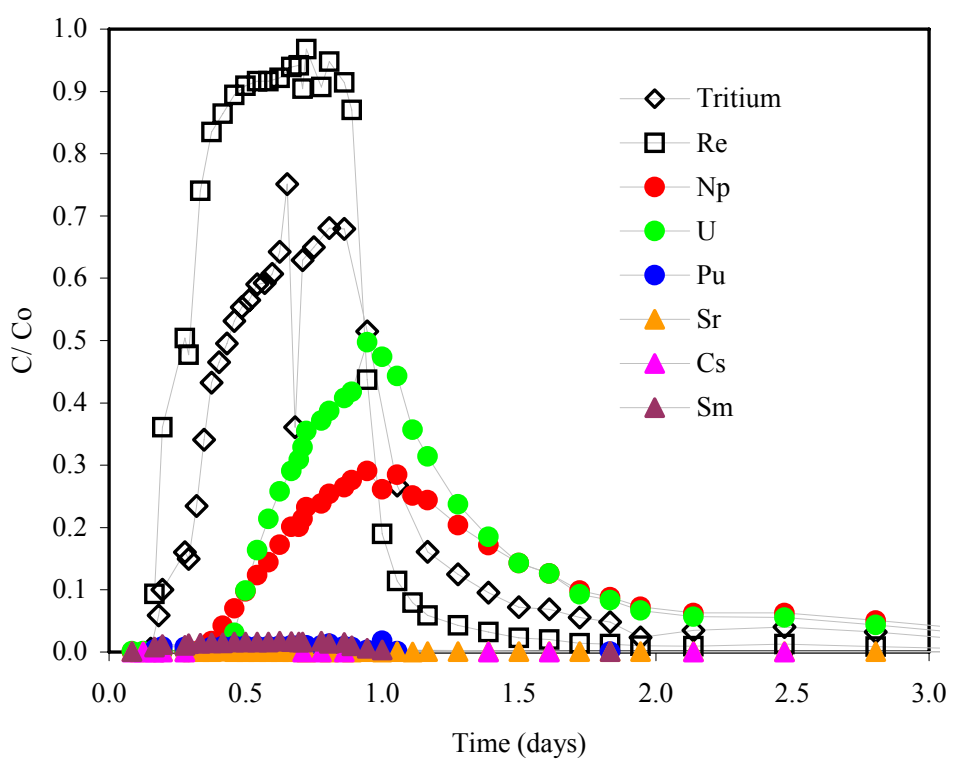

Figure 3.20. TCU-4 sorption pulse (linear scale y-axis). Sorption pulse timeframe magnified. 


\subsubsection{Core Characterization - Laser Ablation}

For both TCU-3 and TCU-4 experiments, Sr and Cs were detected on the fracture surface (Figures 3.21 and 3.22). The magnitude of transport for these isotopes is quite similar among these experiments; both $\mathrm{Sr}$ and $\mathrm{Cs}$ are limited to an area within about $4 \mathrm{~mm}$ of the core inlet. This is in good agreement with the parallel plate fracture results reported earlier. The results suggest that the transport of $\mathrm{Sr}$ and $\mathrm{Cs}$ in TCU fractures will be minimal. More importantly, the results indicate that the behavior observed in simple synthetic parallel plate fractures is equivalent to that observed in real fractures. Since zeolites were a predominant component of both the fracture lining and bulk rock mineralogy, the presence or absence of fracture linings did not affect the transport behavior of radionuclides.

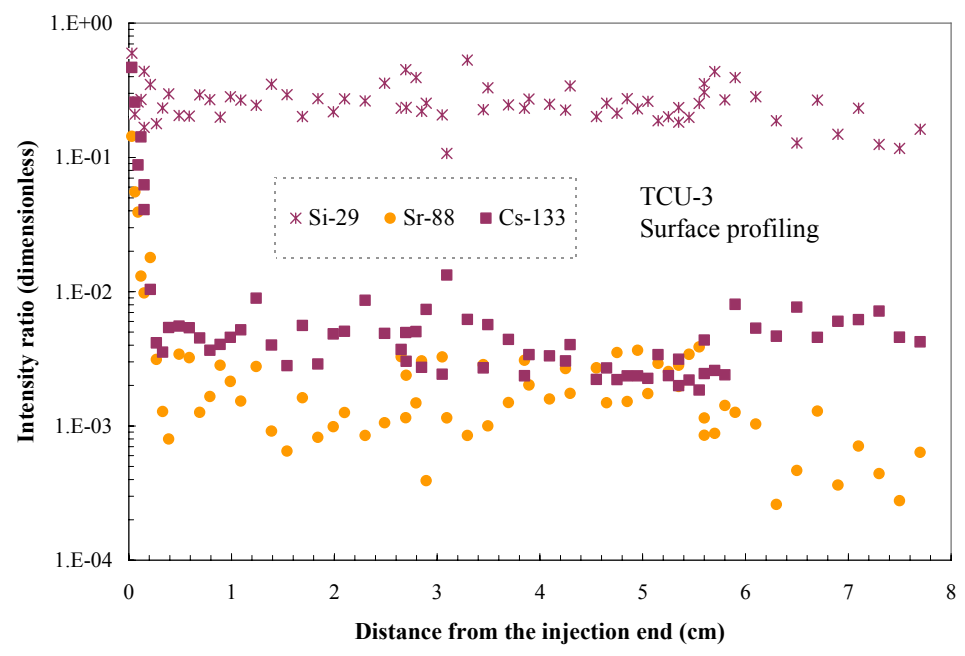

Figure 3.21. Distribution of ${ }^{88} \mathrm{Sr}$ and ${ }^{133} \mathrm{Cs}$ obtained from surface profiling in TCU-3 core using LA/ICP-MS.

The TCU-4 core was analyzed using a newly purchased ICP-MS (Thermo Electron) with a lower detection limit than the HP4500 system. Above-background levels of ${ }^{237} \mathrm{~Np}$ and

${ }^{242} \mathrm{Pu}$ were detected on the fracture surface (Figure 3.22). Though these radionuclides were also found to be present in the effluent samples, their sorption and diffusion into the matrix is observed in the LA/ICP-MS data. 


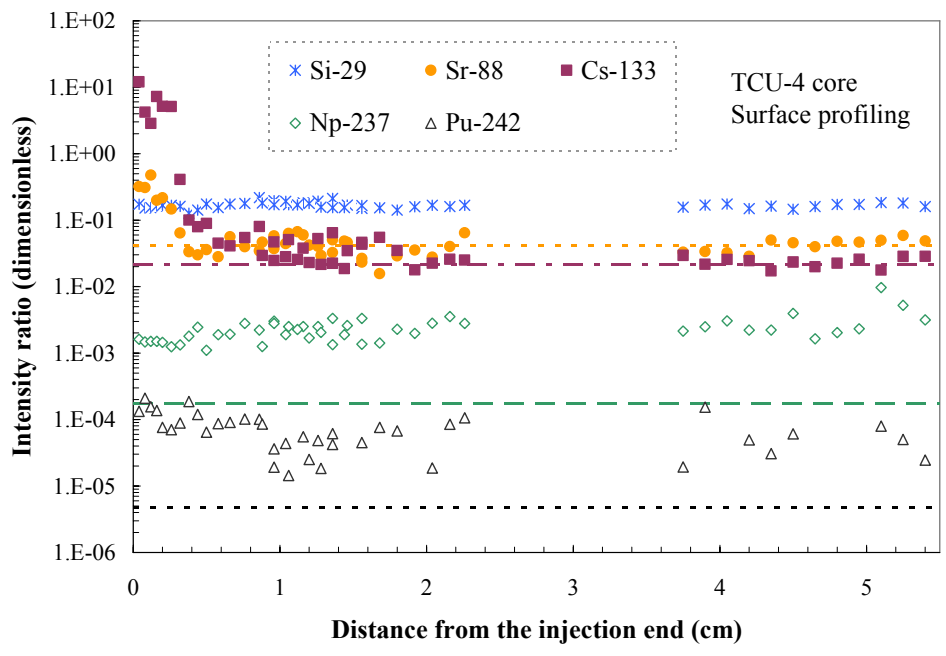

Figure 3.22. Distribution of several isotopes obtained from depth profiling in TCU-4 core sample using LA/ICP-MS. Symbols represent data; lines represent background intensity ratios.

Results from depth profiling confirm that transverse diffusion had occurred during the fracture flow experiment. Fracture lining minerals did not appear to hinder the diffusion of radionuclides into the matrix. Figure 3.23 shows the profiling results obtained at a location $2 \mathrm{~mm}$ from the core inlet, perpendicular to the fracture surface. Concentrations of ${ }^{133} \mathrm{Cs}$, ${ }^{237} \mathrm{~Np}$ and ${ }^{242} \mathrm{Pu}$ decrease gradually and reach steady-state beyond $1 \mathrm{~mm}$. The steady-state signals for all these isotopes, along with ${ }^{88} \mathrm{Sr}$, are consistently higher than background levels, which were obtained from the surface profiling. During depth profiling, the crater depth-to-diameter (aspect) ratio is an important parameter determining the degree of elemental fractionation (Eggins et al., 1998; Borisov et al., 2000). As the aspect ratio increases, the mass removal might change from photo-thermal to plasma-dominated. After a repetitive laser ablation at the same sampling position for 180 seconds on the NIST 610 glass standard, Borisov et al. (2000) observed the formation of a cone-like crater from a 266-nm Gaussian laser beam. With a total crater depth of about $300 \mu \mathrm{m}$, the crater narrowed towards the bottom, and needle-like profiles became more prominent as the number of pulses increased. This was caused by nonuniformity of the laser beam irradiance; the ablation rate was highest in the center of the crater and decreased towards the edges. Therefore, as the crater deepened, the ablation rate (amount of mass removed per laser pulse) decreased. The cone-shaped craters hinder depth profiling because the chemical carry-over in the subsequent laser pulses will lead to averaging over an ever-greater depth range. 


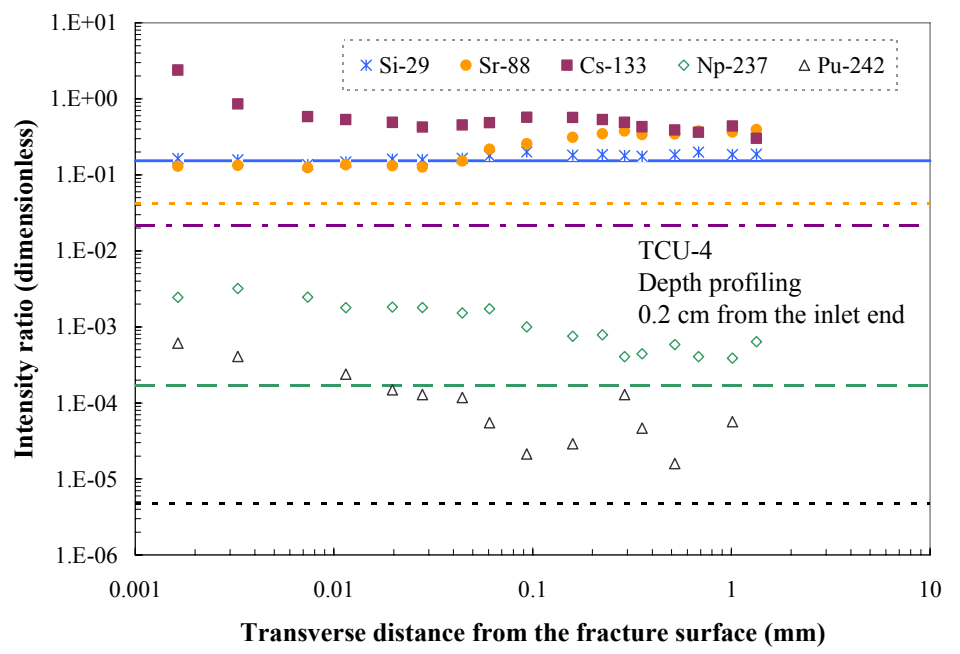

Figure 3.23. Distribution of tracer isotopes obtained from depth profiling in TCU-4 core sample using LA/ICP-MS. Symbols represent data; lines represent background intensity ratios.

\subsection{Carbonate Fractures}

As in the tuff experiments, the breakthrough data from the carbonate synthetic parallelplate fracture experiments and the more topographically heterogeneous Brazil fracture experiment are similar. The sorption results from the carbonate cores, however, show a marked difference with regard to the retardation of certain radionuclides, specifically, the lack of sorption of $\mathrm{Cs}$ and $\mathrm{Sr}$ onto the carbonate surface. Another noticeable result is the markedly lower retardation of Pu, compared to the TCU cores, as indicated by the significant transport of $\mathrm{Pu}$ in all but one of the carbonate core experiments. Samarium is observed in the effluent of LCA-2 (with average concentrations of $\sim 9 \times 10^{-8} \mathrm{~mol} / \mathrm{L}$ ), in part, because of the improved Sm detection limit of the ICP-MS used in the LCA-2 analyses.

\subsubsection{Elution Curves - Synthetic Parallel-Plate Fractures}

Figures 3.24 and 3.25 show the results from LCA-1, a synthetic parallel-plate fracture experiment. Although the tritium and Re breakthrough areo indicative of a non-sorbing tracer, Sr and Cs breakthrough are also indicative of a tracer. Neptunium and U exhibit similar retardation as in the tuff cores: neither is a strong sorbers but both exhibit some retardation. No Sm or Pu breakthrough was detected in LCA-1.

The LCA-1 experiment was performed using a high $\mathrm{pCO}_{2}(\mathrm{~g})$ solution typical of LCA groundwaters. During the flow-through experiments, the rate of fluid flow decreased substantially as a function of time. Upon opening the fracture, it was found that a significant quantity of calcite had precipitated at the upstream end of the fracture. This resulted from the slow degassing of the solution during the experiment timeframe. This 
experiment does not reflect the equilibrium behavior that would be expected in the LCA. Thus, radionuclide transport behavior observed in this experiment may not be analogous to transport at equilibrium field conditions. Nevertheless, the fast transport of $\mathrm{Cs}, \mathrm{Sr}, \mathrm{Np}$, $\mathrm{U}$, and the tracers, even under the conditions of calcite precipitation, suggests that these radionuclides will travel very quickly in the LCA. As will be described in the following two experiments, Sm and Pu may be somewhat less retarded in cases where significant calcite precipitation is not occurring.

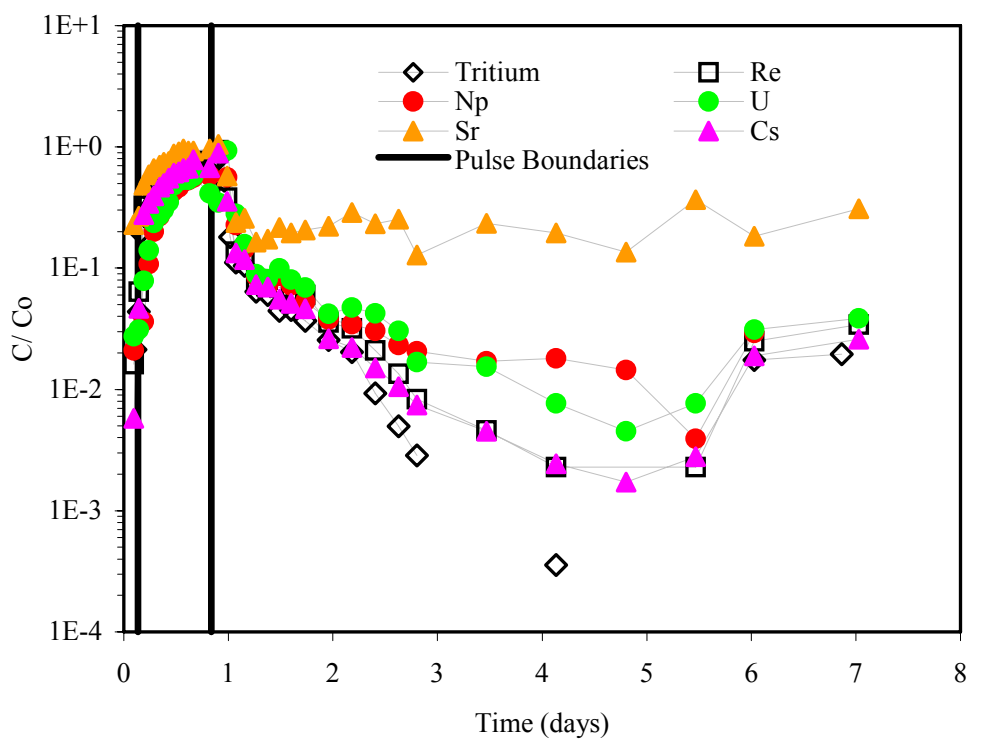

Figure 3.24. LCA-1 breakthrough plot. The two vertical lines represent the beginning and end of the sorption pulse. Sm and Pu not observed. Radionuclide concentration increases after 5 days are attributed to measurement/sampling errors.

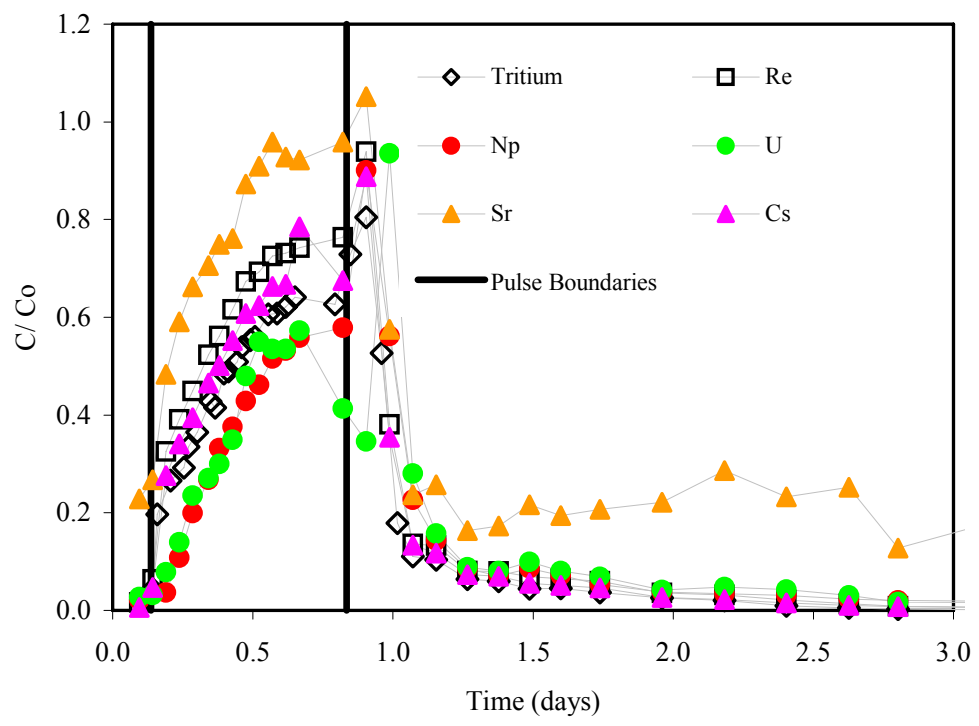

Figure 3.25. LCA-1 sorption pulse. Sorption pulse timeframe magnified. The two vertical lines represent the beginning and end of the sorption pulse. Sm and Pu not observed. 
Figures 3.26 and 3.27 show effluent concentrations from LCA-2, the second carbonate synthetic parallel-plate fracture experiment. This experiment was conducted using a solution with a lower $\mathrm{pCO}_{2}(\mathrm{~g})$ to reduce the likelihood of calcite precipitation (Table 2.4). Results are similar to LCA-1 with respect to the tracers Re and tritium, and as in LCA-1, Cs and Sr exhibit little retardation. Nevertheless, all radionuclides exhibit some matrix diffusion as evidenced by the tailing in the breakthrough curves. Neptunium and $\mathrm{U}$ again exhibit similar retardation trends as seen in all the previously discussed tuff cores. Unlike in LCA-1, Sm and Pu breakthrough is observed in LCA-2. This is most likely the result of two factors - the difference in solution composition between the LCA1 and LCA-2 experiments and the improved detection limit of the ICP-MS used to analyze LCA-2 effluent. In the LCA-1 experiment, we observed significant calcite precipitation as a result of $\mathrm{CO}_{2(\mathrm{~g})}$ degassing. Calcite precipitation resulted in an additional radionuclide sink and drastically reduced the transport rates of the strongly sorbing radionuclides. No calcite precipitation was observed in the LCA-2 experiments. Interestingly, trace quantities of Sm breakthrough in LCA-2 suggest that Sm migration in the LCA, in the absence of colloids, should be negligible. 


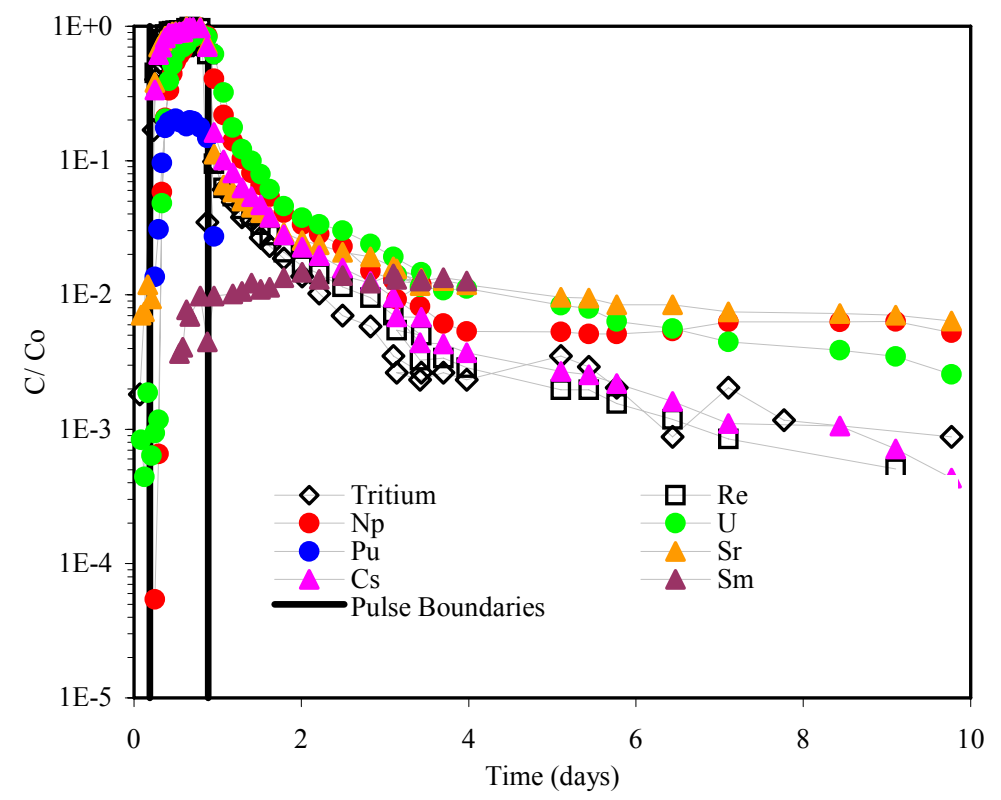

Figure 3.26. LCA-2 breakthrough plot. The two vertical lines represent the beginning and end of the sorption pulse.

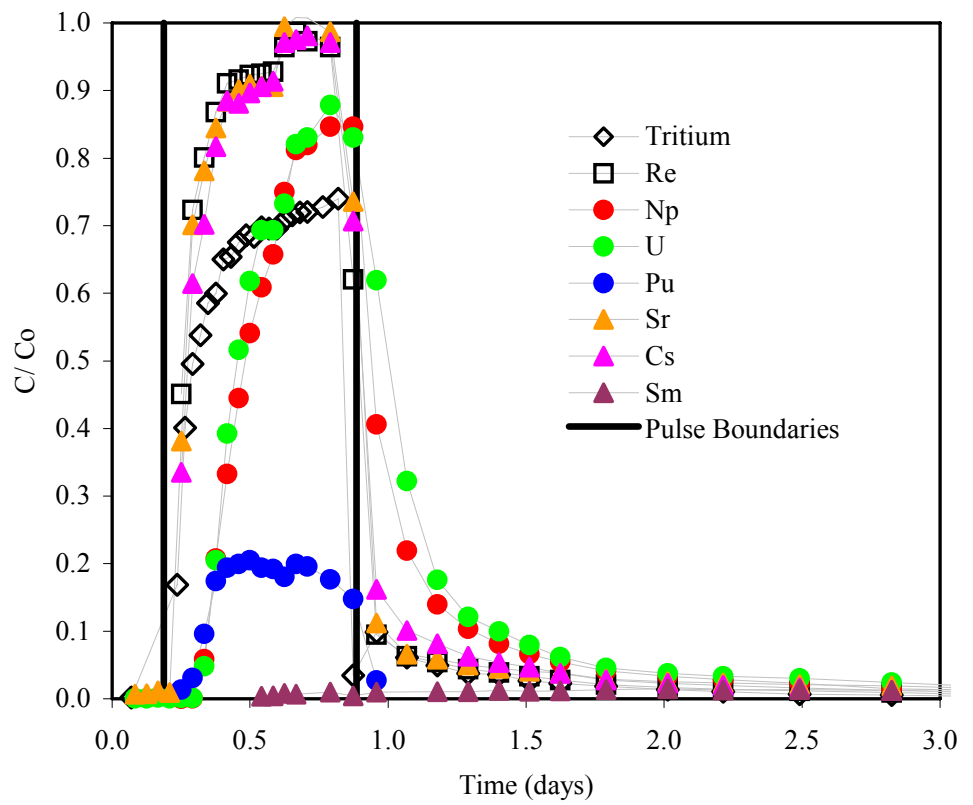

Figure 3.27. LCA-2 sorption pulse. Sorption pulse timeframe magnified. The two vertical lines represent the beginning and end of the sorption pulse. 


\subsubsection{Elution Curves - Brazil Test Induced Fracture}

Figures 3.28 and 3.29 show data from LCA-3, the Brazil test induced fracture experiment. Results are similar to LCA-1 and LCA-2 with respect to the tritium and Re tracers, as well as for Cs and Sr. This suggests that fracture topography neither increased nor decreased the retardation of these radionuclides. Sm was not detected, reflecting the strong sorptive capacity of carbonates for Sm. Neptunium and U again exhibited similar retardation as seen in all the previously discussed cores. The most intriguing result from LCA-3 is the relatively high abundance $\left(\mathrm{C} / \mathrm{C}_{0}\right.$ of 0.6$)$ of $\mathrm{Pu}$ in the outflow solution indicating relatively little retardation. Since colloids were not included in this experiment, we conclude that the migration of $\mathrm{Pu}$ in carbonate fractures may be significant even in the absence of colloids. In this experiment $55 \%$ of the Pu introduced to the fracture was recovered in the effluent despite $0 \%$ of the Pu existing in colloidal form (see Table 2.8). While this is higher than the recovery rate observed in the LCA-2 experiment (16\%), both results suggest that Pu may migrate to some extent in LCA fractures. Based on the mechanistic modeling described in the following section, the results can be explained by the relatively weak sorption of $\mathrm{Pu}$ to calcite and the very low accessible reactive surface area of calcite in the LCA rock (Section 4). 


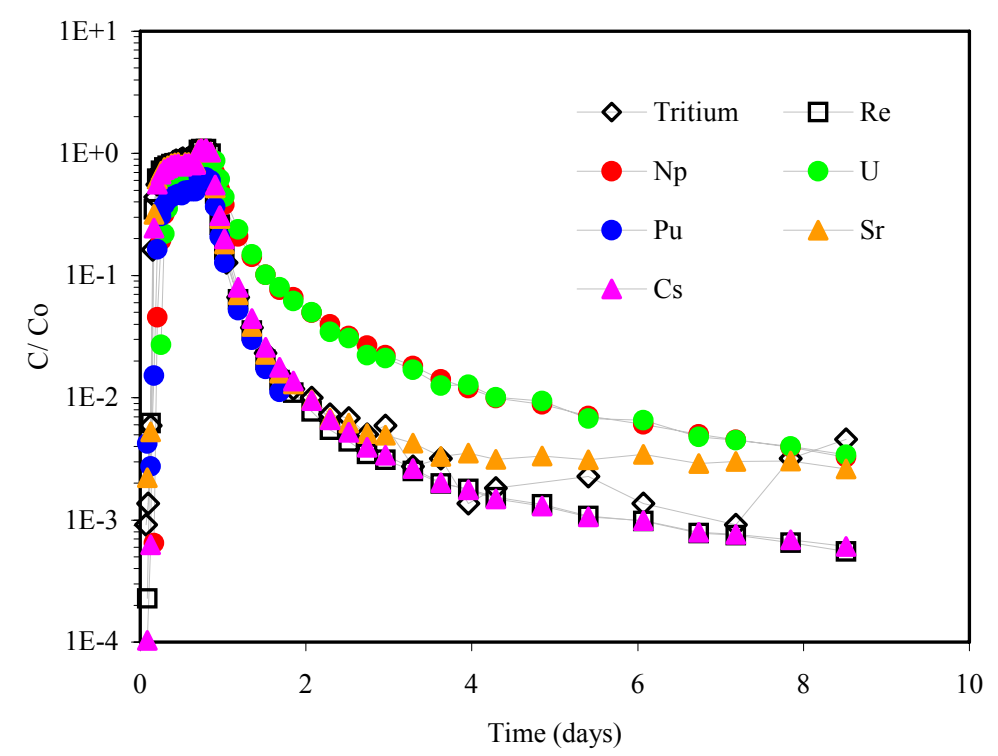

Figure 3.28. LCA-3 breakthrough plot. Sm not observed.

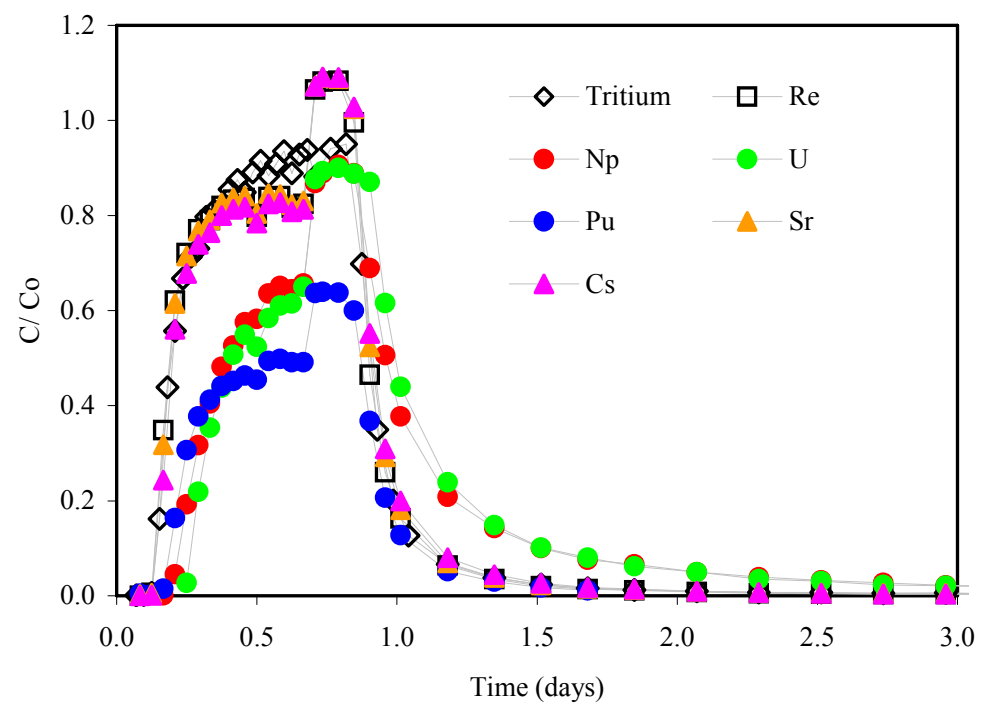

Figure 3.29. LCA-3 sorption pulse. Sorption pulse timeframe magnified. Sm not observed.

\subsubsection{Core Characterization - Autoradiography, SEM, and SIMS}

Although the Pu activity in the LCA-1 experiment is the same as TCU-2 (mostly ${ }^{242} \mathrm{Pu}$ ), the alpha tracks are more visible. The alpha track density is greatest near the inlet and along sealed fractures running the length of the core. However, some tracks can be found over the entire length of the core (Figure 3.30). Curiously, in several places, the mineralogy seems to change, as does the $\alpha$-activity. A reddish colored mineral does not seem to correlate with the high $\alpha$-activity; $\alpha$-activity is correlated with white colored 
minerals. As observed in the tuff flow-through experiments, the distribution of the $\alpha$ activity throughout the core supports the notion that $\mathrm{Pu}$ is transported through the core to some extent. It is likely that low levels of Pu were transported through the core, though the $\mathrm{Pu}$ concentrations were below the detection limit in the effluent.
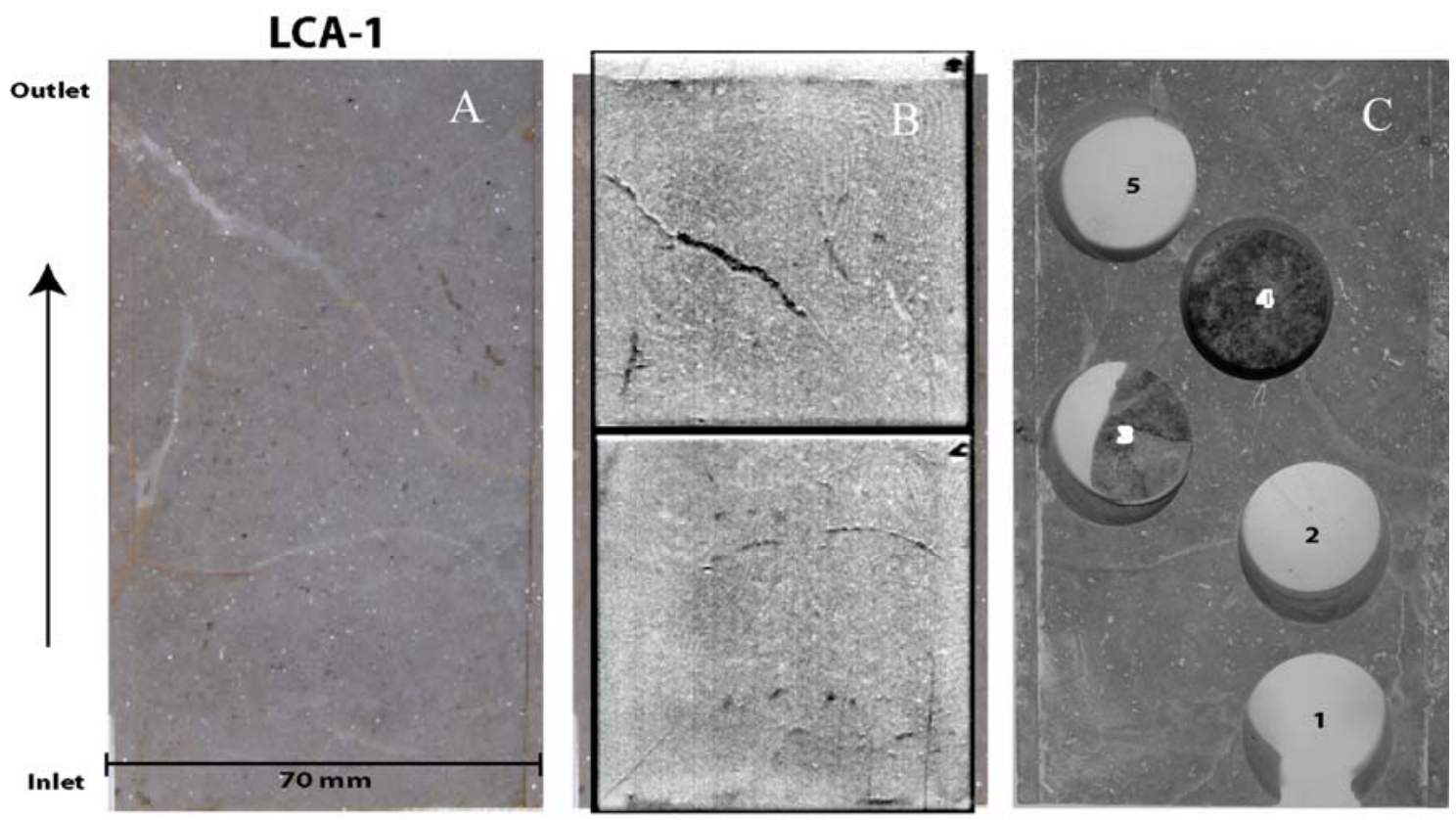

Figure 3.30. (a) Post-test fractured surface of LCA-1. (b) The CR-39 film overlain on LCA1. Alpha tracks are observed throughout, with concentrated clusters visible as dark patches and veins. (c) \#1-5 circles are the location of the plugs used in SEM and SIMS.

The LCA-2 experiment was performed with a higher Pu $\alpha$-activity. Alpha tracks are found throughout LCA-2. The LCA-2 is divided by a sealed natural fracture running through the middle of core, with micro-fractures on the left and a relatively smooth surface on the right (Figure 3.31a). The $\alpha$-activity was concentrated on the left side of the fracture (Figure 3.31b), although alpha tracks are observed on both sides. The alpha tracks at the outlet of the core are consistent with effluent results indicating that $\mathrm{Pu}$ was transported through the core. 


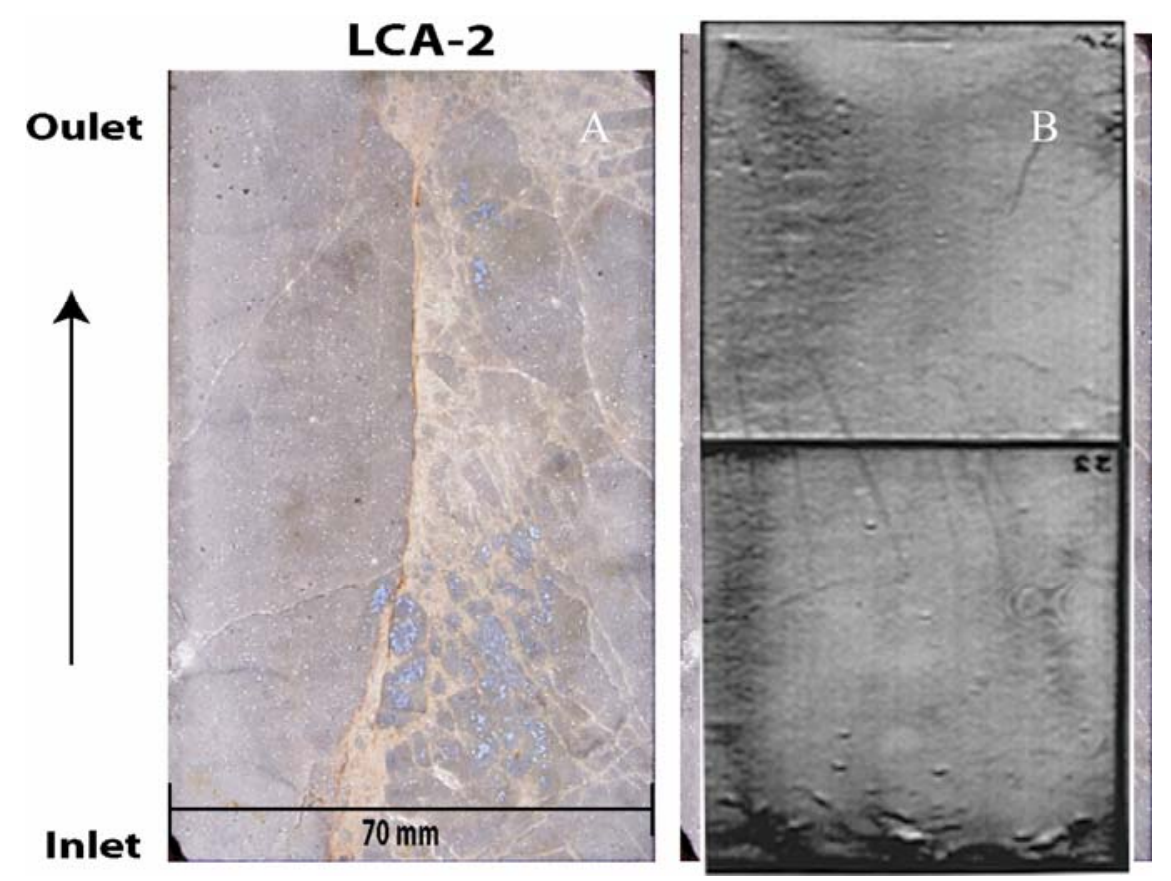

Figure 3.31. (a) The post-test LCA-2 core. (b) alpha tracks are overlain on LCA-2. The dark regions show the alpha tracks.

SIMS analysis was performed on two different areas of the LCA-2 core (see Appendix 8.3, Table 8.25). One transect was at the inlet, where the track density is high: $\mathrm{Pu}, \mathrm{Np}$ and Sm were detected. Another transect was at the outlet: $\mathrm{Pu}, \mathrm{Np}, \mathrm{Sm}, \mathrm{Cs}$ and Sr were detected. The identification of $\mathrm{Pu}, \mathrm{Np}$ and $\mathrm{Sm}$ at the outlet confirms the elution curve data documenting transport of $\mathrm{Pu}, \mathrm{Np}$ and $\mathrm{Sm}$ through the carbonate core.

\subsubsection{Core Characterization - Laser Ablation}

For the fracture flow experiments with carbonate rocks (LCA-1, LCA-2, and LCA-3), effluent samples show the nearly conservative migration of $\mathrm{Cs}$ and $\mathrm{Sr}$, similar to $\mathrm{Re}$ and tritium. Consistently, we did not detect a distribution profile for $\mathrm{Sr}$ or Cs on the fracture surface (Figure 3.32 as an example for LCA-2), with their signals across the fracture surface consistent with background levels. Some delayed transport of U and $\mathrm{Np}$ was obtained from the effluent samples, which is corroborated from the LA/ICP-MS analyses on the core samples. Figure 3.32 presents the higher-than-background levels of ${ }^{237} \mathrm{~Np}$ and ${ }^{238} \mathrm{U}$, along with ${ }^{242} \mathrm{Pu}$. 


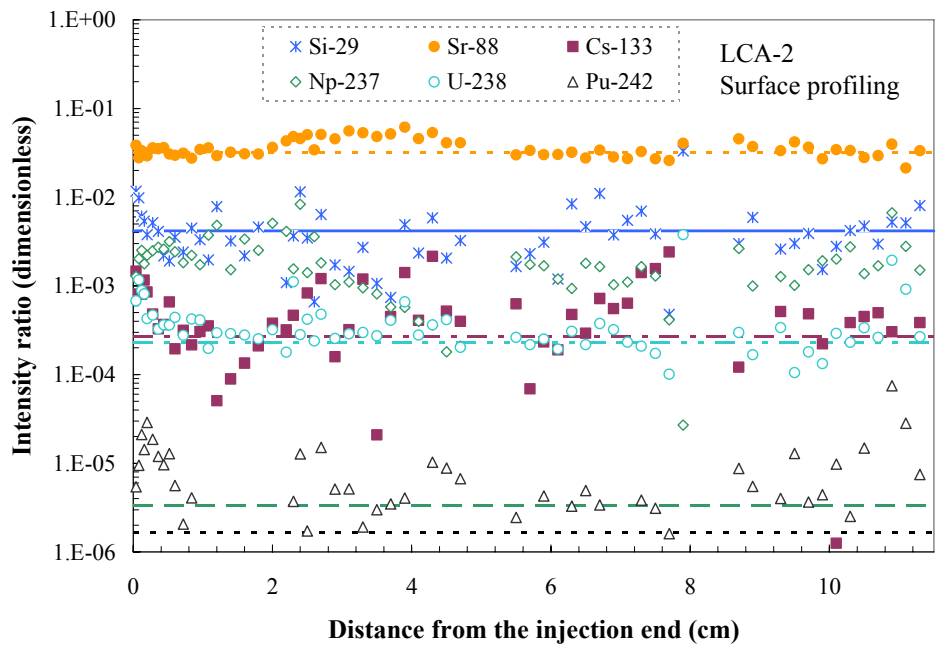

Figure 3.32. Distribution of isotopes obtained from surface profiling in LCA-2 core using LA/ICP-MS. Symbols represent data; lines represent background intensity ratios.

Results from depth profiling confirm that the transverse diffusion had occurred during the fracture flow for the sorbing radionuclides. Figure 3.33 shows the profiling results obtained at a location $2 \mathrm{~mm}$ from the core inlet, perpendicular to the fracture surface. Concentrations of ${ }^{237} \mathrm{~Np}$ decrease gradually and approach background at $1 \mathrm{~mm}$, compared to $0.01 \mathrm{~mm}$ for ${ }^{242} \mathrm{Pu}$ as $\mathrm{Pu}$ is sorbed more than $\mathrm{Np}$.

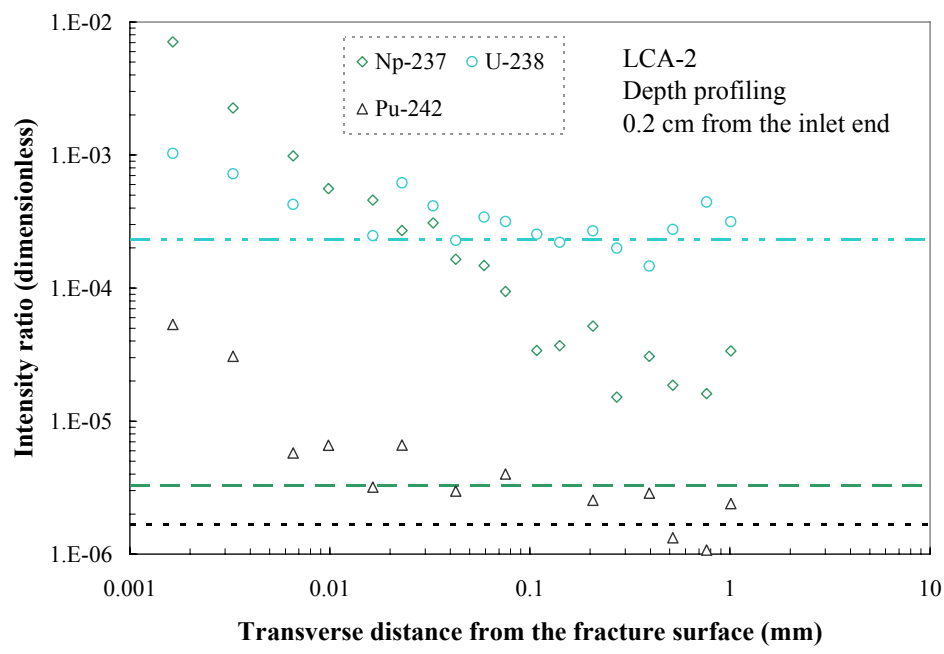

Figure 3.33. Distribution of several isotopes obtained from depth profiling in LCA-2 core sample using LA/ICP-MS. Symbols represent data; lines represent background intensity ratios. 


\subsubsection{Carbonate Core ${ }^{13} \mathrm{C}$ Transport}

During the LCA fracture transport experiments, $\mathrm{a} \mathrm{H}^{13} \mathrm{CO}_{3}$ tracer was added to the stock solution at the beginning of each experiment so that information could be obtained on fluid-rock mass exchange rates. For various reasons, we were unsuccessful in recovering any of the ${ }^{13} \mathrm{C}$-tracer during the first two experiments (LCA-1 and LCA-2). However, during the final experiment (LCA-3), the ${ }^{13} \mathrm{C}$-tracer was detected in one (integrated) fluid sample collected early in the experiment. A second sample taken later in the same experiment showed the ${ }^{13} \mathrm{C}$-tracer solution had fully equilibrated with carbon isotopes in the rock. The results for these samples (together with the initial composition) are given in Table 3.3 below.

Table 3.3. Carbon isotope results from the LCA-3 experiment

\begin{tabular}{lll}
\hline Mean elapsed time (days) & $\delta^{13} \mathrm{C}$ tracer solution (permil) & Fraction Exchanged $(F)$ \\
\hline 0 & +1055 & 0 \\
0.69 & +191 & 0.804 \\
8.92 & -20 & $\sim 1$ \\
\hline
\end{tabular}

The mean elapsed time in Table 3.3 refers to the integrated average time period during which the samples were collected and subsequently combined for analysis. Individual samples did not contain a sufficient amount of dissolved inorganic carbon for $\delta^{13} \mathrm{C}$ analysis, so it was necessary to combine several samples that were collected at closely spaced intervals. The $\delta^{13} \mathrm{C}$ results are plotted as a function of time in Figure 3.34. The data indicate the dissolved ${ }^{13} \mathrm{C}$ underwent rapid exchange with the carbonate rock, exchanging more than $80 \%$ of the tracer in less than 1 day. 


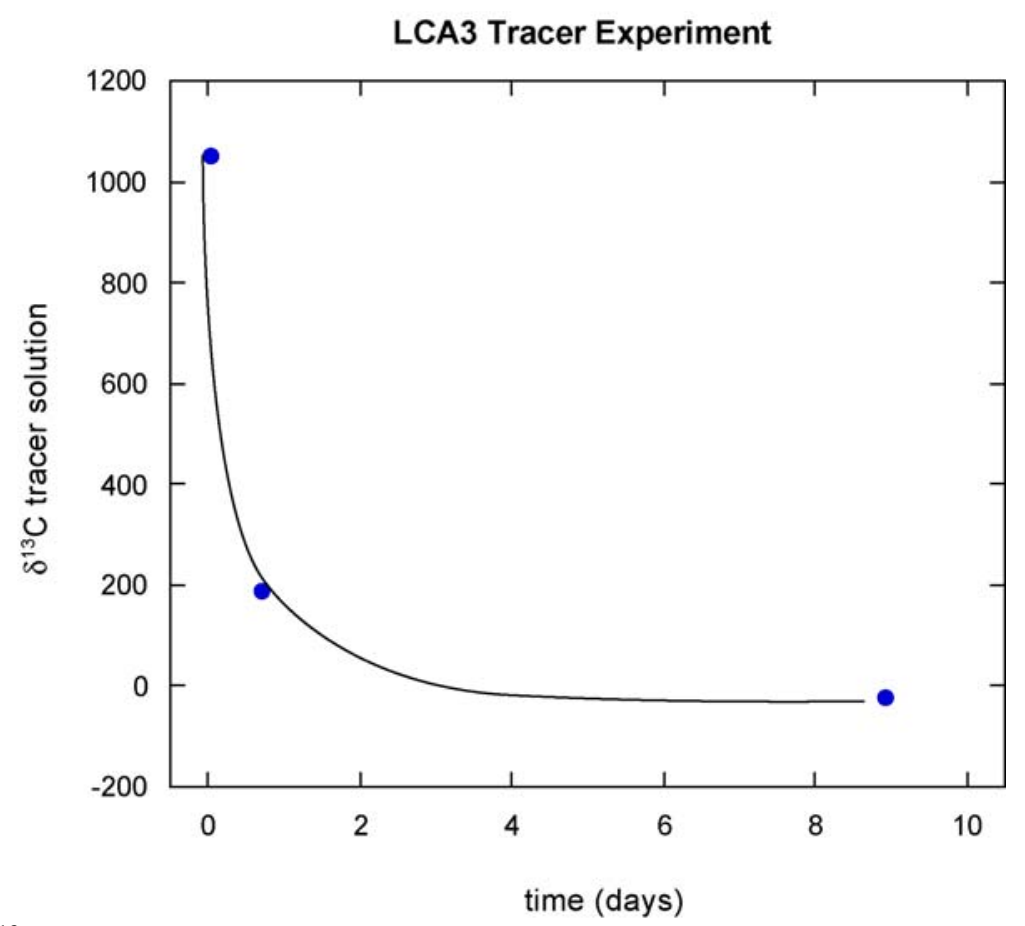

Figure 3.34. $\delta^{13} \mathrm{C}$ (permil) plotted as a function of time for LCA-3 tracer experiment. Values shown are \pm 2 permil.

To quantify the mass exchange rate during the early part of the experiment, we turn to kinetic isotope theory. The rate law for kinetic isotope exchange in mineral-fluid systems is given by the following expression

$d R_{A} / d t=-k\left(R_{A}-\alpha R_{B}\right)$

where $R_{A}$ and $R_{B}$ are the isotope ratios (e.g. ${ }^{13} \mathrm{C} /{ }^{12} \mathrm{C}$ ) in the solid and fluid phase, respectively, $\alpha$ is the isotope fractionation factor between the two phases (where $\alpha=R_{A} / R_{B}$ ), $k$ is the rate constant for the exchange process, and $t$ is time (Criss et al., 1987). During an isotopic exchange process, the gain of a heavy isotope by one phase must occur at the expense of the heavy isotope content of another phase. For a closed binary system, the material balance requires that

$X_{A} d R_{A}=-X_{B} d R_{B}$

where $X_{A}$ and $X_{B}$ are the mole fractions of the element of interest for phases $A$ and $B$, respectively (Criss, 1999). The simultaneous solution to equations (12) and (13) is

$\frac{R_{A}-R_{\text {Aeq }}}{R_{A i}-R_{\text {Aeq }}}=e^{-k t}$ 
where $R_{A e q}$ represents the value that phase $A$ will attain at equilibrium, and $R_{A i}$ is the initial value at $t=0$ (see Criss et al., 1987 for details). The ratio on the left-hand side of the equation is equal to the quantity $1-F$, where $F$ is a progress variable that represents the fractional approach to equilibrium (Criss, 1999). At the beginning of the exchange process, $F=0$, and at equilibrium $F=1$. In addition, the $R$-values on the left-hand side of equation 14 can be replaced with the analogous ratio of $\delta$-values, such that

$1-F=\frac{\delta_{A}-\delta_{\text {Aeq }}}{\delta_{A i}-\delta_{\text {Aeq }}}=e^{-k t}$

$\ln (1-F)=-k t$

In the case of the LCA fracture transport experiments, we need an expression for $k$ that accounts for the mass transfer of carbon between the solution and the dolomite rock matrix. Cole et al. (1983) showed that the rate constant for isotopic exchange during surface reactions is

$k=\frac{-\ln (1-F)(W S)}{(W+S) t A}$

where $W$ and $S$ are the number of moles of the element of interest in the fluid and solid, respectively, $A$ is the surface area, $t$ is time, and $F$ is the reaction progress variable.

We will calculate $k$ for $t=0.69$ days. The quantity $(1-F)$ is determined from equation (15) using the $\delta^{13} \mathrm{C}$-values from Table 3.3. For the sample of interest, $(1-F)=1-0.804$ $=0.196$. The surface area $(A)$ of the LCA-3 fracture was determined from the dimensions of the fracture surface, multiplying by 2 to account for both sides of the fracture:

$A=(11.25 \mathrm{~cm})(7.06 \mathrm{~cm})(2)=158.8 \mathrm{~cm}^{2}$

The number of moles of carbon in the fluid $(W)$ is calculated from the integrated flux of solution that had passed through the reaction cell at $t=0.69$ days, assuming a mean $\mathrm{HCO}_{3}{ }^{-}$concentration of $1 \times 10^{-3} M$. We assume other dissolved inorganic carbon species are present at $<1 \%$ of the $\mathrm{HCO}_{3}{ }^{-}$concentration (at $\mathrm{pH} \sim 8$ ) and can be neglected.

$W=\left(1 \times 10^{-3} \mathrm{~mol} / \mathrm{L}\right)(0.02 \mathrm{~L})=2 \times 10^{-5} \mathrm{~mol} \mathrm{C}$

Finally, the number of moles of carbon in the solid will depend on the assumed exchange volume of the (predominantly) dolomite matrix. We will assume isotopic exchange occurs to a depth of $100 \mu \mathrm{m}$ on the fracture surface. Factoring in the porosity of the LCA-3 core $(1.7 \%$; see Table 2.1$)$, the exchange volume of the solid is estimated to be $\left(158.8 \mathrm{~cm}^{2}\right) *(0.01 \mathrm{~cm}) *(0.017)=0.027 \mathrm{~cm}^{3}$. If we assume the density of the dolomite is $2.8 \mathrm{~g} \mathrm{~cm}^{-3}$, we estimate the mass of the exchange volume to be $0.076 \mathrm{~g}$. From this we can calculate the number of moles of carbon in the solid $(S)$ : 


$$
S=0.076 \mathrm{~g} \mathrm{CaMg}\left(\mathrm{CO}_{3}\right)_{2}\left(\frac{\mathrm{mol} \mathrm{CaMg}\left(\mathrm{CO}_{3}\right)_{2}}{184.4 \mathrm{~g} \mathrm{CaMg}\left(\mathrm{CO}_{3}\right)_{2}}\right)\left(\frac{2 \mathrm{~mol} \mathrm{C}}{1 \mathrm{~mol} \mathrm{CaMg}\left(\mathrm{CO}_{3}\right)_{2}}\right)=8.2 \times 10^{-4} \mathrm{~mol} \mathrm{C}
$$

We now have all of the parameters necessary to calculate the rate constant $(k)$. Inserting appropriate values into equation (17), we obtain $k=2.9 \times 10^{-7} \mathrm{~mol} \mathrm{~cm}^{-2} \mathrm{~d}^{-1}$ (or $3.3 \times 10^{-12}$ mol cm$~^{-2} \mathrm{~s}^{-1}$ ). Our $k$-value is slightly lower than (but within an order of magnitude of) the empirical rate law discussed by Svensson and Dreybrodt (1992) for dissolution kinetics of calcite in $\mathrm{CO}_{2}$-water systems. The difference between the two estimates may be related (in part) to differences in the reaction kinetics for dolomite relative to calcite.

We infer that dissolution/precipitation reactions were the dominant process influencing

${ }^{13} \mathrm{C}$-exchange during the initial phase of the LCA-3 experiment. This conclusion is based on the rapid rate at which the ${ }^{13} \mathrm{C}$ was lost from solution (Figure 3.33). In comparison, Hershey et al. (2003) observed much slower isotope exchange rates during recent ${ }^{13} \mathrm{C}$ batch sorption experiments using crushed limestone. Their results were interpreted to reflect a diffusion-controlled rate mechanism.

We should emphasize that the LCA-3 experiment ran for seven days before the radionuclide sorption solution was introduced to the reaction cell (see section 7.8 of this report). During this time, it is likely that the rate of surface-dominated reactions (dissolution/precipitation) would substantially decrease. However, the point in time when diffusional transport processes overtake surface reactions as the dominant ratecontrolling mechanism will depend on how quickly the fluid-rock system achieves chemical equilibrium.

\section{REACTIVE TRANSPORT MODELING}

As described in Section 2.7, either an analytical solution (based on Tang et al., 1981) or a 2D fracture transport mechanistic model (using the CRUNCH code) was used to model the radionuclide transport experimental results described below. Details regarding these two models are given in Section 2.7.

Table 2.10 lists all the input parameters needed to solve the transport equation of Tang et al. (1981). These are, essentially, the same parameters used in the CRUNCH code.

However, the CRUNCH code calculates $R_{f}$ and $R_{m}$ based on a thermodynamic database of surface complexation, ion exchange, and aqueous speciation constants in combination with mineral composition and mineral characteristics data. Of the parameters listed in Table 2.10, many are measured quantities while others are determined based on model fits to breakthrough data. The fracture half-aperture was measured $(0.25 \mathrm{~mm})$ for synthetic parallel-plate fractures but had to be fit for natural and induced (Brazil test) fractures. The matrix porosity was measured and is listed in Table 2.1. The fluid velocity was calculated based on measured core dimensions (Table 2.1) and the flow rate. The flow rate needed to be adjusted during modeling because we found that the set flow rate 
$(0.02 \mathrm{~mL} / \mathrm{min})$ was rarely sustained; measured flow rates were always up to $25 \%$ lower. As a result, flow rates were adjusted but never to below $75 \%$ of the set rate. The radionuclide concentrations were measured and are listed in Table 2.7. The radionuclide pulse length, experiment time, and fracture length were all measured quantities. The basis for calculating fracture and matrix retardation factors was the mechanistic model developed in Zavarin and Bruton (2004a; 2004b). Details regarding the surface complexation and ion exchange modeling approach and the relevant surface complexation, ion exchange, and speciation constants can be found in those and other recent model validation efforts (Zavarin et al., 2002). Minerals addressed in the surface complexation/ion exchange model included iron oxide, smectite, clinoptilolite, illite/mica, and calcite. The water chemistry (Table 2.4) and rock mineralogy (Table 2.2) were used in the model. Mineral characteristics (surface area, ion exchange capacity, etc.) were taken directly from Zavarin et al. (2002). In the CRUNCH code, radionuclide fracture or matrix retardation was calculated using the mechanistic model directly. For the analytical solution calculations, radionuclide sorption was first calculated using the mechanistic CRUNCH code and then input into the analytical solution as fracture or matrix retardation factors. Radionuclide decay was not relevant to this modeling effort. Diffusion coefficients for all radionuclides were taken primarily from the literature. Tritium, Re, Sr, and Cs diffusion in water was $1.94 \times 10^{-4}, 1.26 \times 10^{-4}, 6.83 \times 10^{-5}$, and $1.78 \times 10^{-4} \mathrm{~m}^{2} /$ day, respectively (Reimus et al., 2002; Hershey et al., 2003; Kemper, 1986; Lide, 2000). The diffusion of all other radionuclides (U, Np, Pu, and $\mathrm{Sm}$ ) was assumed to be equivalent to the diffusion of Tc in water $\left(1.28 \times 10^{-4} \mathrm{~m}^{2} /\right.$ day from Reimus et al., 2002); it was impractical to try to accurately predict the diffusivity of these radionuclides since multiple aqueous species were predicted to be present in solution and each would diffuse at a different rate. The tortuosity and dispersion coefficients were fit during modeling.

For each transport experiment (TCU and LCA rocks), a consistent stepwise modeling approach was taken. All parameter adjustments were accomplished by manually varying the parameters until a visually good fit was found. The stepwise modeling approach included the following steps.

1. Tortuosity, dispersion, the adjusted flow rate, and the fracture aperture (for natural fractures only) were fit to the non-sorbing tracer (tritium and Re) breakthrough data using the Tang et al. (1981) model.

2. The water chemistry, mineralogy, and mineral characteristics, and mechanistic model thermodynamic data were input into the $\mathrm{CRUNCH}$ code to calculate a matrix retardation factor.

3. The adjusted parameters from (1) were combined with matrix retardation factors calculated in (2) to predict the behavior of sorbing radionuclides using the Tang et al. (1981) model. These results were used to test our mechanistic model parameters. Fracture lining mineralogy was ignored.

4. In the case of Sr transport in LCA fractures, the CRUNCH code was used to calculate breakthrough because the background $\mathrm{Sr}$ concentration was high enough to affect the breakthrough profile. This could not easily be addressed with the Tang et al. (1981) analytical solution. 
5. For each sorbing radionuclide, the matrix retardation factor was adjusted to optimize the fit the data. If necessary, a fracture retardation factor was included to produce a good match. The Tang et al. (1981) model was used.

\subsection{Radionuclide Transport in Tuff Cores}

Table 4.1 and Figures 4.1 to 4.4 summarize our effort at modeling the breakthrough of radionuclides from fractured tuff cores. Table 4.1 lists the transport parameters used to fit the breakthrough data (tortuosity, dispersion, adjusted flow rate, fracture aperture (for natural fractures only), and fracture and matrix retardation factors). Table 4.1 also lists the predicted matrix retardation factors based on our mechanistic model. All other parameters used in the modeling were either measured directly (core dimensions, bulk density, porosity, etc. reported in Table 2.1) or taken from the literature $\left(D_{0}\right)$.

The dispersion in the fracture was fit but was always found to be a low value ( 0.001 to $0.005 \mathrm{~m}$ ). The tortuosity of the matrix had a significant effect on the resulting fits. It should be noted that the tortuosity parameter is correlated to $\mathrm{D}_{0}$ (diffusion in water) and porosity. $\mathrm{D}_{0}$ and porosity were taken from the literature or measured. ${ }^{9}$ However, errors in the porosity measurement could affect the value of the fitted tortuosity term; this becomes more relevant in the carbonate core experiments in which the measured porosity was very low. In general, the tortuosity parameter varied between 0.1 and 0.3 . All these values fall within two standard deviations of the average tortuosity previously reported by Reimus et al. (2002) for tuff $(\log (\tau)=-1.1 \pm 0.4,-0.8 \pm 0.5$, and $-1.0 \pm 0.4$ for tritium, $\mathrm{Tc}$, and $\mathrm{HCO}_{3}{ }^{-}$, respectively). However, in TCU-4, the tortuosity fit for $\mathrm{Re}(0.02)$ was unusually low and significantly lower than for tritium $(0.3)$. The TCU-4 was the most zeolitized ( $50 \%$ clinoptilolite/heulandite). Tritium may have been able to diffuse into the tunnel structure of the zeolites while the diffusion of Re (and the other larger radionuclides) through these tunnels would be less likely because of size constraints.

For all sorbing radionuclides, including retardation in the fracture improved the data fit only slightly if at all (except in the case of $U$ in iron oxide coated tuff, TCU-6). This would be expected in the synthesized parallel plate fractures that did not contain fracturelining minerals but was surprising in the case of natural fractures. However, this may be explained by the observed mineralogy of the fracture lining minerals. Fracture lining minerals were dominated by zeolites, as were matrix minerals. Thus, sorption to fracture lining minerals and the underlying matrix minerals was similar.

Predicted matrix retardation factors were based on the surface complexation/ion exchange mechanistic model developed in Zavarin and Bruton (2004a; 2004b). Radionuclide-sorbing minerals in this model include iron oxide, calcite, smectite, illite/mica, and zeolite. The predicted $\mathrm{Np}$ retardation is in good agreement with the fitted retardation factors (Table 4.1). Furthermore, the mechanistic model was able to predict the higher retardation of $\mathrm{Np}$ in TCU-4 compared to the other experiments based on

\footnotetext{
${ }^{9}$ The $\mathrm{D}_{0}$ of $\mathrm{Pu}(\mathrm{IV}), \mathrm{Np}(\mathrm{V}), \mathrm{Sm}(\mathrm{III})$, and $\mathrm{U}(\mathrm{VI})$ were set equal to the $\mathrm{D}_{0}$ of $\mathrm{TcO}_{4}{ }^{-}$.
} 
mineralogic differences of the cores. Predicted U retardation was consistently lower than the measured retardation. However, both the predicted and fitted retardation factors are quite low, suggesting the $\mathrm{U}$ will migrate at a rate nearly equal to the non-sorbing tracers.

Predicting the breakthrough behavior of Pu was difficult. In the absence of colloids, little or no Pu eluted from our columns. However, the small amount of Pu that did elute appeared to travel relatively unretarded. This behavior could not be modeled with a simple retardation model. The small amount of eluted Pu may have been colloidal $\mathrm{Pu}(\mathrm{IV})$ or may have been $\mathrm{Pu}(\mathrm{V})$ which is a weak sorber. Nevertheless, in the absence of colloids, the majority of the $\mathrm{Pu}(\mathrm{IV})$ did not break through. Importantly, our model consistently overpredicted the transport of $\mathrm{Pu}$ (ignoring the early breakthrough of trace $\mathrm{Pu}$ ). Since the dominant $\mathrm{Pu}(\mathrm{IV})$ sorber in these zeolitized tuffs is expected to be smectite, we suspect that our surface complexation model is underpredicting Pu sorption to this mineral. The fitted retardation factors reported in Table 4.1 for Pu were based on predicting the minimum matrix retardation required for the Pu breakthrough concentration to be below the detection limit of the ICP-MS analysis; we ignored any early unretarded (and trace) breakthrough of Pu.

Our models did not include explicit colloid-facilitated transport. Colloid transport was not accounted for even in the TCU-5 experiment in which colloids were introduced to the column. Thus, modeling results for TCU-5 should be interpreted with caution. In the TCU-5 experiment, the effective matrix retardation factor that fits TCU-5 Pu data $(\mathrm{R}=2)$ is much lower than the predicted value $(\mathrm{R}=33)$ and reflects the role of colloid facilitated $\mathrm{Pu}$ transport. However, this model does not appropriately account for the mechanism of colloid transport. The results can only be interpreted as indicating the drastic reduction in $\mathrm{Pu}$ retardation factors in the presence of colloids. Interestingly, if we reduce the rate of $\mathrm{Pu}$ and $\mathrm{Sm}$ diffusion into the matrix by assuming that the colloid-associated radionuclide fraction will not participate in diffusion, our predicted model begins to approach the observed breakthrough behavior (Figure 4.4). Nevertheless, an explicit colloid-facilitated transport model would be needed to properly model these data.

In all cases (including TCU-5), Cs and Sr were predicted to sorb very strongly to the zeolitic matrix and were never observed in significant quantities in the effluent. This is in agreement with laser ablation results which suggest that $\mathrm{Sr}$ and Cs migrated less that 1 $\mathrm{cm}$ in the tuff cores. It is interesting, however, to note that in the TCU-3 experiment, a few effluent samples were run at a very low dilution to improve our detection limit. Based on those samples, it appears that a very small quantities of $\mathrm{Sr}$ and Cs migrated through the column unretarded. This may, in fact, suggest simply that diffusion into the matrix was not fast enough to completely remove $\mathrm{Cs}$ and $\mathrm{Sr}$ from the fracture fluid over the short distance of our core experiments. At the field scale, this effect would probably not be observed.

The transport behavior of Sm mimics that of $\mathrm{Pu}$. Our predicted high Sm retardation was consistent with the little or no breakthrough observed in all but the TCU-5 experiment. In the TCU-5 experiment, the matrix retardation necessary to fit TCU-5 Sm data $(R=2)$ is much lower than the predicted value $(\mathrm{R}=740)$ and reflects the role of colloid facilitated 
Sm transport. In TCU-5, colloids played a prominent role in transporting Sm but our model did not explicitly account for this transport process. Interestingly, if we reduce the rate of Sm diffusion into the matrix by assuming that the colloid-associated radionuclide fraction will not participate in diffusion, our predicted model begins to approach the observed breakthrough behavior (Figure 4.4). However, the model still drastically underestimates transport in the presence of colloids. A colloid transport model would need to be included in our simulations to properly model these results.

To evaluate the effect of the precipitated iron oxide coating on radionuclide transport, transport in TCU-2 and TCU-6 cores should be compared. Interestingly, the iron oxide coating that was prepared in the TCU-6 experiment did not affect the transport behavior of any radionuclide drastically. For $\mathrm{Np}$, the fitted matrix retardation factor was lower by a factor of 2.4 in the presence of iron oxide coatings (TCU-6 core). For U, the fitted matrix retardation factor increased by a factor of 2.5. Also, the fitted fracture retardation factor increased by a factor of 2.5. Nevertheless, retardation factors remained low for both radionuclides. This result appears to suggest that fracture linings may not necessarily drastically affect the transport behavior of some radionuclides. Comparing the fitted $\mathrm{U}$ fracture retardation $(\mathrm{R}=5)$ with the predicted fracture $\mathrm{R}$ based on the iron oxide reactive surface area of $226 \mathrm{~m}^{2} / \mathrm{g}$ and our surface complexation model, we find that the effective thickness of the iron oxide layer is 0.15 micrometers. It appears from this comparison that two conclusions may be made: 1) the iron oxide coating did not drastically affect the transport behavior of $\mathrm{Np}$ and $\mathrm{U}$ and 2) the effective thickness of the iron oxide layer in direct contact with the flowing fluid is extremely small. It should, however, be noted that the fraction of $\mathrm{Np}$ and $\mathrm{U}$ eluted from this column was less than any other fractured tuff experiment (Table 3.1). Further examination of the iron oxide coating would be needed to better understand the role of the iron oxide coating in radionuclide retardation. In the case of $\mathrm{Pu}, \mathrm{Sm}, \mathrm{Sr}$, and $\mathrm{Cs}$, the effect of iron oxide could not be observed since these radionuclides did not elute. Importantly, the results of the TCU-6 experiment and comparison with the coating-free transport experiment suggest that iron oxide coatings may not drastically change the transport behavior of certain radionuclides. This is particularly important to recognize because of the importance often placed on retardation by fracture lining minerals. Also, importantly, the iron oxide coating did not appear to interfere with diffusion of tracers. This result, along with the natural fracture experiments (TCU-3 and TCU-4), suggests that fracture linings will not effectively impede diffusion. 
Table 4.1. Predicted and fitted radionuclide retardation and diffusion parameters for tuff cores.

\begin{tabular}{|c|c|c|c|c|c|c|c|c|}
\hline & ${ }^{3} \mathrm{H}$ & $\operatorname{Re}$ & $\mathrm{Np}$ & $\mathrm{U}$ & $\mathrm{Pu}$ & $\mathrm{Sr}$ & Cs & $\mathrm{Sm}$ \\
\hline \multicolumn{9}{|c|}{ TCU-2 } \\
\hline$\tau$ & 0.15 & 0.15 & 0.15 & 0.15 & 0.15 & 0.15 & 0.15 & 0.15 \\
\hline $\begin{array}{l}\text { dispersion, } \mathrm{m} \\
\text { flow rate. }\end{array}$ & 0.001 & 0.001 & 0.001 & 0.001 & 0.001 & 0.001 & 0.001 & 0.001 \\
\hline $\begin{array}{l}\mathrm{mL} / \mathrm{min} \\
\text { Predicted }\end{array}$ & 0.016 & 0.016 & 0.016 & 0.016 & 0.016 & 0.016 & 0.016 & 0.016 \\
\hline Rmatrix & 1 & 1 & 24 & 1.1 & 120 & 31000 & 280000 & 12000 \\
\hline Fit Rmatrix & 1 & 1 & 6 & 4 & $>600^{\mathrm{a}}$ & $>4000$ & $>1500$ & $>750$ \\
\hline Fit Rfracture & 1 & 1 & 1 & 2 & 1 & 1 & 1 & 1 \\
\hline \multicolumn{9}{|c|}{ TCU-3 } \\
\hline$\tau$ & 0.15 & 0.15 & 0.15 & 0.15 & 0.15 & 0.15 & 0.15 & 0.15 \\
\hline $\begin{array}{l}\text { dispersion, } \mathrm{m} \\
\text { flow rate, }\end{array}$ & 0.001 & 0.001 & 0.001 & 0.001 & 0.001 & 0.001 & 0.001 & 0.001 \\
\hline $\mathrm{mL} / \mathrm{min}$ & 0.018 & 0.018 & 0.018 & 0.018 & 0.018 & 0.018 & 0.018 & 0.018 \\
\hline $\begin{array}{l}\text { Aperture, mm } \\
\text { Predicted }\end{array}$ & 0.2 & 0.2 & 0.2 & 0.2 & 0.2 & 0.2 & 0.2 & 0.2 \\
\hline Rmatrix & 1 & 1 & 7.4 & 1.05 & 26 & 13000 & 36000 & 5100 \\
\hline Fit Rmatrix & 1 & 1 & 1.5 & 2 & $>1000^{\mathrm{a}}$ & $>2000$ & $>1000$ & $>750$ \\
\hline Fit Rfracture & 1 & 1 & 1 & 2 & 1 & 1 & 1 & 1 \\
\hline \multicolumn{9}{|c|}{ TCU-4 } \\
\hline$\tau$ & 0.3 & 0.02 & 0.02 & 0.02 & 0.02 & 0.02 & 0.02 & 0.02 \\
\hline $\begin{array}{l}\text { dispersion, } \mathrm{m} \\
\text { flow rate, }\end{array}$ & 0.001 & 0.001 & 0.001 & 0.001 & 0.001 & 0.001 & 0.001 & 0.001 \\
\hline $\mathrm{mL} / \mathrm{min}$ & 0.015 & 0.015 & 0.015 & 0.015 & 0.015 & 0.015 & 0.015 & 0.015 \\
\hline $\begin{array}{l}\text { aperture, mm } \\
\text { Predicted }\end{array}$ & 1 & 1 & 1 & 1 & 1 & 1 & 1 & 1 \\
\hline Rmatrix & 1 & 1 & 50 & 1.9 & 290 & 67000 & 360000 & 37000 \\
\hline Fit Rmatrix & 1 & 1 & 100 & 40 & $>15000^{\mathrm{a}}$ & $>30000$ & $>35000$ & $>20000$ \\
\hline Fit Rfracture & 1 & 1 & 1 & 2 & 1 & 1 & 1 & 1 \\
\hline \multicolumn{9}{|c|}{ TCU-5 } \\
\hline$\tau$ & 0.2 & 0.1 & 0.1 & 0.1 & 0.1 & 0.1 & 0.1 & 0.1 \\
\hline $\begin{array}{l}\text { dispersion, } \mathrm{m} \\
\text { flow rate, }\end{array}$ & 0.005 & 0.005 & 0.005 & 0.005 & 0.005 & 0.005 & 0.005 & 0.005 \\
\hline $\mathrm{mL} / \mathrm{min}$ & 0.018 & 0.018 & 0.018 & 0.018 & 0.018 & 0.018 & 0.018 & 0.018 \\
\hline $\begin{array}{l}\text { aperture, mm } \\
\text { Predicted }\end{array}$ & 0.5 & 0.5 & 0.5 & 0.5 & 0.5 & 0.5 & 0.5 & 0.5 \\
\hline Rmatrix & 1 & 1 & 2.0 & 1.3 & 32 & 12000 & 29000 & 740 \\
\hline Fit Rmatrix & 1 & 1 & 5 & 8 & 2 & - & - & 2 \\
\hline Fit Rfracture & 1 & 1 & 1 & 1 & 1 & 1 & 1 & 1 \\
\hline
\end{tabular}

* If $\mathrm{R}_{\text {fracture }}>200$, radionuclides would not breakthrough over the timeframe of the experiments.

${ }^{a}$ Breakthrough fitted ignoring the small amount of $\mathrm{Pu}$ breakthrough at early time that was most likely the result of colloid-facilitated transport. 
Table 4.1. (continued).

\begin{tabular}{|c|c|c|c|c|c|c|c|c|}
\hline & ${ }^{3} \mathrm{H}$ & $\mathrm{Re}$ & $\mathrm{Np}$ & $\mathrm{U}$ & $\mathrm{Pu}$ & $\mathrm{Sr}$ & $\mathrm{Cs}$ & $\mathrm{Sm}$ \\
\hline \multicolumn{9}{|c|}{ TCU-6 } \\
\hline$\tau$ & 0.1 & 0.1 & 0.1 & 0.1 & 0.1 & 0.1 & 0.1 & 0.1 \\
\hline $\begin{array}{l}\text { dispersion, } \mathrm{m} \\
\text { flow rate, }\end{array}$ & 0.001 & 0.001 & 0.001 & 0.001 & 0.001 & 0.001 & 0.001 & 0.001 \\
\hline $\begin{array}{l}\mathrm{mL} / \mathrm{min} \\
\text { Predicted }\end{array}$ & 0.018 & 0.018 & 0.018 & 0.018 & 0.018 & 0.018 & 0.018 & 0.018 \\
\hline Rmatrix & 1 & 1 & 5.7 & 1.2 & 60 & 1600 & 7900 & 4300 \\
\hline Fit Rmatrix & 1 & 1 & 2.5 & 10 & $>1000$ & $>3000$ & $>2500$ & $>1000$ \\
\hline Fit Rfracture & 1 & 1 & 1 & 5 & 1 & 1 & 1 & 1 \\
\hline
\end{tabular}

* If $\mathrm{R}_{\text {fracture }}>200$, radionuclides would not breakthrough over the timeframe of the experiments. 

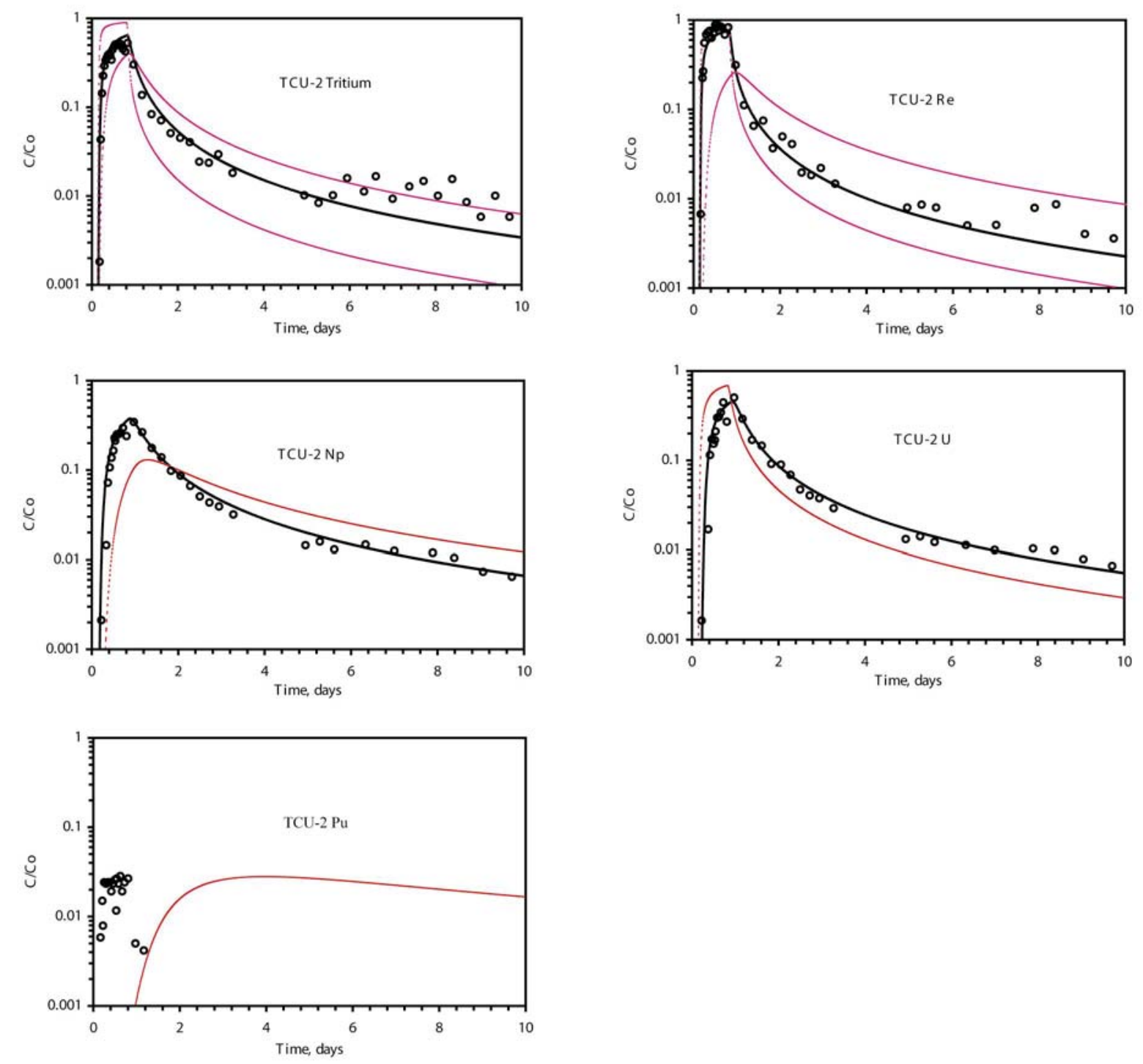

Figure 4.1. Model fits to TCU-2 elution data. Analytical solution fit to data (black) (Pu data not fit; Sm elution not observed); tritium and Re breakthrough over measured Reimus et al. (2002) tortuosity range (purple); Np, $\mathrm{U}$, and Pu breakthrough using predicted retardation (red). 

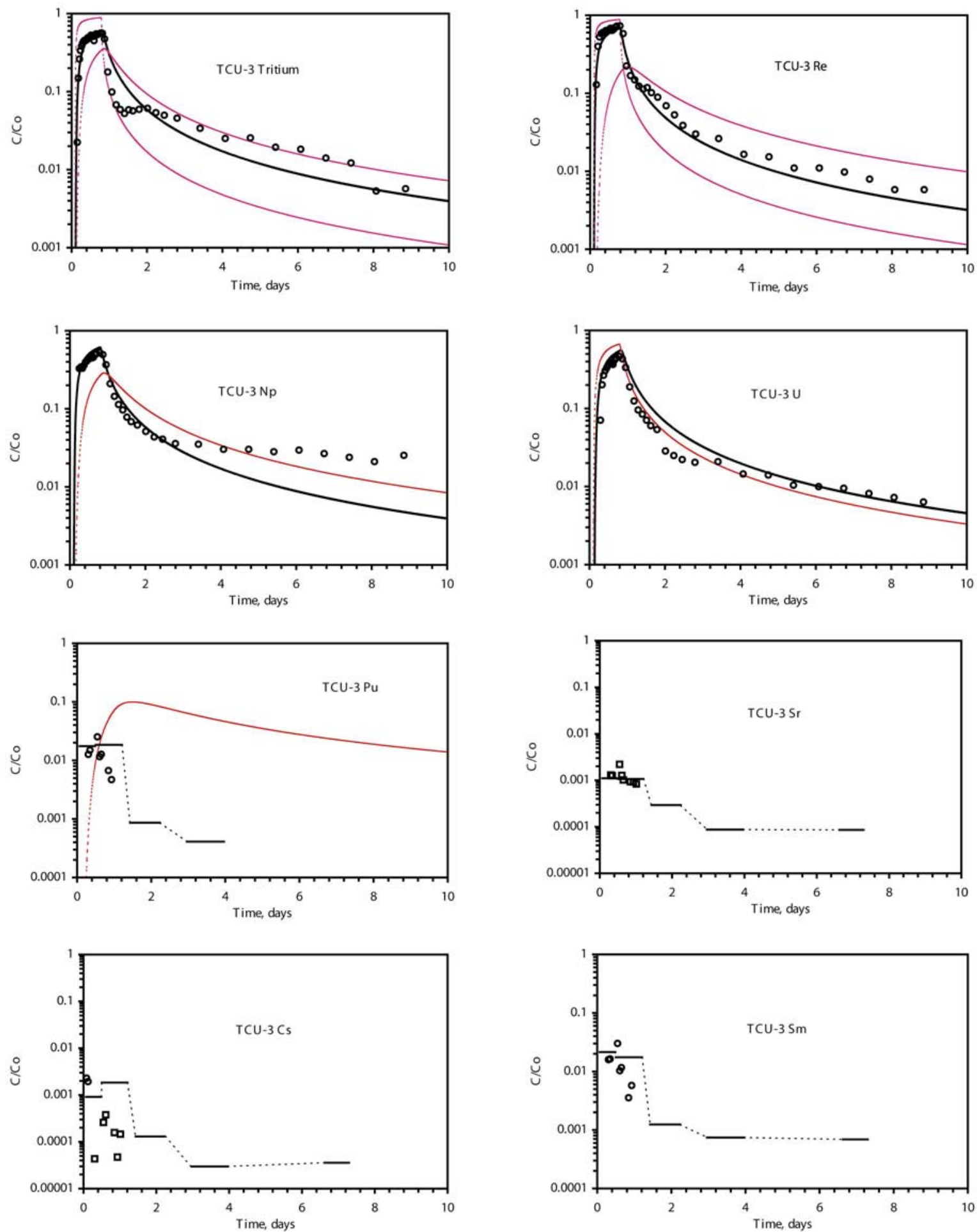

Figure 4.2. Model fits to TCU-3 elution data. Analytical solution fit to data (black) (Pu, Sr, Cs, and Sm data not fit); tritium and Re breakthrough over measured Reimus et al. (2002) tortuosity range (purple); Np, U, and Pu breakthrough using predicted retardation (red); $\mathrm{Pu}, \mathrm{Sr}, \mathrm{Cs}$, and $\mathrm{Sm}$ stepped profiles are measured concentrations integrated over a large sample volume to improve detection limits. 

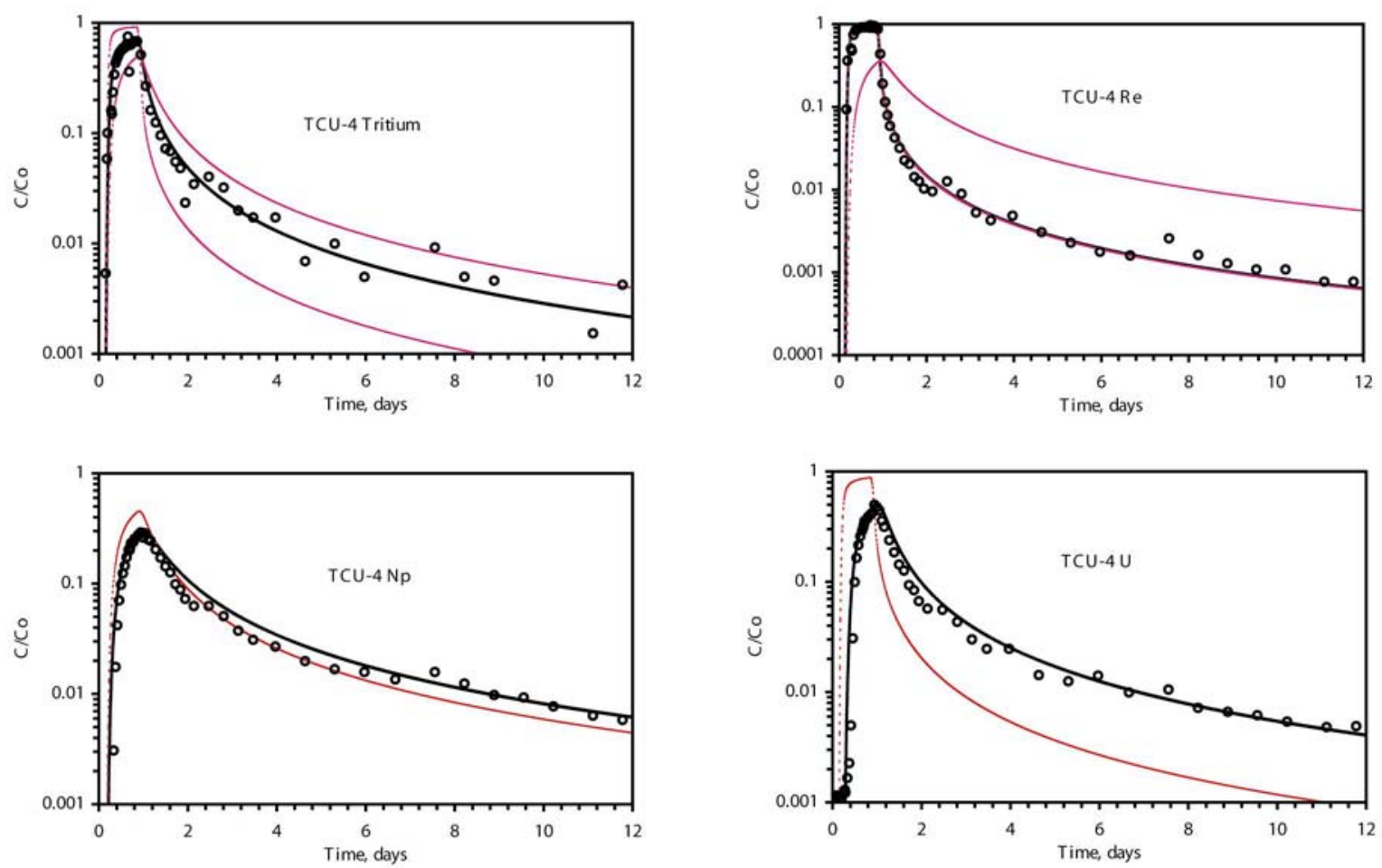

Figure 4.3. Model fits to TCU-4 elution data. Analytical solution fit to data (black); tritium and Re breakthrough over measured Reimus et al. (2002) tortuosity range (purple); Np and $\mathrm{U}$ breakthrough using predicted retardation (red). 

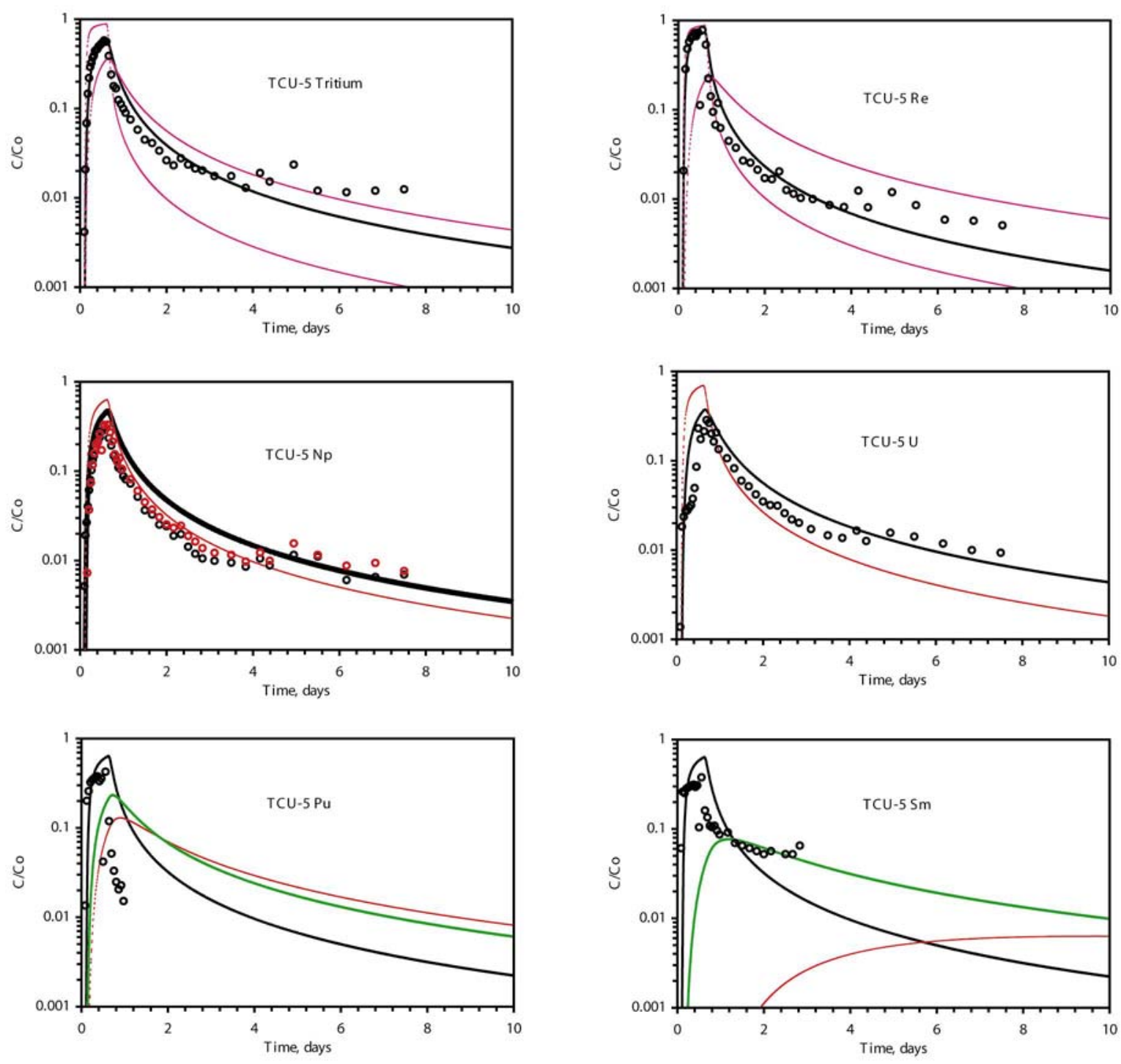

Figure 4.4. Model fits to TCU-5 elution data. Analytical solution fit to data (black); tritium and Re breakthrough over measured Reimus et al. (2002) tortuosity range (purple); Np, U, $\mathrm{Pu}$, and Sm breakthrough using predicted retardation (red); Pu and Sm breakthrough using predicted retardation but assuming colloid-associated radionuclide fraction does not diffuse (green). 

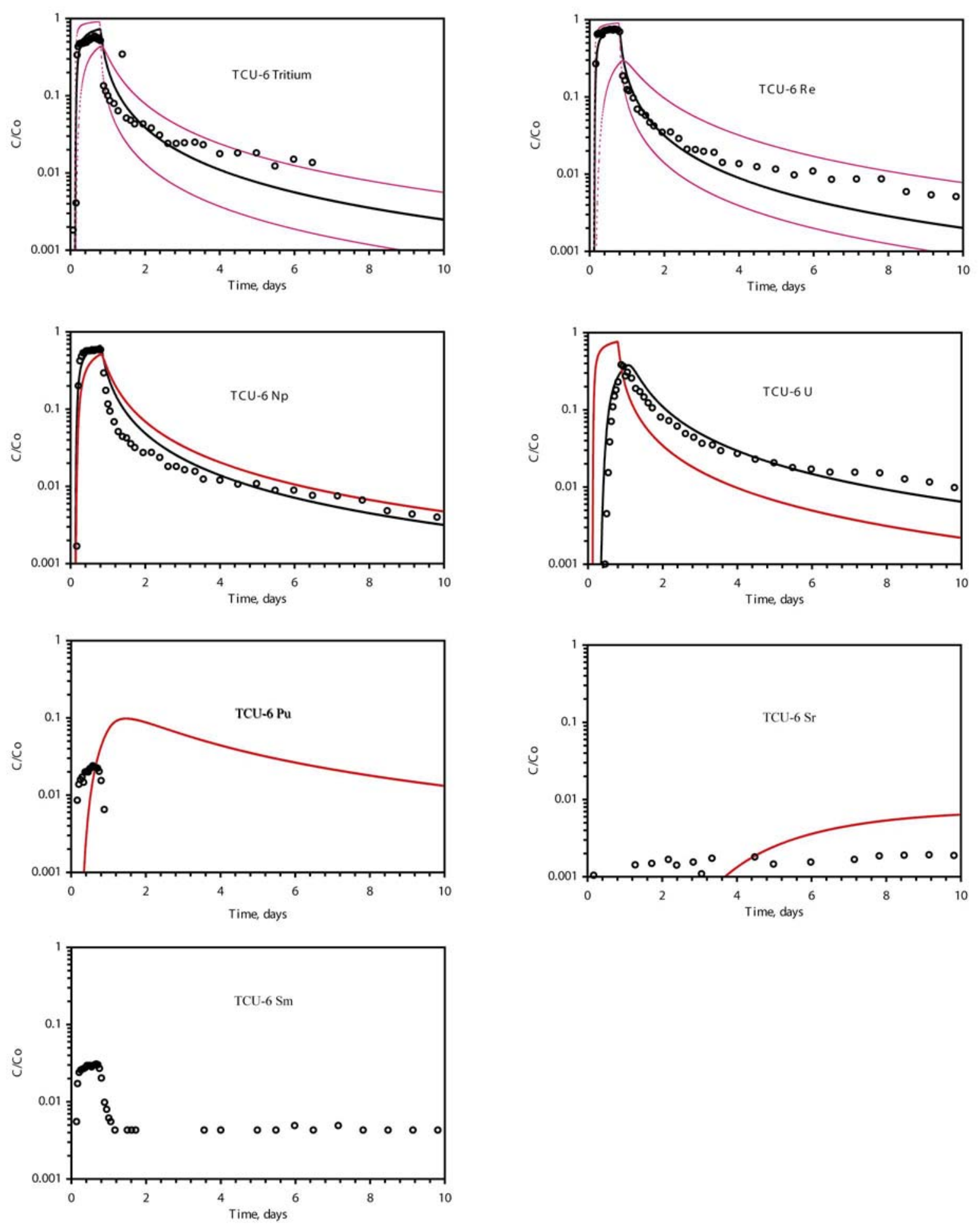

Figure 4.5. Model fits to TCU-6 elution data. Analytical solution fit to data (black) (Pu, Sr, and Sm data not fit; Cs did not elute); tritium and Re breakthrough over measured Reimus et al. (2002) tortuosity range (purple); $\mathrm{Np}, \mathrm{U}, \mathrm{Pu}$, and $\mathrm{Sr}$ breakthrough using predicted retardation (red). 


\subsection{Radionuclide Transport in Carbonate Cores}

Table 4.2 and Figures 4.6 to 4.8 summarize our effort at modeling the breakthrough of radionuclides from fractured carbonate cores. Table 4.2 lists the transport parameters used to fit the breakthrough data (tortuosity $(\tau)$, dispersion, flow rate, fracture aperture (for induced fracture), and fracture and matrix retardation factors). All other parameters used in the modeling were either measured directly (core dimensions, bulk density, porosity, etc. reported in Table 2.1) or based on values from the literature $\left(D_{0}\right)$. The data modeling method used to examine radionuclide transport in the carbonate fractures was essentially the same as that described for the TCU fractures. In the carbonate case, we chose to assume that dolomite and calcite will sorb radionuclides equally well. Thus, the mass fraction of sorbing carbonate was $100 \%$ in all cases in CRUNCH calculations.

Table 4.2. Predicted and fitted radionuclide retardation and diffusion parameters for carbonate cores.

\begin{tabular}{|c|c|c|c|c|c|c|c|c|}
\hline & ${ }^{3} \mathrm{H}$ & $\mathrm{Re}$ & $\mathrm{Np}$ & $\mathrm{U}$ & $\mathrm{Pu}$ & $\mathrm{Sr}$ & $\mathrm{Cs}$ & $\mathrm{Sm}$ \\
\hline \multicolumn{9}{|c|}{ LCA-1 } \\
\hline$\tau$ & 1 & 1 & 1 & 1 & 1 & 1 & 1 & 1 \\
\hline dispersion, $\mathrm{m}$ & 0.01 & 0.01 & 0.01 & 0.01 & 0.01 & 0.01 & 0.01 & 0.01 \\
\hline $\begin{array}{l}\text { flow rate, } \\
\mathrm{mL} / \mathrm{min} \\
\text { Predicted }\end{array}$ & 0.016 & 0.016 & 0.016 & 0.016 & 0.016 & 0.016 & 0.016 & 0.016 \\
\hline Rmatrix & 1 & 1 & 1567 & 7.55 & 24439 & 1.75 & 1 & 2016000 \\
\hline Fit Rmatrix & 1 & 1 & 10 & 6 & $>2000$ & 1 & 1 & $>200$ \\
\hline Fit Rfracture & 1 & 1 & 1 & 1 & 1 & 1 & 1 & 1 \\
\hline \multicolumn{9}{|c|}{ LCA-2 } \\
\hline$\tau$ & 1 & 1 & 1 & 1 & 1 & 1 & 1 & 1 \\
\hline $\begin{array}{l}\text { dispersion, } \mathrm{m} \\
\text { flow rate, }\end{array}$ & 0.005 & 0.005 & 0.005 & 0.005 & 0.005 & 0.005 & 0.005 & 0.02 \\
\hline $\begin{array}{l}\mathrm{mL} / \mathrm{min} \\
\text { Predicted }\end{array}$ & 0.016 & 0.016 & 0.016 & 0.016 & 0.016 & 0.016 & 0.016 & 0.016 \\
\hline Rmatrix & 1 & 1 & 3006 & 10.33 & 192000 & 2.65 & 1 & 4009000 \\
\hline Fit Rmatrix & 1 & 1 & 8 & 6 & $\sim 100$ & 1 & 1 & $\sim 4000$ \\
\hline Fit Rfracture & 1 & 1 & 1 & 1 & 1 & 1 & 1 & 1 \\
\hline \multicolumn{9}{|c|}{ LCA-3 } \\
\hline$\tau$ & 0.6 & 0.6 & 0.6 & 0.6 & 0.6 & 0.6 & 0.6 & 0.6 \\
\hline $\begin{array}{l}\text { dispersion, } \mathrm{m} \\
\text { flow rate, }\end{array}$ & 0.005 & 0.005 & 0.005 & 0.005 & 0.005 & 0.005 & 0.005 & 0.005 \\
\hline $\mathrm{mL} / \mathrm{min}$ & 0.019 & 0.019 & 0.019 & 0.019 & 0.019 & 0.019 & 0.019 & 0.019 \\
\hline $\begin{array}{l}\text { aperture, mm } \\
\text { Predicted }\end{array}$ & 0.3 & 0.3 & 0.3 & 0.3 & 0.3 & 0.3 & 0.3 & 0.3 \\
\hline Rmatrix & 1 & 1 & 2620 & 5.34 & 117000 & 2.45 & 1 & 3391000 \\
\hline Fit Rmatrix & 1 & 1 & 25 & 20 & 50 & 2 & 1 & $>20000$ \\
\hline Fit Rfracture & 1 & 1 & 2 & 2 & 1 & 1 & 1 & 1 \\
\hline
\end{tabular}

$*$ if $\mathrm{R}_{\text {fracture }}>200$, radionuclides would not breakthrough over the timeframe of the experiments. 
In general, varying the dispersion parameter did not greatly improve the overall fit to the data. However, in the LCA-1 experiment, the dispersion was apparently high $(0.01 \mathrm{~m})$. The LCA-1 experiment was plagued by calcite precipitation which likely affected the flow of fluid through the fracture. Calcite precipitation also affected the migration of sorbing radionuclides, as described in Section 3.2.1. As a result, the transport behavior of radionuclides in this experiment may not accurately represent the migration of radionuclides under steady state conditions likely to be observed at the NTS.

As mentioned previously, the tortuosity parameter is correlated with $\mathrm{D}_{0}$ and porosity. The $\mathrm{D}_{0}$ and porosity for each radionuclide and core were taken from the literature or measured directly. However, based on the fact that the fitted tortuosity was consistently high (0.6 to 1.0), we suspect that the actual porosity of the carbonate rock may be somewhat higher than the measured value. Hershey et al. (1998) measured tortuosity values ranging from about 0.2 to 0.4 for $\mathrm{Br}^{-}$diffusion in carbonate.

For all sorbing radionuclides, including retardation in the fracture improved the data fit only slightly if at all. The synthesized parallel plate fractures and the Brazil fracture did not contain fracture lining minerals. Predicted matrix retardation factors were based on the calcite surface complexation mechanistic model developed in Zavarin and Bruton (2004a). The reactive surface area used in the model was $0.1 \mathrm{~m}^{2} / \mathrm{g}$ and was based on model calibration to alluvium flow-through experiments (Zavarin et al., 2002). It was expected that the carbonate surface area in alluvium would be significantly different from the accessible reactive surface in the carbonate rock. However, we did not know a priori whether the surface area of the carbonate rock would be higher or lower than $0.1 \mathrm{~m}^{2} / \mathrm{g}$. The difference between the predicted and fit retardation factors are an indication of the relative reactive surface area of the LCA.

The predicted Np retardation was two orders of magnitude higher than the fitted retardation for all three carbonate cores. This would suggest that the reactive surface area of LCA calcite is approximately $0.001 \mathrm{~m}^{2} / \mathrm{g}$. However, predicted $\mathrm{U}$ retardation was in general agreement with the fitted retardation. If the calcite reactive surface area was reduced to $0.001 \mathrm{~m}^{2} / \mathrm{g}$, U retardation would be underpredicted. Generally, U sorbs very weakly to calcite when in the +6 oxidation state (Zavarin and Bruton, 2004b). Trace quantities of iron oxide or aluminosilicate clays may not have been detected by XRD but could account for the small amount of $U$ retardation in these cores. As in the case of $\mathrm{Np}$, predicted $\mathrm{Pu}$ retardation was at least two orders of magnitude higher than the fitted retardation. This, again, suggests that the reactive surface area of the carbonate is much lower than in alluvium. For the LCA-2 and LCA-3 experiments, Pu retardation in the matrix was estimated to be 100 and 50, respectively. Importantly, colloids were not included in any of these experiments. The higher retardation in LCA-1 mostly likely resulted from calcite precipitation (and $\mathrm{Pu}$ coprecipitation) during the experiment. The relatively low retardation measured in LCA-2 and LCA-3 suggests that Pu may migrate significant distances through fracture carbonate rock. However, it is interesting to note that the lack of tailing in the Pu elution curves could not be fit using the analytical solution of Tang et al. (1981). We suspect that the unusually small tailing in the elution curve may result from irreversible sorption to the calcite surface, possibly as a result of 
slow $\mathrm{Pu}$ incorporation into the calcite bulk. If true, this mechanism would provide a significant sink to Pu over the long-term.

Unlike in the TCU case, Cs and Sr were predicted to and observed to migrate through the calcite fractures effectively unretarded. Thus, we predict that $\mathrm{Sr}$ and $\mathrm{Cs}$ that reaches the LCA aquifer will migrate downstream at a rate equivalent to tritium (or possibly faster due to their slower diffusion rates).

The transport of Sm is greatly retarded. However, our predicted Sm retardation still appears to overpredict retardation by $\sim 2$ orders of magnitude. This is consistent with the modeling observations for $\mathrm{Np}$ and $\mathrm{Pu}$ as well. A very small quantity of Sm was observed only in the LCA-2 effluent. To fit these data, we needed to raise the dispersion coefficient to $0.02 \mathrm{~m}$, which may not be realistic. In all experiments, significant Sm migration in carbonate fractures was not observed. Thus, in the absence of colloids, we would not expect Sm to be transported. Based on their analogous reaction chemistry, it is likely that the transport of any of the trivalent rare earth radionuclides (as well as the Am(III) actinide) will be greatly retarded. However, as suggested by the TCU experiments, the introduction of colloids may significantly enhance the transport behavior of these strongly sorbing radionuclides. 

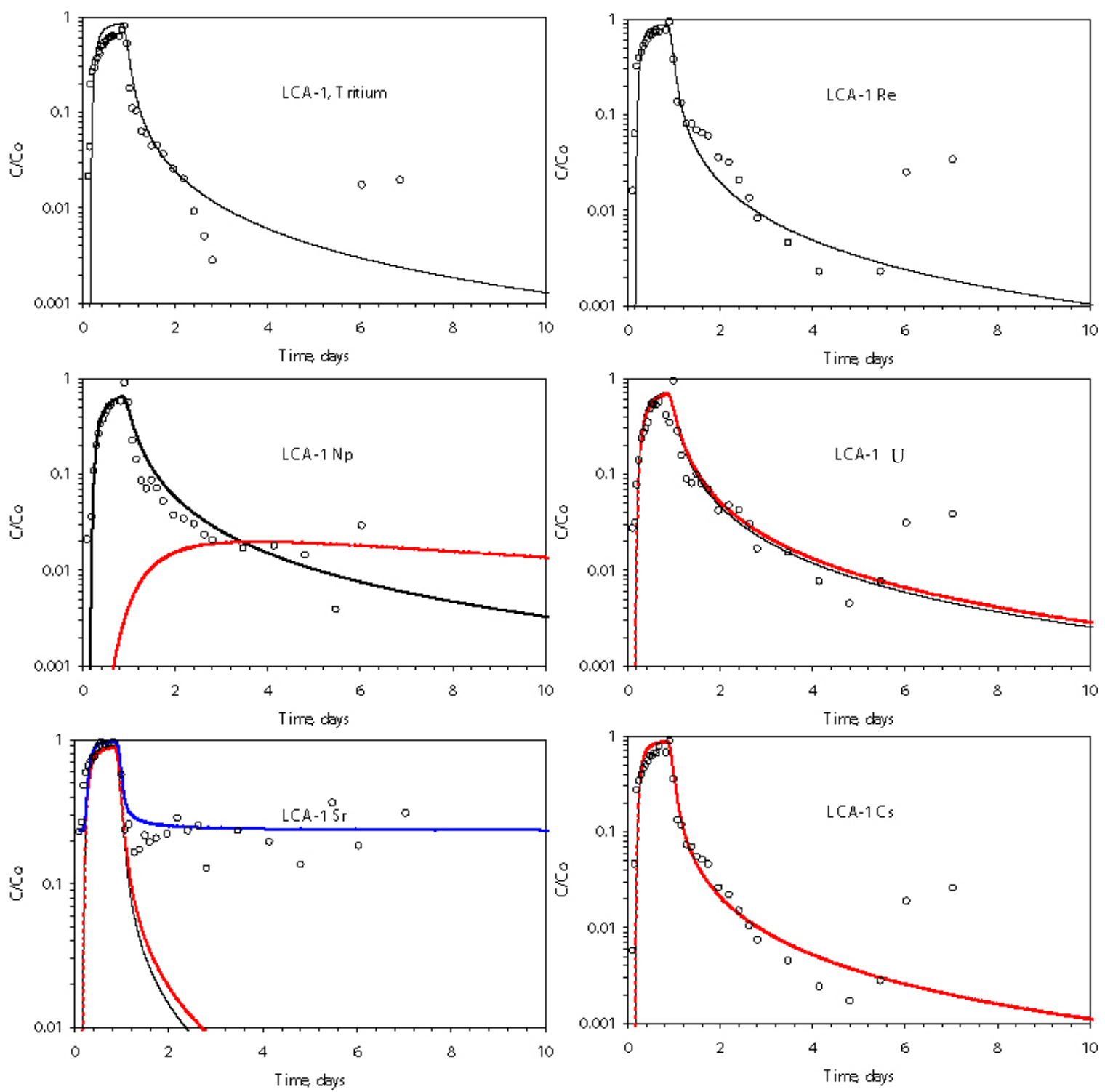

Figure 4.6. Model fits to LCA-1 elution data. Analytical solution fit to data (black); Np, U, $\mathrm{Sr}$, and Cs breakthrough using predicted retardation (red); Sr breakthrough using 2D CRUNCH model which accounts for background radionuclide concentrations(blue). 

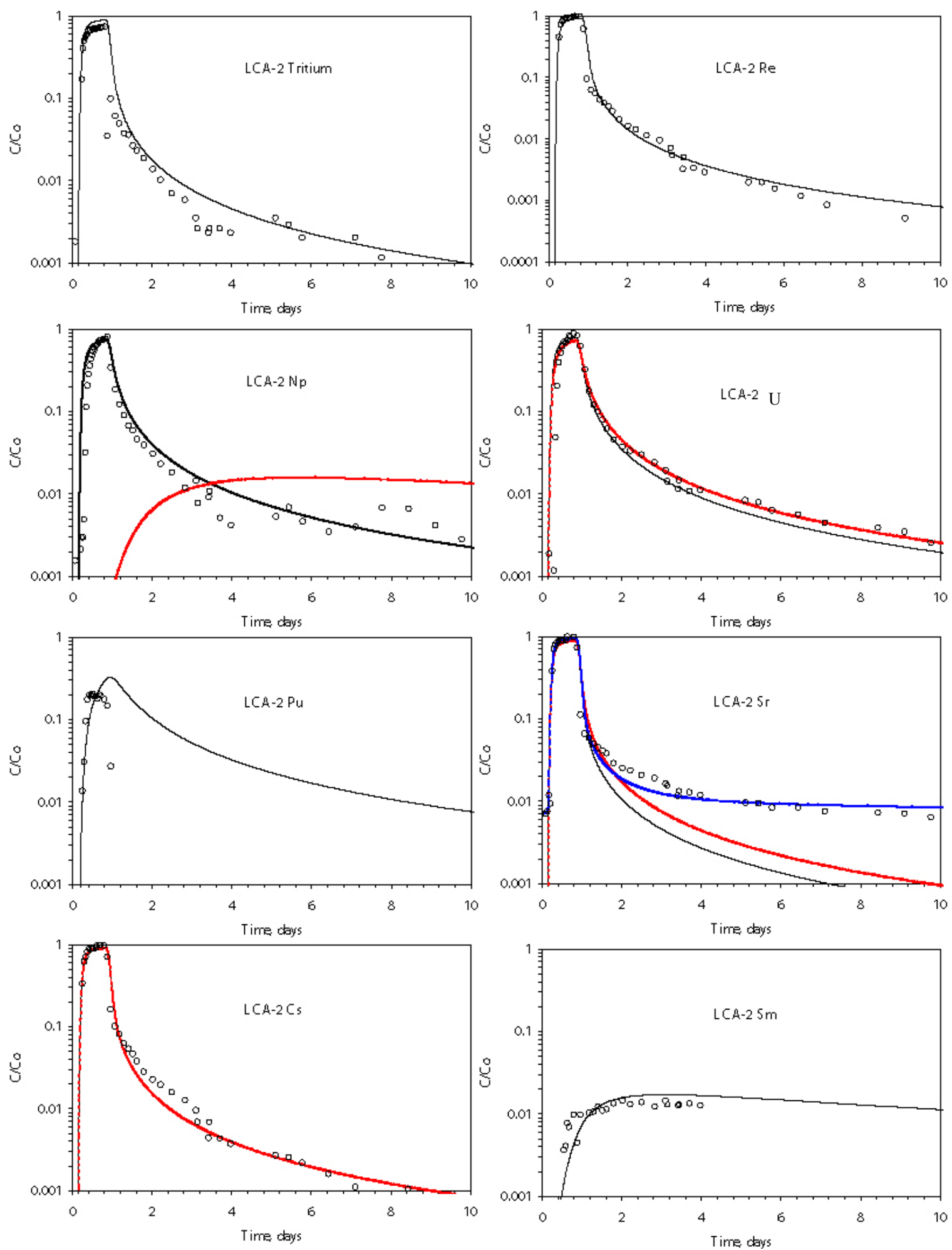

Figure 4.7. Model fits to LCA-2 elution data. Analytical solution fit to data (black); Np, U, $\mathrm{Sr}$, and Cs breakthrough using predicted retardation (red); Sr breakthrough using 2D CRUNCH model which accounts for background radionuclide concentrations(blue). 

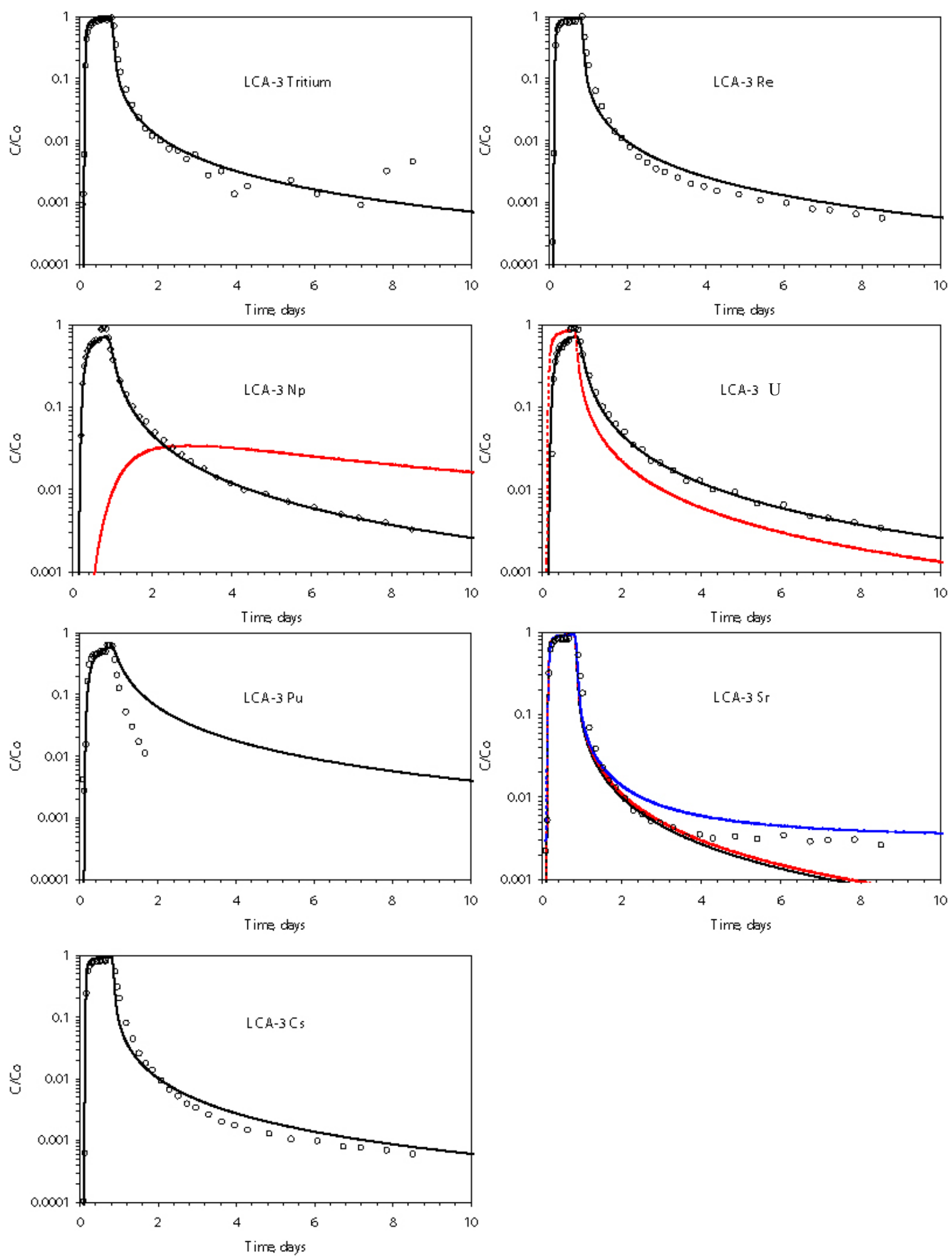

Figure 4.8. Model fits to LCA-3 elution data. Analytical solution fit to data (black); Np, U, $\mathrm{Sr}$, and Cs breakthrough using predicted retardation (red); Sr breakthrough using 2D CRUNCH model which accounts for background radionuclide concentrations(blue). 


\section{CONCLUSIONS AND RECOMMENDATIONS}

Based on the experimental results and modeling described in this report:

$\underline{\text { Transport in TCU fractures }}$

- Tritium and Re behave as tracers that diffuse into the rock matrix at rates proportional to their diffusivities in water $(\operatorname{Re}<$ Tritium).

- Both in the natural and synthetic fractures, $\mathrm{Np}$ and $\mathrm{U}$ breakthrough was retarded only slightly, indicating a low sorption potential of these two radionuclides in the Yucca Flat TCU rock.

- Fracture coatings (natural and iron oxide) did not significantly impede diffusion.

- Colloid facilitated transport was a significant mechanism for the transport of $\mathrm{Np}$ or U.

- In the iron oxide coated fracture, $U$ was retarded more than in the uncoated fracture. However, the difference was much smaller than expected.

- The iron oxide coating had surprisingly little effect on the transport behavior of $\mathrm{Np}$.

- Cs was effectively retained in the zeolitized tuff fractures both in the presence and absence of colloids; its breakthrough was not observed in the effluent but its very slow migration could be measured with spatial mapping of the fracture using laser ablation.

- Sr appears to be effectively retained in the zeolitized tuff. Its breakthrough above background concentrations was not observed in the effluent; its very slow migration could be measured with spatial mapping of the fracture using laser ablation.

- In the presence of colloids, $60 \%$ of the Sm introduced to a tuff fracture eluted compared to $0-16 \%$ in the absence of colloids. Any significant transport of Sm in the TCU fractures will likely be the result of colloid facilitated transport. However, whether the colloid-facilitated transport is significant at the field scale will require further examination.

- Like Sm, Pu breakthrough was significant only in the presence of colloids. Pu migration is likely to occur in the TCU only as a result of colloid facilitated transport.

- Autoradiography was successfully used to image alpha activity in all the smooth, parallel plate experimental cores. Radiography is a powerful tool to characterize the location of the alpha activity and, combined with SEM and SIMS, can help clarify the controls on elution behavior of alpha emitting radionuclides. High 
alpha activity in the cores was found to correlate with dark (Fe- and Mncontaining) minerals.

- Laser ablation identified the migration behavior of Cs and Sr indicating that these radionuclides traveled significantly less than $1 \mathrm{~cm}$ in each experiment over the experiment time period ( $\sim 10$ days). Results from depth profiling confirm that transverse diffusion had occurred during the fracture flow experiment for most radionuclides.

- Using our mechanistic modeling approach, we were successful in predicting the behavior of radionuclides in most cases: the retardation factors predicted a priori compare well with fitted retardation factors. Additional modeling would be necessary to address the observed colloid-facilitated transport; colloid-facilitated transport was not addressed in the modeling effort reported here.

In addition, an important result of these experiments is the overall similarity between the parallel-plate synthetic fracture experiments (TCU-2, TCU-5, and TCU-6) and the results of the natural fracture experiments (TCU-3 and TCU-4). While there are differences in radionuclide transport behavior in the various core flow-through experiments, the transport behavior is qualitatively the same. This suggests that fracture lining minerals and topographically heterogeneous surfaces of natural fractures may not necessarily drastically change the overall transport behavior of radionuclides. A parallel-plate model is, indeed, not an unrealistic starting point for conceptualizing radionuclide fracture transport behavior, particularly in single fracture experiments.

\section{Transport in LCA fractures}

- Tritium and Re behave as tracers that diffuse into the rock matrix at rates proportional to their diffusivities in water $(\mathrm{Re}<$ Tritium). High predicted tortuosity values may have resulted from underestimates of porosity.

- As in TCU fractures, Np and U breakthrough was retarded only slightly, indicating a low sorption potential of these two radionuclides in LCA rock.

- Unlike in TCU fractures, Cs traveled nearly unretarded in the LCA fractures. Laser ablation ICP-MS corroborated these results.

- Unlike the TCU fractures, Sr traveled nearly unretarded.

- In all experiments, Sm migration in carbonate fractures was not observed. Thus, in the absence of colloids, Sm transport is unlikely. Based on their analogous reaction chemistry, it is likely that the transport of any of the trivalent rare earth radionuclides (as well as the Am(III) actinide) will be greatly retarded. However, as suggested by the TCU experiments, the introduction of colloids may significantly enhance transport behavior of these strongly sorbing radionuclides.

- The most intriguing result from LCA-3 is the relatively high abundance of Pu in the outflow solution. Since colloids were not included in this experiment, we 
conclude that the migration of $\mathrm{Pu}$ in carbonate fractures may be significant even in the absence of colloids. In this experiment $55 \%$ of the Pu introduced to the fracture was recovered in the effluent. This is somewhat higher than the recovery rate observed in the LCA-2 experiment (16\%) but both results suggest that $\mathrm{Pu}$ may migrate to some extent in LCA fractures.

- The lack of tailing in the Pu elution curves could not be fit using the analytical fracture transport solution of Tang et al. (1981). We suspect that the unusually small tailing in the elution curve may result from irreversible sorption of Pu to the calcite surface, possibly as a result of slow Pu incorporation into the calcite bulk. If true, this mechanism would provide a significant sink to Pu over the long-term.

- Based on our mechanistic modeling effort, we predict that the reactive surface area of calcite is approximately $0.001 \mathrm{~m} \mathrm{~m}^{2} / \mathrm{g}$; two orders of magnitude lower than that estimated for Frenchman Flat alluvium (e.g. Zavarin et al., 2002).

The combination of transport experiments using a cocktail with many radionuclides, a stepwise approach to examining fracture transport complexity, and detailed post-test characterization of fractures using SIMS, autoradiography, and LA/ICP-MS provided a rich set of data for better understanding the transport behavior of a large fraction of the NTS radiologic source term in contact with zeolitized tuff and carbonate fractures. This data set provides critical radionuclide retardation information that can be used to populate both $\mathrm{HST}^{10}$ (hydrologic source term) and $\mathrm{CAU}^{11}$ (corrective action unit) scale models.

\section{ACKNOWLEDGEMENTS}

Funding for this investigation was provided by the Environment Restoration Division's Underground Test Area Project at the U.S. Department of Energy, National Nuclear Security Administration, Nevada Site Office. This work was performed under the auspices of the U.S. Department of Energy by Lawrence Livermore National Laboratory under contract number W-7405-Eng-48.

\footnotetext{
${ }^{10}$ A Hydrologic Source Term is used in the UGTA project to define the portion of the total radionuclide inventory that is released over time into groundwater following an underground nuclear test. HST models are used to predict this inventory and its transport over time. The focus of these models is to investigate the hydrologic and geochemical processes resulting from the test. The model domain is typically within a few cavity radii of a test.

${ }^{11}$ A Corrective Action Unit is used in the UGTA project to define a region of the NTS for which a corrective action strategy is developed. CAUs are large enough to include multiple tests. They are expected to be orders of magnitude larger in scale than HST models. Due to their scale, these models will typically not be able to address transport processes at the same level of detail as HST models.
} 


\section{REFERENCES}

American Petroleum Institute Recommended Practice (API RP) 27 (1952).

Recommended Practice for Determining Permeability of Porous Media.

American Petroleum Institute, Dallas, Texas, 3rd Ed.

American Petroleum Institute Recommended Practice (API RP) 40 (1960).

Recommended Practice for Core Analysis Procedure. American Petroleum Institute, Dallas, Texas, 1st Ed.

Borisov, O. V., Mao, X. L., and Russo R. E. (2000). Effects of crater development on fractionation and signal intensity during laser ablation inductively coupled plasma mass spectrometry. Spectrochim. Acta, Part B, 55: 1693-1704.

Cartwright, B. G., Shirk, E. K., Price, P. B. (1978). A Nuclear-Track-Recording Polymer of Unique Sensitivity and Resolution. Nuclear Instruments and Methods, v. 153, p. 457-460.

Cole, D.R., Ohmoto, H., and Lasaga, A.C. (1983). Isotopic exchange in mineral-fluid systems. I. Theoretical evaluation of oxygen isotopic exchange accompanying surface reactions and diffusion. Geochim. Cosmochim. Acta, v. 47, p. 1681-1693.

Criss, R.E. (1999). Principles of Stable Isotope Distribution. Oxford University Press, New York, 254 p.

Criss, R. E., Gregory, R. T., and Taylor, H. P., Jr. (1987.) Kinetic theory of oxygen isotope exchange between minerals and water. Geochim. Cosmochim. Acta, v. 51, p. 1099-1108.

Duff, M. C., Hunter, D. B., Triay, I. R., Bertsch, P. M., Reed, D. T., Sutton, S. R. SheaMcCarthy, G., Kitten, J., Eng, P., Chipera, S. J., and Vaniman, D. T. (1999). Mineral associations and average oxidation states of sorbed $\mathrm{Pu}$ on tuff. Environ. Sci. Tech. v. 33, p. 2163-2169.

Durham, W. B., Bourcier, W. L., and Burton, E. A. (2001). Direct observation of reactive flow in a single fracture. Water Resources Research v. 37, p. 1-12.

Esser, B. K., Kersting, A. B. (2003). Characterization of fracture cores post colloid flowthrough experiments. Livermore, California, Lawrence Livermore National Laboratory, UCRL-ID-149688, p. 156-182.

Ghazi, A. M., Shuttleworth, S., Angulo, S. J., and Pashley, D. H. (2000). New applications for laser ablation high resolution ICPMS (LA-HR-ICP-MS): Quantitative measurements of gallium diffusion across human root dentin. $J$. Anal. At. Spectrom. v. 15, p. 1335-1341.

Hershey, R. L., Howcroft, W. and Reimus, P. W. (2003). Laboratory Experiments to Evaluate Diffusion of ${ }^{14} \mathrm{C}$ into Nevada Test Site Carbonate Aquifer Matrix. Las Vegas, Nevada, Desert Research Institute 36. 
Hu, Q., Kneafsey, T. J., Roberts, J. J., Tomutsa, L., and Wang, J. S. Y. (2004). Characterizing unsaturated diffusion in porous tuff gravels. Vadose Zone Journal v. 3 no. 4 , p. $1425-1438$.

Hu, Q., Kneafsey, T., Wang, J. S. Y., Roberts, J. J., and Carlson, S. (2001). Summary report on Phase 1 feasibility study of in-drift diffusion. Berkeley, California, Lawrence Berkeley National Laboratory.

Kemper, W.D. 1986. Solute Diffusivity, in Methods of Soil Analysis, Part 1 - Physical and Mineralogical Methods, SSSA Book Series 5, Chaper 43, American Society of Agronomy, Inc. and Soil Science Society of America, Inc., Madison, Wisconsin.

Kersting, A. B., Efurd, D. W., Finnegan, D. L., Rokop, D. J., Smith, D. K., and Thompson, J. L. (1999). Migration of plutonium in ground water at the Nevada Test Site. Nature v. 397, p. 56-59.

Kersting A. B., Zhao P., Zavarin M., Sylwester E. R., Allen P. A., and Williams R. W. (2003) Sorption of $\mathrm{Pu}(\mathrm{V})$ on Mineral Colloids. In Colloidal-Facilitated Transport of Low-solubility Radionuclides: A Field, Experimental, and Modeling Investigation (ed. A. B. Kersting and P. W. Reimus), UCRL-ID-149688. Lawrence Livermore National Laboratory, Livermore, California

Lide, D.R. 2000. CRC Handbook of Chemistry and Physics, 81 st Edition. Boca Raton, Florida, CRC Press.

Prothro, L. (1998). Analysis of Fractures in Cores from the Tuff Confining Unit Beneath Yucca Flat, Nevada Test Site. Las Vegas, Nevada, Bechtel Nevada.

Reimus, P. W., Ware, S. D., Benedict, F. C., Warren, R. G., Humphrey, A., Adams, A., Wilson, B., and Gonzales, D. (2002). Diffusive and Advective Transport of ${ }^{3} \mathrm{H}$, ${ }^{14} \mathrm{C}$, and ${ }^{99} \mathrm{Tc}$ in Saturated, Fractured Volcanic Rocks from Pahute Mesa, Nevada. Los Alamos, New Mexico, Los Alamos National Laboratory.

Russo, R. E., Mao, X. L., Borisov, O. V., and Liu, H. C., Eds. (2000). Laser ablation in atomic spectroscopy. Encyclopedia of Analytical Chemistry: Instrumentation and Applications. pp. 9485-9506, R. A. Meyers, Ed., John Wiley \& Sons Ltd., Chichster.

Russo, R. E., Mao, X. L., Liu, H. C., Gonzalez, J., and Mao, S. S. (2002). Laser ablation in analytical chemistry - A review. Talanta, 57(3): 425-451.

Shwertmann, U. and Cornell, R. M. (1991). Iron Oxides in the Laboratory. Weinheim, $\mathrm{VCH}$.

Steefel, C. I. and S. B. Yabusaki (1995). OS3D/GIMRT, Software for modeling multicomponent-multidimensional reactive transport, User manual and programmer's guide. Richland, Washington, Pacific Northwest National Laboratory.

SNJV (2004). Geochem04.mdb and A User's Guide to the Comprehensive Water Quality Database for Groundwater in the Vicinity of the Nevada Test Site. StollerNavarro Joint Venture, SN/99205-026, Revision 6, Las Vegas, Nevada. 
Svensson, U., and Dreybrodt, W. (1992). Dissolution kinetics of natural calcite minerals in $\mathrm{CO}_{2}$-water systems approaching calcite equilibrium. Chemical Geology 100(12): $129-145$.

Tang, D. H., Fring, E. O., and Sudicky, E. A. (1981). "Contaminant transport in fractured porous media: Analytical solution for a single fracture." Water Resources Research 17(3): 555-564.

Zavarin M. and Bruton C. J. (2004a). A Non-Electrostatic Surface Complexation Approach to Modeling Radionuclide Migration at the Nevada Test Site: Aluminosilicates. Livermore, California, Lawrence Livermore National Laboratory, UCRL-TR-208672.

Zavarin M. and Bruton C. J. (2004b). A Non-Electrostatic Surface Complexation Approach to Modeling Radionuclide Migration at the Nevada Test Site: Iron Oxides and Calcite. Livermore, California, Lawrence Livermore National Laboratory, UCRL-TR-208673.

Zavarin, M., Carle, S. F., and Maxwell, R. M. (2004). Upscaling Radionuclide Retardation - Linking the Surface Complexation and Ion Exchange Mechanistic Approach to a Linear Kd Approach. Livermore, California, Lawrence Livermore National Laboratory.

Zavarin, M.., Maxwell, R. M ., Kersting, A. B., Zhao, P. Sylwester, E. R., Allen, P. G., Williams, R. W. (2003). Plutonium Colloid-Facilitated Transport in the Environment-Experimental and Transport Modeling Evidence for Plutonium Migration Mechanisms. Livermore, California, Lawrence Livermore National Laboratory, UCRL-JC-151924

Zavarin M., Roberts S. K., Rose T. P., and Phinney D. L. (2002) Validating Mechanistic Sorption Model Parameters and Processes for Reactive Transport in Alluvium. Livermore, California, Lawrence Livermore National Laboratory, UCRL-ID149728. 


\section{APPENDIX. FRACTURE TRANSPORT DATA}

\subsection{Flow-Through Run Parameters and Elution Data}

Table 8.1. TCU-2 Experimental run parameters

TCU-2, core depth $=$ UE7az 1798.8-1799.5

Porosity: $29.1 \%$, Permeability: $0.108 \mathrm{md}$, Bulk density: $1.7 \mathrm{~g} / \mathrm{cm}^{3}$

Sorption solution of $\mathrm{NaHCO}_{3}, \mathrm{Ca}, \mathrm{Mg}, \mathrm{K}, \mathrm{Cs}, \mathrm{Sr}, \mathrm{Sm}, \mathrm{U}, \mathrm{Re}, \mathrm{Pu}, \mathrm{Np}$, Tritium

Experiment started on : 7 May 04 14:09

Start pumping sorption solution at: 18 May 04 16:51

Stopped pumping sorption solution at: 19 May 04 9:06

Average flow rate $(\mathrm{mL} / \mathrm{min}): 0.0152$

Pump and tubing volume $(\mathrm{mL}): 1.718$

Table 8.2. TCU-2 Core mineralogy

\begin{tabular}{ccccccccc}
\hline & Quartz & Cristobalite & Clay & $\begin{array}{c}\text { Na-Ca } \\
\text { Feldspar }\end{array}$ & $\begin{array}{c}\text { K } \\
\text { Feldspar }\end{array}$ & $\begin{array}{c}\text { Clinoptilolite/ } \\
\text { Heulandite }\end{array}$ & Calcite & $\begin{array}{c}\text { total } \\
\text { sorbers }\end{array}$ \\
\hline TCU-2 & 12.8 & 1.7 & 8.9 & 19.5 & 29.0 & 27.1 & 2.1 & 38.1 \\
\hline
\end{tabular}

Table 8.3. TCU-2 Experimental results

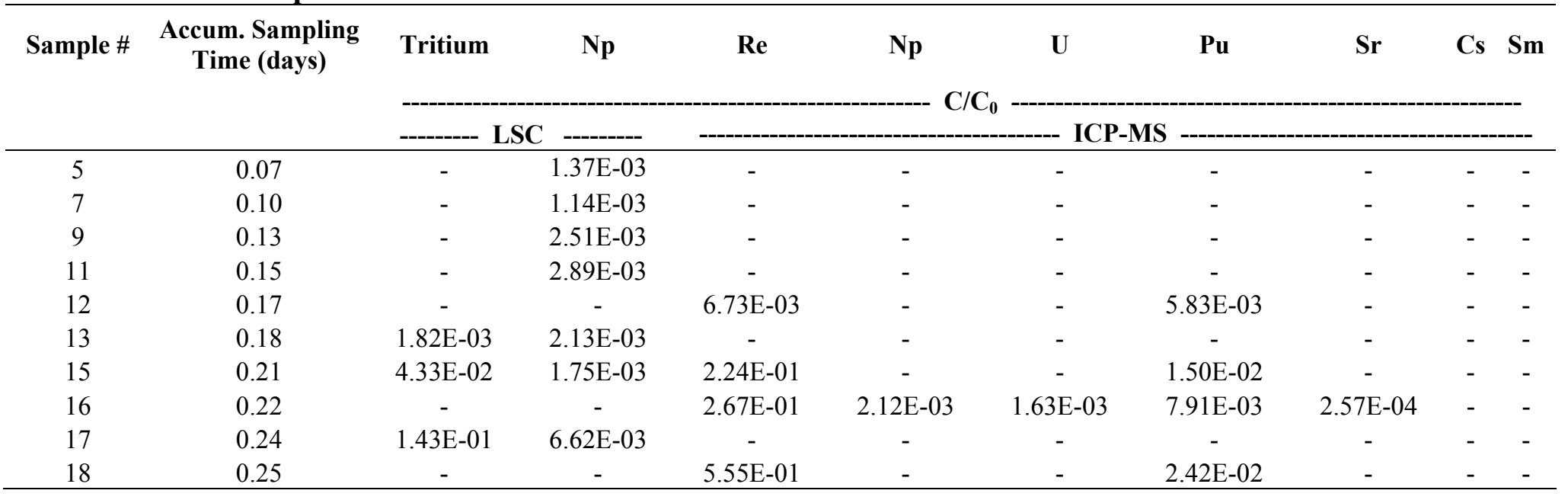


Table 8.3. (continued) TCU-2 Experimental results

\begin{tabular}{|c|c|c|c|c|c|c|c|c|c|c|}
\hline \multirow[t]{2}{*}{ Sample \# } & \multirow[t]{2}{*}{$\begin{array}{c}\text { Accum. Sampling } \\
\text { Time (days) }\end{array}$} & Tritium & $\mathbf{N p}$ & $\mathbf{R e}$ & & $\mathbf{U}$ & \multirow[t]{2}{*}{$\mathbf{P u}$} & \multirow[t]{2}{*}{$\mathbf{S r}$} & \multirow[t]{2}{*}{ Cs } & \multirow[t]{2}{*}{ Sm } \\
\hline & & \multicolumn{2}{|c|}{------- LSC ------- } & - & C/C & ICP-M & & & & \\
\hline 19 & 0.26 & $2.26 \mathrm{E}-01$ & $1.31 \mathrm{E}-02$ & - & - & - & - & - & - & - \\
\hline 21 & 0.29 & $2.92 \mathrm{E}-01$ & $2.24 \mathrm{E}-02$ & $6.88 \mathrm{E}-01$ & - & - & $2.33 \mathrm{E}-02$ & - & - & - \\
\hline 23 & 0.32 & $3.36 \mathrm{E}-01$ & $3.80 \mathrm{E}-02$ & - & - & - & - & - & - & - \\
\hline 24 & 0.33 & - & - & 7.29E-01 & $1.44 \mathrm{E}-02$ & - & $2.42 \mathrm{E}-02$ & - & - & - \\
\hline 27 & 0.38 & $3.86 \mathrm{E}-01$ & $6.63 \mathrm{E}-02$ & $7.55 \mathrm{E}-01$ & $7.22 \mathrm{E}-02$ & $1.70 \mathrm{E}-02$ & $2.42 \mathrm{E}-02$ & - & - & - \\
\hline 29 & 0.40 & $3.98 \mathrm{E}-01$ & $8.23 \mathrm{E}-02$ & - & - & - & - & - & - & - \\
\hline 30 & 0.42 & - & - & $6.30 \mathrm{E}-01$ & $1.07 \mathrm{E}-01$ & $1.15 \mathrm{E}-01$ & $1.92 \mathrm{E}-02$ & - & - & - \\
\hline 31 & 0.43 & $3.81 \mathrm{E}-01$ & $9.80 \mathrm{E}-02$ & - & - & - & - & - & - & - \\
\hline 33 & 0.46 & $3.41 \mathrm{E}-01$ & $1.06 \mathrm{E}-01$ & 7.01E-01 & $1.37 \mathrm{E}-01$ & $1.72 \mathrm{E}-01$ & $2.33 \mathrm{E}-02$ & - & - & - \\
\hline 35 & 0.49 & $4.47 \mathrm{E}-01$ & $1.20 \mathrm{E}-01$ & - & - & - & - & - & - & - \\
\hline 36 & 0.50 & - & - & 8.79E-01 & $1.65 \mathrm{E}-01$ & $1.54 \mathrm{E}-01$ & $2.58 \mathrm{E}-02$ & - & - & - \\
\hline 38 & 0.53 & - & - & $8.16 \mathrm{E}-01$ & $2.29 \mathrm{E}-01$ & $1.68 \mathrm{E}-01$ & $1.17 \mathrm{E}-02$ & - & - & - \\
\hline 39 & 0.54 & $5.08 \mathrm{E}-01$ & $1.78 \mathrm{E}-01$ & $8.95 \mathrm{E}-01$ & $2.12 \mathrm{E}-01$ & $2.11 \mathrm{E}-01$ & $2.67 \mathrm{E}-02$ & - & - & - \\
\hline 41 & 0.57 & $5.10 \mathrm{E}-01$ & $1.90 \mathrm{E}-01$ & - & - & - & - & - & - & - \\
\hline 42 & 0.58 & - & - & $8.43 \mathrm{E}-01$ & $2.50 \mathrm{E}-01$ & $3.00 \mathrm{E}-01$ & 2.33E-02 & - & - & - \\
\hline 43 & 0.60 & $5.00 \mathrm{E}-01$ & $2.07 \mathrm{E}-01$ & - & - & - & - & - & - & - \\
\hline 45 & 0.63 & $4.98 \mathrm{E}-01$ & $2.18 \mathrm{E}-01$ & $8.46 \mathrm{E}-01$ & $2.53 \mathrm{E}-01$ & $3.07 \mathrm{E}-01$ & $2.83 \mathrm{E}-02$ & - & - & - \\
\hline 47 & 0.65 & $5.19 \mathrm{E}-01$ & $2.18 \mathrm{E}-01$ & - & - & - & - & - & - & - \\
\hline 48 & 0.67 & - & - & $8.23 \mathrm{E}-01$ & $2.63 \mathrm{E}-01$ & $3.44 \mathrm{E}-01$ & $1.92 \mathrm{E}-02$ & - & - & - \\
\hline 49 & 0.68 & $4.88 \mathrm{E}-01$ & $2.30 \mathrm{E}-01$ & - & - & - & - & - & - & - \\
\hline 50 & 0.69 & - & - & - & - & - & - & - & - & - \\
\hline 51 & 0.72 & $4.52 \mathrm{E}-01$ & $2.57 \mathrm{E}-01$ & $6.85 \mathrm{E}-01$ & $2.96 \mathrm{E}-01$ & $4.45 \mathrm{E}-01$ & $2.42 \mathrm{E}-02$ & - & - & - \\
\hline 53 & 0.78 & 4.24E-01 & $2.26 \mathrm{E}-01$ & - & - & - & - & - & - & - \\
\hline 54 & 0.81 & - & - & $8.27 \mathrm{E}-01$ & $2.40 \mathrm{E}-01$ & $2.70 \mathrm{E}-01$ & $2.67 \mathrm{E}-02$ & - & - & - \\
\hline 55 & 0.83 & $5.28 \mathrm{E}-01$ & $2.26 \mathrm{E}-01$ & - & - & - & & - & - & - \\
\hline 60 & 0.97 & $3.03 \mathrm{E}-01$ & $2.83 \mathrm{E}-01$ & $3.13 \mathrm{E}-01$ & $3.44 \mathrm{E}-01$ & $5.05 \mathrm{E}-01$ & $5.00 \mathrm{E}-03$ & - & - & - \\
\hline
\end{tabular}


Table 8.3. (continued) TCU-2 Experimental results

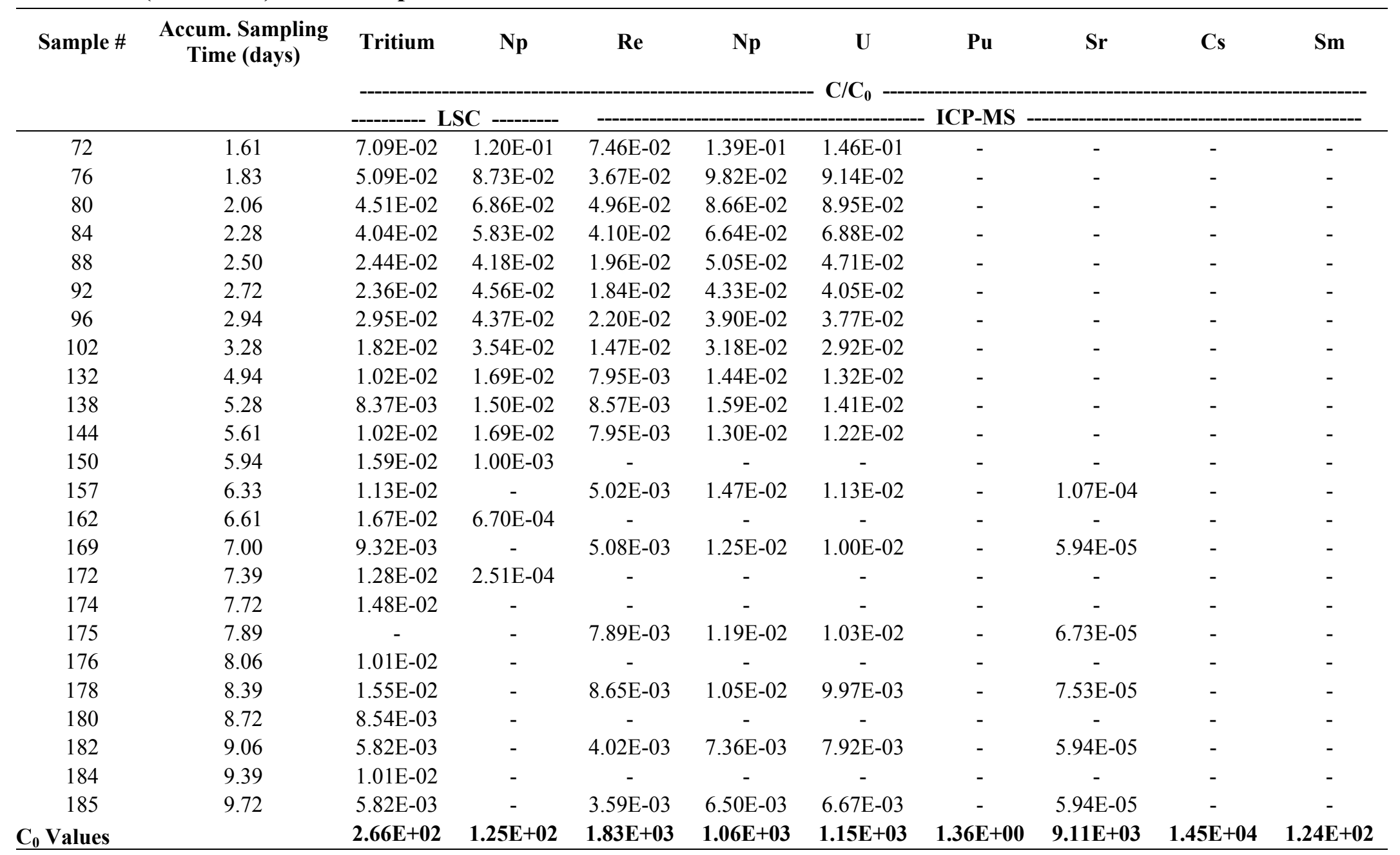

*: $\mathrm{C}_{0}$ values for LSC are in counts/ min; $\mathrm{C}_{0}$ values for ICP-MS are in $\mathrm{ng} / \mathrm{mL}$ 
Table 8.3. (continued) TCU-2 Experimental results

\begin{tabular}{|c|c|c|c|c|c|c|c|}
\hline Sample \# & $\begin{array}{c}\text { Accum. Sampling } \\
\text { Time (days) }\end{array}$ & $\mathbf{p H}$ & HCO3- & $\mathbf{N a}$ & $\mathbf{K}$ & Mg & $\mathrm{Ca}$ \\
\hline 4 & 0.06 & - & $6.40 \mathrm{E}-03$ & - & - & - & - \\
\hline 5 & 0.07 & 8.97 & - & $6.79 \mathrm{E}-03$ & - & $3.57 \mathrm{E}-06$ & $2.00 \mathrm{E}-05$ \\
\hline 10 & 0.14 & 8.93 & - & $6.66 \mathrm{E}-03$ & $3.55 \mathrm{E}-02$ & $5.02 \mathrm{E}-06$ & $5.27 \mathrm{E}-05$ \\
\hline 12 & 0.17 & - & $6.16 \mathrm{E}-03$ & - & - & - & - \\
\hline 15 & 0.21 & 9.21 & - & $7.01 \mathrm{E}-03$ & - & $1.11 \mathrm{E}-06$ & $4.02 \mathrm{E}-06$ \\
\hline 20 & 0.28 & 9.19 & - & $6.13 \mathrm{E}-03$ & $7.56 \mathrm{E}-03$ & $3.57 \mathrm{E}-06$ & $2.72 \mathrm{E}-05$ \\
\hline 22 & 0.31 & - & $5.18 \mathrm{E}-03$ & - & - & - & - \\
\hline 25 & 0.35 & 9.20 & - & $5.82 \mathrm{E}-03$ & - & $1.24 \mathrm{E}-06$ & $5.98 \mathrm{E}-06$ \\
\hline 28 & 0.39 & - & $5.17 \mathrm{E}-03$ & - & - & - & - \\
\hline 30 & 0.42 & 9.23 & - & $6.22 \mathrm{E}-03$ & - & $1.72 \mathrm{E}-06$ & $1.02 \mathrm{E}-05$ \\
\hline 34 & 0.47 & - & $5.26 \mathrm{E}-03$ & - & - & - & - \\
\hline 35 & 0.49 & 9.18 & - & $6.09 \mathrm{E}-03$ & - & $3.49 \mathrm{E}-06$ & $2.85 \mathrm{E}-05$ \\
\hline 40 & 0.56 & 8.97 & - & $6.30 \mathrm{E}-03$ & $3.19 \mathrm{E}-02$ & $4.21 \mathrm{E}-06$ & $4.82 \mathrm{E}-05$ \\
\hline 44 & 0.61 & - & $5.04 \mathrm{E}-03$ & - & & - & - \\
\hline 45 & 0.63 & 9.20 & - & $6.53 \mathrm{E}-03$ & $1.28 \mathrm{E}-04$ & $9.63 \mathrm{E}-07$ & $2.78 \mathrm{E}-06$ \\
\hline 50 & 0.69 & 8.99 & - & $6.59 \mathrm{E}-03$ & 4.64E-03 & $2.30 \mathrm{E}-06$ & $2.96 \mathrm{E}-05$ \\
\hline 52 & 0.75 & - & $6.61 \mathrm{E}-03$ & - & - & - & - \\
\hline 55 & 0.83 & 8.38 & - & $6.18 \mathrm{E}-03$ & - & $2.131 \mathrm{E}-06$ & $2.438 \mathrm{E}-05$ \\
\hline 58 & 0.92 & - & $5.19 \mathrm{E}-03$ & - & - & - & - \\
\hline 75 & 1.78 & - & - & $6.01 \mathrm{E}-03$ & $7.74 \mathrm{E}-05$ & $1.18 \mathrm{E}-06$ & 7.39E-06 \\
\hline 95 & 2.89 & - & - & $6.19 \mathrm{E}-03$ & $4.61 \mathrm{E}-05$ & $1.73 \mathrm{E}-06$ & $1.39 \mathrm{E}-05$ \\
\hline \multicolumn{2}{|c|}{ TCU-2 Initial Sorption Solution } & 8.26 & 4.20E-03 & 4.05E-03 & $1.94 E-04$ & $1.81 \mathrm{E}-05$ & 1.07E-04 \\
\hline
\end{tabular}


Table 8.4. TCU-3 Experimental run parameters

\section{TCU-3, core depth $=$ UE7az1678.2-1679.0}

Porosity: $34.17 \%$, Permeability: $0.128 \mathrm{md}$, Density: $1.49 \mathrm{~g} / \mathrm{m}^{3}$

Sorption solution of $\mathrm{NaHCO}_{3}, \mathrm{Ca}, \mathrm{Mg}, \mathrm{K}, \mathrm{Cs}, \mathrm{Sr}, \mathrm{Sm}, \mathrm{U}, \mathrm{Re}, \mathrm{Pu}, \mathrm{Np}$, Tritium

Experiment started on : 7 June 04 15:42

Start pumping sorption solution at: 15 June 04 16:38

Stopped pumping sorption solution at: 16 June 04 9:25

Average flow rate $(\mathrm{mL} / \mathrm{min}): 0.0147-0.0157$

Pump and tubing volume $(\mathrm{mL}): 1.718$

Table 8.5. TCU-3 Core mineralogy

\begin{tabular}{ccccccccc}
\hline & Quartz & Cristobalite & Clay & $\begin{array}{c}\text { Na-Ca } \\
\text { Feldspar }\end{array}$ & $\begin{array}{c}\text { K } \\
\text { Feldspar }\end{array}$ & $\begin{array}{c}\text { Clinoptilolite/ } \\
\text { Heulandite }\end{array}$ & Calcite & $\begin{array}{c}\text { total } \\
\text { sorbers }\end{array}$ \\
\hline TCU-3 & 6.5 & 7.3 & 1.3 & 1.7 & 40.8 & 41.3 & 1.2 & 34.8 \\
\hline
\end{tabular}

Table 8.6. TCU-3 Experimental results

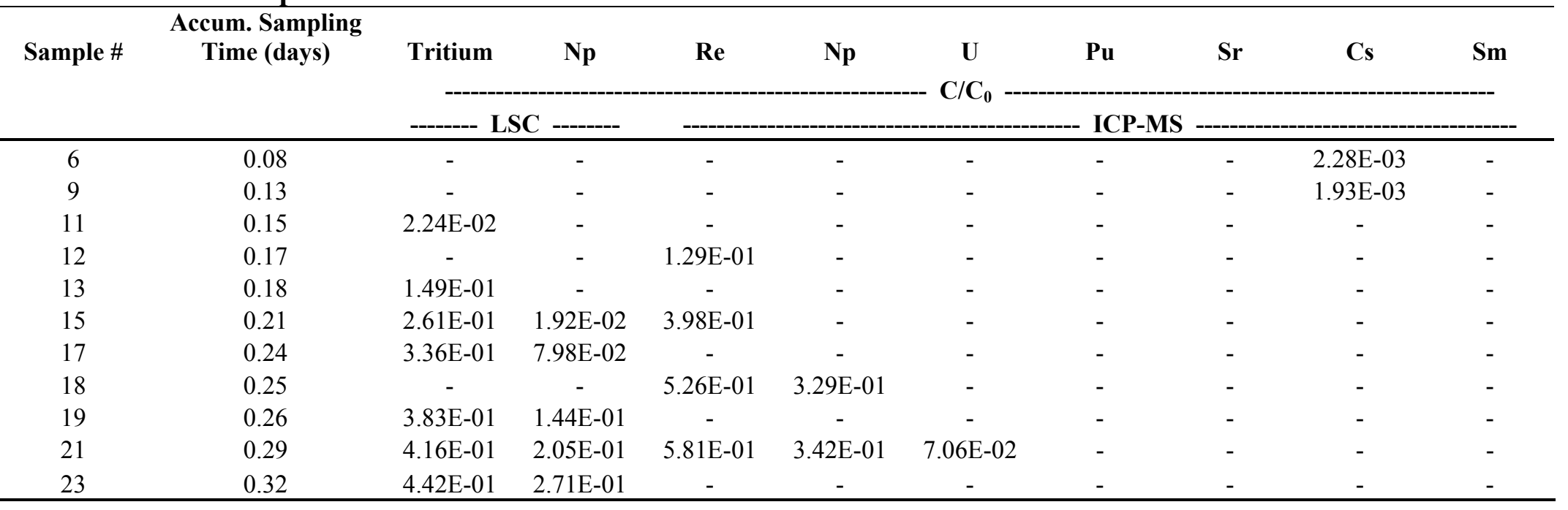


Table 8.6. (continued). TCU-3 experimental results

\begin{tabular}{|c|c|c|c|c|c|c|c|c|c|c|}
\hline \multirow[t]{2}{*}{ Sample \# } & \multirow[t]{2}{*}{$\begin{array}{c}\text { Accum. Sampling } \\
\text { Time (days) }\end{array}$} & Tritium & Np & $\mathbf{R e}$ & Np & \multirow{2}{*}{$\begin{array}{c}\mathrm{U} \\
\mathrm{C} / \mathrm{C}_{0}\end{array}$} & \multirow[t]{2}{*}{$\mathbf{P u}$} & \multirow[t]{2}{*}{ Sr } & \multirow[t]{2}{*}{ Cs } & \multirow[t]{2}{*}{ Sm } \\
\hline & & -------- L & SC -------- & - & 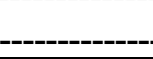 & & & & & \\
\hline 24 & 0.33 & - & - & 5.99E-01 & $3.30 \mathrm{E}-01$ & $2.02 \mathrm{E}-01$ & - & - & - & - \\
\hline 25 & 0.35 & $4.55 \mathrm{E}-01$ & $3.05 \mathrm{E}-01$ & - & - & - & - & - & - & - \\
\hline 27 & 0.38 & $4.51 \mathrm{E}-01$ & $3.30 \mathrm{E}-01$ & 5.99E-01 & $3.59 \mathrm{E}-01$ & $2.67 \mathrm{E}-01$ & - & - & - & - \\
\hline 29 & 0.4 & $4.62 \mathrm{E}-01$ & $3.43 \mathrm{E}-01$ & - & - & - & - & - & - & - \\
\hline 30 & 0.42 & - & - & 6.37E-01 & $3.96 \mathrm{E}-01$ & $3.05 \mathrm{E}-01$ & - & - & - & - \\
\hline 31 & 0.43 & $4.90 \mathrm{E}-01$ & $3.67 \mathrm{E}-01$ & - & - & - & - & - & - & - \\
\hline 33 & 0.46 & $4.82 \mathrm{E}-01$ & $3.85 \mathrm{E}-01$ & $6.40 \mathrm{E}-01$ & 4.14E-01 & $3.32 \mathrm{E}-01$ & - & - & - & - \\
\hline 35 & 0.49 & $5.06 \mathrm{E}-01$ & $4.01 \mathrm{E}-01$ & - & - & - & - & - & - & - \\
\hline 36 & 0.5 & - & - & $6.54 \mathrm{E}-01$ & $4.36 \mathrm{E}-01$ & $3.59 \mathrm{E}-01$ & - & - & - & - \\
\hline 37 & 0.51 & $5.28 \mathrm{E}-01$ & 4.36E-01 & - & - & - & - & - & - & - \\
\hline 39 & 0.54 & $5.16 \mathrm{E}-01$ & 4.32E-01 & $6.80 \mathrm{E}-01$ & 4.65E-01 & $3.87 \mathrm{E}-01$ & - & - & - & - \\
\hline 41 & 0.57 & $5.10 \mathrm{E}-01$ & 4.32E-01 & - & - & - & - & - & - & - \\
\hline 42 & 0.58 & - & - & $6.40 \mathrm{E}-01$ & $4.48 \mathrm{E}-01$ & $3.82 \mathrm{E}-01$ & - & - & - & - \\
\hline 43 & 0.6 & $4.50 \mathrm{E}-01$ & $3.92 \mathrm{E}-01$ & - & - & - & - & - & - & - \\
\hline 45 & 0.63 & $5.26 \mathrm{E}-01$ & 4.32E-01 & $6.60 \mathrm{E}-01$ & $4.56 \mathrm{E}-01$ & $3.66 \mathrm{E}-01$ & - & - & - & - \\
\hline 47 & 0.65 & $5.49 \mathrm{E}-01$ & $4.50 \mathrm{E}-01$ & - & - & - & - & - & - & - \\
\hline 48 & 0.67 & - & - & $7.01 \mathrm{E}-01$ & 4.96E-01 & 4.17E-01 & - & - & - & - \\
\hline 49 & 0.68 & 5.38E-01 & $4.48 \mathrm{E}-01$ & - & - & - & - & - & - & - \\
\hline 51 & 0.71 & $5.44 \mathrm{E}-01$ & 4.67E-01 & $7.24 \mathrm{E}-01$ & $5.08 \mathrm{E}-01$ & $4.45 \mathrm{E}-01$ & - & - & - & - \\
\hline 53 & 0.76 & $5.62 \mathrm{E}-01$ & $4.80 \mathrm{E}-01$ & - & - & - & - & - & - & - \\
\hline 54 & 0.79 & - & - & 7.30E-01 & $5.27 \mathrm{E}-01$ & $4.63 \mathrm{E}-01$ & - & - & - & - \\
\hline 55 & 0.82 & $5.59 \mathrm{E}-01$ & $5.03 \mathrm{E}-01$ & - & - & - & - & - & - & - \\
\hline 57 & 0.88 & $4.72 \mathrm{E}-01$ & 4.73E-01 & $5.81 \mathrm{E}-01$ & 4.94E-01 & $4.33 \mathrm{E}-01$ & - & - & - & - \\
\hline 60 & 0.96 & $1.78 \mathrm{E}-01$ & $3.35 \mathrm{E}-01$ & $2.24 \mathrm{E}-01$ & $3.67 \mathrm{E}-01$ & $3.35 \mathrm{E}-01$ & - & - & - & - \\
\hline 64 & 1.07 & $9.89 \mathrm{E}-02$ & $1.58 \mathrm{E}-01$ & $1.68 \mathrm{E}-01$ & $2.10 \mathrm{E}-01$ & $1.89 \mathrm{E}-01$ & - & - & - & - \\
\hline 68 & 1.18 & $6.77 \mathrm{E}-02$ & $1.00 \mathrm{E}-01$ & $1.48 \mathrm{E}-01$ & $1.44 \mathrm{E}-01$ & $1.25 \mathrm{E}-01$ & - & - & - & - \\
\hline 72 & 1.29 & $5.90 \mathrm{E}-02$ & $7.46 \mathrm{E}-02$ & $1.23 \mathrm{E}-01$ & $1.13 \mathrm{E}-01$ & $9.59 \mathrm{E}-02$ & - & - & - & - \\
\hline
\end{tabular}


Table 8.6. (continued). TCU-3 experimental results

\begin{tabular}{|c|c|c|c|c|c|c|c|c|c|c|}
\hline \multirow[t]{2}{*}{ Sample \# } & \multirow[t]{2}{*}{$\begin{array}{c}\text { Accum. Sampling } \\
\text { Time (days) }\end{array}$} & Tritium & Np & $\mathbf{R e}$ & Np & \multirow{2}{*}{$\begin{array}{c}\mathrm{U} \\
\mathrm{C} / \mathrm{C}_{0}\end{array}$} & $\mathbf{P u}$ & $\mathrm{Sr}$ & Cs & \multirow[t]{2}{*}{ Sm } \\
\hline & & \multicolumn{4}{|c|}{------- LSC ------- } & & --- ICP-MS & -------- & --------------- & \\
\hline 76 & 1.4 & $5.25 \mathrm{E}-02$ & $5.65 \mathrm{E}-02$ & $1.13 \mathrm{E}-01$ & $9.65 \mathrm{E}-02$ & $8.44 \mathrm{E}-02$ & - & - & - & - \\
\hline 80 & 1.51 & $5.86 \mathrm{E}-02$ & $3.54 \mathrm{E}-02$ & $1.18 \mathrm{E}-01$ & $7.82 \mathrm{E}-02$ & $7.06 \mathrm{E}-02$ & - & - & - & - \\
\hline 84 & 1.63 & $5.67 \mathrm{E}-02$ & $3.00 \mathrm{E}-02$ & $1.02 \mathrm{E}-01$ & $6.83 \mathrm{E}-02$ & $6.01 \mathrm{E}-02$ & - & - & - & - \\
\hline 88 & 1.79 & $5.93 \mathrm{E}-02$ & $1.39 \mathrm{E}-02$ & $8.90 \mathrm{E}-02$ & $6.20 \mathrm{E}-02$ & $5.37 \mathrm{E}-02$ & - & - & - & - \\
\hline 92 & 2.01 & $6.12 \mathrm{E}-02$ & $1.23 \mathrm{E}-02$ & $6.90 \mathrm{E}-02$ & $5.13 \mathrm{E}-02$ & $2.85 \mathrm{E}-02$ & - & - & - & - \\
\hline 96 & 2.24 & $5.36 \mathrm{E}-02$ & 7.34E-03 & $5.29 \mathrm{E}-02$ & 4.36E-02 & $2.49 \mathrm{E}-02$ & - & - & - & - \\
\hline 100 & 2.46 & $4.98 \mathrm{E}-02$ & $5.42 \mathrm{E}-03$ & $3.88 \mathrm{E}-02$ & 4.07E-02 & $2.22 \mathrm{E}-02$ & - & - & - & - \\
\hline 106 & 2.8 & $4.57 \mathrm{E}-02$ & 4.17E-03 & 2.99E-02 & $3.58 \mathrm{E}-02$ & $2.04 \mathrm{E}-02$ & - & - & - & - \\
\hline 112 & 3.41 & 3.39E-02 & $2.25 \mathrm{E}-03$ & $2.63 \mathrm{E}-02$ & $3.51 \mathrm{E}-02$ & $2.08 \mathrm{E}-02$ & - & - & - & - \\
\hline 118 & 4.07 & $2.51 \mathrm{E}-02$ & - & $1.65 \mathrm{E}-02$ & $3.02 \mathrm{E}-02$ & $1.45 \mathrm{E}-02$ & - & - & - & - \\
\hline 124 & 4.74 & $2.55 \mathrm{E}-02$ & - & $1.53 \mathrm{E}-02$ & $3.02 \mathrm{E}-02$ & $1.40 \mathrm{E}-02$ & - & - & - & - \\
\hline 130 & 5.41 & $1.94 \mathrm{E}-02$ & - & $1.10 \mathrm{E}-02$ & $2.81 \mathrm{E}-02$ & $1.04 \mathrm{E}-02$ & - & - & - & - \\
\hline 136 & 6.07 & $1.83 \mathrm{E}-02$ & - & $1.10 \mathrm{E}-02$ & $2.95 \mathrm{E}-02$ & $9.95 \mathrm{E}-03$ & - & - & - & - \\
\hline 142 & 6.74 & 1.41E-02 & - & $9.78 \mathrm{E}-03$ & 2.67E-02 & $9.50 \mathrm{E}-03$ & - & - & - & - \\
\hline 148 & 7.41 & $1.22 \mathrm{E}-02$ & - & 7.94E-03 & 2.39E-02 & $8.14 \mathrm{E}-03$ & - & - & - & - \\
\hline 154 & 8.07 & $5.33 \mathrm{E}-03$ & - & $5.80 \mathrm{E}-03$ & $2.11 \mathrm{E}-02$ & $7.24 \mathrm{E}-03$ & - & - & - & - \\
\hline 161 & 8.85 & $5.71 \mathrm{E}-03$ & - & $5.80 \mathrm{E}-03$ & $2.53 \mathrm{E}-02$ & $6.33 \mathrm{E}-03$ & - & - & - & - \\
\hline $\mathrm{C}_{0}$ Values ${ }^{*}:$ & & $2.63 E+02$ & $1.20 \mathrm{E}+02$ & $1.72 \mathrm{E}+03$ & $7.10 \mathrm{E}+02$ & $1.09 \mathrm{E}+03$ & $1.68 \mathrm{E}+00$ & $8.30 \mathrm{E}+03$ & $1.30 \mathrm{E}+04$ & $1.32 \mathrm{E}+02$ \\
\hline
\end{tabular}

*: $\mathrm{C}_{0}$ values for LSC are in counts/ hour; $\mathrm{C}_{0}$ values for ICP-MS are in $\mathrm{ng} / \mathrm{mL}$ 
Table 8.6. (continued). TCU-3 experimental results

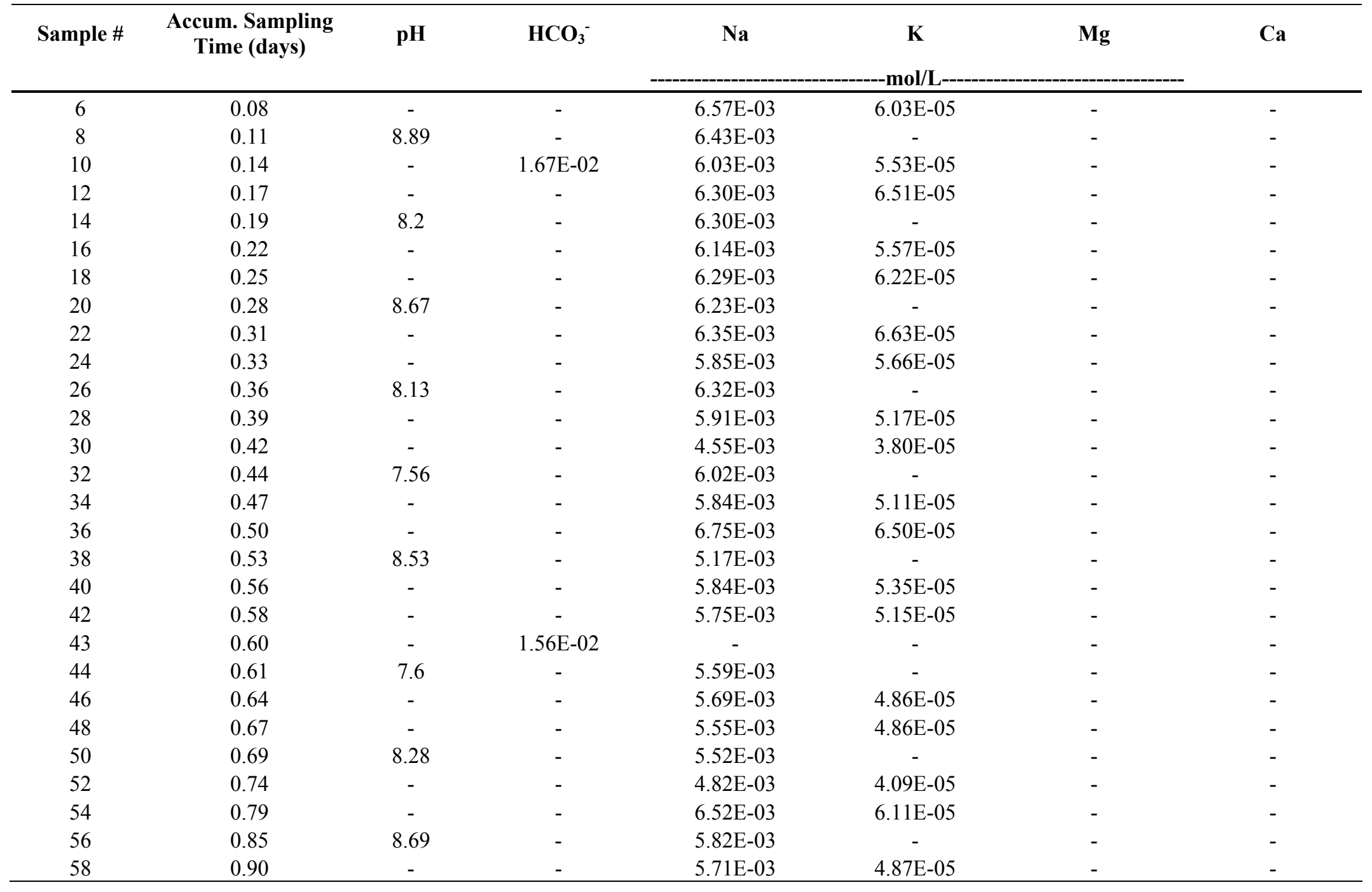


Table 8.6. (continued). TCU-3 experimental results

\begin{tabular}{|c|c|c|c|c|c|c|c|}
\hline Sample \# & $\begin{array}{l}\text { Accum. Sampling } \\
\text { Time (days) }\end{array}$ & pH & $\mathrm{HCO}_{3}^{-}$ & $\mathbf{N a}$ & $\mathbf{K}$ & Mg & $\mathrm{Ca}$ \\
\hline 62 & 101 & 831 & 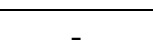 & $504 \mathrm{~F}_{-} 03$ & 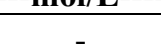 & - & 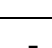 \\
\hline 64 & $\begin{array}{l}1.01 \\
1.07\end{array}$ & - & - & $5.97 \mathrm{E}-03$ & $6.38 \mathrm{E}-05$ & - & - \\
\hline 68 & 1.18 & - & - & 5.97E-03 & $5.50 \mathrm{E}-05$ & - & - \\
\hline 70 & 1.24 & 8.88 & - & - & - & - & - \\
\hline 72 & 1.29 & - & - & $6.28 \mathrm{E}-03$ & $5.52 \mathrm{E}-05$ & - & - \\
\hline 76 & 1.40 & - & - & $4.75 \mathrm{E}-03$ & $4.26 \mathrm{E}-05$ & - & - \\
\hline 78 & 1.46 & 8.7 & - & - & - & - & - \\
\hline 80 & 1.51 & - & - & $5.70 \mathrm{E}-03$ & $4.87 \mathrm{E}-05$ & - & - \\
\hline 83 & 1.60 & - & $2.84 \mathrm{E}-02$ & - & - & - & - \\
\hline 84 & 1.63 & - & - & $6.71 \mathrm{E}-03$ & $6.15 \mathrm{E}-05$ & - & - \\
\hline 86 & 1.68 & 8.23 & - & - & - & - & - \\
\hline 88 & 1.79 & - & - & $5.27 \mathrm{E}-03$ & 4.69E-05 & - & - \\
\hline 92 & 2.01 & - & - & $7.23 \mathrm{E}-03$ & $6.56 \mathrm{E}-05$ & - & - \\
\hline 94 & 2.13 & 8.61 & - & - & - & - & - \\
\hline 96 & 2.24 & - & - & $5.37 \mathrm{E}-03$ & $5.87 \mathrm{E}-05$ & - & - \\
\hline 100 & 2.46 & - & - & $6.48 \mathrm{E}-03$ & $6.20 \mathrm{E}-05$ & - & - \\
\hline 102 & 2.57 & 7.45 & - & - & - & - & - \\
\hline 106 & 2.80 & - & - & $3.92 \mathrm{E}-03$ & $3.18 \mathrm{E}-05$ & - & - \\
\hline 112 & 3.41 & - & - & $4.53 \mathrm{E}-03$ & $3.78 \mathrm{E}-05$ & - & - \\
\hline 118 & 4.07 & - & - & $3.09 \mathrm{E}-03$ & $2.48 \mathrm{E}-05$ & - & - \\
\hline 124 & 4.74 & - & - & $4.53 \mathrm{E}-03$ & $3.84 \mathrm{E}-05$ & - & - \\
\hline 125 & 4.85 & - & $2.09 \mathrm{E}-02$ & - & - & - & - \\
\hline 130 & 5.41 & - & - & $4.55 \mathrm{E}-03$ & $4.03 \mathrm{E}-05$ & - & - \\
\hline 136 & 6.07 & - & - & $4.29 \mathrm{E}-03$ & $3.62 \mathrm{E}-05$ & - & - \\
\hline 142 & 6.74 & - & - & $4.58 \mathrm{E}-03$ & $3.71 \mathrm{E}-05$ & - & - \\
\hline 148 & 7.41 & - & - & $5.02 \mathrm{E}-03$ & $4.03 \mathrm{E}-05$ & - & - \\
\hline 154 & 8.07 & - & - & $4.64 \mathrm{E}-03$ & $3.86 \mathrm{E}-04$ & - & - \\
\hline 161 & 8.85 & - & - & $4.56 \mathrm{E}-03$ & $3.80 \mathrm{E}-05$ & - & - \\
\hline
\end{tabular}


Table 8.6. (continued). TCU-3 experimental results

\begin{tabular}{ccccccc}
\hline Sample \# & $\begin{array}{c}\text { Accum. Sampling } \\
\text { Time (days) }\end{array}$ & $\mathbf{p H}$ & $\mathrm{HCO}_{3}^{-}$ & $\mathrm{Na}$ & $\mathrm{K}$ & $\mathrm{Mg}$ \\
\hline 162 & 8.96 & - & $1.83 \mathrm{E}-02$ & - & - & - \\
TCU-3 Initial Sorption Solution: & & & $\mathbf{4 . 2 1 E - 0 3}$ & $\mathbf{1 . 9 1 E - 0 4}$ & $\mathbf{6 . 8 0 E - 0 6}$ \\
\hline
\end{tabular}

Table 8.7. TCU-4 experimental run parameters

TCU-4, core depth $=$ UE7az1779.95-1780.25

Porosity: $30.80 \%$, Permeability: $0.040 \mathrm{md}$, Density: $1.56 \mathrm{~g} / \mathrm{m}^{3}$

Sorption solution of $\mathrm{NaHCO}_{3}, \mathrm{Ca}, \mathrm{Mg}, \mathrm{K}, \mathrm{Cs}, \mathrm{Sr}, \mathrm{Sm}, \mathrm{U}, \mathrm{Re}, \mathrm{Pu}, \mathrm{Np}$, Tritium

Experiment started on : 7 July 04 10:15

Start pumping sorption solution at: 14 July 04 16:29

Stopped pumping sorption solution at: 15 July 04 9:29

Average flow rate $(\mathrm{mL} / \mathrm{min}): 0.0145-0.01562$

Pump and tubing volume $(\mathrm{mL}): 1.718$

Table 8.8. TCU-4 core mineralogy

$\begin{array}{llllllll}\text { Quartz } & \text { Cristobalite } & \text { Clay } & \begin{array}{c}\text { Na-Ca } \\ \text { Feldspar }\end{array} & \begin{array}{c}\text { K } \\ \text { Feldspar }\end{array} & \begin{array}{c}\text { Clinoptilolite/ } \\ \text { Heulandite }\end{array} & \text { Calcite } & \begin{array}{c}\text { total } \\ \text { sorbers }\end{array}\end{array}$

\begin{tabular}{|c|c|c|c|c|c|c|c|c|}
\hline TCU-4 & 4.4 & 13.0 & $\begin{array}{ll}13.1 \\
\end{array}$ & 6.7 & 11.6 & 499.8 & 1.3 & 64.2 \\
\hline
\end{tabular}


Table 8.9. TCU-4 experimental results

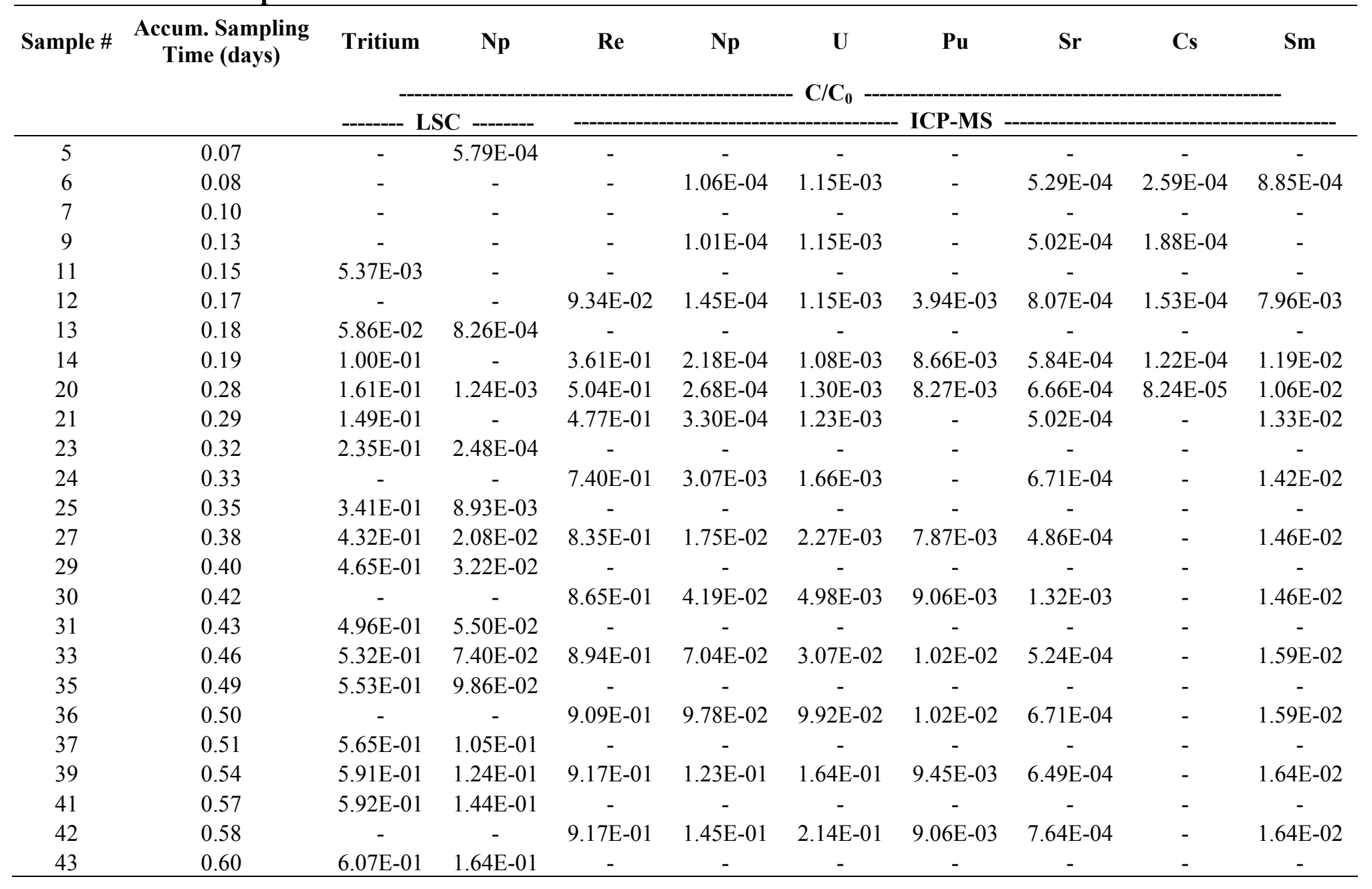


Table 8.9. (continued). TCU-4 experimental results

\begin{tabular}{|c|c|c|c|c|c|c|c|c|c|c|}
\hline \multirow[t]{2}{*}{ Sample \# } & \multirow[t]{2}{*}{$\begin{array}{l}\text { Accum. Sampling } \\
\text { Time (days) }\end{array}$} & Tritium & $\mathbf{N p}$ & $\mathbf{R e}$ & Np & \multirow{2}{*}{$\begin{array}{r}\mathbf{U} \\
\mathbf{C} / \mathbf{C}_{0}\end{array}$} & $\mathbf{P u}$ & $\mathbf{S r}$ & Cs & \multirow[t]{2}{*}{ Sm } \\
\hline & & \multicolumn{4}{|c|}{------ LSC ------- } & & ICP-MS & - & $\cdots$ & \\
\hline 45 & 0.63 & $6.43 \mathrm{E}-01$ & $1.78 \mathrm{E}-01$ & $9.22 \mathrm{E}-01$ & $1.73 \mathrm{E}-01$ & $2.58 \mathrm{E}-01$ & $9.84 \mathrm{E}-03$ & 5.29E-04 & - & $1.73 \mathrm{E}-02$ \\
\hline 47 & 0.65 & $7.51 \mathrm{E}-01$ & $1.85 \mathrm{E}-01$ & - & - & - & - & - & - & - \\
\hline 48 & 0.67 & - & - & $9.39 \mathrm{E}-01$ & $2.01 \mathrm{E}-01$ & $2.91 \mathrm{E}-01$ & $1.06 \mathrm{E}-02$ & $7.26 \mathrm{E}-04$ & - & $1.68 \mathrm{E}-02$ \\
\hline 49 & 0.68 & $3.61 \mathrm{E}-01$ & $1.62 \mathrm{E}-01$ & - & - & - & - & - & - & - \\
\hline 50 & 0.69 & - & - & $9.42 \mathrm{E}-01$ & $2.01 \mathrm{E}-01$ & $3.09 \mathrm{E}-01$ & $1.07 \mathrm{E}-02$ & $4.17 \mathrm{E}-04$ & - & $1.62 \mathrm{E}-02$ \\
\hline 51 & 0.71 & $6.29 \mathrm{E}-01$ & $2.17 \mathrm{E}-01$ & $9.04 \mathrm{E}-01$ & $2.14 \mathrm{E}-01$ & $3.29 \mathrm{E}-01$ & $9.84 \mathrm{E}-03$ & $5.02 \mathrm{E}-04$ & $3.53 \mathrm{E}-05$ & $1.64 \mathrm{E}-02$ \\
\hline 52 & 0.72 & - & - & $9.68 \mathrm{E}-01$ & $2.33 \mathrm{E}-01$ & $3.55 \mathrm{E}-01$ & $1.05 \mathrm{E}-02$ & $1.99 \mathrm{E}-04$ & - & - \\
\hline 53 & 0.75 & $6.50 \mathrm{E}-01$ & $2.38 \mathrm{E}-01$ & - & - & - & - & - & - & - \\
\hline 54 & 0.78 & - & - & $9.07 \mathrm{E}-01$ & $2.39 \mathrm{E}-01$ & $3.71 \mathrm{E}-01$ & $1.06 \mathrm{E}-02$ & 7.42E-04 & $3.14 \mathrm{E}-05$ & $1.73 \mathrm{E}-02$ \\
\hline 55 & 0.81 & $6.81 \mathrm{E}-01$ & $2.48 \mathrm{E}-01$ & $9.48 \mathrm{E}-01$ & $2.54 \mathrm{E}-01$ & $3.87 \mathrm{E}-01$ & $1.36 \mathrm{E}-02$ & $1.06 \mathrm{E}-04$ & - & $1.37 \mathrm{E}-02$ \\
\hline 57 & 0.86 & $6.79 \mathrm{E}-01$ & $2.67 \mathrm{E}-01$ & $9.14 \mathrm{E}-01$ & $2.65 \mathrm{E}-01$ & 4.07E-01 & $9.06 \mathrm{E}-03$ & $9.38 \mathrm{E}-04$ & $3.14 \mathrm{E}-05$ & $1.55 \mathrm{E}-02$ \\
\hline 58 & 0.89 & - & - & $8.71 \mathrm{E}-01$ & $2.76 \mathrm{E}-01$ & $4.18 \mathrm{E}-01$ & $8.24 \mathrm{E}-03$ & $8.61 \mathrm{E}-05$ & - & $9.82 \mathrm{E}-03$ \\
\hline 60 & 0.94 & $5.15 \mathrm{E}-01$ & $2.79 \mathrm{E}-01$ & 4.37E-01 & $2.91 \mathrm{E}-01$ & 4.98E-01 & $3.54 \mathrm{E}-03$ & 7.31E-04 & - & $5.75 \mathrm{E}-03$ \\
\hline 62 & 1.00 & - & - & $1.90 \mathrm{E}-01$ & $2.61 \mathrm{E}-01$ & $4.74 \mathrm{E}-01$ & $1.81 \mathrm{E}-02$ & $2.52 \mathrm{E}-04$ & - & $3.44 \mathrm{E}-03$ \\
\hline 64 & 1.05 & $2.68 \mathrm{E}-01$ & $2.86 \mathrm{E}-01$ & $1.14 \mathrm{E}-01$ & $2.85 \mathrm{E}-01$ & 4.44E-01 & $1.18 \mathrm{E}-03$ & $7.26 \mathrm{E}-04$ & - & - \\
\hline 66 & 1.11 & - & - & 7.94E-02 & $2.51 \mathrm{E}-01$ & $3.57 \mathrm{E}-01$ & - & $3.25 \mathrm{E}-04$ & - & - \\
\hline 68 & 1.17 & $1.61 \mathrm{E}-01$ & $2.49 \mathrm{E}-01$ & $5.86 \mathrm{E}-02$ & $2.44 \mathrm{E}-01$ & $3.14 \mathrm{E}-01$ & - & 7.09E-04 & - & - \\
\hline 72 & 1.28 & $1.25 \mathrm{E}-01$ & $2.02 \mathrm{E}-01$ & $4.25 \mathrm{E}-02$ & $2.04 \mathrm{E}-01$ & $2.38 \mathrm{E}-01$ & - & 7.53E-04 & - & - \\
\hline 76 & 1.39 & $9.54 \mathrm{E}-02$ & $1.74 \mathrm{E}-01$ & $3.18 \mathrm{E}-02$ & $1.72 \mathrm{E}-01$ & $1.85 \mathrm{E}-01$ & - & 7.31E-04 & $5.10 \mathrm{E}-05$ & - \\
\hline 80 & 1.50 & $7.24 \mathrm{E}-02$ & $1.49 \mathrm{E}-01$ & $2.26 \mathrm{E}-02$ & $1.43 \mathrm{E}-01$ & $1.43 \mathrm{E}-01$ & - & $6.71 \mathrm{E}-04$ & - & - \\
\hline 84 & 1.61 & $6.86 \mathrm{E}-02$ & $1.33 \mathrm{E}-01$ & $2.04 \mathrm{E}-02$ & $1.26 \mathrm{E}-01$ & $1.26 \mathrm{E}-01$ & - & $7.31 \mathrm{E}-04$ & $1.06 \mathrm{E}-04$ & - \\
\hline 88 & 1.72 & $5.52 \mathrm{E}-02$ & $1.12 \mathrm{E}-01$ & $1.42 \mathrm{E}-02$ & $9.89 \mathrm{E}-02$ & $9.30 \mathrm{E}-02$ & - & 7.04E-04 & - & - \\
\hline 92 & 1.83 & $4.83 \mathrm{E}-02$ & $9.69 \mathrm{E}-02$ & $1.26 \mathrm{E}-02$ & 8.83E-02 & 8.37E-02 & $3.39 \mathrm{E}-04$ & 7.09E-04 & - & $8.85 \mathrm{E}-04$ \\
\hline 96 & 1.94 & $2.34 \mathrm{E}-02$ & $8.10 \mathrm{E}-02$ & $1.03 \mathrm{E}-02$ & $7.26 \mathrm{E}-02$ & $6.67 \mathrm{E}-02$ & - & $6.98 \mathrm{E}-04$ & - & - \\
\hline 100 & 2.14 & $3.45 \mathrm{E}-02$ & 6.69E-02 & $9.49 \mathrm{E}-03$ & $6.26 \mathrm{E}-02$ & $5.70 \mathrm{E}-02$ & - & $7.26 \mathrm{E}-04$ & $5.88 \mathrm{E}-05$ & - \\
\hline 106 & 2.47 & $4.02 \mathrm{E}-02$ & $7.56 \mathrm{E}-02$ & $1.26 \mathrm{E}-02$ & $6.26 \mathrm{E}-02$ & $5.55 \mathrm{E}-02$ & - & 7.64E-04 & $7.06 \mathrm{E}-05$ & - \\
\hline 112 & 2.80 & $3.22 \mathrm{E}-02$ & $5.27 \mathrm{E}-02$ & 8.89E-03 & $5.07 \mathrm{E}-02$ & 4.33E-02 & - & $6.66 \mathrm{E}-04$ & - & - \\
\hline 118 & 3.14 & $1.99 \mathrm{E}-02$ & $4.36 \mathrm{E}-02$ & $5.29 \mathrm{E}-03$ & $3.74 \mathrm{E}-02$ & $3.00 \mathrm{E}-02$ & - & 6.38E-04 & - & $8.85 \mathrm{E}-04$ \\
\hline
\end{tabular}


Table 8.9. (continued). TCU-4 experimental results

\begin{tabular}{|c|c|c|c|c|c|c|c|c|c|c|}
\hline \multirow[t]{2}{*}{ Sample \# } & \multirow[t]{2}{*}{$\begin{array}{c}\text { Accum. Sampling } \\
\text { Time (days) }\end{array}$} & Tritium & Np & $\mathbf{R e}$ & Np & \multirow{2}{*}{$\begin{array}{r}\mathrm{U} \\
\mathrm{C} / \mathrm{C}_{\mathbf{0}}\end{array}$} & $\mathbf{P u}$ & $\mathrm{Sr}$ & Cs & \multirow[t]{2}{*}{ Sm } \\
\hline & & \multicolumn{4}{|c|}{------ LSC ------- } & & -- ICP-MS & --- & & \\
\hline 124 & 3.47 & $1.72 \mathrm{E}-02$ & $3.87 \mathrm{E}-02$ & $4.27 \mathrm{E}-03$ & $3.09 \mathrm{E}-02$ & $2.46 \mathrm{E}-02$ & - & $6.49 \mathrm{E}-04$ & $6.67 \mathrm{E}-05$ & - \\
\hline 132 & 3.97 & $1.72 \mathrm{E}-02$ & $2.83 \mathrm{E}-02$ & $4.84 \mathrm{E}-03$ & $2.68 \mathrm{E}-02$ & $2.47 \mathrm{E}-02$ & - & 8.07E-04 & - & - \\
\hline 138 & 4.64 & $6.90 \mathrm{E}-03$ & $2.83 \mathrm{E}-02$ & $3.06 \mathrm{E}-03$ & $1.98 \mathrm{E}-02$ & $1.42 \mathrm{E}-02$ & - & $1.04 \mathrm{E}-03$ & - & $8.85 \mathrm{E}-04$ \\
\hline 144 & 5.30 & $9.96 \mathrm{E}-03$ & $2.23 \mathrm{E}-02$ & $2.29 \mathrm{E}-03$ & $1.68 \mathrm{E}-02$ & $1.25 \mathrm{E}-02$ & - & 7.04E-04 & - & - \\
\hline 150 & 5.97 & $4.98 \mathrm{E}-03$ & $1.96 \mathrm{E}-02$ & $1.77 \mathrm{E}-03$ & $1.58 \mathrm{E}-02$ & $1.41 \mathrm{E}-02$ & - & $5.50 \mathrm{E}-04$ & - & - \\
\hline 156 & 6.67 & $7.66 \mathrm{E}-04$ & $2.91 \mathrm{E}-02$ & $1.60 \mathrm{E}-03$ & $1.35 \mathrm{E}-02$ & $9.93 \mathrm{E}-03$ & - & $2.65 \mathrm{E}-04$ & - & - \\
\hline 164 & 7.55 & $9.20 \mathrm{E}-03$ & $1.96 \mathrm{E}-02$ & $2.57 \mathrm{E}-03$ & $1.58 \mathrm{E}-02$ & $1.05 \mathrm{E}-02$ & - & 7.29E-04 & - & $1.13 \mathrm{E}-02$ \\
\hline 170 & 8.22 & $4.98 \mathrm{E}-03$ & $1.30 \mathrm{E}-02$ & $1.63 \mathrm{E}-03$ & $1.24 \mathrm{E}-02$ & 7.19E-03 & - & $6.76 \mathrm{E}-04$ & - & $1.57 \mathrm{E}-02$ \\
\hline 176 & 8.89 & $4.60 \mathrm{E}-03$ & $1.31 \mathrm{E}-02$ & $1.28 \mathrm{E}-03$ & $9.77 \mathrm{E}-03$ & $6.60 \mathrm{E}-03$ & - & $3.45 \mathrm{E}-04$ & - & $1.52 \mathrm{E}-02$ \\
\hline 182 & 9.55 & - & $1.13 \mathrm{E}-02$ & $1.08 \mathrm{E}-03$ & $9.27 \mathrm{E}-03$ & $6.15 \mathrm{E}-03$ & - & 7.42E-04 & - & $1.47 \mathrm{E}-02$ \\
\hline 188 & 10.22 & - & $9.67 \mathrm{E}-03$ & $1.08 \mathrm{E}-03$ & $7.72 \mathrm{E}-03$ & $5.39 \mathrm{E}-03$ & $1.63 \mathrm{E}-03$ & 7.42E-04 & - & $1.47 \mathrm{E}-02$ \\
\hline 196 & 11.11 & $1.53 \mathrm{E}-03$ & $8.10 \mathrm{E}-03$ & 7.71E-04 & $6.36 \mathrm{E}-03$ & $4.81 \mathrm{E}-03$ & - & $3.38 \mathrm{E}-04$ & - & $1.37 \mathrm{E}-02$ \\
\hline 202 & 11.78 & $4.22 \mathrm{E}-03$ & $5.95 \mathrm{E}-03$ & $7.71 \mathrm{E}-04$ & $5.81 \mathrm{E}-03$ & 4.90E-03 & - & $1.34 \mathrm{E}-03$ & - & $1.82 \mathrm{E}-02$ \\
\hline $\mathrm{C}_{0}$ Values*: & & $2.61 \mathrm{E}+02$ & $1.21 \mathrm{E}+02$ & $2.01 E+03$ & $8.95 E+02$ & $1.39 \mathrm{E}+03$ & $1.27 \mathrm{E}+00$ & $9.17 E+03$ & $1.28 \mathrm{E}+04$ & $1.13 E+02$ \\
\hline
\end{tabular}

*: $\mathrm{C}_{0}$ values for LSC are in counts/ hour; $\mathrm{C}_{0}$ values for ICP-MS are in $\mathrm{ng} / \mathrm{mL}$

Table 8.9. (continued). TCU-4 experimental results

\begin{tabular}{|c|c|c|c|c|c|c|c|}
\hline Sample \# & $\begin{array}{c}\text { Accum. Sampling } \\
\text { Time (days) }\end{array}$ & pH & $\mathrm{HCO}_{3}^{-}$ & $\mathbf{N a}$ & $\mathbf{K}$ & Mg & $\mathbf{C a}$ \\
\hline & & & & ------------. & mol/L------ & 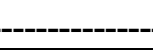 & \\
\hline 5 & 0.07 & - & - & $6.80 \mathrm{E}-03$ & $4.61 \mathrm{E}-05$ & $5.93 \mathrm{E}-06$ & $2.45 \mathrm{E}-05$ \\
\hline 8 & 0.11 & 8.78 & - & - & - & - & - \\
\hline 10 & 0.14 & - & - & $6.24 \mathrm{E}-03$ & $4.06 \mathrm{E}-05$ & 4.44E-06 & $1.59 \mathrm{E}-05$ \\
\hline 14 & 0.19 & 8.63 & - & - & - & - & - \\
\hline 20 & 0.28 & 8.56 & - & - & - & - & - \\
\hline 22 & 0.31 & - & - & $7.18 \mathrm{E}-03$ & $5.05 \mathrm{E}-05$ & $4.30 \mathrm{E}-06$ & $2.12 \mathrm{E}-05$ \\
\hline 26 & 0.36 & 8.67 & - & - & - & - & - \\
\hline
\end{tabular}


Table 8.9. (continued). TCU-4 experimental results

\begin{tabular}{|c|c|c|c|c|c|c|c|}
\hline Sample \# & $\begin{array}{c}\text { Accum. Sampling } \\
\text { Time (days) }\end{array}$ & pH & $\mathrm{HCO}_{3}^{-}$ & $\mathbf{N a}$ & $\mathbf{K}$ & Mg & $\mathrm{Ca}$ \\
\hline & & & & & mol/L------ & |---------' & \\
\hline 28 & 0.39 & - & - & $6.64 \mathrm{E}-03$ & $4.54 \mathrm{E}-05$ & 4.58E-06 & $1.92 \mathrm{E}-05$ \\
\hline 32 & 0.44 & 8.54 & - & - & - & - & - \\
\hline 34 & 0.47 & - & - & $6.71 \mathrm{E}-03$ & $6.14 \mathrm{E}-05$ & $4.31 \mathrm{E}-06$ & $1.85 \mathrm{E}-05$ \\
\hline 38 & 0.53 & 8.45 & - & - & - & - & - \\
\hline 39 & 0.54 & - & - & - & - & - & - \\
\hline 40 & 0.56 & - & - & $6.51 \mathrm{E}-03$ & $4.38 \mathrm{E}-05$ & $2.02 \mathrm{E}-06$ & $9.77 \mathrm{E}-06$ \\
\hline 44 & 0.61 & 8.38 & - & - & - & - & - \\
\hline 46 & 0.64 & - & - & $6.28 \mathrm{E}-03$ & $4.21 \mathrm{E}-05$ & $2.12 \mathrm{E}-06$ & $1.14 \mathrm{E}-05$ \\
\hline 50 & 0.69 & 7.9 & - & - & - & - & - \\
\hline 52 & 0.72 & - & - & $6.45 \mathrm{E}-03$ & 4.60E-05 & $2.35 \mathrm{E}-06$ & $1.93 \mathrm{E}-05$ \\
\hline 56 & 0.83 & 8.29 & - & - & - & - & - \\
\hline 58 & 0.89 & - & - & $6.09 \mathrm{E}-03$ & $4.06 \mathrm{E}-05$ & $1.43 \mathrm{E}-06$ & $1.07 \mathrm{E}-05$ \\
\hline 62 & 1.00 & 8.38 & - & - & - & - & - \\
\hline 63 & 1.03 & - & & - & - & - & - \\
\hline 64 & 1.05 & - & & $6.18 \mathrm{E}-03$ & $4.17 \mathrm{E}-05$ & $1.79 \mathrm{E}-06$ & $1.10 \mathrm{E}-05$ \\
\hline 65 & 1.08 & - & $5.98 \mathrm{E}-03$ & - & - & - & - \\
\hline 66 & 1.11 & - & & - & - & - & - \\
\hline 67 & 1.14 & - & & - & - & - & - \\
\hline 68 & 1.17 & 8.63 & - & - & - & - & - \\
\hline 74 & 1.33 & - & - & $5.83 \mathrm{E}-03$ & $3.87 \mathrm{E}-05$ & $1.35 \mathrm{E}-06$ & $1.07 \mathrm{E}-05$ \\
\hline 76 & 1.39 & 8.56 & - & - & - & - & - \\
\hline 84 & 1.61 & 8.22 & - & $5.98 \mathrm{E}-03$ & $1.21 \mathrm{E}-03$ & $2.88 \mathrm{E}-06$ & $1.40 \mathrm{E}-05$ \\
\hline 93 & 1.86 & 8.41 & - & - & - & - & - \\
\hline 94 & 1.89 & - & - & $5.71 \mathrm{E}-03$ & $9.35 \mathrm{E}-05$ & $1.31 \mathrm{E}-06$ & $9.68 \mathrm{E}-06$ \\
\hline 100 & 2.14 & 8.68 & - & - & - & - & - \\
\hline
\end{tabular}


Table 8.9. (continued). TCU-4 experimental results

\begin{tabular}{|c|c|c|c|c|c|c|c|}
\hline \multirow[t]{2}{*}{ Sample \# } & \multirow[t]{2}{*}{$\begin{array}{l}\text { Accum. Sampling } \\
\text { Time (days) }\end{array}$} & \multirow[t]{2}{*}{ pH } & \multirow[t]{2}{*}{$\mathrm{HCO}_{3}^{-}$} & $\mathbf{N a}$ & $\mathbf{K}$ & Mg & \multirow[t]{2}{*}{$\mathbf{C a}$} \\
\hline & & & & - & mol/L-- & ------ & \\
\hline 104 & 2.36 & - & - & $7.00 \mathrm{E}-03$ & $5.86 \mathrm{E}-05$ & $1.54 \mathrm{E}-06$ & $1.26 \mathrm{E}-05$ \\
\hline 109 & 2.64 & - & \multirow{2}{*}{$6.33 \mathrm{E}-03$} & - & - & - & - \\
\hline 110 & 2.69 & 8.75 & & - & - & - & - \\
\hline 114 & 2.92 & - & - & $5.66 \mathrm{E}-03$ & $3.72 \mathrm{E}-05$ & $1.48 \mathrm{E}-06$ & $9.63 \mathrm{E}-06$ \\
\hline 120 & 3.25 & 8.56 & - & - & - & - & - \\
\hline 124 & 3.47 & - & - & $5.63 \mathrm{E}-03$ & $7.36 \mathrm{E}-05$ & $2.10 \mathrm{E}-06$ & $9.39 \mathrm{E}-06$ \\
\hline 131 & 3.86 & 7.91 & - & - & - & - & - \\
\hline 134 & 4.19 & - & - & $5.67 \mathrm{E}-03$ & $4.37 \mathrm{E}-05$ & $2.03 \mathrm{E}-06$ & $1.05 \mathrm{E}-05$ \\
\hline 140 & 4.86 & 8.26 & - & - & - & - & - \\
\hline 144 & 5.30 & - & $4.75 \mathrm{E}-03$ & $5.14 \mathrm{E}-03$ & $3.54 \mathrm{E}-05$ & $2.05 \mathrm{E}-06$ & $8.68 \mathrm{E}-06$ \\
\hline 150 & 5.97 & 7.8 & - & - & - & - & - \\
\hline 154 & 6.44 & - & - & $5.06 \mathrm{E}-03$ & $3.57 \mathrm{E}-05$ & $1.85 \mathrm{E}-06$ & $8.25 \mathrm{E}-06$ \\
\hline 164 & 7.55 & - & - & $5.57 \mathrm{E}-03$ & $3.86 \mathrm{E}-05$ & $1.91 \mathrm{E}-06$ & $1.04 \mathrm{E}-05$ \\
\hline 174 & 8.67 & - & - & $5.40 \mathrm{E}-03$ & $4.01 \mathrm{E}-05$ & $2.83 \mathrm{E}-06$ & $1.22 \mathrm{E}-05$ \\
\hline 175 & 8.78 & - & $4.25 \mathrm{E}-03$ & - & - & - & - \\
\hline 184 & 9.78 & - & - & $5.43 \mathrm{E}-03$ & $4.31 \mathrm{E}-05$ & $2.49 \mathrm{E}-06$ & $1.08 \mathrm{E}-05$ \\
\hline 194 & 10.89 & - & - & $5.37 \mathrm{E}-03$ & $3.61 \mathrm{E}-05$ & $1.45 \mathrm{E}-06$ & $9.07 \mathrm{E}-06$ \\
\hline 203 & 11.89 & - & $4.76 \mathrm{E}-03$ & - & - & - & - \\
\hline 204 & 11.95 & - & - & $5.15 \mathrm{E}-03$ & $2.52 \mathrm{E}-05$ & $1.91 \mathrm{E}-06$ & $9.54 \mathrm{E}-06$ \\
\hline \multicolumn{4}{|c|}{ TCU-4 Initial Sorption Solution: } & 4.30E-03 & 1.95E-04 & 2.57E-05 & 1.03E-04 \\
\hline
\end{tabular}


Table 8.10. TCU-5 experimental run parameters

\section{TCU-5, core depth $=$ UE7ba1626.2-1627.0}

Porosity: $30.90 \%$, Permeability: $0.124 \mathrm{md}$, Density: $1.64 \mathrm{~g} / \mathrm{m}^{3}$

Sorption solution of $\mathrm{NaHCO}_{3}, \mathrm{Ca}, \mathrm{Mg}, \mathrm{K}, \mathrm{Sm}, \mathrm{U}, \mathrm{Re}, \mathrm{Pu}, \mathrm{Np}$,Tritium

Experiment started on : 4 August 04 17:50

Start pumping sorption solution at: 12 August 04 10:56

Stopped pumping sorption solution at: 12 August 04 23:17

Average flow rate $(\mathrm{mL} / \mathrm{min}): 0.0159$

Pump and tubing volume $(\mathrm{mL}): 1.788$

Table 8.11. TCU-5 core mineralogy

\begin{tabular}{cccccccc}
\hline Quartz & Cristobalite & Clay & $\begin{array}{c}\text { Na-Ca } \\
\text { Feldspar }\end{array}$ & $\begin{array}{c}\text { K } \\
\text { Feldspar }\end{array}$ & $\begin{array}{c}\text { Clinoptilolite/ } \\
\text { Heulandite }\end{array}$ & Calcite & $\begin{array}{c}\text { total } \\
\text { sorbers }\end{array}$ \\
\hline TCU-5 & 11.4 & 2.5 & 1.0 & 31.0 & 37.1 & 16.9 & - \\
\hline--------- & 17.9 \\
\hline
\end{tabular}

Table 8.12. TCU-5 experimental results

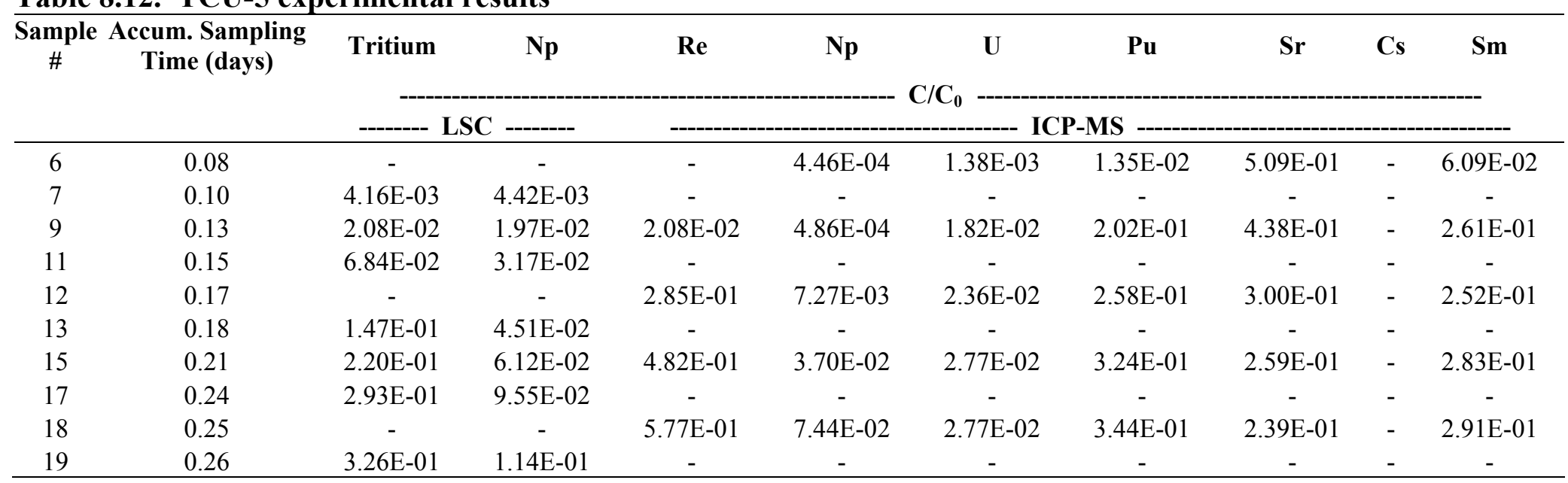


Table 8.12. (continued). TCU-5 experimental results

\begin{tabular}{|c|c|c|c|c|c|c|c|c|c|c|}
\hline \multirow[t]{2}{*}{ Sample \# } & \multirow[t]{2}{*}{$\begin{array}{c}\text { Accum. Sampling } \\
\text { Time (days) }\end{array}$} & Tritium & Np & $\mathbf{R e}$ & Np & \multirow{2}{*}{$\begin{array}{r}U \\
C / C_{0}\end{array}$} & $\mathbf{P u}$ & $\mathrm{Sr}$ & Cs & \multirow[t]{2}{*}{ Sm } \\
\hline & & \multicolumn{2}{|c|}{-------- LSC -------- } & ----------- & ------------- & & - ICP-MS & - & & \\
\hline 21 & 0.29 & $3.70 \mathrm{E}-01$ & $1.65 \mathrm{E}-01$ & $6.32 \mathrm{E}-01$ & $1.18 \mathrm{E}-01$ & $2.98 \mathrm{E}-02$ & $3.60 \mathrm{E}-01$ & $2.50 \mathrm{E}-01$ & - & $3.00 \mathrm{E}-01$ \\
\hline 23 & 0.32 & $3.92 \mathrm{E}-01$ & $1.86 \mathrm{E}-01$ & - & - & - & - & - & - & - \\
\hline 24 & 0.33 & - & - & $6.78 \mathrm{E}-01$ & $1.59 \mathrm{E}-01$ & $3.18 \mathrm{E}-02$ & $3.73 \mathrm{E}-01$ & $2.53 \mathrm{E}-01$ & - & $3.09 \mathrm{E}-01$ \\
\hline 25 & 0.35 & $4.40 \mathrm{E}-01$ & $2.07 \mathrm{E}-01$ & - & - & - & - & - & - & - \\
\hline 27 & 0.38 & $4.55 \mathrm{E}-01$ & $2.44 \mathrm{E}-01$ & $7.21 \mathrm{E}-01$ & $1.99 \mathrm{E}-01$ & $3.76 \mathrm{E}-02$ & $3.77 \mathrm{E}-01$ & $2.38 \mathrm{E}-01$ & - & $3.13 \mathrm{E}-01$ \\
\hline 29 & 0.40 & 4.64E-01 & $2.53 \mathrm{E}-01$ & - & - & - & - & - & - & - \\
\hline 30 & 0.42 & - & - & $6.67 \mathrm{E}-01$ & $2.11 \mathrm{E}-01$ & $4.95 \mathrm{E}-02$ & $3.34 \mathrm{E}-01$ & $2.17 \mathrm{E}-01$ & - & $2.96 \mathrm{E}-01$ \\
\hline 31 & 0.43 & 4.97E-01 & $2.84 \mathrm{E}-01$ & - & - & - & - & - & - & - \\
\hline 33 & 0.46 & $5.11 \mathrm{E}-01$ & $2.81 \mathrm{E}-01$ & 7.33E-01 & $2.60 \mathrm{E}-01$ & $8.53 \mathrm{E}-02$ & $3.57 \mathrm{E}-01$ & $2.29 \mathrm{E}-01$ & - & $3.09 \mathrm{E}-01$ \\
\hline 35 & 0.49 & $5.28 \mathrm{E}-01$ & 3.09E-01 & - & - & - & - & - & - & - \\
\hline 36 & 0.50 & - & - & $1.12 \mathrm{E}-01$ & $1.72 \mathrm{E}-01$ & $2.31 \mathrm{E}-01$ & $4.20 \mathrm{E}-02$ & $4.57 \mathrm{E}-01$ & - & $1.04 \mathrm{E}-01$ \\
\hline 37 & 0.51 & $5.45 \mathrm{E}-01$ & $3.41 \mathrm{E}-01$ & - & - & - & - & - & - & - \\
\hline 39 & 0.56 & $5.78 \mathrm{E}-01$ & $3.77 \mathrm{E}-01$ & $7.80 \mathrm{E}-01$ & $3.30 \mathrm{E}-01$ & $1.74 \mathrm{E}-01$ & $4.26 \mathrm{E}-01$ & $3.05 \mathrm{E}-01$ & - & $3.78 \mathrm{E}-01$ \\
\hline 41 & 0.61 & 5.61E-01 & $3.46 \mathrm{E}-01$ & - & - & - & - & - & - & - \\
\hline 42 & 0.64 & - & - & $5.36 \mathrm{E}-01$ & $3.31 \mathrm{E}-01$ & $2.13 \mathrm{E}-01$ & $1.19 \mathrm{E}-01$ & 4.42E-01 & - & $1.61 \mathrm{E}-01$ \\
\hline 43 & 0.67 & $3.89 \mathrm{E}-01$ & $2.75 \mathrm{E}-01$ & - & - & - & - & - & - & - \\
\hline 44 & 0.69 & - & - & $2.24 \mathrm{E}-01$ & $2.72 \mathrm{E}-01$ & $2.85 \mathrm{E}-01$ & $5.15 \mathrm{E}-02$ & $5.47 \mathrm{E}-01$ & - & $1.35 \mathrm{E}-01$ \\
\hline 45 & 0.72 & $2.40 \mathrm{E}-01$ & $2.31 \mathrm{E}-01$ & - & - & - & - & - & - & - \\
\hline 46 & 0.75 & - & - & $1.41 \mathrm{E}-01$ & $2.15 \mathrm{E}-01$ & $2.64 \mathrm{E}-01$ & $3.30 \mathrm{E}-02$ & $5.11 \mathrm{E}-01$ & - & $1.09 \mathrm{E}-01$ \\
\hline 47 & 0.78 & $1.78 \mathrm{E}-01$ & $1.85 \mathrm{E}-01$ & - & - & - & - & - & - & - \\
\hline 48 & 0.81 & - & - & $9.47 \mathrm{E}-02$ & $1.55 \mathrm{E}-01$ & $2.01 \mathrm{E}-01$ & $2.48 \mathrm{E}-02$ & $5.45 \mathrm{E}-01$ & - & $1.04 \mathrm{E}-01$ \\
\hline 49 & 0.83 & $1.68 \mathrm{E}-01$ & $1.65 \mathrm{E}-01$ & - & - & - & - & - & - & - \\
\hline 50 & 0.86 & - & - & $6.78 \mathrm{E}-02$ & $1.27 \mathrm{E}-01$ & $1.64 \mathrm{E}-01$ & $2.05 \mathrm{E}-02$ & $5.14 \mathrm{E}-01$ & - & $1.09 \mathrm{E}-01$ \\
\hline 51 & 0.89 & $1.25 \mathrm{E}-01$ & $1.33 \mathrm{E}-01$ & - & - & - & - & - & - & - \\
\hline 52 & 0.92 & - & - & $1.19 \mathrm{E}-01$ & $1.41 \mathrm{E}-01$ & $2.06 \mathrm{E}-01$ & $2.28 \mathrm{E}-02$ & $4.56 \mathrm{E}-01$ & - & $9.57 \mathrm{E}-02$ \\
\hline 53 & 0.94 & $1.12 \mathrm{E}-01$ & $1.26 \mathrm{E}-01$ & - & - & - & - & - & - & - \\
\hline 54 & 0.97 & - & - & $6.27 \mathrm{E}-02$ & $1.06 \mathrm{E}-01$ & $1.34 \mathrm{E}-01$ & $1.52 \mathrm{E}-02$ & 4.99E-01 & - & $8.70 \mathrm{E}-02$ \\
\hline 55 & 1.00 & $9.94 \mathrm{E}-02$ & $1.09 \mathrm{E}-01$ & - & - & - & - & - & - & - \\
\hline
\end{tabular}


Table 8.12. (continued). TCU-5 experimental results

\begin{tabular}{|c|c|c|c|c|c|c|c|c|c|c|}
\hline \multirow[t]{2}{*}{ Sample \# } & \multirow[t]{2}{*}{$\begin{array}{l}\text { Accum. Sampling } \\
\text { Time (days) }\end{array}$} & Tritium & Np & $\mathbf{R e}$ & $\mathbf{N p}$ & \multirow{2}{*}{$\begin{array}{c}\mathrm{U} \\
\mathrm{C} / \mathrm{C}_{0}\end{array}$} & $\mathbf{P u}$ & $\mathbf{S r}$ & Cs & \multirow[t]{2}{*}{ Sm } \\
\hline & & \multicolumn{2}{|c|}{------- LSC -------- } & \multicolumn{2}{|c|}{----------------------------------------' } & & ICP-MS - & - & 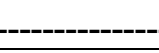 & \\
\hline 59 & 1.17 & $7.54 \mathrm{E}-02$ & $8.32 \mathrm{E}-02$ & 4.47E-02 & $8.11 \mathrm{E}-02$ & $1.07 \mathrm{E}-01$ & - & $5.51 \mathrm{E}-01$ & - & $9.13 \mathrm{E}-02$ \\
\hline 62 & 1.33 & $5.78 \mathrm{E}-02$ & $5.78 \mathrm{E}-02$ & $3.76 \mathrm{E}-02$ & $6.02 \mathrm{E}-02$ & $8.22 \mathrm{E}-02$ & - & $5.22 \mathrm{E}-01$ & - & $6.96 \mathrm{E}-02$ \\
\hline 65 & 1.50 & 4.49E-02 & $3.88 \mathrm{E}-02$ & 2.69E-02 & $4.50 \mathrm{E}-02$ & $5.98 \mathrm{E}-02$ & - & $5.36 \mathrm{E}-01$ & - & $6.52 \mathrm{E}-02$ \\
\hline 71 & 1.83 & $3.38 \mathrm{E}-02$ & $3.00 \mathrm{E}-02$ & $2.13 \mathrm{E}-02$ & $3.06 \mathrm{E}-02$ & 4.19E-02 & - & $5.10 \mathrm{E}-01$ & - & $5.65 \mathrm{E}-02$ \\
\hline 74 & 2.00 & $2.64 \mathrm{E}-02$ & $2.53 \mathrm{E}-02$ & $1.72 \mathrm{E}-02$ & $2.55 \mathrm{E}-02$ & $3.50 \mathrm{E}-02$ & - & 4.99E-01 & - & $5.22 \mathrm{E}-02$ \\
\hline 77 & 2.17 & $2.31 \mathrm{E}-02$ & $2.28 \mathrm{E}-02$ & $1.67 \mathrm{E}-02$ & $2.32 \mathrm{E}-02$ & $3.18 \mathrm{E}-02$ & - & $5.24 \mathrm{E}-01$ & - & $5.65 \mathrm{E}-02$ \\
\hline 80 & 2.33 & $2.77 \mathrm{E}-02$ & $2.67 \mathrm{E}-02$ & $2.04 \mathrm{E}-02$ & $2.45 \mathrm{E}-02$ & $3.13 \mathrm{E}-02$ & - & $5.05 \mathrm{E}-01$ & - & - \\
\hline 83 & 2.50 & $2.36 \mathrm{E}-02$ & $1.88 \mathrm{E}-02$ & $1.26 \mathrm{E}-02$ & $1.88 \mathrm{E}-02$ & $2.58 \mathrm{E}-02$ & - & $5.27 \mathrm{E}-01$ & - & $5.22 \mathrm{E}-02$ \\
\hline 86 & 2.67 & $2.13 \mathrm{E}-02$ & $1.82 \mathrm{E}-02$ & $1.15 \mathrm{E}-02$ & $1.63 \mathrm{E}-02$ & $2.19 \mathrm{E}-02$ & - & $5.32 \mathrm{E}-01$ & - & $5.22 \mathrm{E}-02$ \\
\hline 89 & 2.83 & $2.03 \mathrm{E}-02$ & $1.47 \mathrm{E}-02$ & $1.03 \mathrm{E}-02$ & $1.38 \mathrm{E}-02$ & $2.01 \mathrm{E}-02$ & - & $5.23 \mathrm{E}-01$ & - & $6.52 \mathrm{E}-02$ \\
\hline 101 & 3.50 & $1.76 \mathrm{E}-02$ & $9.09 \mathrm{E}-03$ & 8.58E-03 & $1.15 \mathrm{E}-02$ & $1.46 \mathrm{E}-02$ & - & $5.19 \mathrm{E}-01$ & - & - \\
\hline 107 & 3.83 & $1.29 \mathrm{E}-02$ & $6.91 \mathrm{E}-03$ & $8.14 \mathrm{E}-03$ & $9.72 \mathrm{E}-03$ & $1.36 \mathrm{E}-02$ & - & 4.77E-01 & - & - \\
\hline 111 & 4.17 & $1.90 \mathrm{E}-02$ & $1.22 \mathrm{E}-02$ & $1.24 \mathrm{E}-02$ & $1.22 \mathrm{E}-02$ & $1.65 \mathrm{E}-02$ & - & 4.77E-01 & 4.09E-02 & - \\
\hline 113 & 4.39 & $1.53 \mathrm{E}-02$ & $9.98 \mathrm{E}-03$ & 8.08E-03 & $9.94 \mathrm{E}-03$ & $1.26 \mathrm{E}-02$ & - & $5.21 \mathrm{E}-01$ & $2.60 \mathrm{E}-02$ & - \\
\hline 118 & 4.94 & $2.36 \mathrm{E}-02$ & $1.65 \mathrm{E}-02$ & 1.19E-02 & $1.56 \mathrm{E}-02$ & $1.56 \mathrm{E}-02$ & - & $5.16 \mathrm{E}-01$ & - & - \\
\hline 123 & 5.50 & $1.20 \mathrm{E}-02$ & $1.08 \mathrm{E}-02$ & $8.55 \mathrm{E}-03$ & $1.16 \mathrm{E}-02$ & $1.42 \mathrm{E}-02$ & - & $5.11 \mathrm{E}-01$ & - & - \\
\hline 129 & 6.17 & $1.16 \mathrm{E}-02$ & $7.38 \mathrm{E}-03$ & 5.89E-03 & $8.74 \mathrm{E}-03$ & $1.18 \mathrm{E}-02$ & - & $5.33 \mathrm{E}-01$ & - & - \\
\hline 133 & 6.83 & $1.20 \mathrm{E}-02$ & $7.64 \mathrm{E}-03$ & $5.71 \mathrm{E}-03$ & $9.40 \mathrm{E}-03$ & $9.96 \mathrm{E}-03$ & - & $5.25 \mathrm{E}-01$ & - & - \\
\hline 137 & 7.50 & $1.25 \mathrm{E}-02$ & $6.91 \mathrm{E}-03$ & $5.09 \mathrm{E}-03$ & $7.62 \mathrm{E}-03$ & $9.33 \mathrm{E}-03$ & - & $5.17 \mathrm{E}-01$ & - & - \\
\hline $\mathrm{C}_{0}$ Values": & & $7.11 \mathrm{E}+01$ & $2.19 \mathrm{E}+02$ & $1.69 \mathrm{E}+03$ & $1.12 E+03$ & $9.43 \mathrm{E}+02$ & $1.51 \mathrm{E}+00$ & $8.77 E+01$ & $1.35 \mathrm{E}+01$ & $1.15 \mathrm{E}+01$ \\
\hline
\end{tabular}

*: $\mathrm{C}_{0}$ values for LSC are in counts/ hour; $\mathrm{C}_{0}$ values for ICP-MS are in $\mathrm{ng} / \mathrm{mL}$ 
Table 8.12. (continued). TCU-5 experimental results

\begin{tabular}{|c|c|c|c|c|c|c|c|}
\hline Sample \# & $\begin{array}{c}\text { Accum. Sampling } \\
\text { Time (days) }\end{array}$ & pH & $\mathrm{HCO}_{3}^{-}$ & $\mathbf{N a}$ & $\mathbf{K}$ & Mg & $\mathrm{Ca}$ \\
\hline & & & & & -mol/L---- & & \\
\hline 5 & 0.07 & - & - & $8.58 \mathrm{E}-03$ & $8.74 \mathrm{E}-05$ & $8.86 \mathrm{E}-06$ & $3.04 \mathrm{E}-05$ \\
\hline 8 & 0.11 & 8.6 & - & - & - & - & - \\
\hline 13 & 0.18 & - & - & $1.03 \mathrm{E}-02$ & 8.38E-05 & $7.31 \mathrm{E}-06$ & $2.45 \mathrm{E}-05$ \\
\hline 16 & 0.22 & 8.5 & - & - & - & - & - \\
\hline 20 & 0.28 & - & - & $1.13 \mathrm{E}-02$ & $8.50 \mathrm{E}-05$ & $6.30 \mathrm{E}-06$ & $2.21 \mathrm{E}-05$ \\
\hline 25 & 0.35 & 8.53 & - & - & - & - & - \\
\hline 28 & 0.39 & - & - & $1.20 \mathrm{E}-02$ & $9.71 \mathrm{E}-05$ & 7.17E-06 & $2.48 \mathrm{E}-05$ \\
\hline 34 & 0.47 & 8.25 & - & - & - & - & - \\
\hline 36 & 0.50 & - & - & $1.24 \mathrm{E}-02$ & $9.19 \mathrm{E}-05$ & $6.53 \mathrm{E}-06$ & $2.11 \mathrm{E}-05$ \\
\hline 41 & 0.61 & - & - & $1.19 \mathrm{E}-02$ & $9.25 \mathrm{E}-05$ & $6.60 \mathrm{E}-06$ & $2.19 \mathrm{E}-05$ \\
\hline 43 & 0.67 & 8.54 & - & - & - & - & - \\
\hline 45 & 0.72 & - & - & $9.07 \mathrm{E}-03$ & $9.33 \mathrm{E}-05$ & $7.68 \mathrm{E}-06$ & $3.19 \mathrm{E}-05$ \\
\hline 51 & 0.89 & 8.38 & - & - & - & - & - \\
\hline 52 & 0.92 & - & - & 8.60E-03 & $9.75 \mathrm{E}-05$ & $7.04 \mathrm{E}-06$ & $2.58 \mathrm{E}-05$ \\
\hline 53 & 0.94 & - & $2.30 \mathrm{E}-03$ & - & - & - & - \\
\hline 57 & 1.06 & - & - & 8.13E-03 & $1.10 \mathrm{E}-04$ & $9.43 \mathrm{E}-06$ & $4.23 \mathrm{E}-05$ \\
\hline 60 & 1.22 & - & - & 8.48E-03 & 8.30E-05 & $5.88 \mathrm{E}-06$ & $2.44 \mathrm{E}-05$ \\
\hline 63 & 1.39 & - & - & 8.07E-03 & 8.67E-05 & 7.43E-06 & $2.93 \mathrm{E}-05$ \\
\hline 66 & 1.56 & - & - & $8.12 \mathrm{E}-03$ & 8.98E-05 & $7.60 \mathrm{E}-06$ & $3.33 \mathrm{E}-05$ \\
\hline 70 & 1.78 & - & - & 8.02E-03 & 8.33E-05 & $6.59 \mathrm{E}-06$ & $2.75 \mathrm{E}-05$ \\
\hline 77 & 2.17 & - & - & 7.84E-03 & $8.15 \mathrm{E}-05$ & $6.40 \mathrm{E}-06$ & $2.65 \mathrm{E}-05$ \\
\hline 83 & 2.50 & - & - & 7.82E-03 & $7.51 \mathrm{E}-05$ & $6.18 \mathrm{E}-06$ & $2.43 \mathrm{E}-05$ \\
\hline 84 & 2.56 & - & $2.84 \mathrm{E}-03$ & - & - & - & - \\
\hline 90 & 2.89 & - & - & 7.29E-03 & $7.70 \mathrm{E}-05$ & $6.56 \mathrm{E}-06$ & $2.63 \mathrm{E}-05$ \\
\hline 96 & 3.22 & - & - & 7.23E-03 & 7.53E-05 & $6.52 \mathrm{E}-06$ & $2.38 \mathrm{E}-05$ \\
\hline 100 & 3.44 & - & $3.57 \mathrm{E}-03$ & - & - & - & - \\
\hline 102 & 3.56 & - & - & 7.59E-03 & $8.15 \mathrm{E}-05$ & $6.99 \mathrm{E}-06$ & $2.50 \mathrm{E}-05$ \\
\hline 113 & 4.39 & - & - & $7.25 \mathrm{E}-03$ & $8.15 \mathrm{E}-05$ & $7.39 \mathrm{E}-06$ & $2.85 \mathrm{E}-05$ \\
\hline 121 & 5.28 & - & - & $7.48 \mathrm{E}-03$ & 8.34E-05 & $6.32 \mathrm{E}-06$ & $2.72 \mathrm{E}-05$ \\
\hline
\end{tabular}


Table 8.12. (continued). TCU-5 experimental results

\begin{tabular}{|c|c|c|c|c|c|c|c|}
\hline Sample \# & $\begin{array}{c}\text { Accum. Sampling } \\
\text { Time (days) }\end{array}$ & pH & $\mathrm{HCO}_{3}^{-}$ & $\mathbf{N a}$ & $\mathbf{K}$ & Mg & $\mathbf{C a}$ \\
\hline & & & & . & $101 / 12-2$ & $---\cdot$ & \\
\hline 129 & 6.17 & - & - & $7.32 \mathrm{E}-03$ & $8.51 \mathrm{E}-05$ & $6.99 \mathrm{E}-06$ & $3.38 \mathrm{E}-05$ \\
\hline 134 & 7.00 & - & - & 7.43E-03 & $7.63 \mathrm{E}-05$ & $6.43 \mathrm{E}-06$ & $2.85 \mathrm{E}-05$ \\
\hline 139 & 7.83 & - & $2.69 \mathrm{E}-03$ & - & - & - & - \\
\hline \multicolumn{2}{|c|}{ TCU-5 Initial Sorption Solution: } & 8.09 & 2.55E-03 & 1.12E-02 & 2.90E-04 & 4.24E-05 & 1.08E-04 \\
\hline
\end{tabular}

Table 8.13. TCU-6 Experimental run parameters

\section{TCU-6, core depth $=$ UE7az1678.2-1679.0}

Porosity: $34.17 \%$, Permeability: $0.128 \mathrm{md}$, Density: $1.49 \mathrm{~g} / \mathrm{m}^{3}$

Sorption solution of $\mathrm{NaHCO} 3, \mathrm{Ca}, \mathrm{Mg}, \mathrm{K}, \mathrm{Cs}, \mathrm{Sr}, \mathrm{Sm}, \mathrm{U}, \mathrm{Re}, \mathrm{Pu}, \mathrm{Np}$

Experiment started on : 3 September 04 16:37

Start pumping sorption solution at: 9 September 04 16:37

Stopped pumping sorption solution at: 10 September 04 08:41

Average flow rate $0.02 \mathrm{~mL} / \mathrm{min}$

Pump and tubing volume (mL): 1.788

Table 8.14. TCU-6 core mineralogy

\begin{tabular}{cccccc}
\hline & quartz & illite & albite & clinop & total sorbers \\
\hline & - & - & - & Weight Percent & - \\
\hdashline$-a-1$ & 15.7 & 30.2 & 47.0 & 62.7 \\
\hline TCU-6 avg & 7.1 & & & & \\
\hline
\end{tabular}

Table 8.15. TCU-6 experimental results

\begin{tabular}{|c|c|c|c|c|c|c|c|c|c|c|}
\hline \multirow[t]{2}{*}{ Sample \# } & \multirow{2}{*}{$\begin{array}{c}\text { Accum. } \\
\text { Sampling Time } \\
\text { (days) }\end{array}$} & Tritium & Np & $\mathbf{R e}$ & Np & \multirow{2}{*}{$\begin{array}{c}\mathrm{U} \\
\mathrm{C} / \mathrm{C}_{\mathbf{0}}\end{array}$} & \multirow[b]{2}{*}{ CP-Ms } & \multirow[t]{2}{*}{$\mathrm{Sr}$} & \multirow[t]{2}{*}{ Cs } & \multirow[t]{2}{*}{ Sm } \\
\hline & & - & - & & 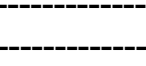 & & & & & \\
\hline 5 & 0.07 & $1.82 \mathrm{E}-03$ & - & - & - & - & - & - & - & - \\
\hline 6 & 0.08 & - & & - & - & - & - & $8.86 \mathrm{E}-04$ & - & - \\
\hline 10 & 0.14 & - & & - & $6.48 \mathrm{E}-04$ & 8.54E-04 & - & $3.68 \mathrm{E}-04$ & - & $5.54 \mathrm{E}-03$ \\
\hline 11 & 0.15 & $4.10 \mathrm{E}-03$ & - & - & - & - & - & - & - & - \\
\hline
\end{tabular}


Table 8.15. (continued). TCU-6 experimental results

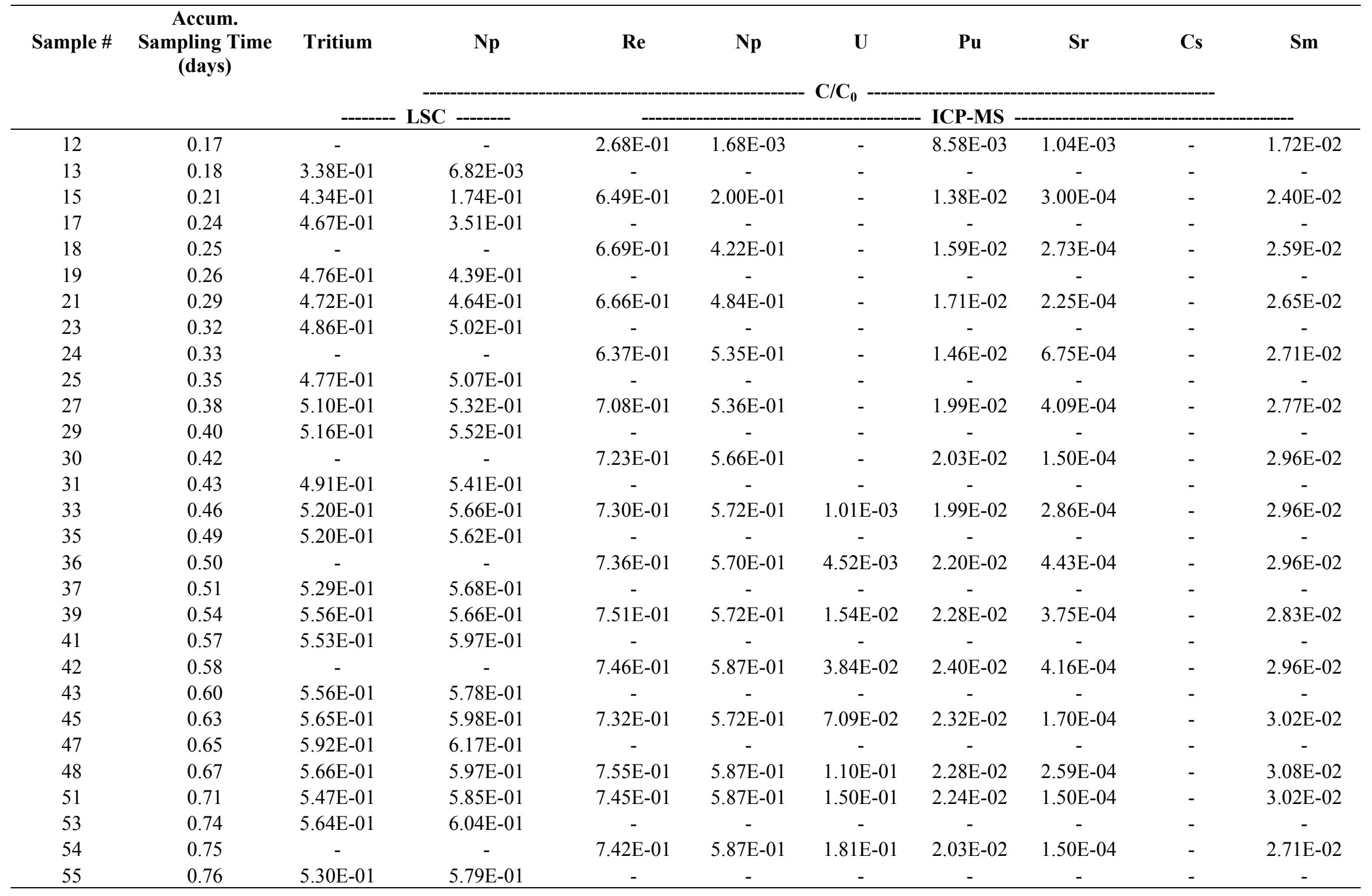


Table 8.15. (continued). TCU-6 experimental results

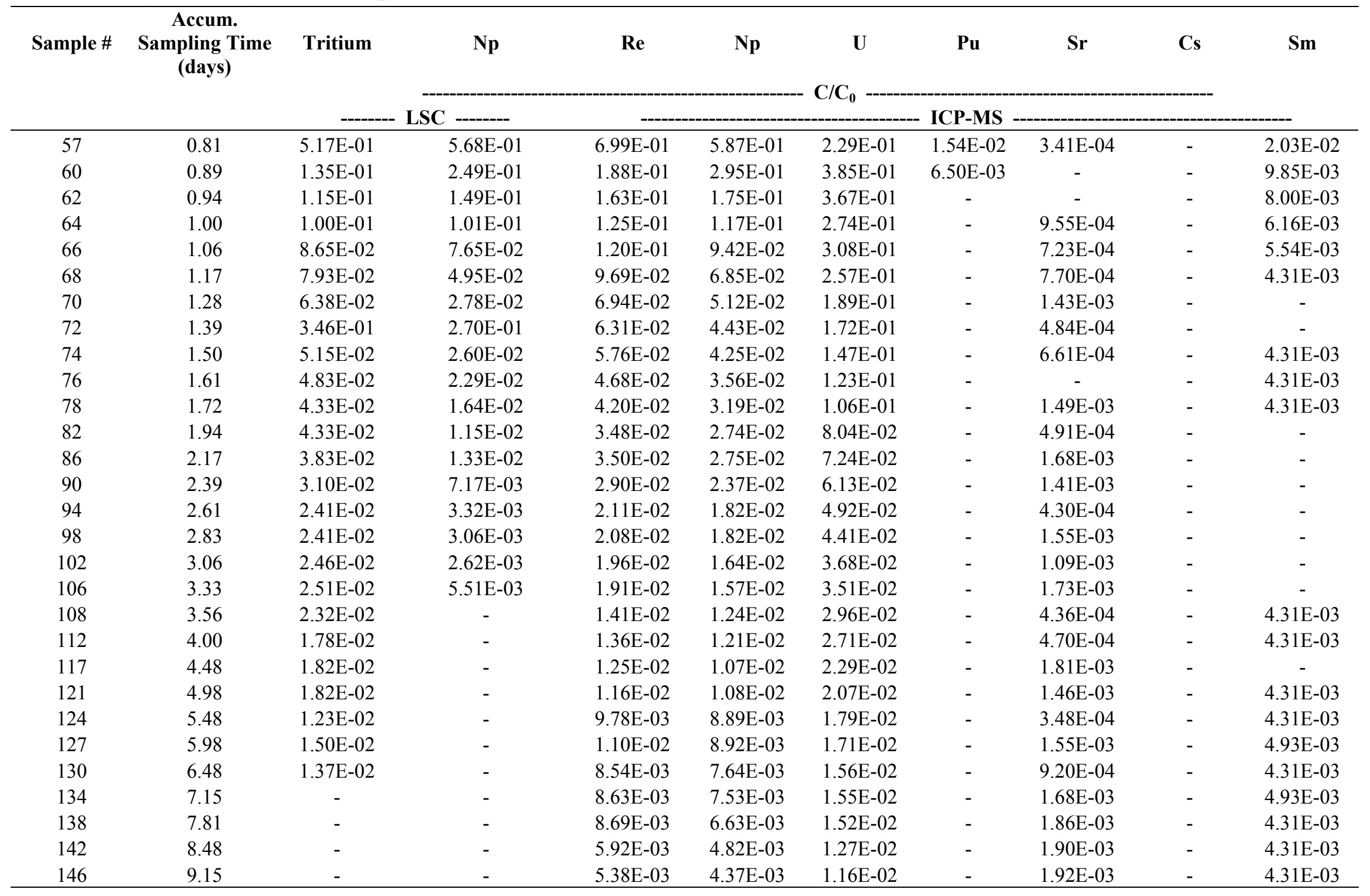


Table 8.15. (continued). TCU-6 experimental results

\begin{tabular}{|c|c|c|c|c|c|c|c|c|c|c|}
\hline \multirow[t]{2}{*}{ Sample \# } & \multirow[t]{2}{*}{$\begin{array}{c}\text { Accum. } \\
\text { Sampling Time } \\
\text { (days) }\end{array}$} & \multirow[t]{2}{*}{ Tritium } & Np & $\mathbf{R e}$ & Np & $\mathbf{U}$ & $\mathbf{P u}$ & $\mathbf{S r}$ & Cs & \multirow[t]{2}{*}{ Sm } \\
\hline & & & C ------- & --- & --------------- & - & ICP-MS & ------------ & ------ & \\
\hline 150 & 9.81 & - & - & $5.13 \mathrm{E}-03$ & 3.99E-03 & $9.85 \mathrm{E}-03$ & - & $1.88 \mathrm{E}-03$ & - & $4.31 \mathrm{E}-03$ \\
\hline 154 & 10.48 & - & - & $4.59 \mathrm{E}-03$ & $3.77 \mathrm{E}-03$ & $9.35 \mathrm{E}-03$ & - & $1.88 \mathrm{E}-03$ & - & 4.93E-03 \\
\hline$C_{0}$ Values ${ }^{*}$ : & & $7.11 \mathrm{E}+01$ & $2.19 \mathrm{E}+02$ & $1.57 E+03$ & $6.64 \mathrm{E}+02$ & $9.95 \mathrm{E}+02$ & $1.23 \mathrm{E}+00$ & $7.33 \mathrm{E}+03$ & $1.12 \mathrm{E}+04$ & $8.12 \mathrm{E}+01$ \\
\hline
\end{tabular}

Table 8.15. (continued). TCU-6 experimental results

\begin{tabular}{|c|c|c|c|c|c|c|c|}
\hline Sample \# & $\begin{array}{c}\text { Accum. Sampling } \\
\text { Time (days) }\end{array}$ & $\mathbf{p H}$ & $\mathrm{HCO}_{3}^{-}$ & $\mathbf{N a}$ & $\mathbf{K}$ & Mg & $\mathbf{C a}$ \\
\hline 5 & 0.07 & - & - & $1.88 \mathrm{E}-02$ & $2.46 \mathrm{E}-03$ & $5.79 \mathrm{E}-05$ & $2.55 \mathrm{E}-04$ \\
\hline 6 & 0.08 & 8.42 & - & - & - & - & - \\
\hline 13 & 0.18 & - & - & $1.86 \mathrm{E}-02$ & $2.42 \mathrm{E}-03$ & $4.96 \mathrm{E}-05$ & $2.40 \mathrm{E}-04$ \\
\hline 14 & 0.19 & 8.82 & - & - & - & - & - \\
\hline 18 & 0.25 & - & $7.08 \mathrm{E}-03$ & - & - & - & - \\
\hline 20 & 0.28 & - & - & $1.77 \mathrm{E}-02$ & $2.30 \mathrm{E}-03$ & 4.64E-05 & $2.28 \mathrm{E}-04$ \\
\hline 23 & 0.32 & 8.71 & - & - & - & - & - \\
\hline 28 & 0.39 & - & - & $1.68 \mathrm{E}-02$ & $2.16 \mathrm{E}-03$ & $4.09 \mathrm{E}-05$ & $2.19 \mathrm{E}-04$ \\
\hline 32 & 0.44 & 8.1 & - & - & - & - & - \\
\hline 36 & 0.50 & - & - & $1.65 \mathrm{E}-02$ & $2.10 \mathrm{E}-03$ & $3.89 \mathrm{E}-05$ & $2.20 \mathrm{E}-04$ \\
\hline 38 & 0.53 & - & $4.95 \mathrm{E}-03$ & - & - & - & - \\
\hline 40 & 0.56 & 8.68 & - & - & - & - & - \\
\hline 41 & 0.57 & - & - & $1.67 \mathrm{E}-02$ & $2.16 \mathrm{E}-03$ & $4.13 \mathrm{E}-05$ & $2.25 \mathrm{E}-04$ \\
\hline 45 & 0.63 & - & - & $1.64 \mathrm{E}-02$ & $2.10 \mathrm{E}-03$ & $3.25 \mathrm{E}-05$ & $1.76 \mathrm{E}-04$ \\
\hline 50 & 0.69 & 8.03 & - & - & - & - & - \\
\hline 52 & 0.72 & - & - & $1.64 \mathrm{E}-02$ & $2.10 \mathrm{E}-03$ & $3.02 \mathrm{E}-05$ & $1.79 \mathrm{E}-04$ \\
\hline 57 & 0.81 & - & - & $1.64 \mathrm{E}-02$ & $2.11 \mathrm{E}-03$ & $3.32 \mathrm{E}-05$ & $1.96 \mathrm{E}-04$ \\
\hline 58 & 0.83 & - & $3.42 \mathrm{E}-03$ & - & - & - & - \\
\hline 60 & 0.89 & - & - & $1.60 \mathrm{E}-02$ & $2.05 \mathrm{E}-03$ & $3.15 \mathrm{E}-05$ & $1.83 \mathrm{E}-04$ \\
\hline 63 & 0.97 & - & - & $1.77 \mathrm{E}-02$ & $2.31 \mathrm{E}-03$ & $3.95 \mathrm{E}-05$ & $2.40 \mathrm{E}-04$ \\
\hline 66 & 1.06 & - & - & $1.80 \mathrm{E}-02$ & $2.26 \mathrm{E}-03$ & $3.76 \mathrm{E}-05$ & $2.22 \mathrm{E}-04$ \\
\hline
\end{tabular}


Table 8.15. (continued). TCU-6 experimental results

\begin{tabular}{|c|c|c|c|c|c|c|c|}
\hline Sample \# & $\begin{array}{c}\text { Accum. Sampling } \\
\text { Time (days) }\end{array}$ & pH & $\mathrm{HCO}_{3}{ }^{-}$ & $\mathbf{N a}$ & $\mathbf{K}$ & Mg & $\mathbf{C a}$ \\
\hline 70 & 128 & - & - & $155 \mathrm{E}-02$ & $196 \mathrm{E}-03$ & $296 \mathrm{E}-05$ & $179 \mathrm{E}-04$ \\
\hline 77 & 1.67 & - & - & $1.42 \mathrm{E}-02$ & $1.74 \mathrm{E}-03$ & $2.74 \mathrm{E}-05$ & $1.60 \mathrm{E}-04$ \\
\hline 83 & 2.00 & - & - & $1.47 \mathrm{E}-02$ & $1.84 \mathrm{E}-03$ & $2.77 \mathrm{E}-05$ & $1.63 \mathrm{E}-04$ \\
\hline 88 & 2.28 & - & $5.54 \mathrm{E}-03$ & - & - & - & - \\
\hline 90 & 2.39 & - & - & $1.56 \mathrm{E}-02$ & $1.97 \mathrm{E}-03$ & $3.14 \mathrm{E}-05$ & $1.74 \mathrm{E}-04$ \\
\hline 96 & 2.72 & - & - & $1.36 \mathrm{E}-02$ & $1.64 \mathrm{E}-03$ & $2.40 \mathrm{E}-05$ & $1.42 \mathrm{E}-04$ \\
\hline 102 & 3.06 & - & - & $1.38 \mathrm{E}-02$ & $1.68 \mathrm{E}-03$ & $2.14 \mathrm{E}-05$ & $1.12 \mathrm{E}-04$ \\
\hline 113 & 4.11 & - & - & $1.26 \mathrm{E}-02$ & $1.53 \mathrm{E}-03$ & $1.47 \mathrm{E}-05$ & $8.30 \mathrm{E}-05$ \\
\hline 118 & 4.59 & - & 4.64E-03 & - & - & - & - \\
\hline 121 & 4.98 & - & - & $1.15 \mathrm{E}-02$ & $1.35 \mathrm{E}-03$ & $1.14 \mathrm{E}-05$ & $6.14 \mathrm{E}-05$ \\
\hline 129 & 6.31 & - & - & $1.11 \mathrm{E}-02$ & $1.30 \mathrm{E}-03$ & $8.65 \mathrm{E}-06$ & 4.99E-05 \\
\hline 138 & 7.81 & - & $4.52 \mathrm{E}-03$ & - & - & - & - \\
\hline \multicolumn{3}{|c|}{ TCU-6 Initial Sorption Solution: } & $3.65 \mathrm{E}-03$ & 4.42E-03 & $1.48 \mathrm{E}-04$ & $2.50 \mathrm{E}-05$ & 9.59E-05 \\
\hline
\end{tabular}

Table 8.16. LCA-1 Experimental run parameters

LCA-1, core depth $=$ ER-6-1 2604.7-2605.7

Porosity: $2.2 \%$, Permeability: $0 . .009 \mathrm{md}$, Bulk density: $2.77 \mathrm{~g} / \mathrm{m}^{3}$

Sorption solution of $\mathrm{NaHCO}_{3}, \mathrm{Ca}, \mathrm{Mg}, \mathrm{K}, \mathrm{Cs}, \mathrm{Sr}, \mathrm{Sm}, \mathrm{U}, \mathrm{Re}, \mathrm{Pu}, \mathrm{Np}$,Tritium

Experiment started on : 6 June 04 16:14

Start pumping sorption solution at: 15 June 04 16:40

Stopped pumping sorption solution at: 16 June 04 9:27

Average flow rate $0.014 \mathrm{~mL} / \mathrm{min}$

Pump and tubing volume (mL): 2.504

Table 8.17. LCA-1 core mineralogy

\begin{tabular}{|c|c|c|}
\hline & calcite & dolomite \\
\hline & \multicolumn{2}{|c|}{ Weight Percent - } \\
\hline LCA-1 & 10.7 & 89.3 \\
\hline
\end{tabular}


Table 8.18. LCA-1 experimental results

\begin{tabular}{|c|c|c|c|c|c|c|c|c|c|c|}
\hline \multirow[t]{2}{*}{$\begin{array}{c}\text { Sample } \\
\#\end{array}$} & \multirow[t]{2}{*}{$\begin{array}{c}\text { Accum. Sampling } \\
\text { Time (days) }\end{array}$} & Tritium & $\mathbf{N p}$ & $\mathbf{R e}$ & $\mathbf{N p}$ & \multirow{2}{*}{$\begin{array}{l}\mathrm{U} \\
\mathrm{C} / \mathrm{C}_{0}\end{array}$} & $\mathbf{P u}$ & $\mathbf{S r}$ & Cs & Sm \\
\hline & & \multicolumn{4}{|c|}{-------- LSC -------- } & & ICP. & ------------ & & - \\
\hline 6 & 0.1 & - & - & $1.62 \mathrm{E}-02$ & 2.09E-02 & $2.75 \mathrm{E}-02$ & - & $2.28 \mathrm{E}-01$ & $5.76 \mathrm{E}-03$ & - \\
\hline 7 & 0.11 & $2.14 \mathrm{E}-02$ & - & - & - & - & - & - & - & - \\
\hline 9 & 0.14 & $4.38 \mathrm{E}-02$ & - & $6.38 \mathrm{E}-02$ & - & $3.12 \mathrm{E}-02$ & - & $2.68 \mathrm{E}-01$ & $4.66 \mathrm{E}-02$ & - \\
\hline 10 & 0.16 & $1.97 \mathrm{E}-01$ & 8.77E-04 & - & - & - & - & - & - & - \\
\hline 12 & 0.19 & - & - & $3.26 \mathrm{E}-01$ & $3.62 \mathrm{E}-02$ & 7.82E-02 & - & $4.83 \mathrm{E}-01$ & $2.76 \mathrm{E}-01$ & - \\
\hline 13 & 0.21 & $2.66 \mathrm{E}-01$ & $3.77 \mathrm{E}-02$ & - & - & - & - & - & - & - \\
\hline 15 & 0.24 & - & - & $3.92 \mathrm{E}-01$ & $1.08 \mathrm{E}-01$ & $1.40 \mathrm{E}-01$ & - & $5.91 \mathrm{E}-01$ & $3.41 \mathrm{E}-01$ & - \\
\hline 16 & 0.25 & $2.92 \mathrm{E}-01$ & $1.08 \mathrm{E}-01$ & - & - & - & - & - & - & - \\
\hline 17 & 0.27 & $3.35 \mathrm{E}-01$ & $1.30 \mathrm{E}-01$ & - & - & - & - & - & - & - \\
\hline 18 & 0.29 & - & - & 4.49E-01 & $2.00 \mathrm{E}-01$ & $2.35 \mathrm{E}-01$ & - & $6.62 \mathrm{E}-01$ & $3.95 \mathrm{E}-01$ & - \\
\hline 19 & 0.3 & $3.65 \mathrm{E}-01$ & $1.77 \mathrm{E}-01$ & - & - & - & - & - & - & - \\
\hline 21.5 & 0.34 & - & - & $5.23 \mathrm{E}-01$ & $2.68 \mathrm{E}-01$ & $2.71 \mathrm{E}-01$ & - & $7.05 \mathrm{E}-01$ & 4.66E-01 & - \\
\hline 22 & 0.35 & $4.28 \mathrm{E}-01$ & $2.53 \mathrm{E}-01$ & - & - & - & - & - & - & - \\
\hline 23 & 0.36 & $4.15 \mathrm{E}-01$ & $2.78 \mathrm{E}-01$ & - & - & - & - & - & - & - \\
\hline 24 & 0.38 & - & - & $5.61 \mathrm{E}-01$ & $3.32 \mathrm{E}-01$ & $3.00 \mathrm{E}-01$ & - & 7.49E-01 & $5.01 \mathrm{E}-01$ & - \\
\hline 25 & 0.4 & $4.85 \mathrm{E}-01$ & $3.03 \mathrm{E}-01$ & - & - & - & - & - & - & - \\
\hline 26 & 0.41 & $4.89 \mathrm{E}-01$ & $3.27 \mathrm{E}-01$ & - & - & - & - & - & - & - \\
\hline 27 & 0.43 & - & - & $6.16 \mathrm{E}-01$ & $3.76 \mathrm{E}-01$ & $3.50 \mathrm{E}-01$ & - & 7.61E-01 & $5.52 \mathrm{E}-01$ & - \\
\hline 28 & 0.44 & $5.09 \mathrm{E}-01$ & $3.76 \mathrm{E}-01$ & - & - & - & - & - & - & - \\
\hline 29 & 0.46 & $5.39 \mathrm{E}-01$ & $3.96 \mathrm{E}-01$ & - & - & - & - & - & - & - \\
\hline 30 & 0.48 & - & - & $6.74 \mathrm{E}-01$ & 4.29E-01 & $4.80 \mathrm{E}-01$ & - & $8.73 \mathrm{E}-01$ & $6.08 \mathrm{E}-01$ & - \\
\hline 31 & 0.49 & $5.53 \mathrm{E}-01$ & $4.27 \mathrm{E}-01$ & - & - & - & - & - & - & - \\
\hline 32 & 0.51 & $5.60 \mathrm{E}-01$ & 4.34E-01 & - & - & - & - & - & - & - \\
\hline 33 & 0.52 & - & - & $6.93 \mathrm{E}-01$ & 4.62E-01 & $5.49 \mathrm{E}-01$ & - & $9.10 \mathrm{E}-01$ & $6.24 \mathrm{E}-01$ & - \\
\hline 35 & 0.56 & $6.06 \mathrm{E}-01$ & $4.51 \mathrm{E}-01$ & - & - & - & - & - & - & - \\
\hline 36 & 0.57 & - & - & $7.26 \mathrm{E}-01$ & $5.15 \mathrm{E}-01$ & $5.35 \mathrm{E}-01$ & - & $9.59 \mathrm{E}-01$ & $6.63 \mathrm{E}-01$ & - \\
\hline 37 & 0.59 & $6.08 \mathrm{E}-01$ & $5.06 \mathrm{E}-01$ & - & - & - & - & - & - & - \\
\hline 47 & 0.79 & $6.27 \mathrm{E}-01$ & 4.98E-01 & - & - & - & - & - & - & - \\
\hline 48 & 0.82 & - & - & 7.64E-01 & $5.78 \mathrm{E}-01$ & 4.13E-01 & - & $9.59 \mathrm{E}-01$ & $6.75 \mathrm{E}-01$ & - \\
\hline 49 & 0.85 & 7.29E-01 & $4.52 \mathrm{E}-01$ & - & - & - & - & - & - & - \\
\hline
\end{tabular}


Table 8.18. (continued). TCU-6 experimental results

\begin{tabular}{|c|c|c|c|c|c|c|c|c|c|c|}
\hline \multirow[t]{2}{*}{ Sample \# } & \multirow[t]{2}{*}{$\begin{array}{c}\text { Accum. } \\
\text { Sampling Time } \\
\text { (days) }\end{array}$} & Tritium & Np & $\mathbf{R e}$ & Np & \multirow{2}{*}{$\begin{array}{r}\mathbf{U} \\
\mathbf{C} / \mathbf{C}_{0}\end{array}$} & $\mathbf{P u}$ & $\mathbf{S r}$ & Cs & \multirow[t]{2}{*}{ Sm } \\
\hline & & \multicolumn{2}{|c|}{------- LSC ------- } & -------- & --------------י & & \multicolumn{3}{|c|}{ ICP-MS } & \\
\hline 51 & 0.9 & $8.05 \mathrm{E}-01$ & $8.02 \mathrm{E}-01$ & $9.39 \mathrm{E}-01$ & $9.01 \mathrm{E}-01$ & $3.46 \mathrm{E}-01$ & - & $1.05 \mathrm{E}+00$ & $8.88 \mathrm{E}-01$ & - \\
\hline 53 & 0.96 & $5.26 \mathrm{E}-01$ & $7.42 \mathrm{E}-01$ & - & - & - & - & - & - & - \\
\hline 54 & 0.99 & - & - & $3.81 \mathrm{E}-01$ & $5.62 \mathrm{E}-01$ & $9.36 \mathrm{E}-01$ & - & $5.75 \mathrm{E}-01$ & $3.55 \mathrm{E}-01$ & - \\
\hline 55 & 1.02 & $1.79 \mathrm{E}-01$ & $3.55 \mathrm{E}-01$ & - & - & - & - & - & - & - \\
\hline 57 & 1.07 & $1.11 \mathrm{E}-01$ & $1.96 \mathrm{E}-01$ & $1.36 \mathrm{E}-01$ & $2.27 \mathrm{E}-01$ & $2.80 \mathrm{E}-01$ & - & $2.37 \mathrm{E}-01$ & $1.33 \mathrm{E}-01$ & - \\
\hline 60 & 1.15 & $1.04 \mathrm{E}-01$ & $1.11 \mathrm{E}-01$ & $1.33 \mathrm{E}-01$ & $1.43 \mathrm{E}-01$ & $1.58 \mathrm{E}-01$ & - & $2.57 \mathrm{E}-01$ & $1.17 \mathrm{E}-01$ & - \\
\hline 64 & 1.27 & $6.37 \mathrm{E}-02$ & $5.15 \mathrm{E}-02$ & $8.11 \mathrm{E}-02$ & 8.54E-02 & 8.89E-02 & - & $1.64 \mathrm{E}-01$ & 7.30E-02 & - \\
\hline 68 & 1.38 & $5.98 \mathrm{E}-02$ & $4.23 \mathrm{E}-02$ & $8.05 \mathrm{E}-02$ & 7.08E-02 & $8.10 \mathrm{E}-02$ & - & $1.73 \mathrm{E}-01$ & $6.99 \mathrm{E}-02$ & - \\
\hline 72 & 1.49 & $4.45 \mathrm{E}-02$ & $5.20 \mathrm{E}-02$ & $6.93 \mathrm{E}-02$ & 8.61E-02 & $9.96 \mathrm{E}-02$ & - & $2.17 \mathrm{E}-01$ & $5.52 \mathrm{E}-02$ & - \\
\hline 76 & 1.6 & $4.52 \mathrm{E}-02$ & $4.38 \mathrm{E}-02$ & $6.52 \mathrm{E}-02$ & 7.18E-02 & $8.05 \mathrm{E}-02$ & - & $1.94 \mathrm{E}-01$ & $5.13 \mathrm{E}-02$ & - \\
\hline 80 & 1.74 & $3.67 \mathrm{E}-02$ & $3.00 \mathrm{E}-02$ & $6.00 \mathrm{E}-02$ & $5.29 \mathrm{E}-02$ & $6.94 \mathrm{E}-02$ & - & $2.07 \mathrm{E}-01$ & 4.62E-02 & - \\
\hline 84 & 1.96 & $2.56 \mathrm{E}-02$ & $2.64 \mathrm{E}-02$ & $3.56 \mathrm{E}-02$ & 3.77E-02 & $4.21 \mathrm{E}-02$ & - & $2.22 \mathrm{E}-01$ & $2.61 \mathrm{E}-02$ & - \\
\hline 88 & 2.18 & $2.03 \mathrm{E}-02$ & 2.91E-02 & $3.18 \mathrm{E}-02$ & $3.44 \mathrm{E}-02$ & 4.75E-02 & - & $2.86 \mathrm{E}-01$ & $2.22 \mathrm{E}-02$ & - \\
\hline 92 & 2.4 & $9.25 \mathrm{E}-03$ & $2.49 \mathrm{E}-02$ & $2.09 \mathrm{E}-02$ & $3.05 \mathrm{E}-02$ & $4.25 \mathrm{E}-02$ & - & $2.32 \mathrm{E}-01$ & $1.51 \mathrm{E}-02$ & - \\
\hline 96 & 2.63 & 4.98E-03 & $1.73 \mathrm{E}-02$ & $1.35 \mathrm{E}-02$ & 2.33E-02 & $3.03 \mathrm{E}-02$ & - & $2.52 \mathrm{E}-01$ & $1.05 \mathrm{E}-02$ & - \\
\hline 100 & 2.8 & $2.85 \mathrm{E}-03$ & $1.08 \mathrm{E}-02$ & 8.32E-03 & $2.06 \mathrm{E}-02$ & $1.67 \mathrm{E}-02$ & - & $1.28 \mathrm{E}-01$ & $7.43 \mathrm{E}-03$ & - \\
\hline 106 & 3.47 & $0.00 \mathrm{E}+00$ & $5.34 \mathrm{E}-03$ & $4.59 \mathrm{E}-03$ & $1.70 \mathrm{E}-02$ & $1.54 \mathrm{E}-02$ & - & $2.33 \mathrm{E}-01$ & $4.51 \mathrm{E}-03$ & - \\
\hline 112 & 4.14 & $3.56 \mathrm{E}-04$ & 8.77E-04 & $2.29 \mathrm{E}-03$ & $1.80 \mathrm{E}-02$ & 7.69E-03 & - & $1.95 \mathrm{E}-01$ & $2.43 \mathrm{E}-03$ & - \\
\hline 118 & 4.8 & $0.00 \mathrm{E}+00$ & $0.00 \mathrm{E}+00$ & - & $1.44 \mathrm{E}-02$ & $4.52 \mathrm{E}-03$ & - & $1.35 \mathrm{E}-01$ & $1.72 \mathrm{E}-03$ & - \\
\hline 124 & 5.47 & $0.00 \mathrm{E}+00$ & $0.00 \mathrm{E}+00$ & $2.29 \mathrm{E}-03$ & $3.93 \mathrm{E}-03$ & 7.69E-03 & - & $3.66 \mathrm{E}-01$ & 2.79E-03 & - \\
\hline 130 & 6.03 & $1.74 \mathrm{E}-02$ & $1.36 \mathrm{E}-02$ & $2.50 \mathrm{E}-02$ & $2.91 \mathrm{E}-02$ & $3.12 \mathrm{E}-02$ & - & $1.83 \mathrm{E}-01$ & $1.89 \mathrm{E}-02$ & - \\
\hline 135 & 6.86 & $1.96 \mathrm{E}-02$ & $0.00 \mathrm{E}+00$ & - & - & - & - & - & - & - \\
\hline 136 & 7.03 & - & - & $3.41 \mathrm{E}-02$ & - & $3.85 \mathrm{E}-02$ & - & $3.08 \mathrm{E}-01$ & $2.60 \mathrm{E}-02$ & - \\
\hline$C_{0}$ Values": & & $2.81 \mathrm{E}+2$ & $2.62 \mathrm{E}+2$ & $1.74 E+3$ & $1.53 \mathrm{E}+3$ & $1.11 E+3$ & 1.62 & $8.13 E+3$ & $1.54 E+4$ & $1.27 E+2$ \\
\hline
\end{tabular}

*: $\mathrm{C}_{0}$ values for LSC are in counts/ hour; $\mathrm{C}_{0}$ values for ICP-MS are in $\mathrm{ng} / \mathrm{mL}$ 
Table 8.18. (continued). LCA-1 experimental results

\begin{tabular}{|c|c|c|c|c|c|c|c|}
\hline Sample \# & $\begin{array}{c}\text { Accum. } \\
\text { Sampling Time } \\
\text { (days) }\end{array}$ & pH & $\mathrm{HCO3}^{-}$ & $\mathbf{N a}$ & $\mathbf{K}$ & Mg & $\mathrm{Ca}$ \\
\hline & & & & & $\mathrm{mol} / \mathrm{L}$ & -- & ------ \\
\hline 5 & 0.08 & - & - & $3.50 \mathrm{E}-03$ & $2.01 \mathrm{E}-03$ & 8.89E-04 & $2.34 \mathrm{E}-03$ \\
\hline 8 & 0.13 & 7.37 & - & - & - & - & - \\
\hline $10-11$ & 0.17 & - & $5.00 \mathrm{E}-03$ & - & - & - & - \\
\hline 14 & 0.22 & 7.33 & - & - & - & - & - \\
\hline 15 & 0.24 & - & - & $3.75 \mathrm{E}-03$ & $2.52 \mathrm{E}-03$ & $9.04 \mathrm{E}-04$ & $3.12 \mathrm{E}-03$ \\
\hline 20 & 0.32 & 7.02 & - & - & - & - & - \\
\hline 26 & 0.41 & - & $1.67 \mathrm{E}-02$ & $3.37 \mathrm{E}-03$ & $2.05 \mathrm{E}-03$ & $8.26 \mathrm{E}-04$ & $2.61 \mathrm{E}-03$ \\
\hline $31-33$ & 0.51 & - & $9.22 \mathrm{E}-03$ & - & - & - & - \\
\hline 34 & 0.54 & 7.63 & - & - & - & - & - \\
\hline 35 & 0.56 & - & - & $3.46 \mathrm{E}-03$ & $2.41 \mathrm{E}-03$ & $8.02 \mathrm{E}-04$ & $2.78 \mathrm{E}-03$ \\
\hline 38 & 0.60 & 8.48 & - & - & - & - & - \\
\hline 48 & 0.82 & 7.86 & - & $3.86 \mathrm{E}-03$ & $2.36 \mathrm{E}-03$ & $9.40 \mathrm{E}-04$ & $3.02 \mathrm{E}-03$ \\
\hline 56 & 1.04 & 8.27 & - & - & - & - & - \\
\hline 58 & 1.10 & - & - & $3.45 \mathrm{E}-03$ & $1.49 \mathrm{E}-03$ & $9.05 \mathrm{E}-04$ & $1.80 \mathrm{E}-03$ \\
\hline 62 & 1.21 & 7.94 & $6.12 \mathrm{E}-03$ & - & - & - & - \\
\hline 68 & 1.38 & - & - & $3.93 \mathrm{E}-03$ & $1.67 \mathrm{E}-03$ & $1.05 \mathrm{E}-03$ & $2.10 \mathrm{E}-03$ \\
\hline 70 & 1.43 & 8.00 & - & - & - & - & - \\
\hline 78 & 1.65 & 7.87 & - & $3.13 \mathrm{E}-03$ & $1.71 \mathrm{E}-03$ & $8.27 \mathrm{E}-04$ & $2.00 \mathrm{E}-03$ \\
\hline 86 & 2.07 & 8.02 & - & - & - & - & - \\
\hline 88 & 2.18 & - & - & $5.06 \mathrm{E}-04$ & $3.69 \mathrm{E}-04$ & $1.13 \mathrm{E}-04$ & 4.47E-04 \\
\hline 94 & 2.52 & 7.68 & - & - & - & - & - \\
\hline 96 & 2.63 & - & $7.98 \mathrm{E}-03$ & - & - & - & - \\
\hline 98 & 2.74 & - & - & $3.59 \mathrm{E}-03$ & $2.18 \mathrm{E}-03$ & $8.86 \mathrm{E}-04$ & $2.74 \mathrm{E}-03$ \\
\hline 108 & 3.69 & - & - & $3.91 \mathrm{E}-03$ & $2.42 \mathrm{E}-03$ & $9.73 \mathrm{E}-04$ & $3.00 \mathrm{E}-03$ \\
\hline 118 & 4.80 & - & - & $3.27 \mathrm{E}-03$ & $1.70 \mathrm{E}-03$ & $8.23 \mathrm{E}-04$ & $2.05 \mathrm{E}-03$ \\
\hline 127 & 5.80 & - & $1.07 \mathrm{E}-02$ & - & - & - & - \\
\hline 128 & 5.91 & - & - & $3.57 \mathrm{E}-03$ & $3.28 \mathrm{E}-03$ & $7.58 \mathrm{E}-04$ & $3.69 \mathrm{E}-03$ \\
\hline \multicolumn{3}{|c|}{ LCA-1 Initial Sorption Solution: } & $5.47 E-04$ & 2.35E-03 & 2.23E-04 & 6.87E-04 & 4.61E-04 \\
\hline
\end{tabular}


Table 8.19. LCA-2 experimental run parameters

LCA-2, core depth $=$ ER-6-1 2732.2-2733.1

Porosity: $1.6 \%$, Permeability: $0 . .043 \mathrm{md}$, Bulk density: $2.79 \mathrm{~g} / \mathrm{m}^{3}$

Sorption solution of $\mathrm{NaHCO}_{3}, \mathrm{Ca}, \mathrm{Mg}, \mathrm{K}, \mathrm{Cs}, \mathrm{Sr}, \mathrm{Sm}, \mathrm{U}, \mathrm{Re}, \mathrm{Pu}, \mathrm{Np}$, Tritium

Experiment started on : 12 July 04 15:33

Start pumping sorption solution at: 20July 04 16:29

Stopped pumping sorption solution at: 21 July 04 9:12

Average flow rate $0.0215 \mathrm{~mL} / \mathrm{min}$

Pump and tubing volume (mL): 2.149

Table 8.20. LCA-2 core mineralogy

\begin{tabular}{ccc}
\hline & \multicolumn{3}{c}{ calcite } & dolomite \\
& --- Weight Percent & --- \\
\hline LCA-2 & 17.3 & 82.8 \\
\hline
\end{tabular}

Table 8.21. LCA-2 experimental results

\begin{tabular}{|c|c|c|c|c|c|c|c|c|c|c|}
\hline \multirow[t]{2}{*}{$\begin{array}{c}\text { Sample } \\
\#\end{array}$} & \multirow[t]{2}{*}{$\begin{array}{c}\text { Accum. Sampling } \\
\text { Time (days) }\end{array}$} & Tritium & Np & $\mathbf{R e}$ & Np & \multirow{2}{*}{$\begin{array}{r}\mathbf{U} \\
\mathrm{C} / \mathbf{C}_{\mathbf{0}}\end{array}$} & \multirow{2}{*}{\multicolumn{2}{|c|}{$\mathbf{P u}$}} & \multirow[t]{2}{*}{ Cs } & \multirow{2}{*}{ Sm } \\
\hline & & \multicolumn{4}{|c|}{--- LSC - - } & & & & & \\
\hline 5 & 0.07 & $1.81 \mathrm{E}-03$ & $8.76 \mathrm{E}-04$ & - & - & - & - & - & - & - \\
\hline 6 & 0.08 & - & - & - & - & $8.36 \mathrm{E}-04$ & - & $7.08 \mathrm{E}-03$ & - & - \\
\hline 9 & 0.13 & - & - & - & - & $4.42 \mathrm{E}-04$ & - & 7.49E-03 & - & - \\
\hline 12 & 0.17 & - & - & - & - & $1.87 \mathrm{E}-03$ & - & $1.19 \mathrm{E}-02$ & - & - \\
\hline 15 & 0.21 & - & - & - & - & $6.39 \mathrm{E}-04$ & - & $9.34 \mathrm{E}-03$ & - & - \\
\hline 17 & 0.24 & $1.69 \mathrm{E}-01$ & 2.09E-01 & - & - & - & - & - & - & - \\
\hline 18 & 0.25 & - & - & $4.51 \mathrm{E}-01$ & $5.41 \mathrm{E}-05$ & $9.34 \mathrm{E}-04$ & $1.36 \mathrm{E}-02$ & $3.81 \mathrm{E}-01$ & $3.35 \mathrm{E}-01$ & - \\
\hline 19 & 0.26 & 4.01E-01 & $5.00 \mathrm{E}-01$ & - & - & - & - & - & - & - \\
\hline 21 & 0.29 & $4.96 \mathrm{E}-01$ & $6.13 \mathrm{E}-01$ & $7.23 \mathrm{E}-01$ & $6.57 \mathrm{E}-04$ & $1.18 \mathrm{E}-03$ & $3.07 \mathrm{E}-02$ & $7.01 \mathrm{E}-01$ & $6.14 \mathrm{E}-01$ & - \\
\hline 23 & 0.32 & 5.38E-01 & $6.67 \mathrm{E}-01$ & - & - & - & - & - & - & - \\
\hline 24 & 0.33 & - & - & 8.01E-01 & $5.84 \mathrm{E}-02$ & $4.82 \mathrm{E}-02$ & $9.60 \mathrm{E}-02$ & $7.81 \mathrm{E}-01$ & $7.02 \mathrm{E}-01$ & - \\
\hline
\end{tabular}


Table 8.21. (continued). LCA-2 experimental results

\begin{tabular}{|c|c|c|c|c|c|c|c|c|c|c|}
\hline \multirow[t]{2}{*}{$\begin{array}{c}\text { Sample } \\
\#\end{array}$} & \multirow[t]{2}{*}{$\begin{array}{l}\text { Accum. Sampling } \\
\text { Time (days) }\end{array}$} & Tritium & $\mathbf{N p}$ & $\mathbf{R e}$ & $\mathbf{N p}$ & \multirow{2}{*}{$\begin{array}{r}\mathrm{U} \\
\mathrm{C} / \mathrm{C}_{0}\end{array}$} & \multirow{2}{*}{$\begin{array}{c}\mathrm{Pu} \\
--\mathrm{ICP}-\mathrm{MS} \\
\end{array}$} & \multirow[t]{2}{*}{$\mathrm{Sr}$} & \multirow[t]{2}{*}{ Cs } & \multirow[t]{2}{*}{ Sm } \\
\hline & & \multicolumn{4}{|c|}{-------- LSC -------- } & & & & & \\
\hline 25 & 0.35 & $5.85 \mathrm{E}-01$ & $7.30 \mathrm{E}-01$ & - & - & - & - & - & - & - \\
\hline 27 & 0.38 & $6.00 \mathrm{E}-01$ & $7.43 \mathrm{E}-01$ & $8.68 \mathrm{E}-01$ & $2.08 \mathrm{E}-01$ & $2.05 \mathrm{E}-01$ & $1.75 \mathrm{E}-01$ & $8.44 \mathrm{E}-01$ & 8.17E-01 & - \\
\hline 29 & 0.40 & $6.50 \mathrm{E}-01$ & $8.04 \mathrm{E}-01$ & - & - & - & - & - & - & - \\
\hline 30 & 0.42 & - & - & $9.11 \mathrm{E}-01$ & 3.32E-01 & $3.92 \mathrm{E}-01$ & $1.94 \mathrm{E}-01$ & $8.84 \mathrm{E}-01$ & $8.85 \mathrm{E}-01$ & - \\
\hline 31 & 0.43 & $6.54 \mathrm{E}-01$ & $8.11 \mathrm{E}-01$ & - & - & - & - & - & - & - \\
\hline 33 & 0.46 & $6.75 \mathrm{E}-01$ & $8.38 \mathrm{E}-01$ & $9.16 \mathrm{E}-01$ & $4.45 \mathrm{E}-01$ & $5.16 \mathrm{E}-01$ & $2.00 \mathrm{E}-01$ & $9.02 \mathrm{E}-01$ & 8.81E-01 & - \\
\hline 35 & 0.49 & $6.86 \mathrm{E}-01$ & 8.49E-01 & - & - & - & - & - & - & - \\
\hline 36 & 0.50 & - & - & $9.23 \mathrm{E}-01$ & $5.41 \mathrm{E}-01$ & $6.18 \mathrm{E}-01$ & $2.05 \mathrm{E}-01$ & $9.09 \mathrm{E}-01$ & 8.97E-01 & - \\
\hline 37 & 0.51 & $6.83 \mathrm{E}-01$ & $8.46 \mathrm{E}-01$ & - & - & - & - & - & - & - \\
\hline 39 & 0.54 & $6.97 \mathrm{E}-01$ & $8.66 \mathrm{E}-01$ & $9.25 \mathrm{E}-01$ & $6.09 \mathrm{E}-01$ & $6.93 \mathrm{E}-01$ & $1.94 \mathrm{E}-01$ & $9.06 \mathrm{E}-01$ & $9.06 \mathrm{E}-01$ & $3.67 \mathrm{E}-03$ \\
\hline 41 & 0.57 & $6.95 \mathrm{E}-01$ & $8.64 \mathrm{E}-01$ & - & - & - & - & - & - & - \\
\hline 42 & 0.58 & - & - & $9.28 \mathrm{E}-01$ & $6.57 \mathrm{E}-01$ & $6.93 \mathrm{E}-01$ & $1.92 \mathrm{E}-01$ & $9.06 \mathrm{E}-01$ & $9.13 \mathrm{E}-01$ & $4.08 \mathrm{E}-03$ \\
\hline 43 & 0.60 & $6.96 \mathrm{E}-01$ & $8.66 \mathrm{E}-01$ & - & - & - & - & - & - & - \\
\hline 45 & 0.63 & $7.08 \mathrm{E}-01$ & $8.78 \mathrm{E}-01$ & $9.64 \mathrm{E}-01$ & $7.50 \mathrm{E}-01$ & $7.32 \mathrm{E}-01$ & $1.80 \mathrm{E}-01$ & $9.94 \mathrm{E}-01$ & $9.71 \mathrm{E}-01$ & $7.74 \mathrm{E}-03$ \\
\hline 47 & 0.65 & $7.15 \mathrm{E}-01$ & $8.84 \mathrm{E}-01$ & - & - & - & - & - & - & - \\
\hline 48 & 0.67 & - & - & $9.87 \mathrm{E}-01$ & $8.12 \mathrm{E}-01$ & $8.21 \mathrm{E}-01$ & $2.00 \mathrm{E}-01$ & $1.01 \mathrm{E}+00$ & $9.75 \mathrm{E}-01$ & $6.93 \mathrm{E}-03$ \\
\hline 49 & 0.68 & $7.20 \mathrm{E}-01$ & 8.99E-01 & - & - & - & - & - & - & - \\
\hline 51 & 0.71 & $7.20 \mathrm{E}-01$ & 8.93E-01 & $9.73 \mathrm{E}-01$ & $8.20 \mathrm{E}-01$ & 8.31E-01 & $1.96 \mathrm{E}-01$ & $1.01 \mathrm{E}+00$ & $9.81 \mathrm{E}-01$ & - \\
\hline 53 & 0.76 & $7.28 \mathrm{E}-01$ & $9.01 \mathrm{E}-01$ & - & - & - & - & - & - & - \\
\hline 54 & 0.79 & - & - & $9.64 \mathrm{E}-01$ & $8.47 \mathrm{E}-01$ & 8.79E-01 & $1.77 \mathrm{E}-01$ & $9.87 \mathrm{E}-01$ & $9.71 \mathrm{E}-01$ & $9.78 \mathrm{E}-03$ \\
\hline 55 & 0.82 & $7.40 \mathrm{E}-01$ & $9.12 \mathrm{E}-01$ & - & - & - & - & - & - & - \\
\hline 57 & 0.87 & $3.48 \mathrm{E}-02$ & $3.50 \mathrm{E}-02$ & $6.20 \mathrm{E}-01$ & $8.47 \mathrm{E}-01$ & 8.31E-01 & $1.48 \mathrm{E}-01$ & $7.36 \mathrm{E}-01$ & 7.07E-01 & $4.48 \mathrm{E}-03$ \\
\hline 60 & 0.96 & 9.84E-02 & $1.20 \mathrm{E}-01$ & $9.50 \mathrm{E}-02$ & $4.06 \mathrm{E}-01$ & $6.19 \mathrm{E}-01$ & $2.73 \mathrm{E}-02$ & $1.12 \mathrm{E}-01$ & $1.62 \mathrm{E}-01$ & $9.78 \mathrm{E}-03$ \\
\hline 64 & 1.07 & $6.07 \mathrm{E}-02$ & $7.53 \mathrm{E}-02$ & $6.26 \mathrm{E}-02$ & 2.19E-01 & $3.22 \mathrm{E}-01$ & - & $6.61 \mathrm{E}-02$ & $1.01 \mathrm{E}-01$ & - \\
\hline 68 & 1.18 & 4.94E-02 & $6.07 \mathrm{E}-02$ & $5.44 \mathrm{E}-02$ & $1.40 \mathrm{E}-01$ & $1.76 \mathrm{E}-01$ & - & $5.82 \mathrm{E}-02$ & $8.13 \mathrm{E}-02$ & $1.02 \mathrm{E}-02$ \\
\hline 72 & 1.29 & $3.77 \mathrm{E}-02$ & 4.73E-02 & 4.37E-02 & $1.03 \mathrm{E}-01$ & $1.21 \mathrm{E}-01$ & - & 4.99E-02 & $6.27 \mathrm{E}-02$ & $1.06 \mathrm{E}-02$ \\
\hline 76 & 1.40 & $3.59 \mathrm{E}-02$ & $4.41 \mathrm{E}-02$ & $3.86 \mathrm{E}-02$ & $8.12 \mathrm{E}-02$ & $9.98 \mathrm{E}-02$ & - & 4.49E-02 & $5.38 \mathrm{E}-02$ & $1.22 \mathrm{E}-02$ \\
\hline 80 & 1.51 & $2.66 \mathrm{E}-02$ & $3.21 \mathrm{E}-02$ & 3.33E-02 & $6.61 \mathrm{E}-02$ & $7.96 \mathrm{E}-02$ & - & 4.09E-02 & $4.66 \mathrm{E}-02$ & $1.10 \mathrm{E}-02$ \\
\hline
\end{tabular}


Table 8.21. (continued). LCA-2 experimental results

\begin{tabular}{|c|c|c|c|c|c|c|c|c|c|c|}
\hline \multirow[t]{2}{*}{ Sample \# } & \multirow[t]{2}{*}{$\begin{array}{l}\text { Accum. Sampling } \\
\text { Time (days) }\end{array}$} & Tritium & $\mathbf{N p}$ & $\mathbf{R e}$ & $\mathbf{N p}$ & \multirow{2}{*}{$\begin{array}{c}\mathrm{U} \\
\mathrm{C} / \mathrm{C}_{0} \\
-\end{array}$} & $\mathbf{P u}$ & Sr & Cs & \multirow[t]{2}{*}{ Sm } \\
\hline & & \multicolumn{2}{|c|}{-------- LSC -------- } & \multicolumn{3}{|c|}{ - } & & & & \\
\hline 88 & 1.79 & $1.87 \mathrm{E}-02$ & $2.22 \mathrm{E}-02$ & $2.08 \mathrm{E}-02$ & 4.10E-02 & $4.58 \mathrm{E}-02$ & - & $2.90 \mathrm{E}-02$ & $2.80 \mathrm{E}-02$ & $1.35 \mathrm{E}-02$ \\
\hline 92 & 2.01 & $1.37 \mathrm{E}-02$ & $1.66 \mathrm{E}-02$ & $1.64 \mathrm{E}-02$ & $3.32 \mathrm{E}-02$ & $3.75 \mathrm{E}-02$ & - & $2.53 \mathrm{E}-02$ & $2.26 \mathrm{E}-02$ & $1.47 \mathrm{E}-02$ \\
\hline 96 & 2.21 & $1.02 \mathrm{E}-02$ & $1.17 \mathrm{E}-02$ & $1.43 \mathrm{E}-02$ & $2.83 \mathrm{E}-02$ & $3.34 \mathrm{E}-02$ & - & $2.36 \mathrm{E}-02$ & $1.95 \mathrm{E}-02$ & $1.30 \mathrm{E}-02$ \\
\hline 107 & 2.83 & $5.84 \mathrm{E}-03$ & $7.59 \mathrm{E}-03$ & $9.53 \mathrm{E}-03$ & $1.50 \mathrm{E}-02$ & 2.39E-02 & - & $1.91 \mathrm{E}-02$ & $1.26 \mathrm{E}-02$ & $1.22 \mathrm{E}-02$ \\
\hline 112 & 3.10 & $3.50 \mathrm{E}-03$ & 4.67E-03 & $7.05 \mathrm{E}-03$ & $1.28 \mathrm{E}-02$ & $1.92 \mathrm{E}-02$ & - & $1.62 \mathrm{E}-02$ & $9.57 \mathrm{E}-03$ & $1.43 \mathrm{E}-02$ \\
\hline 118 & 3.44 & $2.63 \mathrm{E}-03$ & $3.21 \mathrm{E}-03$ & $5.02 \mathrm{E}-03$ & $1.20 \mathrm{E}-02$ & $1.47 \mathrm{E}-02$ & - & $1.33 \mathrm{E}-02$ & $6.83 \mathrm{E}-03$ & $1.30 \mathrm{E}-02$ \\
\hline 124 & 3.14 & $2.63 \mathrm{E}-03$ & $3.50 \mathrm{E}-03$ & $5.47 \mathrm{E}-03$ & $9.28 \mathrm{E}-03$ & $1.42 \mathrm{E}-02$ & - & $1.56 \mathrm{E}-02$ & $6.88 \mathrm{E}-03$ & $1.30 \mathrm{E}-02$ \\
\hline 130 & 3.42 & $2.34 \mathrm{E}-03$ & $2.63 \mathrm{E}-03$ & $3.27 \mathrm{E}-03$ & $8.20 \mathrm{E}-03$ & $1.15 \mathrm{E}-02$ & - & 1.17E-02 & $4.42 \mathrm{E}-03$ & $1.26 \mathrm{E}-02$ \\
\hline 136 & 3.70 & 2.63E-03 & $2.63 \mathrm{E}-03$ & $3.38 \mathrm{E}-03$ & $6.11 \mathrm{E}-03$ & $1.08 \mathrm{E}-02$ & - & $1.28 \mathrm{E}-02$ & 4.33E-03 & $1.35 \mathrm{E}-02$ \\
\hline 142 & 3.98 & $2.34 \mathrm{E}-03$ & $2.34 \mathrm{E}-03$ & $2.88 \mathrm{E}-03$ & $5.34 \mathrm{E}-03$ & $1.12 \mathrm{E}-02$ & - & $1.19 \mathrm{E}-02$ & $3.73 \mathrm{E}-03$ & $1.26 \mathrm{E}-02$ \\
\hline 154 & 5.44 & $2.92 \mathrm{E}-03$ & $3.21 \mathrm{E}-03$ & $1.97 \mathrm{E}-03$ & $5.10 \mathrm{E}-03$ & 7.91E-03 & - & $9.47 \mathrm{E}-03$ & $2.55 \mathrm{E}-03$ & - \\
\hline 160 & 5.77 & $2.04 \mathrm{E}-03$ & $2.63 \mathrm{E}-03$ & $1.55 \mathrm{E}-03$ & $5.10 \mathrm{E}-03$ & $6.34 \mathrm{E}-03$ & - & $8.42 \mathrm{E}-03$ & 2.19E-03 & - \\
\hline 166 & 6.44 & $8.76 \mathrm{E}-04$ & $1.17 \mathrm{E}-03$ & $1.18 \mathrm{E}-03$ & 5.37E-03 & $5.60 \mathrm{E}-03$ & - & $8.42 \mathrm{E}-03$ & $1.61 \mathrm{E}-03$ & - \\
\hline 172 & 7.10 & $2.04 \mathrm{E}-03$ & $1.75 \mathrm{E}-03$ & $8.46 \mathrm{E}-04$ & $6.30 \mathrm{E}-03$ & $4.47 \mathrm{E}-03$ & - & 7.49E-03 & $1.11 \mathrm{E}-03$ & - \\
\hline 178 & 7.77 & 1.17E-03 & $1.46 \mathrm{E}-03$ & - & - & - & - & - & - & - \\
\hline 184 & 8.44 & - & - & - & $6.30 \mathrm{E}-03$ & $3.88 \mathrm{E}-03$ & - & 7.27E-03 & $1.06 \mathrm{E}-03$ & - \\
\hline 190 & 9.10 & - & $5.84 \mathrm{E}-04$ & $5.08 \mathrm{E}-04$ & $6.34 \mathrm{E}-03$ & $3.49 \mathrm{E}-03$ & - & $7.08 \mathrm{E}-03$ & 7.12E-04 & - \\
\hline 196 & 9.77 & $8.76 \mathrm{E}-04$ & $5.84 \mathrm{E}-04$ & - & $5.22 \mathrm{E}-03$ & $2.56 \mathrm{E}-03$ & - & $6.40 \mathrm{E}-03$ & 4.33E-04 & - \\
\hline $\mathrm{C}_{0}$ Values ${ }^{*}$ : & & $2.76 \mathrm{E}+02$ & $3.42 \mathrm{E}+02$ & $1.77 E+03$ & $1.29 \mathrm{E}+03$ & $1.02 \mathrm{E}+03$ & $1.30 \mathrm{E}+00$ & $7.34 \mathrm{E}+03$ & $1.04 E+04$ & $1.23 E+02$ \\
\hline
\end{tabular}

*: $\mathrm{C}_{0}$ values for LSC are in counts/ hour; $\mathrm{C}_{0}$ values for ICP-MS are in $\mathrm{ng} / \mathrm{mL}$ 
Table 8.21. (continued). LCA-2 experimental results

\begin{tabular}{|c|c|c|c|c|c|c|c|}
\hline Sample \# & $\begin{array}{c}\text { Accum. Sampling } \\
\text { Time (days) }\end{array}$ & pH & $\mathrm{HCO3}^{-}$ & $\mathrm{Na}$ & $\mathbf{K}$ & Mg & $\mathrm{Ca}$ \\
\hline 5 & 0.07 & - & - & $2.72 \mathrm{E}-03$ & $3.45 \mathrm{E}-04$ & $8.35 \mathrm{E}-04$ & $1.52 \mathrm{E}-03$ \\
\hline 8 & 0.11 & 8.24 & - & - & - & - & - \\
\hline 13 & 0.18 & - & - & $2.73 \mathrm{E}-03$ & $3.68 \mathrm{E}-04$ & $9.43 \mathrm{E}-04$ & $1.76 \mathrm{E}-03$ \\
\hline 14 & 0.19 & 8.40 & - & - & - & - & - \\
\hline 20 & 0.28 & 8.38 & - & - & - & - & - \\
\hline 22 & 0.31 & - & - & $3.01 \mathrm{E}-03$ & $3.52 \mathrm{E}-04$ & $8.68 \mathrm{E}-04$ & $1.62 \mathrm{E}-03$ \\
\hline 26 & 0.36 & 8.33 & - & - & - & - & - \\
\hline 30 & 0.42 & - & - & $3.08 \mathrm{E}-03$ & $3.49 \mathrm{E}-04$ & $8.48 \mathrm{E}-04$ & $1.58 \mathrm{E}-03$ \\
\hline 32 & 0.44 & 8.28 & - & - & - & - & - \\
\hline 38 & 0.53 & - & - & $3.08 \mathrm{E}-03$ & - & 8.37E-04 & $1.56 \mathrm{E}-03$ \\
\hline 44 & 0.61 & 8.14 & - & - & - & - & - \\
\hline 46 & 0.64 & - & - & 2.99E-03 & $3.28 \mathrm{E}-04$ & $7.41 \mathrm{E}-04$ & $1.35 \mathrm{E}-03$ \\
\hline 50 & 0.69 & 7.81 & - & - & - & - & - \\
\hline 54 & 0.79 & - & - & $2.88 \mathrm{E}-03$ & $3.17 \mathrm{E}-04$ & 7.52E-04 & $1.38 \mathrm{E}-03$ \\
\hline 56 & 0.85 & 8.05 & - & - & - & - & - \\
\hline 62 & 1.01 & 8.10 & - & - & - & - & - \\
\hline 64 & 1.07 & - & - & $2.63 \mathrm{E}-03$ & $3.29 \mathrm{E}-04$ & $8.07 \mathrm{E}-04$ & $1.47 \mathrm{E}-03$ \\
\hline 68 & 1.18 & 8.28 & - & - & - & - & - \\
\hline $69-71$ & 1.23 & - & $1.47 \mathrm{E}-03$ & - & - & - & - \\
\hline 72 & 1.29 & - & - & $2.73 \mathrm{E}-03$ & $3.37 \mathrm{E}-04$ & $8.46 \mathrm{E}-04$ & $1.56 \mathrm{E}-03$ \\
\hline 76 & 1.40 & 8.20 & - & - & - & - & - \\
\hline 83 & 1.60 & - & - & $2.55 \mathrm{E}-03$ & $3.14 \mathrm{E}-04$ & $7.86 \mathrm{E}-04$ & $1.46 \mathrm{E}-03$ \\
\hline 85 & 1.65 & 7.91 & - & - & - & - & - \\
\hline 96 & 2.21 & - & - & $2.54 \mathrm{E}-03$ & $3.12 \mathrm{E}-04$ & 7.89E-04 & $1.49 \mathrm{E}-03$ \\
\hline 108 & 2.88 & - & - & $2.68 \mathrm{E}-03$ & $3.35 \mathrm{E}-04$ & $8.35 \mathrm{E}-04$ & $1.59 \mathrm{E}-03$ \\
\hline $115-116$ & 3.30 & - & $1.37 \mathrm{E}-03$ & - & - & - & - \\
\hline 119 & 3.49 & - & - & $2.67 \mathrm{E}-03$ & $3.29 \mathrm{E}-04$ & $8.31 \mathrm{E}-04$ & $1.58 \mathrm{E}-03$ \\
\hline 132 & 4.21 & - & - & $2.48 \mathrm{E}-03$ & $3.04 \mathrm{E}-04$ & 7.64E-04 & $1.46 \mathrm{E}-03$ \\
\hline 144 & 4.88 & - & - & $2.61 \mathrm{E}-03$ & $3.23 \mathrm{E}-04$ & 8.18E-04 & $1.59 \mathrm{E}-03$ \\
\hline 150 & 5.21 & - & $9.13 \mathrm{E}-04$ & - & - & - & - \\
\hline 119 & 3.49 & - & - & $2.67 \mathrm{E}-03$ & $3.29 \mathrm{E}-04$ & $8.31 \mathrm{E}-04$ & $1.58 \mathrm{E}-03$ \\
\hline
\end{tabular}


Table 8.21. (continued). LCA-2 experimental results

\begin{tabular}{|c|c|c|c|c|c|c|c|}
\hline Sample \# & $\begin{array}{c}\text { Accum. Sampling } \\
\text { Time (days) }\end{array}$ & pH & $\mathrm{HCO3}^{-}$ & $\mathrm{Na}$ & $\mathbf{K}$ & Mg & $\mathbf{C a}$ \\
\hline & & & & & $\mathrm{mol} / \mathrm{L}$ & ----- & -------- \\
\hline 156 & 5.55 & - & - & $2.61 \mathrm{E}-03$ & $3.36 \mathrm{E}-04$ & 7.97E-04 & $1.55 \mathrm{E}-03$ \\
\hline 168 & 6.66 & - & - & $2.64 \mathrm{E}-03$ & 3.31E-04 & 8.41E-04 & $1.68 \mathrm{E}-03$ \\
\hline 180 & 7.99 & - & - & $2.58 \mathrm{E}-03$ & $3.06 \mathrm{E}-04$ & 7.87E-04 & $1.48 \mathrm{E}-03$ \\
\hline 192 & 9.33 & - & - & $2.53 \mathrm{E}-03$ & $3.00 \mathrm{E}-04$ & 7.87E-04 & $1.49 \mathrm{E}-03$ \\
\hline 196 & 9.77 & - & $1.10 \mathrm{E}-03$ & - & - & - & - \\
\hline LCA-2 Initia & Sorption Solution: & 7.93 & $2.35 \mathrm{E}-04$ & $2.95 \mathrm{E}-03$ & $2.79 \mathrm{E}-04$ & $6.50 \mathrm{E}-04$ & 9.88E-04 \\
\hline
\end{tabular}

Table 8.22. LCA-3 experimental run parameters

LCA-3, core depth $=$ ER-6-1 2552.1-2553.1

Porosity: $1.7 \%$, Permeability: $0.002 \mathrm{md}$, Density: $2.80 \mathrm{~g} / \mathrm{m}^{3}$

Sorption solution of $\mathrm{NaHCO}_{3}, \mathrm{Ca}, \mathrm{Mg}, \mathrm{K}, \mathrm{Cs}, \mathrm{Sr}, \mathrm{Sm}, \mathrm{U}, \mathrm{Re}, \mathrm{Pu}, \mathrm{Np}$, Tritium

Experiment started on : 4 August 04 17:50

Start pumping sorption solution at: 11 August 18:45

Stopped pumping sorption solution at: 12 August 11:26

Average flow rate $0.0194 \mathrm{~mL} / \mathrm{min}$

Pump and tubing volume (mL): 2.015

Table 8.23. LCA-3 core mineralogy calcite dolomite --- Weight Percent ---

$\begin{array}{lll}\text { LCA-3 } & 12.7 & 87.3\end{array}$

Table 8.24. LCA-3 experimental results

\begin{tabular}{|c|c|c|c|c|c|c|c|c|c|c|}
\hline \multirow[t]{2}{*}{$\begin{array}{c}\text { Sample } \\
\#\end{array}$} & \multirow[t]{2}{*}{$\begin{array}{l}\text { Accum. Sampling } \\
\text { Time (days) }\end{array}$} & Tritium & Np & $\mathbf{R e}$ & Np & \multirow{2}{*}{$\begin{array}{c}\mathrm{U} \\
\mathrm{C} / \mathrm{C}\end{array}$} & $\mathbf{P u}$ & Sr & Cs & \multirow[t]{2}{*}{ Sm } \\
\hline & & -------- L & -------- & - & 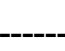 & & -- ICP-MS & ----- & ------------- & \\
\hline 5 & 0.07 & $5.92 \mathrm{E}-03$ & - & - & - & - & - & - & - & - \\
\hline 6 & 0.08 & - & - & $2.29 \mathrm{E}-04$ & - & - & 4.22E-03 & $2.22 \mathrm{E}-03$ & $1.03 \mathrm{E}-04$ & - \\
\hline 7 & 0.10 & $1.62 \mathrm{E}-01$ & - & - & - & - & - & - & - & - \\
\hline 9 & 0.13 & 4.39E-01 & - & $6.21 \mathrm{E}-03$ & - & - & $2.75 \mathrm{E}-03$ & $5.24 \mathrm{E}-03$ & $6.25 \mathrm{E}-04$ & - \\
\hline
\end{tabular}


Table 8.24. (continued). LCA-3 experimental results

\begin{tabular}{|c|c|c|c|c|c|c|c|c|c|c|}
\hline \multirow[t]{2}{*}{$\begin{array}{c}\text { Sample } \\
\#\end{array}$} & \multirow[t]{2}{*}{$\begin{array}{l}\text { Accum. Sampling } \\
\text { Time (days) }\end{array}$} & Tritium & $\mathbf{N p}$ & $\mathbf{R e}$ & $\mathbf{N p}$ & \multirow{2}{*}{$\begin{array}{c}\mathbf{U} \\
\mathrm{C} / \mathrm{C}_{0}\end{array}$} & $\mathbf{P u}$ & $\mathbf{S r}$ & Cs & \multirow[t]{2}{*}{ Sm } \\
\hline & & \multicolumn{2}{|c|}{-------- LSC -------- } & $--\cdot$ & $---\cdot$ & & --- ICP-MS & ---------- & ------------- & \\
\hline 11 & 0.15 & $5.57 \mathrm{E}-01$ & - & - & - & - & - & - & - & - \\
\hline 12 & 0.17 & - & - & $3.49 \mathrm{E}-01$ & $6.48 \mathrm{E}-04$ & - & $1.52 \mathrm{E}-02$ & $3.18 \mathrm{E}-01$ & $2.43 \mathrm{E}-01$ & - \\
\hline 13 & 0.18 & $6.67 \mathrm{E}-01$ & $2.24 \mathrm{E}-03$ & - & - & - & - & - & - & - \\
\hline 15 & 0.21 & $7.13 \mathrm{E}-01$ & $6.46 \mathrm{E}-02$ & $6.21 \mathrm{E}-01$ & 4.54E-02 & - & $1.64 \mathrm{E}-01$ & $6.15 \mathrm{E}-01$ & $5.60 \mathrm{E}-01$ & - \\
\hline 17 & 0.24 & $7.31 \mathrm{E}-01$ & $1.71 \mathrm{E}-01$ & - & - & - & - & - & - & - \\
\hline 18 & 0.25 & - & - & $7.21 \mathrm{E}-01$ & $1.93 \mathrm{E}-01$ & $2.70 \mathrm{E}-02$ & $3.06 \mathrm{E}-01$ & 7.15E-01 & $6.78 \mathrm{E}-01$ & - \\
\hline 19 & 0.26 & $7.97 \mathrm{E}-01$ & $2.75 \mathrm{E}-01$ & - & - & - & - & - & - & - \\
\hline 21 & 0.29 & $8.10 \mathrm{E}-01$ & 3.39E-01 & $7.71 \mathrm{E}-01$ & $3.17 \mathrm{E}-01$ & $2.19 \mathrm{E}-01$ & $3.77 \mathrm{E}-01$ & 7.68E-01 & $7.40 \mathrm{E}-01$ & - \\
\hline 23 & 0.32 & $8.04 \mathrm{E}-01$ & $4.25 \mathrm{E}-01$ & - & - & - & - & - & - & - \\
\hline 24 & 0.33 & - & - & $7.91 \mathrm{E}-01$ & $4.05 \mathrm{E}-01$ & $3.54 \mathrm{E}-01$ & 4.12E-01 & 7.91E-01 & 7.64E-01 & - \\
\hline 25 & 0.35 & $8.55 \mathrm{E}-01$ & $4.73 \mathrm{E}-01$ & - & - & - & - & - & - & - \\
\hline 27 & 0.38 & $8.75 \mathrm{E}-01$ & $5.08 \mathrm{E}-01$ & $8.20 \mathrm{E}-01$ & $4.82 \mathrm{E}-01$ & $4.38 \mathrm{E}-01$ & $4.41 \mathrm{E}-01$ & $8.26 \mathrm{E}-01$ & $8.00 \mathrm{E}-01$ & - \\
\hline 29 & 0.40 & 8.49E-01 & $5.76 \mathrm{E}-01$ & - & - & - & - & - & - & - \\
\hline 30 & 0.42 & - & - & $8.33 \mathrm{E}-01$ & $5.27 \mathrm{E}-01$ & $5.07 \mathrm{E}-01$ & $4.52 \mathrm{E}-01$ & $8.36 \mathrm{E}-01$ & $8.13 \mathrm{E}-01$ & - \\
\hline 31 & 0.43 & 8.91E-01 & 5.99E-01 & - & - & - & - & - & - & - \\
\hline 33 & 0.46 & $9.15 \mathrm{E}-01$ & $5.90 \mathrm{E}-01$ & $8.36 \mathrm{E}-01$ & $5.75 \mathrm{E}-01$ & $5.49 \mathrm{E}-01$ & $4.64 \mathrm{E}-01$ & $8.41 \mathrm{E}-01$ & $8.17 \mathrm{E}-01$ & - \\
\hline 35 & 0.49 & $8.83 \mathrm{E}-01$ & $6.77 \mathrm{E}-01$ & - & - & - & - & - & - & - \\
\hline 36 & 0.50 & - & - & 7.97E-01 & $5.83 \mathrm{E}-01$ & $5.24 \mathrm{E}-01$ & $4.55 \mathrm{E}-01$ & 8.04E-01 & $7.84 \mathrm{E}-01$ & - \\
\hline 37 & 0.51 & $9.08 \mathrm{E}-01$ & $6.99 \mathrm{E}-01$ & - & - & - & - & - & - & - \\
\hline 39 & 0.54 & $9.36 \mathrm{E}-01$ & $6.92 \mathrm{E}-01$ & $8.40 \mathrm{E}-01$ & $6.36 \mathrm{E}-01$ & $5.84 \mathrm{E}-01$ & 4.94E-01 & $8.46 \mathrm{E}-01$ & $8.24 \mathrm{E}-01$ & - \\
\hline 41 & 0.57 & $8.89 \mathrm{E}-01$ & $7.28 \mathrm{E}-01$ & - & - & - & - & - & - & - \\
\hline 42 & 0.58 & - & - & $8.40 \mathrm{E}-01$ & $6.52 \mathrm{E}-01$ & $6.11 \mathrm{E}-01$ & 4.99E-01 & $8.45 \mathrm{E}-01$ & $8.27 \mathrm{E}-01$ & - \\
\hline 43 & 0.60 & $9.28 \mathrm{E}-01$ & $7.31 \mathrm{E}-01$ & - & - & - & - & - & - & - \\
\hline 45 & 0.63 & $9.38 \mathrm{E}-01$ & $7.38 \mathrm{E}-01$ & $8.16 \mathrm{E}-01$ & $6.45 \mathrm{E}-01$ & $6.15 \mathrm{E}-01$ & $4.91 \mathrm{E}-01$ & $8.23 \mathrm{E}-01$ & $8.07 \mathrm{E}-01$ & - \\
\hline 47 & 0.65 & $8.82 \mathrm{E}-01$ & 7.70E-01 & - & - & - & - & - & - & - \\
\hline 48 & 0.67 & - & - & $8.24 \mathrm{E}-01$ & $6.57 \mathrm{E}-01$ & $6.50 \mathrm{E}-01$ & $4.91 \mathrm{E}-01$ & $8.30 \mathrm{E}-01$ & $8.13 \mathrm{E}-01$ & - \\
\hline 49 & 0.68 & $9.40 \mathrm{E}-01$ & 7.70E-01 & - & - & - & - & - & - & - \\
\hline 51 & 0.71 & $9.51 \mathrm{E}-01$ & $7.61 \mathrm{E}-01$ & $1.07 \mathrm{E}+00$ & $8.68 \mathrm{E}-01$ & $8.77 \mathrm{E}-01$ & $6.37 \mathrm{E}-01$ & $1.07 \mathrm{E}+00$ & $1.07 \mathrm{E}+00$ & - \\
\hline 52 & 0.74 & - & - & $1.08 \mathrm{E}+00$ & 8.89E-01 & 8.94E-01 & $6.39 \mathrm{E}-01$ & $1.09 \mathrm{E}+00$ & $1.09 \mathrm{E}+00$ & - \\
\hline
\end{tabular}


Table 8.24. (continued). LCA-3 experimental results

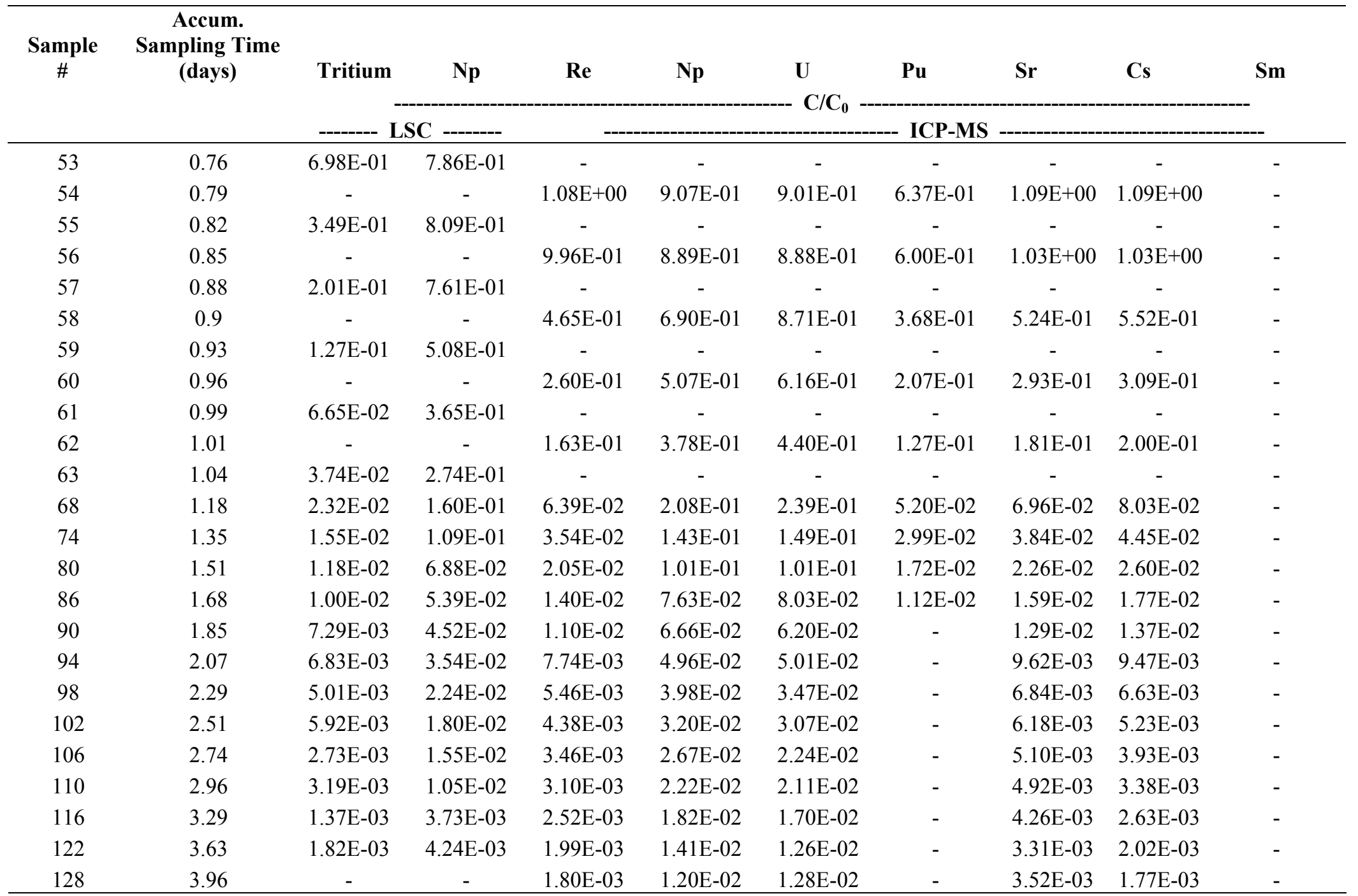


Table 8.24. (continued). LCA-3 experimental results

\begin{tabular}{|c|c|c|c|c|c|c|c|c|c|c|}
\hline \multirow[t]{2}{*}{$\begin{array}{c}\text { Sample } \\
\#\end{array}$} & \multirow[t]{2}{*}{$\begin{array}{l}\text { Accum. } \\
\text { Sampling Time } \\
\text { (days) }\end{array}$} & Tritium & Np & $\mathbf{R e}$ & Np & \multirow{2}{*}{$\begin{array}{l}\mathbf{U} \\
\mathrm{C} / \mathrm{C}_{\mathbf{0}}\end{array}$} & $\mathbf{P u}$ & $\mathbf{S r}$ & Cs & \multirow[t]{2}{*}{ Sm } \\
\hline & & ------- LS & C ------ & -- & -------------- & & ICP-MS & ----------- & -----------. & \\
\hline 134 & 4.29 & $2.28 \mathrm{E}-03$ & - & $1.54 \mathrm{E}-03$ & $9.97 \mathrm{E}-03$ & $1.01 \mathrm{E}-02$ & - & $3.14 \mathrm{E}-03$ & $1.49 \mathrm{E}-03$ & - \\
\hline 142 & 4.85 & $1.37 \mathrm{E}-03$ & - & $1.34 \mathrm{E}-03$ & $8.86 \mathrm{E}-03$ & 9.39E-03 & - & $3.33 \mathrm{E}-03$ & $1.30 \mathrm{E}-03$ & - \\
\hline 147 & 5.4 & - & - & $1.08 \mathrm{E}-03$ & 7.11E-03 & $6.77 \mathrm{E}-03$ & - & $3.11 \mathrm{E}-03$ & $1.06 \mathrm{E}-03$ & - \\
\hline 153 & 6.07 & $9.11 \mathrm{E}-04$ & - & $9.80 \mathrm{E}-04$ & $6.08 \mathrm{E}-03$ & $6.55 \mathrm{E}-03$ & - & $3.43 \mathrm{E}-03$ & $9.87 \mathrm{E}-04$ & - \\
\hline 159 & 6.74 & $3.19 \mathrm{E}-03$ & - & 7.84E-04 & $5.01 \mathrm{E}-03$ & 4.78E-03 & - & $2.89 \mathrm{E}-03$ & 7.94E-04 & - \\
\hline 162 & 7.18 & $4.56 \mathrm{E}-03$ & - & $7.51 \mathrm{E}-04$ & $4.52 \mathrm{E}-03$ & $4.50 \mathrm{E}-03$ & - & $3.01 \mathrm{E}-03$ & $7.66 \mathrm{E}-04$ & - \\
\hline 166 & 7.85 & - & - & $6.53 \mathrm{E}-04$ & $3.94 \mathrm{E}-03$ & $3.98 \mathrm{E}-03$ & - & $3.05 \mathrm{E}-03$ & $6.91 \mathrm{E}-04$ & - \\
\hline 170 & 8.51 & - & - & $5.55 \mathrm{E}-04$ & $3.26 \mathrm{E}-03$ & $3.42 \mathrm{E}-03$ & - & $2.62 \mathrm{E}-03$ & $6.06 \mathrm{E}-04$ & - \\
\hline$C_{0}$ Values ${ }^{*}:$ & & $2.20 \mathrm{E}+02$ & $2.36 \mathrm{E}+02$ & $1.53 \mathrm{E}+03$ & $1.12 E+03$ & $8.78 \mathrm{E}+02$ & $1.02 \mathrm{E}+00$ & $7.07 E+03$ & $1.06 \mathrm{E}+04$ & $7.33 \mathrm{E}+01$ \\
\hline
\end{tabular}

*: $\mathrm{C}_{0}$ values for LSC are in counts/ hour; $\mathrm{C}_{0}$ values for ICP-MS are in $\mathrm{ng} / \mathrm{mL}$

Table 8.24. (continued). LCA-3 experimental results

\begin{tabular}{|c|c|c|c|c|c|c|c|}
\hline Sample \# & $\begin{array}{l}\text { Accum. Sampling } \\
\text { Time (days) }\end{array}$ & pH & $\mathrm{HCO}_{3}^{-}$ & $\mathbf{N a}$ & $\mathbf{K}$ & Mg & $\mathrm{Ca}$ \\
\hline 5 & 0.07 & - & - & $3.27 \mathrm{E}-03$ & $3.75 \mathrm{E}-04$ & $1.27 \mathrm{E}-03$ & $1.84 \mathrm{E}-03$ \\
\hline 8 & 0.11 & 8.17 & - & - & - & - & - \\
\hline 13 & 0.18 & - & - & $3.50 \mathrm{E}-03$ & $3.59 \mathrm{E}-04$ & $1.21 \mathrm{E}-03$ & $1.74 \mathrm{E}-03$ \\
\hline 16 & 0.22 & 8.27 & - & - & - & - & - \\
\hline 20 & 0.28 & - & - & $3.48 \mathrm{E}-03$ & $3.46 \mathrm{E}-04$ & $1.14 \mathrm{E}-03$ & $1.59 \mathrm{E}-03$ \\
\hline 25 & 0.35 & 8.15 & - & - & - & - & - \\
\hline 28 & 0.39 & - & - & $3.73 \mathrm{E}-03$ & $3.55 \mathrm{E}-04$ & $1.21 \mathrm{E}-03$ & $1.67 \mathrm{E}-03$ \\
\hline 34 & 0.47 & 8.13 & - & - & - & - & - \\
\hline 36 & 0.50 & - & - & $3.57 \mathrm{E}-03$ & $3.44 \mathrm{E}-04$ & $1.15 \mathrm{E}-03$ & $1.59 \mathrm{E}-03$ \\
\hline 43 & 0.60 & 8.08 & - & - & - & - & - \\
\hline 44 & 0.61 & - & - & $3.39 \mathrm{E}-03$ & $3.20 \mathrm{E}-04$ & $1.07 \mathrm{E}-03$ & $1.48 \mathrm{E}-03$ \\
\hline
\end{tabular}


Table 8.24. (continued). LCA-3 experimental results

\begin{tabular}{|c|c|c|c|c|c|c|c|}
\hline Sample \# & $\begin{array}{c}\text { Accum. Sampling } \\
\text { Time (days) }\end{array}$ & pH & $\mathrm{HCO}_{3}^{-}$ & $\mathbf{N a}$ & $\mathbf{K}$ & Mg & $\mathrm{Ca}$ \\
\hline 50 & 0.69 & - & - & $349 F_{-} 03$ & $327 F_{-} 04$ & 1 10F_03 & $153 \mathrm{~F}_{-} 03$ \\
\hline 52 & 0.74 & - & & - & - & - & - \\
\hline 53 & 0.76 & 8.04 & & - & - & - & - \\
\hline 54 & 0.79 & - & & - & - & - & - \\
\hline 55 & 0.82 & - & $2.04 \mathrm{E}-03$ & - & - & - & - \\
\hline 57 & 0.88 & - & - & $3.09 \mathrm{E}-03$ & $3.05 \mathrm{E}-04$ & $1.06 \mathrm{E}-03$ & $1.49 \mathrm{E}-03$ \\
\hline 61 & 0.99 & 8.06 & - & - & - & - & - \\
\hline 63 & 1.04 & - & - & $3.12 \mathrm{E}-03$ & $3.32 \mathrm{E}-04$ & $1.13 \mathrm{E}-03$ & $1.63 \mathrm{E}-03$ \\
\hline 69 & 1.21 & 8.16 & - & - & - & - & - \\
\hline 70 & 1.24 & - & - & $3.06 \mathrm{E}-03$ & $5.02 \mathrm{E}-04$ & $1.17 \mathrm{E}-03$ & $1.70 \mathrm{E}-03$ \\
\hline 76 & 1.40 & - & - & $2.98 \mathrm{E}-03$ & $3.51 \mathrm{E}-04$ & $1.15 \mathrm{E}-03$ & $1.67 \mathrm{E}-03$ \\
\hline 77 & 1.43 & 8.07 & - & - & - & - & - \\
\hline 82 & 1.57 & - & - & $3.03 \mathrm{E}-03$ & $3.32 \mathrm{E}-04$ & $1.17 \mathrm{E}-03$ & $1.72 \mathrm{E}-03$ \\
\hline 85 & 1.65 & 7.74 & - & - & - & - & - \\
\hline 88 & 1.74 & - & - & $2.76 \mathrm{E}-03$ & 2.97E-04 & $1.08 \mathrm{E}-03$ & $1.58 \mathrm{E}-03$ \\
\hline 92 & 1.96 & - & $1.51 \mathrm{E}-03$ & - & - & - & - \\
\hline 93 & 2.01 & - & & - & - & - & - \\
\hline 94 & 2.07 & - & - & $3.18 \mathrm{E}-03$ & $3.50 \mathrm{E}-04$ & $1.24 \mathrm{E}-03$ & $1.82 \mathrm{E}-03$ \\
\hline 101 & 2.46 & - & - & $3.06 \mathrm{E}-03$ & 3.34E-04 & $1.20 \mathrm{E}-03$ & $1.77 \mathrm{E}-03$ \\
\hline 107 & 2.79 & - & - & $3.02 \mathrm{E}-03$ & $3.30 \mathrm{E}-04$ & $1.16 \mathrm{E}-03$ & $1.73 \mathrm{E}-03$ \\
\hline 113 & 3.13 & - & - & $2.86 \mathrm{E}-03$ & $3.11 \mathrm{E}-04$ & $1.11 \mathrm{E}-03$ & $1.65 \mathrm{E}-03$ \\
\hline 119 & 3.46 & - & - & $3.04 \mathrm{E}-03$ & $3.30 \mathrm{E}-04$ & $1.15 \mathrm{E}-03$ & $1.72 \mathrm{E}-03$ \\
\hline 135 & 4.35 & - & - & $2.92 \mathrm{E}-03$ & $3.20 \mathrm{E}-04$ & $1.07 \mathrm{E}-03$ & $1.57 \mathrm{E}-03$ \\
\hline 139 & 4.57 & - & $1.04 \mathrm{E}-03$ & - & - & - & - \\
\hline 145 & 5.18 & - & - & $2.85 \mathrm{E}-03$ & $3.11 \mathrm{E}-04$ & $1.07 \mathrm{E}-03$ & $1.58 \mathrm{E}-03$ \\
\hline 153 & 6.07 & - & - & $2.90 \mathrm{E}-03$ & $3.27 \mathrm{E}-04$ & $1.11 \mathrm{E}-03$ & $1.63 \mathrm{E}-03$ \\
\hline 161 & 7.01 & - & - & $2.80 \mathrm{E}-03$ & $3.08 \mathrm{E}-04$ & $1.04 \mathrm{E}-03$ & $1.54 \mathrm{E}-03$ \\
\hline 170 & 8.51 & - & $1.70 \mathrm{E}-03$ & - & - & - & - \\
\hline \multicolumn{2}{|c|}{ LCA-3 Initial Sorption Solution: } & 7.94 & 2.99E-04 & $6.46 \mathrm{E}-03$ & 6.05E-04 & $1.35 \mathrm{E}-03$ & 2.05E-03 \\
\hline
\end{tabular}


8.2 Photographs of TCU And LCA Cores Used in Flow-Through Experiments

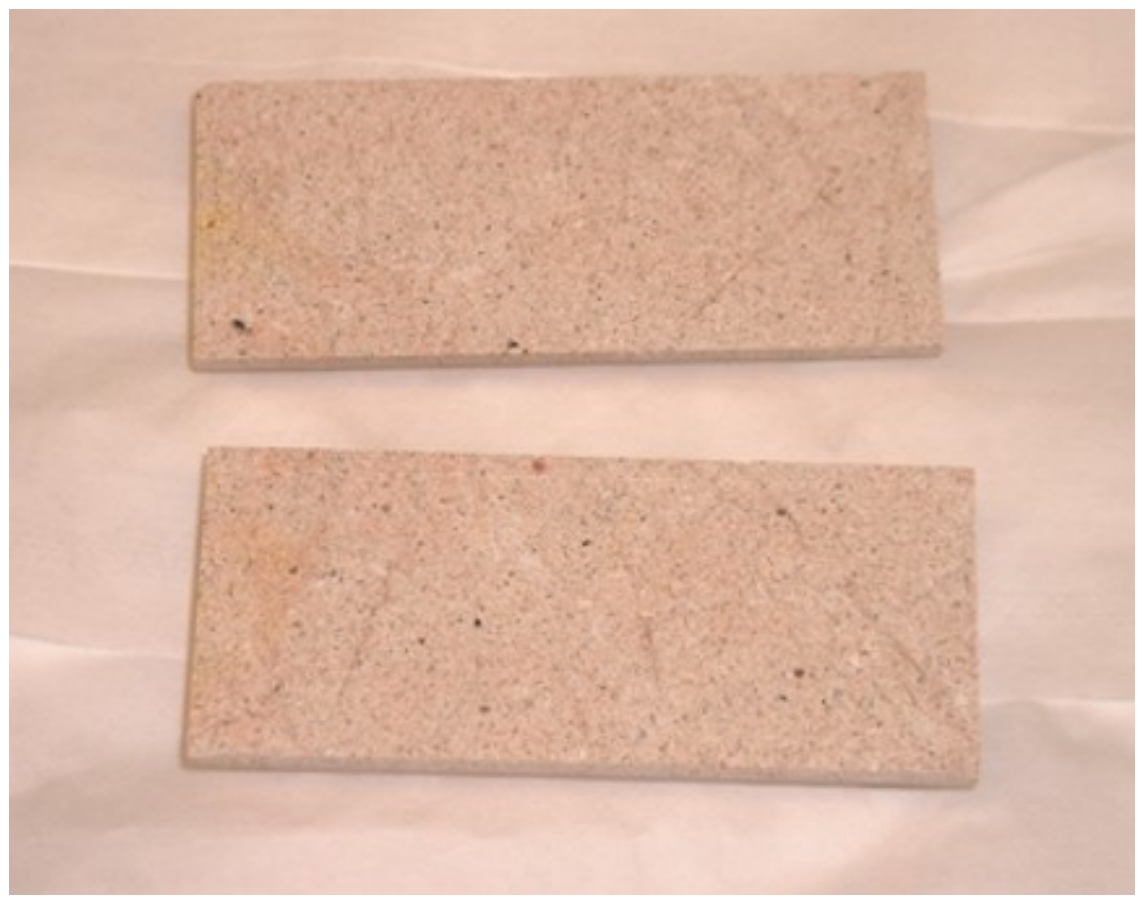

Figure 8.1. TCU-2 Synthetic parallel plate "slotted" fracture

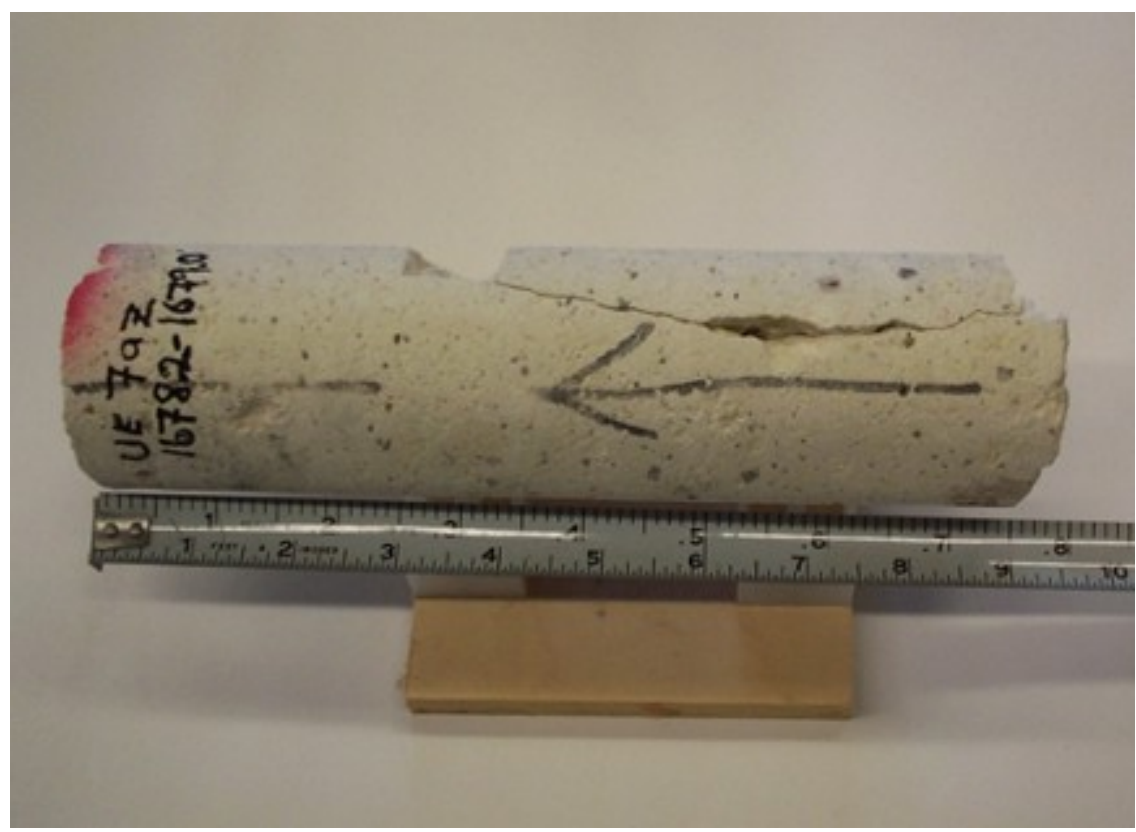

Figure 8.2. TCU-3 Natural fracture 


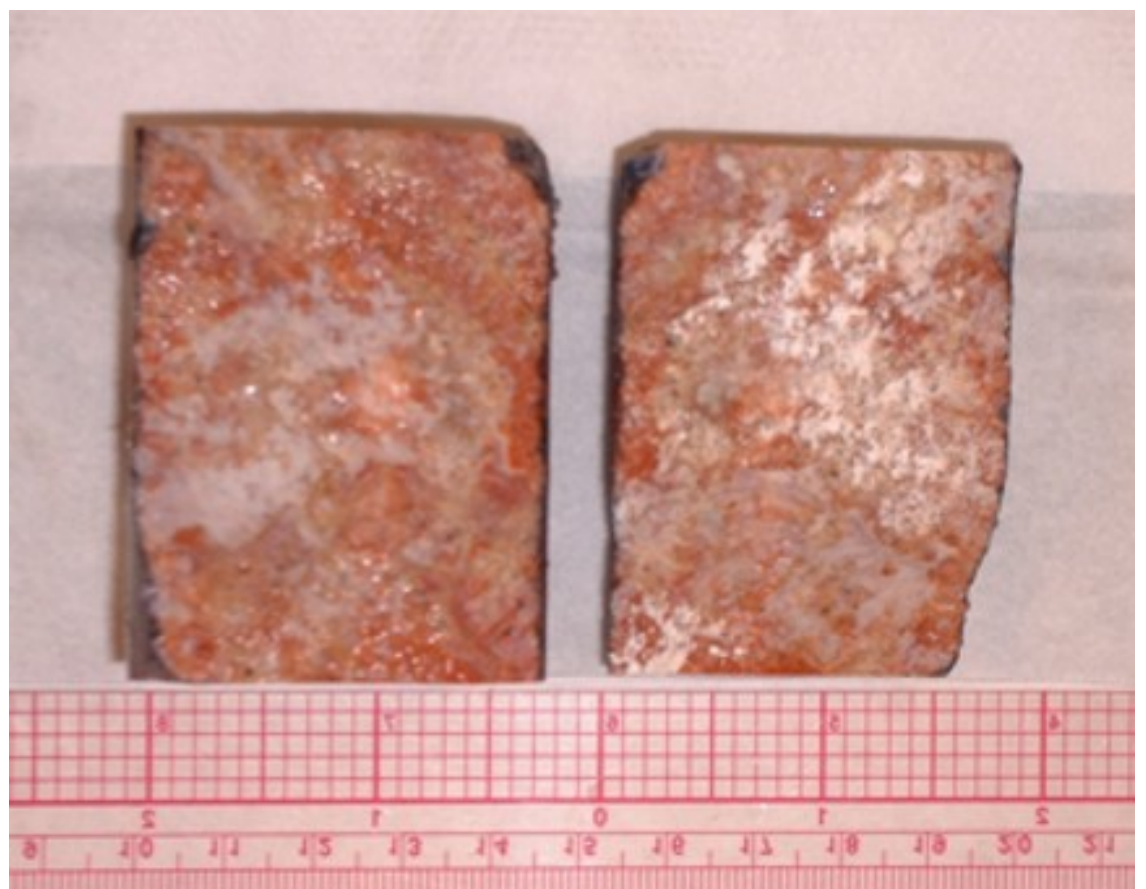

Figure 8.3. TCU-4 Natural fracture

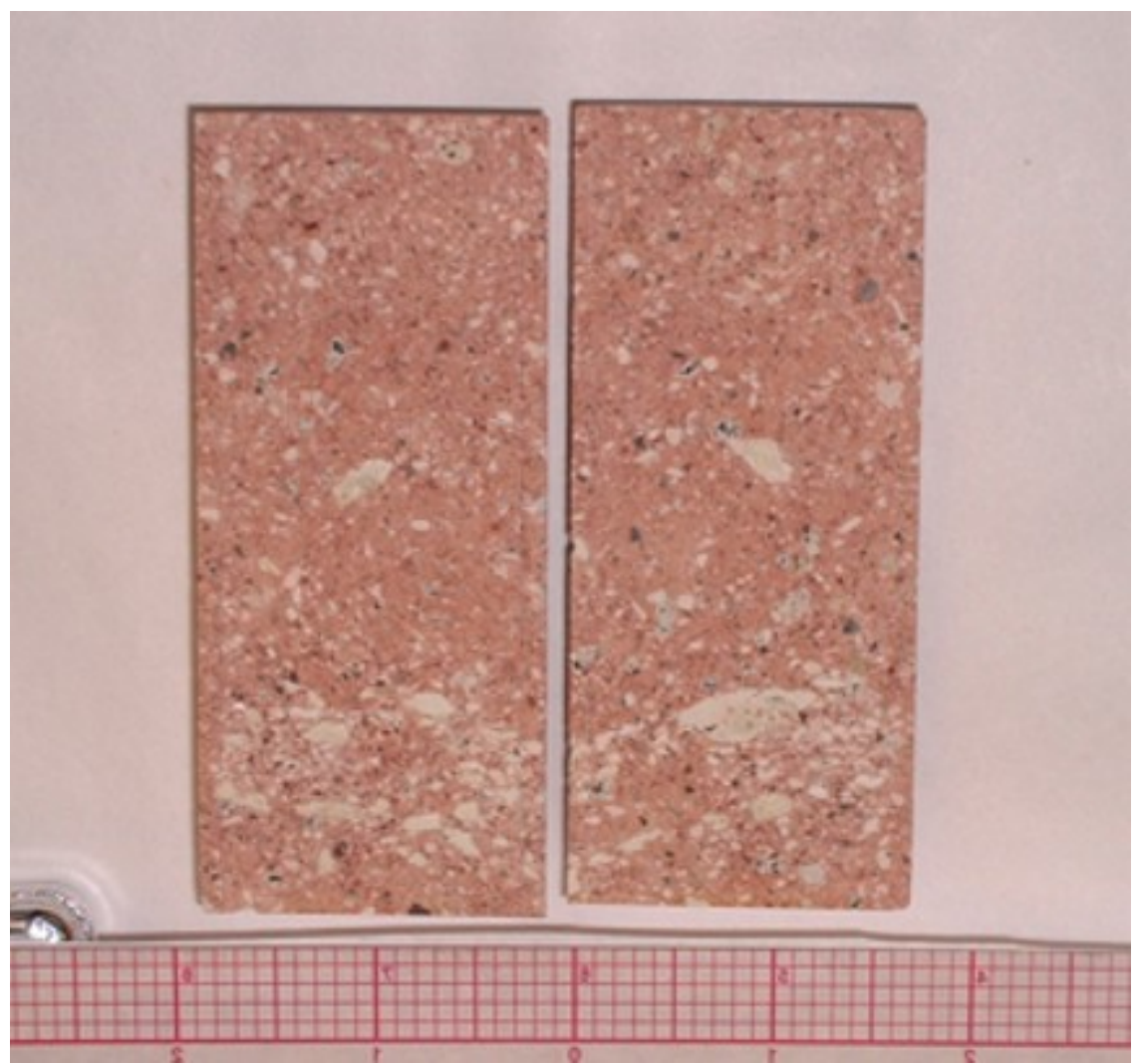

Figure 8.4. TCU-5 Synthetic parallel plate "slotted" fracture 


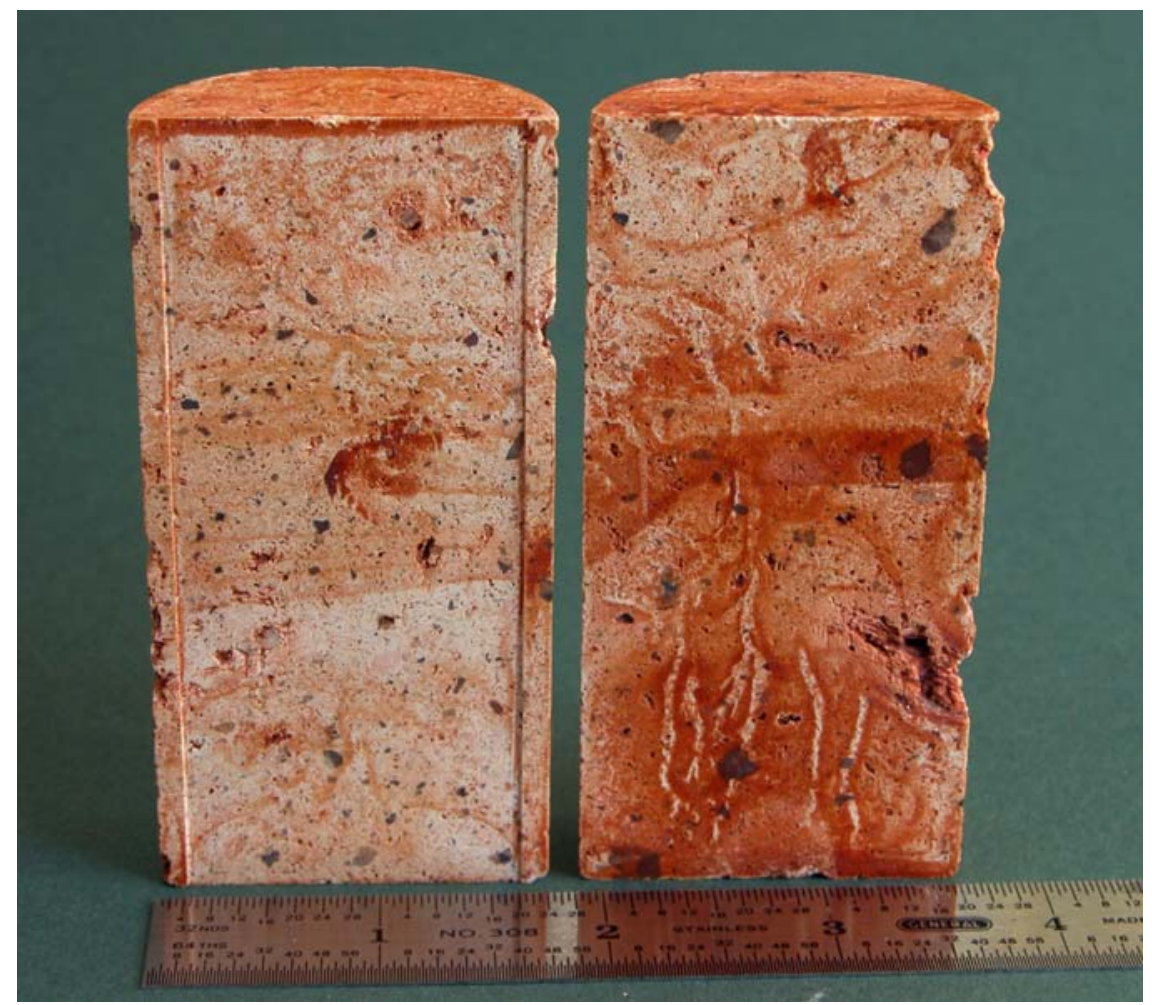

Figure 8.5. TCU-6 Iron oxide coated synthetic parallel plate "slotted" fracture

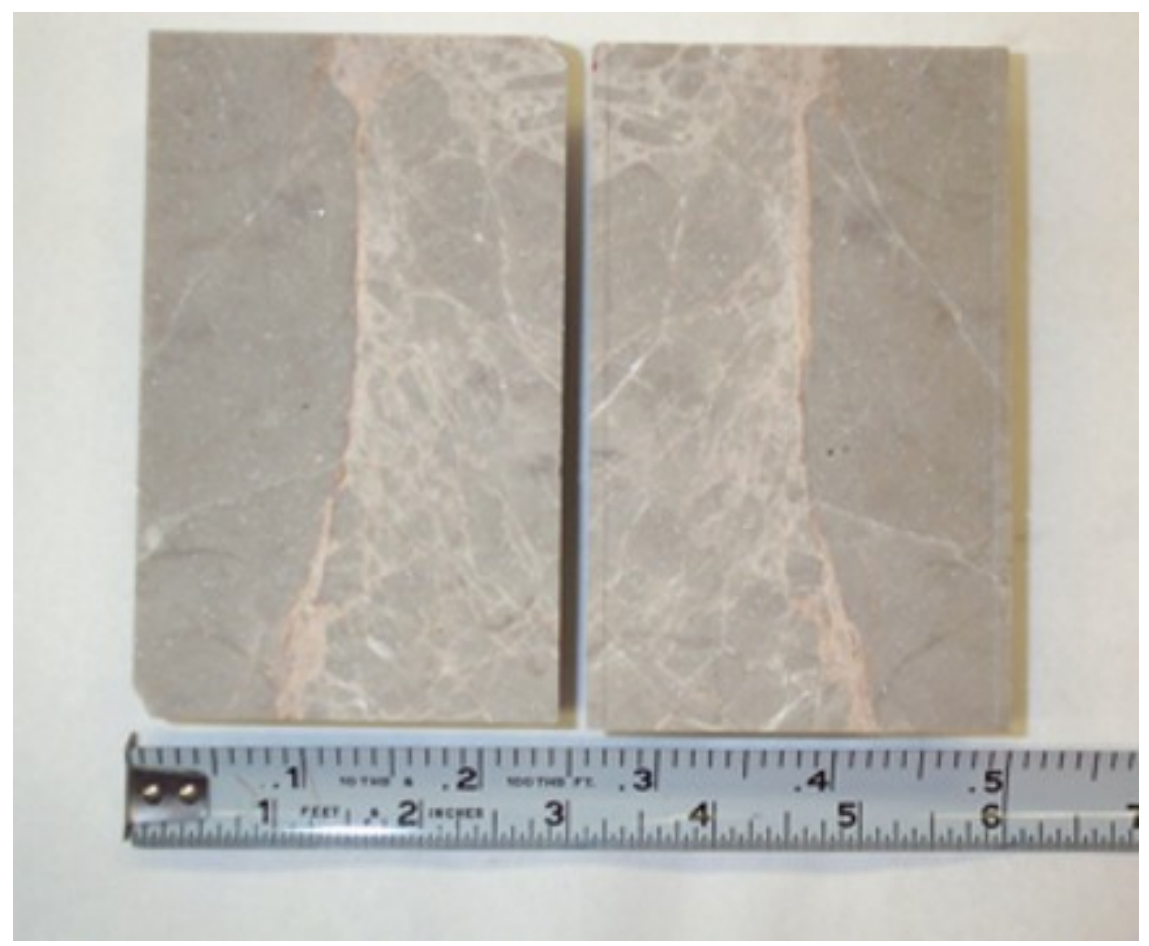

Figure 8.6. LCA-2 Synthetic parallel plate "slotted" fracture 


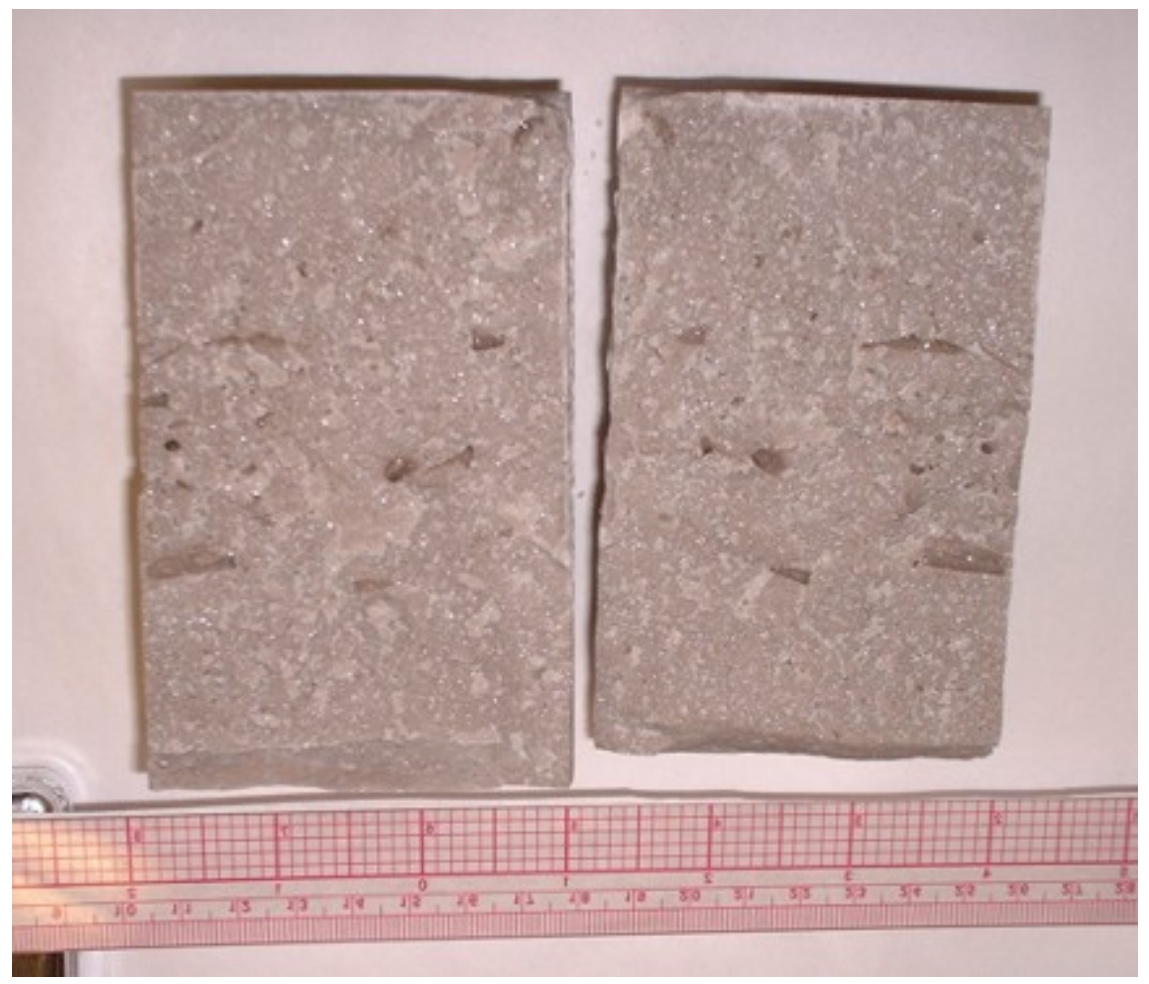

Figure 8.7. LCA-3 Brazil test induced fracture 


\subsection{SIMS Data}

Table 8.25. Data from SIMS measurements for TCU-5

\begin{tabular}{|c|c|c|c|c|c|c|}
\hline \multicolumn{7}{|c|}{ A (Sites with lower than $10 \operatorname{cps}^{1} \mathrm{Pu}$ ) } \\
\hline $\begin{array}{c}\text { Measurement } \\
\text { Number }\end{array}$ & $\begin{array}{c}{ }^{55} \mathrm{Mn} \text { Mean } \\
\text { Intensity } \\
\text { (counts/sec) }\end{array}$ & $\begin{array}{l}{ }^{56} \text { Fe Mean } \\
\text { Intensity } \\
\text { (counts/sec) }\end{array}$ & $\begin{array}{l}{ }^{149} \text { Sm Mean } \\
\text { Intensity } \\
\text { (counts/sec) }\end{array}$ & $\begin{array}{l}{ }^{235} \mathrm{U} \text { Mean } \\
\text { Intensity } \\
\text { (counts/sec) }\end{array}$ & $\begin{array}{l}{ }^{237} \mathrm{~Np} \text { Mean } \\
\text { Intensity } \\
\text { (counts/sec) }\end{array}$ & $\begin{array}{l}{ }^{242} \mathrm{Pu} \text { Mean } \\
\text { Intensity } \\
\text { (counts/sec) }\end{array}$ \\
\hline$\overline{1}$ & 159394.83 & 7394906.50 & 73.83 & 3.17 & 7.80 & 3.07 \\
\hline 2 & 139511.42 & 3663111.25 & 76.00 & 1.67 & 9.17 & 1.90 \\
\hline 3 & 175554.89 & 2494750.25 & 49.17 & 0.33 & 6.07 & 1.47 \\
\hline 4 & 207226.14 & 5994093.50 & 51.50 & 1.50 & 9.50 & 1.07 \\
\hline 5 & 123715.01 & 4138878.75 & 61.50 & 1.67 & 6.87 & 2.27 \\
\hline 6 & 115498.16 & 5961524.00 & 63.33 & 1.83 & 6.57 & 2.03 \\
\hline 8 & 299211.50 & 1197614.38 & 10.33 & 0.50 & 1.87 & 0.97 \\
\hline 9 & 244370.94 & 1143557.13 & 14.50 & 0.17 & 2.13 & 0.80 \\
\hline 10 & 222894.77 & 7812729.50 & 97.17 & 2.00 & 8.73 & 2.50 \\
\hline 11 & 1466208.38 & 17091186.00 & 2544.49 & 8.33 & 9.30 & 3.17 \\
\hline 12 & 93326.13 & 7465825.50 & 45.33 & 1.83 & 6.53 & 2.07 \\
\hline 13 & 147859.36 & 7253105.50 & 94.67 & 2.33 & 8.87 & 2.53 \\
\hline 15 & 81741.85 & 907020.81 & 14.50 & 0.33 & 3.77 & 0.77 \\
\hline 18 & 232562.27 & 4554199.50 & 59.83 & 1.83 & 7.20 & 0.87 \\
\hline 19 & 156038.39 & 4231864.50 & 134.28 & 3.00 & 10.20 & 2.87 \\
\hline 20 & 221336.36 & 1620862.63 & 94.67 & 1.67 & 13.07 & 4.40 \\
\hline 23 & 210184.92 & 2904350.75 & 483.22 & 9.00 & 17.77 & 5.57 \\
\hline 24 & 209539.30 & 7925252.00 & 409.17 & 5.17 & 13.33 & 5.20 \\
\hline 26 & 2772906.25 & 2497680.50 & 49.89 & 1.83 & 1.90 & 6.83 \\
\hline 29 & 132159.61 & 1340326.13 & 251.00 & 3.50 & 8.33 & 2.50 \\
\hline 31 & 90212.02 & 4530630.50 & 98.50 & 7.00 & 165.03 & 7.77 \\
\hline 32 & 120943.53 & 5585883.50 & 101.56 & 2.50 & 62.53 & 4.43 \\
\hline
\end{tabular}


Table 8.25 (continued). Data from SIMS measurements for TCU-5

\begin{tabular}{|c|c|c|c|c|c|c|}
\hline \multicolumn{7}{|c|}{ B (Sites with higher than 10 cps Pu) } \\
\hline $\begin{array}{c}\text { Measurement } \\
\text { Number }\end{array}$ & $\begin{array}{c}{ }^{55} \mathrm{Mn} \text { Mean } \\
\text { Intensity } \\
\text { (counts/sec) }\end{array}$ & $\begin{array}{c}{ }^{56} \text { Fe Mean } \\
\text { Intensity } \\
\text { (counts/sec) }\end{array}$ & $\begin{array}{c}{ }^{149} \text { Sm Mean } \\
\text { Intensity } \\
\text { (counts/sec) }\end{array}$ & $\begin{array}{c}{ }^{235} \mathrm{U} \text { Mean } \\
\text { Intensity } \\
\text { (counts/sec) }\end{array}$ & $\begin{array}{c}{ }^{237} \mathrm{~Np} \text { Mean } \\
\text { Intensity } \\
\text { (counts/sec) }\end{array}$ & $\begin{array}{c}{ }^{242} \mathrm{Pu} \text { Mean } \\
\text { Intensity } \\
\text { (counts/sec) }\end{array}$ \\
\hline 7 & 153224.38 & 3165677.00 & 47.50 & 4.67 & 6.70 & 115.77 \\
\hline 14 & 87263240.00 & 24691142.00 & 9862.09 & 1155.67 & 1564.53 & 381.83 \\
\hline 16 & 78812952.00 & 57458944.00 & 13193.70 & 1668.83 & 2416.80 & 814.07 \\
\hline 17 & 833991.31 & 11769637.00 & 2162.66 & 45.50 & 134.20 & 54.90 \\
\hline 21 & 62739376.00 & 44084668.00 & 8883.55 & 528.17 & 618.33 & 265.13 \\
\hline 22 & 101880232.00 & 25022110.00 & 14793.33 & 2382.33 & 3803.42 & 1053.27 \\
\hline 25 & 2230577.00 & 1943945.75 & 267.80 & 60.80 & 46.16 & 225.56 \\
\hline 27 & 130619656.00 & 21200876.00 & 29914.32 & 1303.67 & 4221.72 & 585.03 \\
\hline 28 & 334348.72 & 2428727.50 & 6259.97 & 117.83 & 74.13 & 34.87 \\
\hline 30 & 186609.58 & 2901314.00 & 2574.83 & 50.00 & 41.57 & 15.07 \\
\hline
\end{tabular}

${ }^{1} \mathrm{cps}=$ counts per second

Table 8.26. Data from SIMS measurements for LCA-2.

\begin{tabular}{cccc}
\hline & ${ }^{149} \mathrm{Sm}$ Mean & ${ }^{237} \mathrm{~Np}$ Mean & ${ }^{242} \mathrm{Pu}$ Mean \\
Number & Intensity & Intensity & Intensity \\
& (counts/sec) & $($ counts/sec) & (counts/sec) \\
\hline
\end{tabular}

\begin{tabular}{llll} 
Plug 1(Inlet) & & & \\
1 & 13.65 & 12.43 & 0.26 \\
2 & 22.02 & 19.52 & 0.38 \\
3 & 24.13 & 14.82 & 0.39 \\
4 & 19.63 & 22.91 & 0.37 \\
5 & 21.54 & 28.32 & 0.55 \\
Average & 20.19 & 19.60 & 0.39 \\
\hline Plug 5 (Outlet) & & & \\
1 & 6.99 & 2.25 & 0.65 \\
2 & 6.74 & 4.24 & 0.34 \\
3 & 5.22 & 3.03 & 0.16 \\
4 & 4.00 & 2.45 & 0.14 \\
5 & 0.46 & 0.25 & 0.13 \\
Average & 4.68 & 2.44 & 0.28 \\
\hline
\end{tabular}

